\title{
The Geomorphic Response \\ of the Passive Continental Margin of Northern Namibia \\ to Gondwana Break-Up and Global Scale Tectonics
}

\author{
Dissertation \\ zur Erlangung des Doktorgrades \\ der Mathematisch-Naturwissenschaftlichen Fakultäten \\ der Georg-August-Universität zu Göttingen
}

vorgelegt von

Matthias Johannes Raab

aus Göttingen

Göttingen 2001 
D7

Referent:

Prof. Dr. K. Weber

Korreferent:

Dr. R.W. Brown

Tag der mündlichen Prüfung:

21.06.2001 


\section{Contents}

Acknowledgments iv

1 Introduction 1

$1.1 \quad \operatorname{Aim} \ldots \ldots \ldots \ldots \ldots \ldots 1$

1.2 Purpose and Scope . . . . . . . . . . . . . . . . 1

1.3 Outline of this Thesis . . . . . . . . . . . . . 3

2 Geology, Geomorphology and Tectonics 5

2.1 Introduction . . . . . . . . . . . . . 5

2.2 Geology ......................... 6

2.2 .1 Overview ................... 6

2.2.2 Origin of Major Lineaments . . . . . . . . . . . . . . . 8

2.2.3 The Karoo Igneous Province . . . . . . . . . . . . . . 9

2.2.4 The Paraná-Etendeka Province . . . . . . . . . . . . . . 10

2.2.5 The Damaraland Igneous Province . . . . . . . . . . . . 11

2.2.6 Cretaceous Dyke Swarms . . . . . . . . . . . 13

2.2.7 Gondwana Fragmentation . . . . . . . . . . . . . . . 14

2.2 .8 Offshore Basins . . . . . . . . . . . . . . . 16

2.2.9 Post Break-Up Geology . . . . . . . . . . . . . 17

2.3 Geomorphology . . . . . . . . . . . . . . . . 18

2.3.1 Quantifying Geomorphic Development . . . . . . . . 18

2.3.2 Morphology of the Margin . . . . . . . . . . . . . . . 19

2.3.3 Evolution of High Elevated Margins . . . . . . . . . . . 20

2.4 Tectonics . . . . . . . . . . . . . . . . 23

3 Fission Track Thermochronology 2

3.1 Introduction . . . . . . . . . . . . . . . . 25

3.2 Fission Track Data . . . . . . . . . . . . . . . . . . 29

3.2.1 Track Formation . . . . . . . . . . . . . . . 29

3.2.2 Track Annealing and the Effects of Temperature . . . . . 31

3.2.3 Compositional Affects on Annealing . . . . . . . . . . . . 32

3.3 Concepts behind Age Determination . . . . . . . . . . . . . 34

3.3 .1 Methods .................... 34 
3.3.2 Age Equations . . . . . . . . . . . . . . . . . 35

3.3 .3 Error Calculation . . . . . . . . . . . . . . . . . . . . . 39

3.3.4 Calculation of Uranium Content . . . . . . . . . . . 40

3.4 Deriving Thermal Histories from Fission Track Data . . . . . . 41

3.4.1 Presentation of Fission Track Data . . . . . . . . . . . . 41

3.4 .2 Vertical Profiles . . . . . . . . . . . . . . . . . 43

3.4.3 Thermal Modelling . . . . . . . . . . . . . . . . . . 46

4 Fission Track Results from Vertical Relief Profiles 48

4.1 Introduction . . . . . . . . . . . . . . . . . . 48

4.2 Thermal and Numerical Modelling . . . . . . . . . . . . 50

4.3 Calculation of Palaeogeothermal Gradient and Denudation . . . . 50

4.4 The Brandberg Profile . . . . . . . . . . . . . . . . . . . 51

4.4 .1 Fission Track Results . . . . . . . . . . . . . . . . . . . 54

4.4 .2 Discussion . . . . . . . . . . . . . . . . 56

4.4 .3 Summary . . . . . . . . . . . . . . . . 61

4.5 The Okenyenya Profile . . . . . . . . . . . . . . . . . 63

4.5.1 Fission Track Results . . . . . . . . . . . . . . . . . 63

4.5 .2 Discussion . . . . . . . . . . . . . . . . . . . . . . 64

4.5 .3 Summary . . . . . . . . . . . . . . . . . 68

4.6 The Windhoekgraben Profile . . . . . . . . . . . . . . . . 71

4.6 .1 Fission Track Results . . . . . . . . . . . . . . . . . 71

4.6 .2 Discussion . . . . . . . . . . . . . . . 71

4.6 .3 Summary . . . . . . . . . . . . . . . . . . . . 75

4.7 Conclusions . . . . . . . . . . . . . . . . . . 77

5 Late Cretaceous Reactivation of Major Shear Zones in Northern Namibia $\quad 79$

5.1 Introduction . . . . . . . . . . . . . . . . . . 79

5.2 Methodology . . . . . . . . . . . . . . . 83

5.3 Previous Fission Track Work . . . . . . . . . . . . . . 83

5.4 Fission Track Results . . . . . . . . . . . . . . . . . . . . . . . . 84

5.5 Thermal Modelling . . . . . . . . . . . . . . . . . . . . 89

5.6 Constraining Reactivation and Denudation . . . . . . . . . . 89

5.7 Discussion . . . . . . . . . . . . . . . . . . . . . . 91

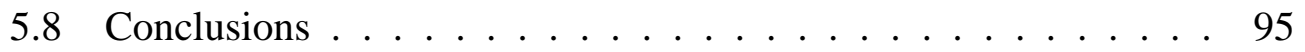

6 Denudation Chronology of Northern Namibia 100

6.1 Introduction . . . . . . . . . . . . . . . . . . 100

6.2 Previous Work in Low Temperature Thermochronology . . . . . . 101

6.3 Quantifying Long-Term Denudation . . . . . . . . . . . . 102

6.4 Denudation Chronology . . . . . . . . . . . . . . . . . . 103

6.5 Summary . . . . . . . . . . . . . . . . . . 116 
A Applied Statistics $\quad 120$

A.1 Introduction . . . . . . . . . . . . . . . . 120

A.2 The Chi-Square Test . . . . . . . . . . . . . . . . 120

A.3 Method of Least Squares . . . . . . . . . . . . . . . . 121

A.4 Weighted Mean . . . . . . . . . . . . . . . . . . 122

B Sample Preparation and Experimental Conditions 124

B.1 Introduction . . . . . . . . . . . . . . . . . . . . . . 124

B.2 Sample Preparation . . . . . . . . . . . . . . 125

B.3 Experimental Conditions . . . . . . . . . . . . . 126

B.3.1 Fission Track Dating . . . . . . . . . . . . 126

B.3.2 Track Length Measurements . . . . . . . . . . . 127

B.3.3 Calibration . . . . . . . . . . . . . . 127

B.3.4 Microprobe Analysis . . . . . . . . . . . . . . 128

C Fission Track Data Files 131

C.1 Sample Localities and Descriptions . . . . . . . . . . . . . 132

C.2 Analytical Results . . . . . . . . . . . . . . . . . . 135

C.3 Raw Data Files . . . . . . . . . . . . . . . . . . 141

D GMT-Scripts $\quad \mathbf{2 2 2}$

D.1 Introduction . . . . . . . . . . . . . . . . . . 222

D.2 Contouring Fission Track Data . . . . . . . . . . . 222

D.3 Generating Location Maps . . . . . . . . . . . . . 223

D.4 Generating Age Dependent Location Map . . . . . . . . . . . 224

D.5 Generating Maps for Animations . . . . . . . . . . . . . . . 225

E Data-CD $\quad 235$

E.1 Contents . . . . . . . . . . . . . . . . . 235

$\begin{array}{lr}\text { References } & 236\end{array}$ 


\section{Acknowledgments}

Writing a PhD-thesis is a huge undertaking and a very long process. It takes years of research and experience, involving a lot of happy days with splendid ideas and research results, and many less happy days with disappointments and scientific and financial setbacks.

The path towards a $\mathrm{PhD}$ is a stony one, but luckily I was fortunate enough to have more people than I would ever have imagined to help, support and encourage me to reach the end of that path, and I would like to express my appreciation to all of them.

First of all, I would like to thank Prof. Klaus Weber, my supervisor, for his constant support and his understanding. Throughout this research and several field campaigns in Namibia he made countless helpful, inspiring suggestions and observations. It was he who initiated this project with a funding from the Deutsche Forschungsgemeinschaft (DFG), no. WE488-48/1, and succeeded to keep my fundings, and consequently this research, running.

Dr. Roderick Brown, my co-supervisor, supplied me with all the information, scripts and papers possible, and guided me through all the tasks of my fission track thesis. This enabled me to get a much better perspective on my own results. Without his input this thesis would have been only a fraction of what it is now. Over the previous two and a half years he has guided me, has provided profound advice, a car, fine dining and friendship.

Dr. Roderick Brown is a member of the Australian Fission Track Research Group. I was fortunate enough to meet members of the group in Harare/Zimbabwe in 1997. All the group members are wonderful people and their intellectual input and support were fundamental for my research. Their unique contributions, their positive and encouraging influence on me, and their thirst for knowledge have had a huge impact on my work.

Specifically, I thank Prof. Andrew Gleadow, the head of department at La Trobe University and, later at The University of Melbourne, for inviting me to Australia, and giving me the privilege to work with his group in Melbourne for more than two and a half years. He was immensely helpful and supportive, and through his invitation made it possible to continue, and ultimately carry out my research.

I am also grateful to Dr. Barry Kohn, the managing director of the Fission Track Research Group. He always took the time to listen to my problems and ideas, and found ways for me to support my family financially. I greatly benefited from his numerous suggestions for my thesis, and for my first publication.

Dr. Kerry Gallagher is to be thanked for modelling my data with Suntrax, 
converting them into a useful format (GMT readable) for me. His speedy return of a revised manuscript of mine, which was important for this thesis, was also very much appreciated.

Dr. Hermione Cockburn's expertise and constructive comments on special topics in this thesis were of great help. Dr. Asaf Raza shared his knowledge of the most sophisticated way of fission track analysis and preparation with me, and provided many useful advice and strategies as well as friendly encouragement at all times. Dr. Paul O'Sullivan trained me to become a confident operator and gave me deep insight into the variability of counting. I would like to thank all three of them very much.

I am also grateful to Eva Wynn who thoroughly proofread this thesis. During the last years she has become a very important and close friend to my family and of me. It is a pleasure knowing her.

Furthermore I would like to thank David Belton, on the one hand, for his friendship and unending readiness to help; and, on the other, for great scientific discussions we engaged in. Special thanks, too, to Dr. Sara Vassolo and Ingo Bardenhagen for their friendship and support in Windhoek/Namibia during my fieldworks. We had a magnificent time, with interesting talks, good fun, good wine and good food.

Anja Böhm, Ulrich Hilken, Jeannette and Dr. Thomas Becker, who accompanied the Brandberg expedition in 1996; my "Hiwis" in Göttingen, Helge Knieriem, Markus Nörtemann, Christian Gross, Annett Büttner, Thomas Wink and Thomas Buchholtz, should all be mentioned, too. I thank them for their work and all the good and bad times we had together.

Also, I am grateful to the Deutscher Akademischer Austauschdienst (DAAD). Their scholarship, which was awarded to me for the period from September 1998 until February 2000, was crucial for a successful start of this project in Australia.

Finally, I am most grateful to my wife Claudia and my son Connor for their love. They were always with me in the most difficult and demanding time of my life.

July 5, 2001 


\section{Chapter 1}

\section{Introduction}

\subsection{Aim}

The overall aim of this thesis is to elucidate the low temperature thermotectonic evolution of the passive continental margin of northern Namibia, southwest Africa. The thesis seeks to provide detailed thermochronologic data to augment the currently available regional data coverage for this area, by utilising apatite fission track analysis. Apatite fission track analysis constitutes a powerful and unique tool for quantifying the cooling rates of rocks in the shallow crust $(3-5 \mathrm{~km})$ that occur in response to surface processes such as denudation and tectonic activity.

\subsection{Purpose and Scope}

Plate tectonics may successfully explain the primary topographic features of the Earth's surface such as mountain belts, the division between continents and oceans, and sedimentary basins at plate boundaries. But finding sufficient explanations for the more complex tectonic and geomorphic evolution of passive continental margins, including the feedback effects of surface processes such as denudation and sedimentation, still remains a problem. This is particularly true in regions like northern Namibia where the topography is highly variable, and the interaction with tectonics appears complex.

This insufficiency of explanation is mainly due to the fact that our understanding of how landscapes evolve over time is restricted; and the restriction in turn is caused by a lack of data of a certain kind - that is data which are sensitive to denudation of the upper few kilometers of the crust.

To a certain extent, the onshore geology of Namibia provides useful con- 
straints on gross estimates of denudation and scarp retreat that have occurred since the break-up of the South Atlantic. For example, numerous kimberlite intrusions and associated alkaline pipes have been recognised inland of the continental margins in South Africa and Namibia. The preserved original crater infill that is to be found in some of these kimberlites, suggests that the net denudation since the Late Cretaceous to Early Tertiary has been relatively insignificant, i.e. in the order of less than 100 m (Janse 1975, Smith 1986, DeWit et al. 1992). In contrast, subvolcanic alkaline intrusions of the Damaraland Igneous Province closer to the continental edge imply large amounts of denudation in the order, in some areas, of approximately $2 \mathrm{~km}$. For example, the Brandberg complex intruded into the crust approximately $132 \mathrm{Ma}$ ago. Nowadays, it forms the highest mountain in Namibia $(2573 \mathrm{~m})$ as an isolated massif, rising $1.8 \mathrm{~km}$ above the surrounding plains. This indicates that at least $1.8 \mathrm{~km}$ of denudation has occurred locally since the Early Cretaceous.

Furthermore, geological information on rates of scarp retreat can be inferred from dated in situ fossilised bird eggs, such as those found in the Tsondab Sandstone Formation in central Namibia. Eggs of middle Miocene age (ca. $13 \mathrm{Ma}$ ), as well as younger eggs, were found between the Tsondab and Tsauchab rivers, approximately $20 \mathrm{~km}$ west of the base of the escarpment (Pickford et al. 1995, Senut and Pickford 1995). It is highly significant that these remnants of the Tsondab Sandstone Formation occur immediately seaward of the present escarpment in this region, because they imply an average escarpment retreat of less than $1.5 \mathrm{~km}$ over the past $13 \mathrm{Ma}$ (Cockburn 1998, Gallagher and Brown 1999a). This rate is inconsistent with classical escarpment evolution models, and highlights the need for further information about landscape evolution in this area.

Estimates of present denudation rates can also be derived from various other sources, such as sediment yield data from large drainage basins (Summerfield and Hulton 1994). Existing estimates of long term rates and amounts of onshore denudation (based on calculations of marine sediment volumes (Rust and Summerfield 1990)) have a weak spatial resolution since the information is averaged over large and poorly constrained areas. These calculations are undoubtedly important as they provide first order estimates of denudation on a regional scale. Rust and Summerfield's (1990) approach indicates, for example, that the total volume of sediment within the Orange and Walvis Basin is equivalent to an average of $1.8 \mathrm{~km}$ of post-rift denudation over the total area of the Orange river. But the problem remains that both, the chronology and spatial distribution of onshore denudation are prone to be highly variable, depending as they do on a number of diverse factors, such as: post break-up tectonics; the pattern of drainage development; lithological heterogeneity; and long term climatic variations. In fact, many methods to quantify denudation are insensitive to these factors.

Rates and patterns of denudation provide a fundamental insight into the re- 
sponse of landscapes to various tectonic processes, and provide a quantitative calibration of the evolution of the Earth's surface. Therefore it is of great importance to discriminate phases of accelerated denudation; and remains a fundamental task to improve on existing, but unsatisfactory, averages of erosion rates over several tens of million years.

Advances in low temperature thermochronology during the last 25 years have made it possible to apply techniques sensitive to temperatures below $\sim 110^{\circ} \mathrm{C}$. Since the development of apatite fission track analysis $\left(\sim 110^{\circ} \mathrm{C}\right)$ and U/Th-He $\left(\sim 70^{\circ} \mathrm{C}\right)$ dating, it has become possible to estimate the timing of cooling from temperatures found in the upper few kilometers of the Earth's crust over long periods of time. In fact, apatite fission track thermochronology is effective over time scales of millions, to hundreds of millions, of years. It can be applied directly to enhance understanding of long-term landscape evolution. Samples can be collected relatively easily from large areas of the crust that enable an insight into regional patterns of long term crustal cooling and denudation, and, compared with previous approaches offer a high spatial resolution (Gleadow and Brown 2000).

In order to estimate denudation rates, and to investigate the landscape evolution relating to the topic of this thesis, 195 samples were collected and processed. Apatite fission track thermochronology has been applied to 158 samples distributed over a large area in central and northern Namibia between $19^{\circ} 30^{\prime} \mathrm{S}$ and $23^{\circ} 55^{\prime} \mathrm{S}$ latitude and $14^{\circ} 15^{\prime} \mathrm{E}$ and $17^{\circ} 50^{\prime} \mathrm{E}$ longitude. The sampling strategy was to extend a preexisting dataset by Haack (1983) and Brown (1992) into areas without apatite fission track data, as well as to collect samples from vertical relief profiles. Vertical relief profiles were sampled across the Brandberg igneous complex, the Spitzkoppe, the Erongo crater, the Windhoekgraben, and the Spreetshoogte Pass. Only samples from the Brandberg, Windhoekgraben had sufficient apatite yields. Apatite mounts from the Okenyenya complex were provided by Roderick Brown. In total 158 apatite fission track analyses were performed, and the results are presented in this thesis.

\subsection{Outline of this Thesis}

The thesis has been divided into seven chapters: the first three chapters introduce the study, the methodology and approach, as well as the regional geological setting of Namibia. The power of vertical profile dating is demonstrated in Chapter Four, constraining the palaeogeothermal gradient for three different locations in the Late Cretaceous. Chapter Five elucidates in detail the application of fission track analysis to assessing crustal movements, and to constraining the timing and magnitude of tectonic reactivation. Parts of this chapter have been accepted for publication in Tectonophysics (Raab et al. in press). The sixth chapter reviews 
the denudation chronology derived from the apatite fission track data on a subcontinental scale. An introduction into previous thermochronological studies is also given here. The final chapter summarises the outcome of this research, and presents ideas for future work.

Five appendices conclude this thesis. Appendix One covers the statistical methods that were necessary for data calculations. The background to sample preparation and experimental conditions is given in the second appendix. A brief sample description, and the full analytical results of fission track dating, are listed in the third appendix. For generating maps and animations, the Generic Mapping Tool (GMT), version 3.3.4, was used (Wessel and Smith 1991). All major GMTscripts are presented in Appendix Four. Animated movies and raw data files are on the CD-ROM attached to this thesis (Appendix E). 


\section{Chapter 2}

\section{Geology, Geomorphology and Tectonics}

\subsection{Introduction}

This chapter reviews the main geological, geomorphological and tectonic events and features of the passive margin of northern Namibia that are relevant for understanding the low temperature thermochronology in this region. The history starts with the Pan-African Damara Orogeny in the Neoproterozoic, when peak metamorphism of the Damara Orogeny reset the geological clock in terms of the low temperature history. This "resetting" can be inferred by apatite fission track analysis. Consequently, apatite fission track ages older than the Cambrian are unlikely to be found in the study area.

For an overall understanding of low temperature thermochronology and landscape evolution in northern Namibia, the following events are of major importance: global scale tectonics; the reactivation of pre-existing shear zones; sedimentary coverage; denudation; and the development of offshore basins. These mechanisms are discussed in detail in the Geology section.

The geomorphology section presents ideas about the evolution of the distinctive morphology of the onshore component of passive margins. Passive continental margins arise from the process of extension, rifting and ocean basin formation that originate from the breaking apart of tectonic plates and the divergent motion of the lithospheric fragments. The primary results of this divergence are subsidence and the formation of basins, which are fairly well known and well researched features (Allen and Allen 1990). In contrast, other resulting features, such as escarpments that characterise passive margin topography in southern Africa and parts of South America, India, Australia and the Red Sea, remain problematic. Their evolution needs to be addressed in the context of surface 
processes and tectonics.

A brief summary of Phanerozoic crustal reactivation is given in the Tectonics section. This section also refers to continental deformation in response to changes in the spreading geometry of Central and South Atlantic Ocean basins, that are closely related to the onshore response of the field area.

\subsection{Geology}

\subsubsection{Overview}

The regional basement structure in northern Namibia is dominated by the northeast to southwest striking intracontinental branch of the Pan-African Damara mobile belt (Tankard et al. 1982). The Damara Orogen separates the Congo and Kalahari cratonic terranes, and is divided into several tectonostratigraphic zones. The main units are subdivided by lineaments forming deep, steeply dipping, ductile shear zones (Miller 1983, Daly 1986, Daly 1989). These regional lineaments form southwest to northeast striking boundaries, and can be traced at least $150 \mathrm{~km}$ offshore (Clemson et al. 1997, Clemson et al. 1999). They extend the Precambrian transcontinental Mwembeshi Shear Zone (MSZ) (Coward and Daly 1984), which continues then across the African sub-continent from northern Namibia through Botswana, Zambia and Malawi (Daly 1986, Daly 1989). An intracontinental extension, accompanied by strike-slip deformation and subsequent reactivation of steeply dipping Proterozoic crustal shear zones, has occurred within the region during multiple episodes in the Phanerozoic (Daly 1989, Daly et al. 1991).

Proterozoic and Phanerozoic metamorphosed rocks, as well as Mesozoic sedimentary and igneous rocks, characterise the region of the study area (Fig. 2.1). The Proterozoic cratonic rocks in the north are exposed as the Kamanjab Inlier. These occur within the overlying Neoproterozoic to Early Cambrian Damara rocks, which accumulated in a continental rift as a cover sequence over the southern margin of the Congo Craton. Peak metamorphism, as a consequence of cratonic collision, occurred in the Middle Cambrian to Lower Ordovician between $534 \pm 7 \mathrm{Ma}$ and 508 $\pm 2 \mathrm{Ma}$ (Miller 1983). K-Ar cooling ages by Haack (1983) indicate temperatures of ca. $300^{\circ} \mathrm{C}$ at ca. $481 \pm 25 \mathrm{Ma}$.

Deep erosion of the Pan-African Damara Orogen, Permo-Triassic collisional processes along the southern margin of Gondwana and eastern margin of Africa (Coward and Daly 1984, Daly et al. 1991), as well as deposition of the Nama Group sediments and the Karoo megasequence, affected Namibia from PermoCarboniferous times to Mid Jurassic times. Early Mesozoic tectonic reactivation of some of the regional lineaments is recorded by coarse clastic sediments deposited within northeast striking half-graben structures between the Otjohorongo 


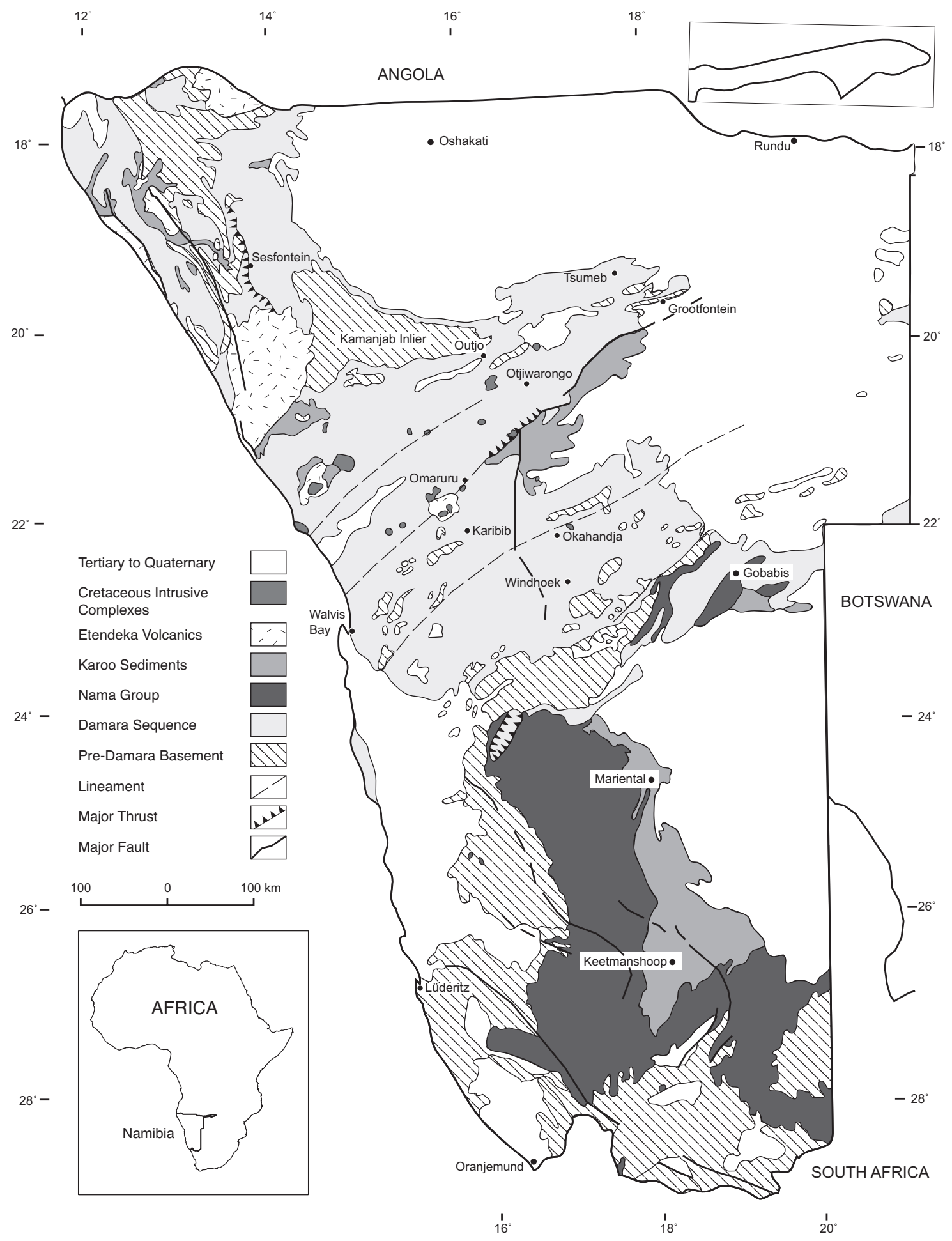

Figure 2.1: Simplified geological map of Namibia. 
Thrust and the Omaruru Lineament-Waterberg Thrust (Hegenberger 1988).

Two episodes of continental flood basalt volcanism occurred in Namibia in the Mesozoic, interpreted as main episodes in a multiple stage history of disintegration of Gondwana (Storey 1995). The Early Jurassic Karoo lavas erupted rapidly over a vast asymmetric region of Gondwanaland at $183 \pm 1 \mathrm{Ma}$, ca. 50 Ma prior to continental rifting in the South Atlantic (Duncan et al. 1997). Early Cretaceous continental break-up, and initial sea-floor spreading in the South Atlantic, were accompanied by eruption of large amounts of continental flood basalts and extensive mafic dike swarms on both sides of the Atlantic Ocean. During the latter episode the Paraná-Etendeka flood basalts were erupted slightly before or contemporaneously with continental rifting in the Early Cretaceous over a short period of time at 132 $\pm 1 \mathrm{Ma}$ (Renne et al. 1992, Milner et al. 1995, Stewart et al. 1996, Turner et al. 1996). Approximately 26 Early Cretaceous alkaline intrusions (137-124 Ma) were preferentially emplaced along the Mesozoic half-graben structures and form the Damaraland Igneous Province (Watkins et al. 1994, Milner et al. 1995). In the northern Etendeka province in Namibia, the lava sequence is preserved within narrow, coast-parallel, fault-bounded half-grabens. In the same area, a conglomerate, consisting entirely of basaltic clasts derived from the west, was deposited within an active half-graben structure (Ward and Martin 1987). These half-graben structures clearly post-date the volcanism, and significant tectonism and erosion of the lava sequence is indicated at some time after ca. 124 Ma.

The morphology of the Atlantic margin is characterised by an interior highland region separated from a dissected coastal zone by a prominent erosional escarpment. The Great Escarpment is one of the most prominent geomorphological features in Namibia. It runs parallel to, and $200 \mathrm{~km}$ inboard of, the present coastline (Ollier 1985, Brown et al. 2000). The escarpment diminishes over a ca. $160 \mathrm{~km}$ wide zone, confined by the Autseib Fault-Otjohorongo Thrust and the Okahandja Lineament. Deep erosion associated with the period of reactivation has obliterated the escarpment within the Central Zone of the Damara Orogen, and the regional topography now rises gently from sea level towards the interior, forming a regional ramp of less than $1^{\circ}$.

Remnants of Permo-Carboniferous glaciogenic deposits indicate that parts of the present land surface in the north correspond with the Permo-Carboniferous land surface (Martin 1975).

\subsubsection{Origin of Major Lineaments}

The major tectonic boundaries within the Damara Belt in northern Namibia are formed by regional lineaments, with the most prominent being the Okahandja Lineament (OKL), the Omaruru Lineament (OML) and the Autseib Fault (AF). 
The Omaruru Lineament extends into the Waterberg Thrust (WT), while the Autseib Fault extends into the Otjohorongo Thrust (OT). The orientation of these lineaments reflects the regional structural trends that existed in the pre-Damara metamorphic basement. These structures form deep crustal ductile shear zones, and appear to have controlled the location of the rift basin into which the early Damara sediments were deposited (Tankard et al. 1982, Miller 1983, Martin and Eder 1983). They divide the Pan-African Damara Orogen into several tectonostratigraphic units, and are at least in part recognisable by aeromagnetic data (Corner 1983).

The Okahandja Lineament represents a zone of differential movement between the Central and Southern Zone of the Damara Orogen. During the last deformation event at $520 \mathrm{Ma}$, the Central Zone was downfolded under the Southern Zone. This fold is the present expression of the Okahandja Lineament (Downing and Cowards 1981).

The Omaruru Lineament-Waterberg Thrust divides the Central Zone of the Damara Orogen (Miller 1983); and periodic fault movement during the Mesozoic (Permian to Early Triassic) is supposed to have controlled subsidence and sediment supply of the Karoo strata in the Waterberg region (Johnson et al. 1996, Holzförster et al. 1999).

The Autseib Fault-Otjohorongo Thrust is formed by southward dipping reverse faults separating the northern Central Zone (Damara Belt) and the Northern Zone (Kaoko Belt) of the Damara Orogen. Late to post-Karoo rejuvenation of this fault was first reported by Miller (1980). The rejuvenated fault acted as an accommodation zone during Karoo rifting, and separated different styles of faulting, that were controlled by underlying Pan-African basement fabrics (Clemson et al. 1999).

While the Okahandja Lineament diminishes to the west under the Namib Sand Sea, the Omaruru Lineament and Autseib Fault can be traced for at least $150 \mathrm{~km}$ offshore (e.g. Clemson et al. 1997, Clemson et al. 1999). The Omaruru Lineament and Autseib Fault, as well as the adjacent basement fabrics, are generally steep dipping, and are known to have strongly influenced the rift geometry in this area (e.g. Clemson et al. 1999).

\subsubsection{The Karoo Igneous Province}

Early Jurassic eruption of voluminous basalts terminated the terrestrial Karoo Sequence (Permian to Triassic) in southern Africa within a relatively short period. The associated remnants of the thick volcanic succession of lava flows, and extensive dike and sill complexes of similar composition, are grouped together as the Karoo Igneous Province in southern Africa (Duncan et al. 1997). The Ka- 
roo basalts are of tholeiitic composition on the basis of major and trace elements (Marsh et al. 1997) but vary texturally as a function of cooling rate. The Karoo Igneous Province covers an elongated area, and reflects the relationship to the geometry and melting regime of the subduction zone operating along the Pacific margins of Gondwana.

The Karoo Igneous Province is one of the largest and best exposed of the large continental flood basalt provinces (Erlank 1984, Cox 1988). It comprises thick sequences of volcanic rocks preserved in erosional remnants, and a well developed subvolcanic plexus of dykes and sills scattered throughout southern Africa. Karoo igneous rocks have been emplaced in different tectonic settings, and with considerable differences in lithostratigraphic sequences, across the province. Because of its variety of settings, the temporal and spatial evolution of the entire Karoo magmatism has been difficult to correlate. Duncan et al. (1997) confined the majority of igneous activity with new ${ }^{40} \mathrm{Ar} /{ }^{39} \mathrm{Ar}$ data into a very narrow time frame of $3 \mathrm{Ma}$ at $183 \pm 1 \mathrm{Ma}$. These ages match with other igneous provinces like the Ferrar province in Antarctica, indicating that the Karoo Igneous Province has been rapidly erupted over a vast, asymetric region of Gondwana, prior to continental rifting.

\subsubsection{The Paraná-Etendeka Province}

Basalts, rhyolite sheets and central intrusive complexes in northwestern Namibia that form the Etendeka Province were previously included in the Karoo Igneous Province but are now known to be of Early Cretaceous age (O'Connor and le Roex 1992, Renne et al. 1992), and hence coeval with volcanic activity of the Paraná flood basalt province of central eastern South America. The intrusion of the Paraná-Etendeka flood basalts occured slightly before, or contemporaneously with, continental rifting in the South Atlantic (Renne et al. 1992). Most of the magmatic activity occured over a short period of time, at $132 \pm 1$ Ma (Renne et al. 1992, Turner et al. 1994, Milner et al. 1995, Renne et al. 1996a, Renne et al. 1996b, Stewart et al. 1996), based on laser spot ${ }^{40} \mathrm{Ar} /{ }^{39} \mathrm{Ar}$ analysis on feldspar. A late tholeiitic magmatic episode at $128-119 \mathrm{Ma}$ is represented by coast parallel dykes, e.g. Ponta Grossa (NE dykes) and Santos-Rio de Janeiro dykes in Brazil, and Horingbaai dykes in Namibia (Erlank 1984, Renne et al. 1996a).

The Paraná-Etendeka Province is, with its large aerial extent in excess of ca. 2.5 million $\mathrm{km}^{2}$, the estimated volume of ca. 1.5 million $\mathrm{km}^{3}$, and dominance of basaltic compositions, one of the largest continental igneous provinces. It is comparable to other major continental flood basalt provinces such as the Siberian, Deccan, and Karoo-Ferrar provinces (Erlank 1984, Peate 1997) as described in 2.2.3. The Etendeka Flood Basalt Province represents approximately 5\% of the entire Paraná-Etendeka Province. The major part of the Etendeka Formation en- 
compasses an area of ca. $78000 \mathrm{~km}^{2}$ between Cape Cross and Cape Fria. Consisting of subaerially erupted tholeiitic lavas $\left(51-59 \% \mathrm{SiO}_{2}\right)$ interbedded with quartz latite units (66-69\% $\mathrm{SiO}_{2}$ ), the main Etendeka lava field interbeds with aeolian sandstones of the Etjo Formation up to $130 \mathrm{~m}$ above the volcanic succession (Milner et al. 1995, Jerram et al. 1999).

The aerial coverage of the Paraná-Etendeka Province may have been much larger than indicated above. Moreover, petrologic, geochemical, and geochronologic data presented by Marzoli et al. (1999) demonstrated the province's extent into the Kwanza basin in central western Angola. This indicates that the Paraná-Etendeka Province extends by ca. $400 \mathrm{~km}$ further to the North-East than previously recognised. Marzoli et al. (1999) also show that younger $( \pm 125 \mathrm{Ma})$ coast-parallel dykes from Angola are coeval with those from much farther south in Brazil, perhaps weakening the case for northward-progressive opening of the south Atlantic.

Stratigraphic relations between the basal Etendeka flows, and the underlying Etjo Formation (equivalent to the Botucatu Formation in Brazil), provide evidence of the existence of a vast desert throughout the province at the time of the onset of flood volcanism (Jerram et al. 1999).

Using the anisotropy of magnetic susceptibility as an approximation for lava flow direction for stratigraphic sections in the southern Paraná Basin, Tamrat and Ernesto (1999) suggest that the flows were more likely to have been controlled by variable topography or other factors.

\subsubsection{The Damaraland Igneous Province}

Over twenty Early Cretaceous intrusions form the Damaraland Alkaline Igneous Province (DIP), and were emplaced as subvolcanic ring complexes into the shallower crust (Diehl 1990). All of the complexes are aligned along a northeasttrending, $130 \mathrm{~km}$ wide and $350 \mathrm{~km}$ long, zone which coincides with the northeasterly strike direction of the Pan-African Damara Orogen, and follows its inherited basement structures and lineament zones (Fig. 2.2). A number of Mesozoic, coast parallel, and north-south striking faults have been recognised by Diehl (1986), and are believed to have additionally contributed to the emplacement of the complexes controlled by the old major lineaments.

A wide span of isotopic ages was reported for the Mesozoic ring complexes and the Etendeka volcanic succession. The most robust ages determined by the $\mathrm{Rb}-\mathrm{Sr}$ and ${ }^{40} \mathrm{Ar} /{ }^{39} \mathrm{Ar}$ methods point to a rapid eruption of the Etendeka Province, and an almost simultaneous emplacement of some of the ring complexes. Laser spot ${ }^{40} \mathrm{Ar} /{ }^{39} \mathrm{Ar}$ analysis on feldspar could bracket the Etendeka lavas in a very narrow time frame of 132 $\pm 1 \mathrm{Ma}$ (Renne et al. 1992, Turner et al. 1994, Renne et al. 


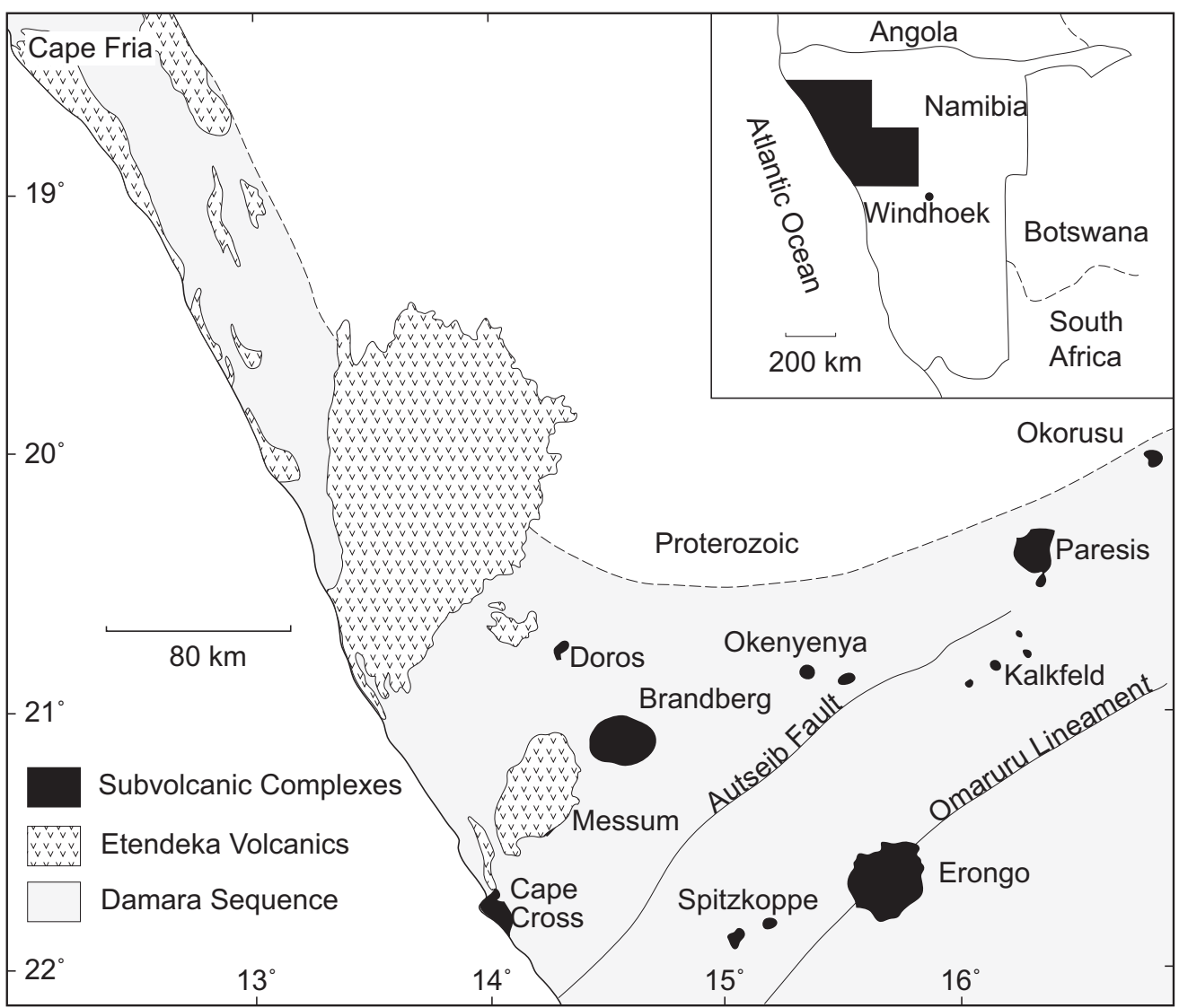

Figure 2.2: Map of northwestern Namibia showing the distribution of Etendeka volcanics and the Mesozoic ring complexes of the Damaraland Igneous Province (after Milner et al. 1995).

1996a, Renne et al. 1996b, Stewart et al. 1996). ${ }^{40} \mathrm{Ar} /{ }^{39} \mathrm{Ar}$ age determinations on metaluminous and peralkaline units of the Brandberg complex range from 132$130 \mathrm{Ma}$. This indicates the contemporaneous formation with flood basalts and associated felsic volcanism in the Paraná-Etendeka Province (Schmitt et al. 2000). Identical $\mathrm{Rb}-\mathrm{Sr}$ isochron ages of $132 \pm 4 \mathrm{Ma}$ were reported by Manton and Siedner (1967) for a suite of comendite rocks from the Paresis complex; and 132 $\pm 2 \mathrm{Ma}$ were reported by Allsop et al. (1984) for biotite-bearing gabbros from the Messum complex. K-Ar age determinations on mineral separates from the Okenyenya are observed by Watkins et al. (1994). This would restrict magmatic activity of the Okenyenya complex into a time interval of 133-128 Ma, with a mean of $130 \pm 2 \mathrm{Ma}$. The same interval of magmatic activity over $5 \mathrm{Ma}$ is assumed for the Messum complex by Milner et al. (1995). Their Rb-Sr whole rock and ${ }^{40} \mathrm{Ar} /{ }^{39} \mathrm{Ar}$ dating produced ages for the Messum nepheline syenite of $127 \pm 1$ Ma. Similar ages were obtained from the Okorusu complex (127 $\pm 7 \mathrm{Ma}$ ). Ages pre-dating the eruption of the Etendeka volcanics were obtained from the Paresis complex with 
$137 \pm 1 \mathrm{Ma}$, and from the Cape Cross complex with $135 \pm 1 \mathrm{Ma}$.

The onset of igneous activity is believed to have started approximately 137$135 \mathrm{Ma}$ ago with limited activity, and the emplacement of the Paresis (137 $\pm 1 \mathrm{Ma}$ ) and Cape Cross complex (135 $\pm 1 \mathrm{Ma}$ ). Voluminous eruptions of Etendeka flood basalts (132 $\pm 1 \mathrm{Ma})$ happened at the same time as the intrusion of the Brandberg. Magmatic activity along the Damaraland Ignous Province continued for approximately $10 \mathrm{Ma}$, and terminated after the onset of sea-floor spreading in this area (Milner et al. 1995). The Horingbaai dolerite intrusion appeared in response to, and contemporaneously with, the onset of sea-floor spreading at ca. 130-125 Ma (Erlank 1984, Renne et al. 1996b).

The basement geology of that area consists of Proterozoic rocks (2.1-1.7 Ga) which form the southernmost extent of the Congo Craton. The Proterozoic inliers are bound to the west and southeast, and are also partially overlain, by rocks of the Pan-African Damara Sequence (Miller 1983). The Damara Sequence itself is unconformably overlain by sediments of the Karoo Sequence, while Etendeka volcanics conformably overlay deposits of the Karoo sedimentary succession, and also often lie directly on pre-Karoo basement (Milner et al. 1995) (Fig. 2.2). Numerous basic dykes and sills intrude the basement, the Karoo sedimentary rocks and the overlying lavas.

\subsubsection{Cretaceous Dyke Swarms}

Regional dyke swarms are a dominant feature of the coastal geology of northern Namibia. Along the length of Namibia, numerous dolerite dykes penetrate the Damara basement in swarms trending mainly north to northeast. The dykes were erupted immediately prior to the splitting of Western Gondwana and the Southern Atlantic Ocean, and are associated with the initial continental rifting processes. Many dykes have acted as feeders to the extensive Etendeka flood basalts, which were subsequently erupted over much of this area. A set of north-northeast trending dyke swarms covering most of the western part of the Central Zone, are described by Lord et al. (1996), using Landsat imagery. Magnetotelluric profiling (Ritter et al. subm.) reveal a concentration of subsurface and mainly northeast striking mafic dykes, named Hentjies Bay-Outjo dyke swarms (HOD). The latter are restricted to the Central Damara Zone, but trend further northeast over $300 \mathrm{~km}$ inland and follow predominantly the tectonostratigraphic structures of the Damara Orogen. Hunter and Reid (1987) note that other mafic dyke swarms located elsewhere in southern Africa appear to have been controlled by pre-existing zones of crustal weakness. They noted for example the spatial coincidence of $1.9 \mathrm{Ga}$ ultramafic dykes, Jurassic and younger kimberlite pipes; as well as a later dyke swarm all of which are to be found in the Transkei and in southern Namibia. They suggest that this swarm marks the site of a long-lived, deep-seated (sub-crustal) 
lineament.

Lord et al. (1996) state that the distribution of Mesozoic dykes in Namibia generally reflects that little control by the tectonic fabric was imposed during the Damara tectonothermal event; whereas Ritter et al. (subm.) clearly point to the influence of pre-existing basement structures as the main control factor for dyke emplacement. Striking with $30^{\circ}-40^{\circ}$ northeast, the dykes are subparallel to the regional trend of foliation, faults and lineaments. However, the Central Damara Zone, confined within two prominent lineaments (Autseib FaultOtjohorongo Thrust and Omaruru Lineament-Waterberg Thrust), is characterised by pre-Damara basement granitic gneisses which generally form flat-topped, elongated domes. These domes are separated by medium- to high-grade, predominantly metasedimentary, cover rocks. The elongate nature of domes and synclines imparts a very strong northeast trend to the regional structure of this part of the orogen.

K-Ar and Rb-Sr dates (Hunter and Reid 1987, Milner et al. 1995) show that the dominant dyke swarms were emplaced within two main periods in Early Jurassic (Karoo) and Early Cretaceous (Etendeka). The Etendeka volcanics erupted over a very short period of $2 \mathrm{Ma}$ at $132 \pm 1$ (Duncan et al. 1997). The presence of dykes along the present coastline of South America indicates an initial phase in the continental rupture of Gondwana during the Early Cretaceous.

The contemporaneous eruption of mafic dyke swarms along the coastline of southwest Africa and the eastern coastline of South America is believed to have occurred as a response to the initial rifting processes which led to the fragmentation of western Gondwana. Regional domal uplift above newly established mantle plumes, and the associated crustal extension, led not only to the development of new, broadly coast parallel fractures, but also to the reactivation of pre-existing ones. These fractures acted as loci for the emplacement of the dolerite dykes, many of which acted as feeders to flood basalts that were subsequently poured out over a large area of the juxtaposed continents. This may suggest the presence of a large and prolonged mantle plume beneath the Paraná-Etendeka area. The dykes record an initial phase of Gondwanan rupture immediately before continental drift was established, and the separation of Africa and South America took place.

\subsubsection{Gondwana Fragmentation}

The break-up and dispersal of a supercontinent like Gondwana represents a radical change in the plate tectonic regime. Supercontinents are assembled as a consequence of plate movements, and they are likely to have significant effect on the thermal structure of the upper mantle, and on global climate. While the causes of break-up of supercontinents are still a matter of debate (Anderson 1982, Bott 
1992, Wilson 1993), the break-up was a highly significant tectonic event in terms of landscape evolution at the macroscale, and created many new passive continental margins (Summerfield 1991). Several models have been proposed, including: lithospheric extension in response to subduction (Storey et al. 1992); and the dynamic response to the emplacement of deep-seated mantle plumes (Hill 1991, Storey and Kyle 1997). It has been argued that supercontinents will tend to fragment in response to the build-up of heat and resultant magmatism (Anderson 1982) and, alternatively, that the break-up of megacontinents requires the emplacement of a megaplume (Storey and Kyle 1997). Due to the low rate of heat loss through continents, both models imply a major role for mantle hotspots, which are linked to models for the generation of continental flood basalts (Turner et al. 1996). Current models for supercontinent break-up invoke the plate and boundary forces that drive plate motions or some active internal mantle processes (Sengor and Burke 1978).

The fragmentation of Gondwana began during the Late Triassic/Early Jurassic, and was associated with an increase in the rate of mantle convection to the south of the continent (Park and Jaroszewski 1994). The process of continental breakup was initiated by newly established mantle plumes. These produced an initial decrease in density of the lithosphere in their vicinity, which caused the domal uplift of brittle upper crust along the incipient South Atlantic. To accommodate the crustal stretching associated with doming, Gondwanan continental crust then began to rupture along a series of northward progressing rifts. These rifts then led out from plumes/hotspots located along the developing margin between South America and Africa. However, the rift propagation of the entire Atlantic Ocean follows the trend of pre-existing orogenic fabric of the plates, systematically reactivating ancient lithospheric structures. Rifting was not just related to the regions above the plume head; it began more or less simultaneously along segments which follow almost exactly the trend of Hercynian, Pan-African and Caledonian belts (Tommasi and Vauchez 2001). The linking of adjacent rifts led to the full development of the ridge-transform boundary, and to the start, between the late Jurassic and the Cretaceous, of the separation of the South American and African plates.

Continued heating above the plume led to further regional up-warping and lithospheric thinning along the newly formed divergent margin. This was associated with crustal dilation and the formation of tensional fractures, broadly parallel to the developing coastline. These newly formed discontinuities helped determine the location of regional sheeted dyke swarms, which were subsequently emplaced in the relatively weaker crust. The trend of many of these regional dyke swarms is related to the trajectories of the local stress field associated with the original divergent plate movements (Gudmundsson 1990).

Continental rifting between South America and Africa began in Namibia during the Late Jurassic about 150 Ma ago (Rift Stage I) (Nürnberg and Müller 
1991, Light et al. 1992, Light et al. 1993). Rift Stage II has been bracketed into the Late Hauterivian - Barremian (130-120 Ma), coinciding with the initiation of seafloor spreading in the south, and slightly post-dating the beginning of the ParanáEtendeka flood basalt volcanism (132 Ma) in the north (Turner et al. 1994, Milner et al. 1995, Renne et al. 1996b, Stewart et al. 1996). Rifting is supposed to have propagated from the Falkland-Agulhas fracture zone in the south to the Walvis Ridge-Rio Grande Rise in the north. The oldest magnetic anomaly (M4) has been dated back to $130 \pm 1 \mathrm{Ma}$ and is identifiable on both sides of the South Atlantic. The oldest anomaly near the Walvis Ridge-Rio Grande Rise (M0) is supposed to be 5 Ma younger (125 Ma) (Wickens and McLachlan 1990, Nürnberg and Müller 1991). Rifting north of the Walvis Ridge-Rio Grande Rise began during the Late Jurassic to Early Cretaceous between Tithonian - Barremian (152-125 Ma) (Castro 1987, Chang et al. 92). Terrestrial sedimentation marked the initial phase of the developing marginal rift basins in the South Atlantic. The transition to marine depositonal environments is marked by a well developed 'drift-onset' unconformity shortly after break-up (Brown et al. 1995) at the end of the Hauterivian (130 Ma).

\subsubsection{Offshore Basins}

The offshore margin of southwest Africa consists of four major basins. These are from south to north the Orange, Lüderitz, Walvis and Namibe Basins. Sedimentary sequences in the main depocenters of these basins are generally less than $6 \mathrm{~km}$ thick, but can exceed $12 \mathrm{~km}$ in the northern Walvis Basin (Gerrard and Smith 1982, Rust and Summerfield 1990, Maslanyj et al. 1992).

According to Rust and Summerfield (1990), as well as Brown et al. (1995), the majority of sediment volumes within the Orange and Walvis Basins were deposited during the Late Cretaceous-Early Tertiary. Rust and Summerfield (1990) determined the offshore sediments to equate a depth of denudation of $1.8 \mathrm{~km}$ averaged over the Orange River catchment and other Atlantic draining catchments up to the Walvis Ridge. The total volume of sediments in the basins offshore Namibia (Orange, Lüderitz and Walvis Basin) clearly indicate that averaged amounts of at least $2 \mathrm{~km}$ of denudation occurred since their formation in the Middle Jurassic to Early Cretaceous (Section 1.2).

Intensive seismic exploration along the entire Namibian margin has provided excellent profiles across the sedimentary basins offshore Namibia. Results and interpretations have been published by several authors (e.g. Light et al. 1993, Maslanyj et al. 1992, Brown et al. 1995) in the past decade, but due to the lack of biostratigraphic data, interpretation is still an ongoing process. The only available information from offshore boreholes in Namibia is from the Kudu gasfield south of Lüderitz. 
The burial history of Cretaceous sediments of the Kudu gasfield is based on the interpretation of biostratigraphy and vitrinite reflectance values from well data (Wickens and McLachlan 1990, Davies and van der Spuy 1992). The vitrinite reflectance values indicate sedimentary thicknesses of at least $3000 \mathrm{~m}$ for Late Cretaceous sediments (Early Cenomanium to Campanian).

The compaction corrected burial history reconstruction of Davies and van der Spuy (1992) shows that Lower Cretaceous deep marine sediments were deposited during Late Barremian to Early Aptian $( \pm 115 \mathrm{Ma})$. Moderate sedimentation and burial rates remained until Turonian $(90 \mathrm{Ma})$ in the Late Cretaceous. A total thickness of $2500 \mathrm{~m}$ was deposited with extremely high sedimentation rates from Turonian to Santonian (91-83 Ma). From the start of the Campanian (83 Ma), moderate sedimentation rates were twice interrupted by erosional events in Mid Campanian ( $\pm 78 \mathrm{Ma}$ ) and Miocene until Late Miocene.

The present palaeogeothermal gradient, derived from borehole temperatures, indicates a present gradient of $3.5^{\circ} \mathrm{C} / 100 \mathrm{~m}$, while the palaeogeothermal gradient across the Cretaceous and Tertiary section, derived from vitrinite reflectance values, indicates an average gradient of $3.8^{\circ} \mathrm{C} / 100 \mathrm{~m}$.

\subsubsection{Post Break-Up Geology}

Terrestrial sedimentation in Namibia after break-up was largely restricted to a $150 \mathrm{~km}$ wide zone during the Cenozoic. This region on the bedrock platform of the coastal plain is now occupied by the Namib Sand Sea in central Namibia (Ward 1987). The oldest unit, the Tsondab Sandstone Formation, has a preserved thickness of less than $300 \mathrm{~m}$ and is believed to have a maximum age of early Palaeocene (Ward 1987, Ward 1988). The Tsondab Sandstone Formation unconformably overlies an extensive erosional surface (Namib Unconformity Surface) which cuts into the predominantly Late Precambrian basement rocks (Ollier 1978, Ward 1987, Ward 1988). The chronology of the upper part of this sequence has been dated through the correlation of giant bird eggs with associated micromammals in East Africa, and appeared to span a period of $11 \mathrm{Ma}$ from middle Miocene (ca. $13 \mathrm{Ma}$ ) to Pliocene (ca. $2 \mathrm{Ma}$ ) (Senut and Pickford 1995). Exposed remnants of the Tsondab Sandstone Formation preserved the escarpment to within 3-30 km of its base along the eastern edge of the present day sand sea borders (Ward 1987, Besler 1996).

Some denudation of the escarpment during the Miocene is implied by the accumulation of rounded clasts of basement rocks of the alluvial Karpfencliff Conglomerate Formation (Ward 1987). The fluvial character of this deposit is the earliest record of a well-developed, westerly directed, drainage system and indicates a change from arid to semi arid conditions (Ward 1987). A return to arid 
conditions occurred in the Late Miocene with the development of the Benguela Current, leading into the current climatic conditions of the Namib Desert regime (Siesser 1978, Siesser 1980) with the formation of the Soussus Sand Formation and main Namib Sand Sea south of the Kuiseb river (Ward 1987).

Numerous kimberlite intrusions and associated alkaline pipes have been recognised inland in South Africa and Namibia. In some localities in Namaqualand, the preserved crater facies sedimentary sequences imply only minimal net denudation in the order of less than $100 \mathrm{~m}$ since the Late Cretaceous (Smith 1986, DeWit et al. 1992).

\subsection{Geomorphology}

\subsubsection{Quantifying Geomorphic Development}

Constraining the geomorphic development of passive margins requires an understanding of the pattern and rate of denudation. Advances in monitoring long term denudation rates have resulted from new quantitative techniques in the past twenty years. $\mathrm{K}-\mathrm{Ar}$ and ${ }^{40} \mathrm{Ar} /{ }^{39} \mathrm{Ar}$ dating of volcanic rocks, for example, led to significantly more age control in onshore landscape assemblages and sedimentary sequences. Identification of dated material at a certain distance away from a source rock or at a certain depth in a deposit can provide some estimates on rates of denudation. However, these techniques require datable material of significant age that can be closely correlated with landforms or denudation events. This is particularly difficult on landscapes dominated by denudation, such as passive margins. Analysis of offshore basins is another method which has successfully been used to determine long term denudation rates (e.g. Rust and Summerfield 1990, Pazzaglia and Gardner 2000). Uncertainties can be very high due to large basins and poorly constrained catchment areas for sediment supply. Subtle changes in drainage networks can have dramatic effects in sediment supply to offshore basins.

Since thermochronologic techniques, such as apatite fission track dating, are sensitive to low temperatures, they have provided new insights into the regional denudation history of landscapes in passive margin settings, such as the Transantarctic Mountains (Gleadow and Fitzgerald 1987, Fitzgerald and Gleadow 1988), western Brazil (Harman et al. 1998) and southern Africa (Brown et al. 1990, Brown 1992, Gallagher and Brown 1997, Gallagher and Brown 1999a, Gallagher and Brown 1999b, Brown et al. 2000).

Cosmogenic isotope analysis of in situ produced cosmogenic isotopes, such

as ${ }^{10} \mathrm{Be},{ }^{26} \mathrm{Al}$ and ${ }^{36} \mathrm{Cl}$, has been employed to calculate site-specific denudation rates, and is valid over time scales of $10^{4}-10^{6}$ a (Biermann 1994, Cockburn et al. 1999, Fleming et al. 1999, Cockburn et al. 2000). 
Combining these techniques carries great potential as a means of distinguishing between discrete phases of accelerated denudation that has occurred as a consequence of large scale tectonics from slow climatic controlled downwearing processes, which have shaped the present landscape.

\subsubsection{Morphology of the Margin}

Larger scale erosional escarpments are common features of rifted margins that have high elevation inland, such as southern Africa, eastern Brazil, western India and the Red Sea (Gilchrist and Summerfield 1994). These escarpments, which can be $1 \mathrm{~km}$ high, and up to several hundred kilometers from the coastline, separate a low elevation coastal area with typically low relief, from the inland higher elevation area. Ollier (1985) interpreted these escarpments to be genetically related to continental rifting. He suggested that they have retreated inland from the rifting hinge zone since continental break-up, when local base levels dropped considerably and/or margin flanks were uplifted. Geodynamic explanations for the tectonic rift flank-uplift include: differential stretching between crust and mantle (Royden and Keen 1980); lateral heat flow (Cochran 1983); dynamical effects due to secondary mantle convection (Buck 1986); magmatic underplating (White and McKenzie 1989); and flexural unloading of deep lithospheric necking. The last mechanism is favoured (Braun and Beaumont 1989) when flank uplifts at rifted margins persist for $100 \mathrm{Ma}$ and more. That is longer than the time (ca. $60 \mathrm{Ma}$ ) required for the lithosphere to cool, contract and subside from a hot syn-rift state, suggesting that a non-thermal mechanism is required. The margin flank-uplift affects the morphology and general elevation of passive margins far inland, and may also initiate the formation of the large erosional escarpments observed on some margins.

The morphology of the passive margin of Namibia is characterised by a high elevation interior plateau with a mean elevation above $1 \mathrm{~km}$ and a major seaward facing escarpment (Great Escarpment), separating a variable dissected coastal plain from the interior over a width of approximately $150 \mathrm{~km}$ (Ollier 1985, Gilchrist et al. 1994, Brown et al. 2000). The Great Escarpment reaches elevations of up to $2350 \mathrm{~m}$ and can be roughly traced around the edge of the southern African plateau, from central Angola to the eastern edge of South Africa, where the Great Escarpment is particularly well developed in the Drakensberg region. However, considerable variations are notable along its length, reflecting variations in the tectonic history, in lithologies and in the drainage system. The escarpment region in the field area merges with the northeast-trending highland region of the Khomas Hochland. In the Central Damara zone, the escarpment is replaced by a gradual rise from the coast to the elevated interior over a zone of approximately $350 \mathrm{~km}$. This zone is characterised by major lineaments, and superimposed on this re- 
gional morphology are the isolated massifs of the Damaraland Igneous Province. In northern Namibia the escarpment rises again and extends into central Angola, where it locally reaches elevations of over $2500 \mathrm{~m}$ (see Figure 5.4 and 6.2).

\subsubsection{Evolution of High Elevated Margins}

Current landscape evolution models for passive margins can be broadly divided into three different classes (Gallagher et al. 1998, Gallagher and Brown 1999a). All three conceptual models - the downwarp, scarp retreat and pinned divide model - are considered applicable to passive margins characterised by a welldefined escarpment separating a high elevated interior plateau from a low elevated coastal platform. The three different models predict various styles of denudation. The style of denudation will determine the cooling history of a margin; and this means that the models can predict a distinct spatial distribution of expected fission track ages (Figure 2.3d). Fission track thermochronology is therefore an excellent tool for testing the models by assessing the characteristic denudational histories they predict (Gallagher et al. 1998, Gallagher and Brown 1999a).

Quantitative surface process models have been developed to explain the denudation and morphological development of high elevated margins (Gilchrist et al. 1994, Tucker and Slingerland 1994, Kooi and Beaumont 1994). These surface process models produce very realistic landforms, but their usefulness is limited by the lack of empirical constraints on how escarpment systems respond to different conditions, such as tectonics, drainage divide, and lithological differences (van der Beek and Braun 1998). However, despite this, surface process models have been useful in highlighting the role of drainage divide location, leading to formulation of the pinned divide model (see below).

The downwarp models (King 1962, Ollier and Pain 1997) propose a broad monocline formed by long-wavelength downflexing of the newly formed land surface after continental rifting (Figure 2.3a). Moderate amounts of denudation are predicted to occur between the crest of the escarpment and the coast, with only minimal denudation occurring inland of the escarpment. Based on this model, remnants of the old land surface will be found along the coast and inland of the escarpment. Therefore, older apatite fission track ages (as old or older than the initial surface) will be observed along the coast and the margin interior. Apatite fission track ages observed inbetween the coast and the escarpment will therefore only be moderately reduced.

The downwarp models do not take into account the isostatic rebound of the lithosphere to denudational unloading. The isostatic rebound is taken into account by the scarp retreat models (Gilchrist and Summerfield 1990, Gilchrist et al. 1994, Tucker and Slingerland 1994) which suggest that an initial escarpment was 

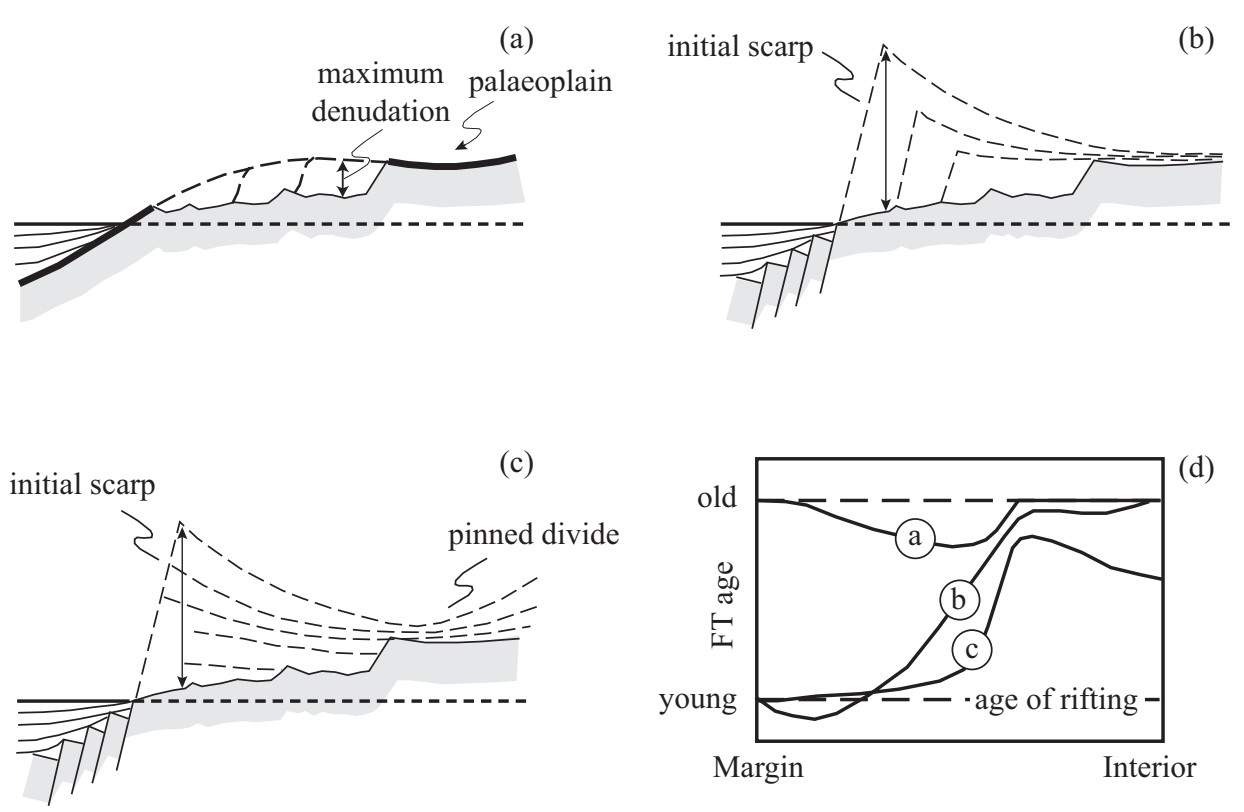

Figure 2.3: Schematic models for the evolution of high elevated passive margins with steep escarpments (after Gallagher et al. 1998). (a) Downwarp model, (b) scarp retreat model, (c) pinned divide model, (d) spatial distribution of expected fission track ages across the margin.

formed by differential vertical displacement across normal faults (Figure 2.3b). As a consequence of the newly formed high relief, maximum denudation rates are expected to occur immediately seaward of the escarpment. High rates of escarpment retreat in the order of approximately $1 \mathrm{~km} \mathrm{Ma}^{-1}$ are commonly assumed for retreat of the Great Escarpment in Namibia (King 1983, Selby 1993, Ollier and Pain 1997). These rates are based on the assumption of uniform retreat of an escarpment from the coast since the initiation of continental break-up, and are often used as a basic model component for passive margin evolution (Gilchrist and Summerfield 1990). Denudation rates decrease along the coastal region to moderate, and the interior is characterised by very low rates. This strong gradient in denudation rates will be reflected by a strong gradient in fission track ages. The oldest apparent ages are therefore expected in the continental interior, with a strong younging towards the coast.

The pinned divide model (Gilchrist et al. 1994, Kooi and Beaumont 1994) enhances the scarp retreat models, in that it takes a preexisting drainage divide into account (Figure 2.3d). It also incorporates a steep escarpment that formed during continental rifting into the initial margin topography. The position of the drainage divide is placed in the order of $100 \mathrm{~km}$ inland from the initial escarpment. A gentle slope towards the rift escarpment allows rapid stream incision draining seawards. Denudation rates remain uniform until a new escarpment position is 
produced close to the initial location of the drainage divide. The pinned drainage divide model also allows significant denudation inland of the drainage divide if the base level of the inland drainage is lowered during the formation of the initial escarpment. The 'pinning' occurs so that the position of the initial drainage divide forms the maximum downwearing, or retreat boundary and is represented by the current position of the escarpment. This results in the assumption that the drainage divide started near its present position, and the initial escarpment - formed at the coast - would have been denuded by large scale downwearing of the coastal plain, and then reformed at the drainage divide.

While the pinned divide model produces a down-wearing of the landsurface compared with a retreat pattern of the scarp retreat models, the major differences between these models are the prediction of denudation, and its timing across the margin, as well as the amount of denudation occurring inland of the final position of the escarpment.

In Namibia, as for southern Africa as a whole, the scarp retreat model has dominated (King 1962, Gilchrist and Summerfield 1990). However, surface process modelling has suggested other possibilities (Gilchrist et al. 1994). Recent work has focussed on providing empirical denudation chronologies to distinguish between the models (Figure 2.3) as well as on much needed constraints for surface process models.

In addition to previous apatite fission track research (Section 6.2), in situ produced cosmogenic isotope analysis has been used on specific landscape elements in Namibia. Denudation rates calculated from concentrations of in situ cosmogenic ${ }^{10} \mathrm{Be}$ and ${ }^{26} \mathrm{Al}$ on summits of granite bornhardts in the central Namib Desert imply average denudation rates of $\pm 5 \mathrm{~m} \mathrm{Ma}^{-1}$ (Cockburn et al. 1999, Cockburn et al. 2000). Cockburn et al. (1999) suggest this average denudation rate has characterised the rate of granite inselberg lowering in the central Namib Desert for at least the past $10^{3}-10^{6}$ a. Due to the persistence of arid climatic conditions throughout the Cenozoic in the central Namib Desert, the low mean denudation rates may have been valid for the past 10-12 Ma, and also possibly since the Early Tertiary (Cockburn et al. 1999). A low retreat rate in the order of $10 \mathrm{~m} \mathrm{Ma}^{-1}$ has also been determined at the Gamsberg on the Great Escarpment in central Namibia (Cockburn et al. 2000). These data were interpreted to be representative for at least $1 \mathrm{Ma}$ and possibly for the entire Quarternary period. This rate is also assumed to be representative for the rest of the escarpment, given the overall similarity of lithology, climate and morphology at other locations as well as the consistent present day distance between the escarpment and the coast along its length (Cockburn 1998).

Considering all currently available low temperature thermochronological data for the Namibian margin (Brown 1992, Gallagher and Brown 1997, Gallagher et al. 1998, Cockburn et al. 1999, Gallagher and Brown 1999a, Gallagher and Brown 
1999b, Cockburn et al. 2000, Brown et al. 2000), the validity of the scarp retreat model is highly problematic. The pinned divide model appears to be the most appropriate, although even here further constraints are required.

\subsection{Tectonics}

As previously stated, the regional basement structure in northern Namibia is controlled by the northeast to southwest strike of the intracontinental branch of the Pan-African Damara metamorphic belt (Tankard et al. 1982, Miller 1983). The alignment of the Damara Belt changes into the coast-parallel trends of the Gariep Belt in the south and the Kaoko Belt in the north. Permo-Triassic reactivation of the intracontinental Mwembeshi Shear Zone, extending from Zambia through northern Botswana into Namibia, is reported by Daly (1989) and Daly et al. (1991). Further reactivation of major basement structures during and after breakup has strongly influenced the pattern and location of offshore sedimentation (Fuller 1971, LePichon and Hayes 1971), as well as the Early Cretaceous synrift volcanism (Marsh 1973, Turner et al. 1994, Watkins et al. 1994, Milner et al. 1995), and has been discussed in detail by Brown (1992) and Brown et al. (2000).

Intensive seismic reflection studies along the Namibian margin have documented substantial cross-margin strike-slip structures associated with structural basement highs which are believed to have been active until the Late Cretaceous (Light et al. 1992). Fuller (1971) correlated major oceanic transform faults/fracture zones with some of these basement highs. Seismicity also revealed that seaward dipping reflectors and basaltic underplated layers are present along much of northern Namibia (Gladzenko et al. 1997, Bauer et al. subm.).

Neotectonic activity of the Mwembeshi Shear Zone has been documented by e.g. Reeves (1972) and interpreted as incipient rifting in the Kalahari. Displaced Cenozoic Sediments of the Kalahari Basin and their isopachs revealed an elongated depocenter located immediately north of the Mwembeshi Shear Zone (Thomas and Shaw 1990). This indicates tectonic activity at least until the Early Cenozoic (Brown et al. 2000).

The structural style of many of the newly formed South Atlantic Basins indicates that they were formed within continental-scale strike-slip zones. Especially West and Central African basins were deformed during a compressional-shear episode in the latest Cretaceous (Fairhead 1988, Unternehr et al. 1988, Fairhead and Brinks 1991, Nürnberg and Müller 1991). This period of Late Cretaceous intracontinental deformation has been related to major changes in the geometry and relative motions of the plates involved in the opening of the Central and South Atlantic Ocean basins (Fairhead and Brinks 1991, Janssen et al. 1995). Cande et al. (1988) and Royer et al. (1988) reported a significant increase in the number 


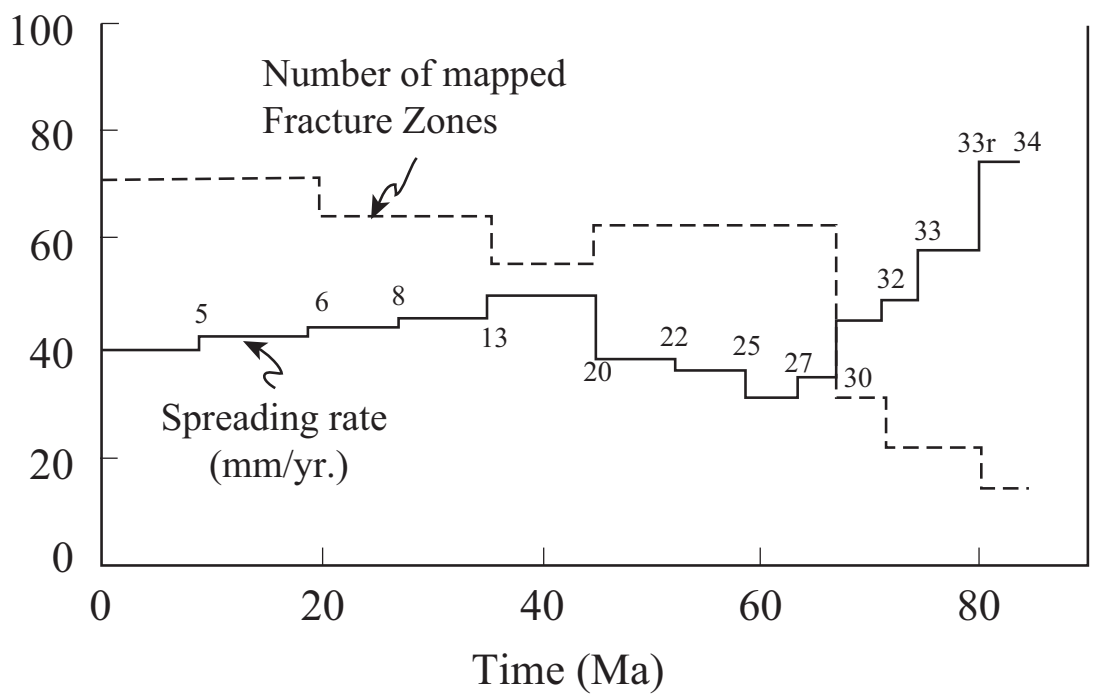

Figure 2.4: Comparison of the number of fracture zones and the full spreading rate in the South Atlantic since chron C34 (after Cande et al. 1988).

of fracture zones, along with a simultaneous decrease in the spreading rate from $43 \mathrm{~mm} \mathrm{a}^{-1}$ to $28 \mathrm{~mm} \mathrm{a}^{-1}$ (Figure 2.4). This change affected the South Atlantic and the western Indian Ocean basins between magnetic anomalies C34 (83 Ma) and C31 (67 Ma). Because of the onset of asymmetry in spreading rates in the South Atlantic, other major changes in plate geometry and motion were recognised on ridge segment jumps south of the Rio Grande Rise (Cande et al. 1988). This resulted in different rift-velocities north of the Tristan da Cunha fracture zone and south of the Gough fracture zone between anomalies C34 (83 Ma) and C22 (50 Ma) (Figure 2.4). 


\section{Chapter 3}

\section{Fission Track Thermochronology}

\subsection{Introduction}

As a temperature-sensitive thermochronological technique, apatite fission track analysis is a powerful tool for constraining the low temperature history of rocks over a range of 60 to $110^{\circ} \mathrm{C}$. These temperatures, depending on the geothermal gradient, represent a burial depth of 3 to $5 \mathrm{~km}$. Due to advances in understanding the temperature dependence of fission track annealing in apatite, and the interpretation of the information contained in fission track length distributions, the data provide detailed information of the low temperature thermal history of rocks below $110^{\circ} \mathrm{C}$. Consequently, the method can reconstruct the cooling history of rocks as they approached the surface in response to erosion and tectonic processes.

Fission track analysis can be applied to a variety of geological problems; examples to date include studies of young orogenic belts (Hurford et al. 1989, Foster et al. 1994), rifted continental margins (Gleadow and Lovering 1978, Moore et al. 1986, Bohannon et al. 1989, Omar et al. 1989, Brown et al. 1990, Foster and Gleadow 1992a, Gallagher et al. 1994, Omar and Steckler 1995), continental extension zones (Gleadow and Fitzgerald 1987, Fitzgerald and Gleadow 1988, Foster et al. 1993, Foster and Gleadow 1996) and sedimentary basins (Gleadow et al. 1983, Green et al. 1989a). Of the three minerals (apatite, zircon and sphene) commonly used in fission track dating, only the kinetics of track annealing in apatite has been studied in greatest detail. As this study uses apatite fission track thermochronology exclusively, the theoretical background given in this thesis refers only to this particular mineral.

Fission track dating is a radiogenic method of age estimation based on the natural decay by spontaneous fission of the ${ }^{238} \mathrm{U}$ isotope and the accumulation of the resulting damage trails (Figure 3.1). The major difference between fission track dating and other conventional isotopic dating methods (e.g. K-Ar dating) 


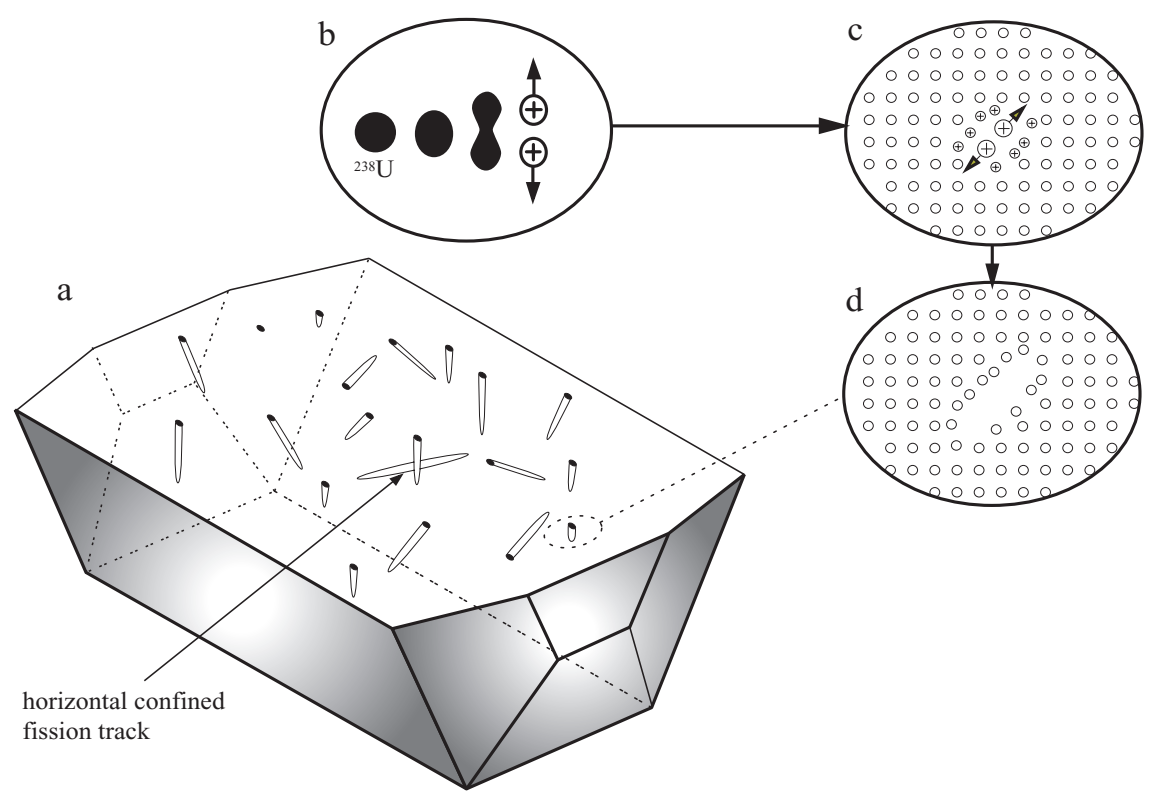

Figure 3.1: Formation of fission tracks in apatite. (a) A polished and etched surface is cut through the mineral grain and reveals randomly orientated fission tracks. The number of tracks is proportional to the number of spontaneous fissions of ${ }^{238} U$. Confined fission tracks for length measurements are surface parallel and have been etched through a crossing track. $(b-d)$ Ion spike model of track formation. The area of lattice damage is etched to reveal the fission tracks (modified from Noble 1997).

is that the daughter product is physical damage to the crystal lattice, rather than another (daughter) isotope. Moreover, it is important to note that fission tracks in apatite are progressively shortened with increasing temperature until they are completely annealed. By understanding the thermal annealing behaviour of fission tracks, it is possible to extract thermal history information rather than just a closure temperature, and thus to greatly enhance the value of the technique. Details of track formation and annealing are discussed in the following subsections.

The application of fission track analysis in a wide variety of fields was pioneered by the physicists Fleischer, Price and Walker in the early 1960s. Their fundamental research over 15 years at General Electric Company's Research Laboratories in New York State was motivated by the first transmission electron microscope observations of latent fission tracks in mica (Silk and Barnes 1959). Silk and Barnes originally observed fission fragment tracks in cloud chambers and photographic emulsions. They produced artificial tracks in muscovite by irradiating uranium-coated flakes in a reactor. The resulting fragment tracks were observed at high magnification under the electron microscope.

Price and Walker (1962a) showed that when irradiated material was abraded to expose fission tracks at the surface, the damage zone could be preferentially dis- 
solved by mineral acids, leading initially to a very fine channel only $25 \AA$ wide. Price and Walker (1962b) first discovered 'fossil' fission tracks in minerals, created by the spontaneous fission of dispersed uranium atoms. One year later Price and Walker (1963) went on to suggest that the density of these tracks could be used as a dating tool for geological materials up to a billion years old. Subsequently they discovered that these channels, or damage trails, could be enlarged by further chemical etching with hydrofluoric acid to yield a wide pit which is observable under the optical microscope. Gleadow et al. (1983) proved by showing that the distribution of the length of confined tracks in apatite, i.e. those tracks totally within the body of the crystal (Figure 3.1), could be used to reveal unique information on the thermal history of a sample in the range 20 to $110^{\circ} \mathrm{C}$ (for burial times of the order of $\sim 10 \mathrm{Ma}$ ).

Since then, development of consistent sample preparation and calibration techniques have been made (Hurford 1990b, Hurford 1990a), and fission track dating in the mineral apatite has indeed become an unique method for constraining the timing of cooling, and the denudational history, of a sample of shallow levels of the Earth's crust over time-frames of $10^{6}$ to $10^{8} \mathrm{a}$.

Fission tracks are formed continuously throughout time, and therefore the final track length distribution contains the full detail of the temperature variation with time below $110^{\circ} \mathrm{C}$. The sample's cooling history below $110^{\circ} \mathrm{C}$ could, at least in principle, be extracted from the confined track length distribution (Figure 3.2). Each track has experienced a different proportion of the total thermal history of the sample, and thus contains different information. The final distribution of track lengths and the measured apparent fission track age of a sample therefore represents an integrated record of its total thermal history over the temperature range within fission tracks are preserved (Brown et al. 1994b). To achieve an estimate of the true track length distribution, only horizontal confined tracks are measured. Confined tracks are those entirely below the surface (Laslett et al. 1982, Gleadow et al. 1986) and are easily to identify, as the total length is more or less in focus. The advantage of measuring horizontal confined tracks is that the full etchable length of the track is being measured (Figure 3.1 and 3.4).

An apatite fission track age must therefore be understood as an indication of both the time over which tracks have been retained, as well as the amount of shortening that has taken place during that time. Since the track length distribution is a function of the thermal history, the fission track age will represent an integrated measure of that thermal history. Only for samples with track length distributions with mean lengths in the range of $14-15 \mu \mathrm{m}$ with standard deviations $\leq 1 \mu \mathrm{m}$ will the fission track age be interpretable in terms of a specific event (Green 1988) e.g. subaerial eruptions or rapid cooling through the partial annealing zone (PAZ) (Figure 3.2). The fission track age of such samples then approximates the time of cooling through $110^{\circ} \mathrm{C}$. 

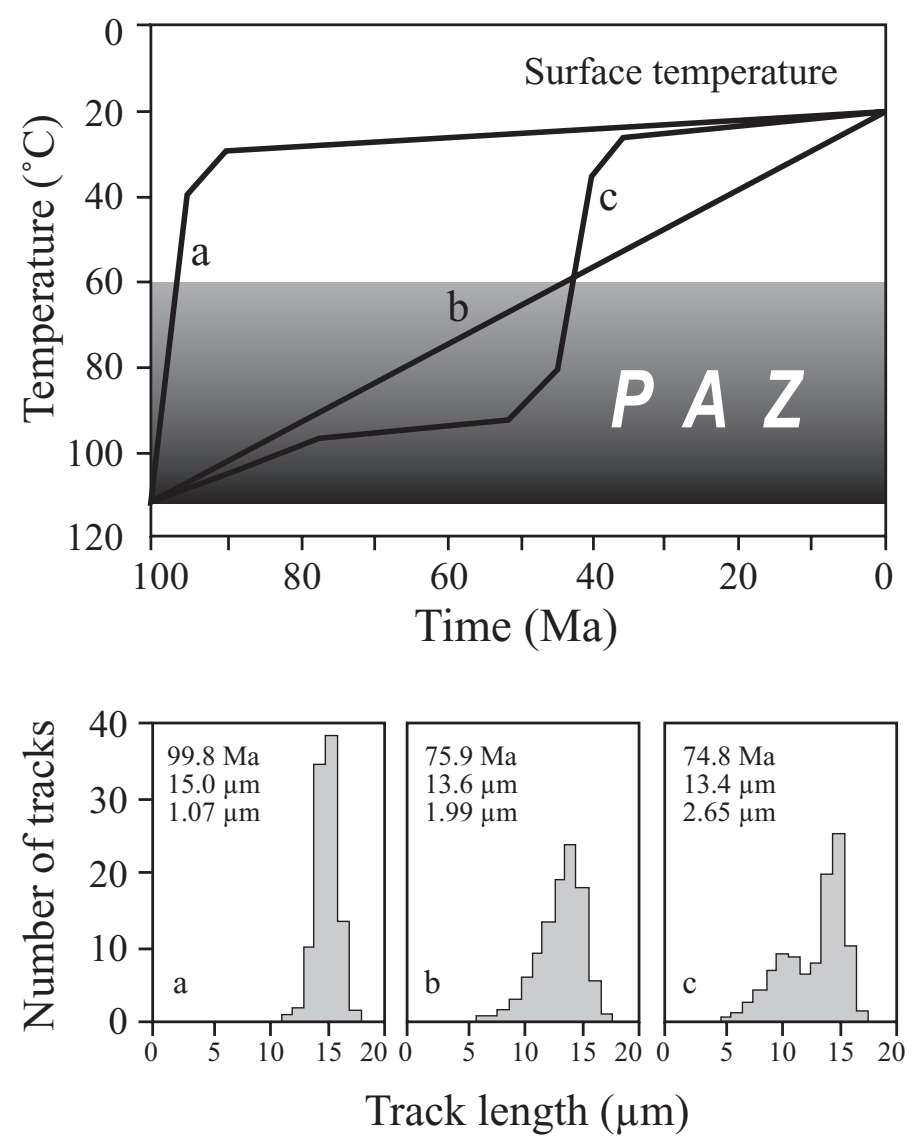

Figure 3.2: The fission track length distribution of a sample (shown in histograms $a, b$ and $c)$ is directly caused by the type of thermal history $(a, b$ or $c)$ it has undergone, since cooling below $\sim 110^{\circ} \mathrm{C}$. The area between 60 and $110^{\circ} \mathrm{C}$ is referred to as the partial annealing zone (PAZ), where most of the track shortening occurs (modified from Gleadow and Brown 2000).

In contrast, samples that remained at shallower crustal levels in the PAZ for a more protracted period, or underwent a more complex cooling history before exhumation, will retain large numbers of partially annealed tracks (Figure 3.2). The sample's fission track age will therefore be mixed, in other words will have partly reset with ages older than the time of cooling. The track length distribution will be dominated by the shortened tracks that formed and partially annealed before the given sample cooled below $60^{\circ} \mathrm{C}$, and consequently the standard deviation will be larger (Figure 3.2b and c). Single grain ages may then show a broad spread, because some, but not all, grains may have been reset completely to zero age before cooling.

The actual degree of spread is strongly dependent on the spread in apatite composition present in that particular sample. Therefore it must be recognised that most fission track ages are reduced by thermal annealing, and we can con- 
sider a fission track age only as an "apparent" age. The apparent fission track age for complex cooling histories indicates only a minimum estimate of when the sample cooled below $110^{\circ} \mathrm{C}$. It will be shown later in this study that the apparent age might differ by more than hundreds of million years from an initial cooling below $110^{\circ} \mathrm{C}$, and for another very large time span before the sample finally cooled below $60^{\circ} \mathrm{C}$ due to complex cooling patterns. The fission track age data in this study have therefore been taken only to constrain temperature histories, and to estimate maximum palaeotemperatures experienced at a given time, in the temperature range detectable with apatite fission track analysis. The way thermal histories are derived is explained in Section 3.4.3.

\subsection{Fission Track Data}

\subsubsection{Track Formation}

The current model for the formation of fission tracks is the ion spike explosion model (Figure 3.1b-d) developed by Fleischer et al. (1975): A disordered crystal lattice with damage trails is left by expelled nuclei after fission decay of the uranium isotope ${ }^{238} \mathrm{U}$. The frequency of fission events is as low as about one for every $2 \times 10^{6} \alpha$-particle decay events. In fission decay, the nucleus spontaneously splits into two nuclei with mass numbers of $\sim 85$ to 105 and $\sim 130$ to 150 . Every fission event releases about $200 \mathrm{MeV}$ of energy (Fleischer et al. 1975). The two nuclei are highly charged and so mutually repel each other as a result of Coulomb repulsion, and travel directly away from each other in a straight line. As they travel they dissipate their kinetic energy to the host crystal lattice. The highly charged particles recoil, and simultaneously interact with atoms in the lattice initially by electron stripping or ionisation. This leads to further deformation of the lattice as the ionised lattice atoms repel each other, leaving a damage trail or fission track. Limits of this model are discussed in Chadderton (1988). Newly formed tracks in apatite are about $16 \pm 1 \mu \mathrm{m}$ in length and $0.008 \mu \mathrm{m}$ in diameter (Donelick et al. 1990).

The linear damage trails appear as randomly orientated tubes intersecting the polished surface of the host crystal after a standardised chemical etching treatment (Green et al. 1986). The disordered lattice damage in the track is chemically reactive, and may be widened by chemical etching to reveal a fission track, which is then readily observed under the optical microscope under high magnification $(\sim 1250 \mathrm{x})$ (Figure 3.3a).

The ability to generate tracks depends on the mass of the ionising particle and the density of the medium. In muscovite, the lowest mass particle which can generate tracks by irradiation is about 30 atomic mass units (amu). Fission 


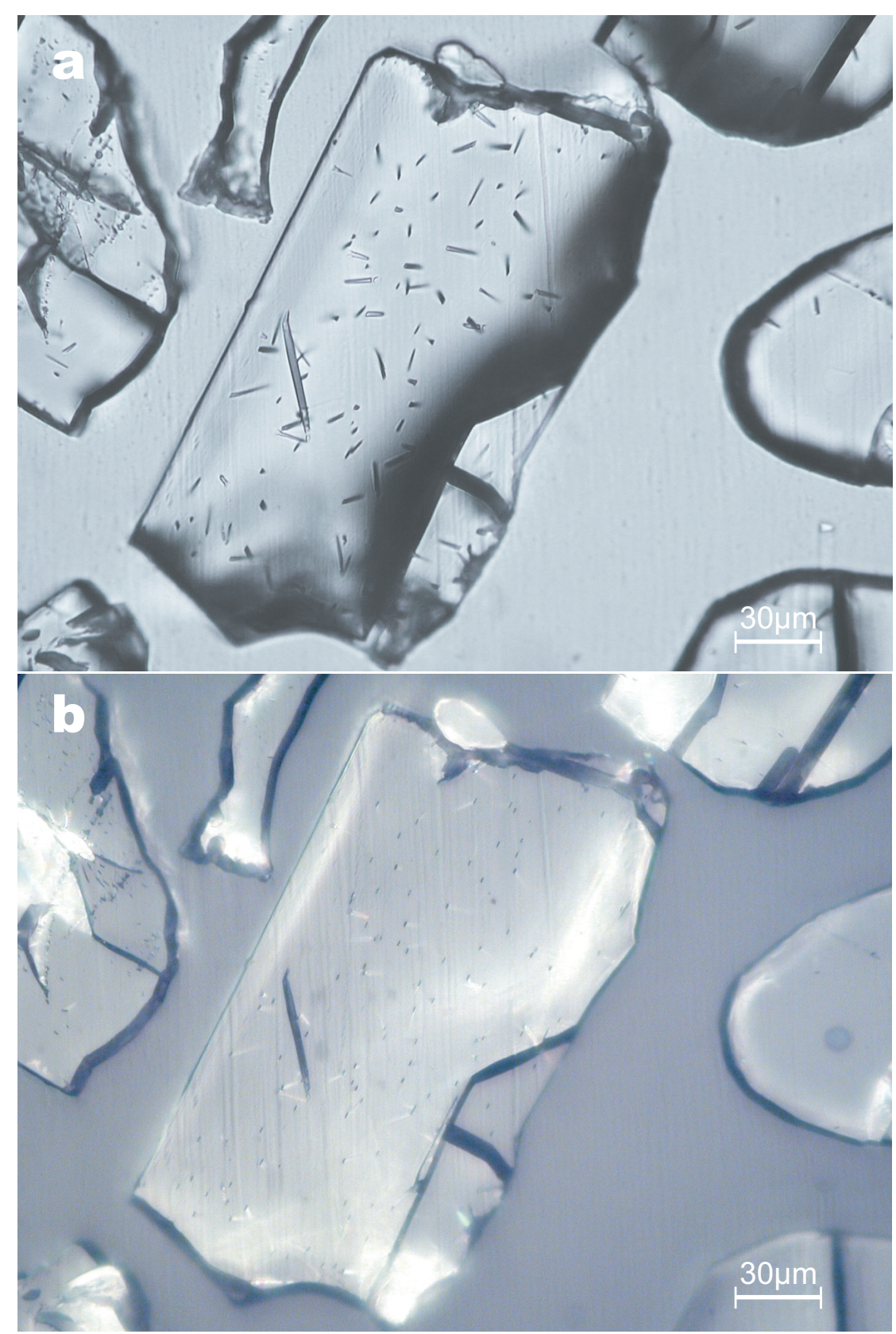

Figure 3.3: $C$-axis parallel apatite grain with fission tracks. a) Grain showing randomly orientated fission tracks intersecting the exposed surface with etch pits and track tails under transmitted light, b) same grain under reflected light. Alignment parallel c-axis is given due to parallel, elongated etch pits, which is a critical selection criteria for datable apatites.

fragments, with masses of ca. 90 and 135 amu respectively, are well above this threshold, so that they always generate tracks. On the other hand, $\alpha$-particles as 


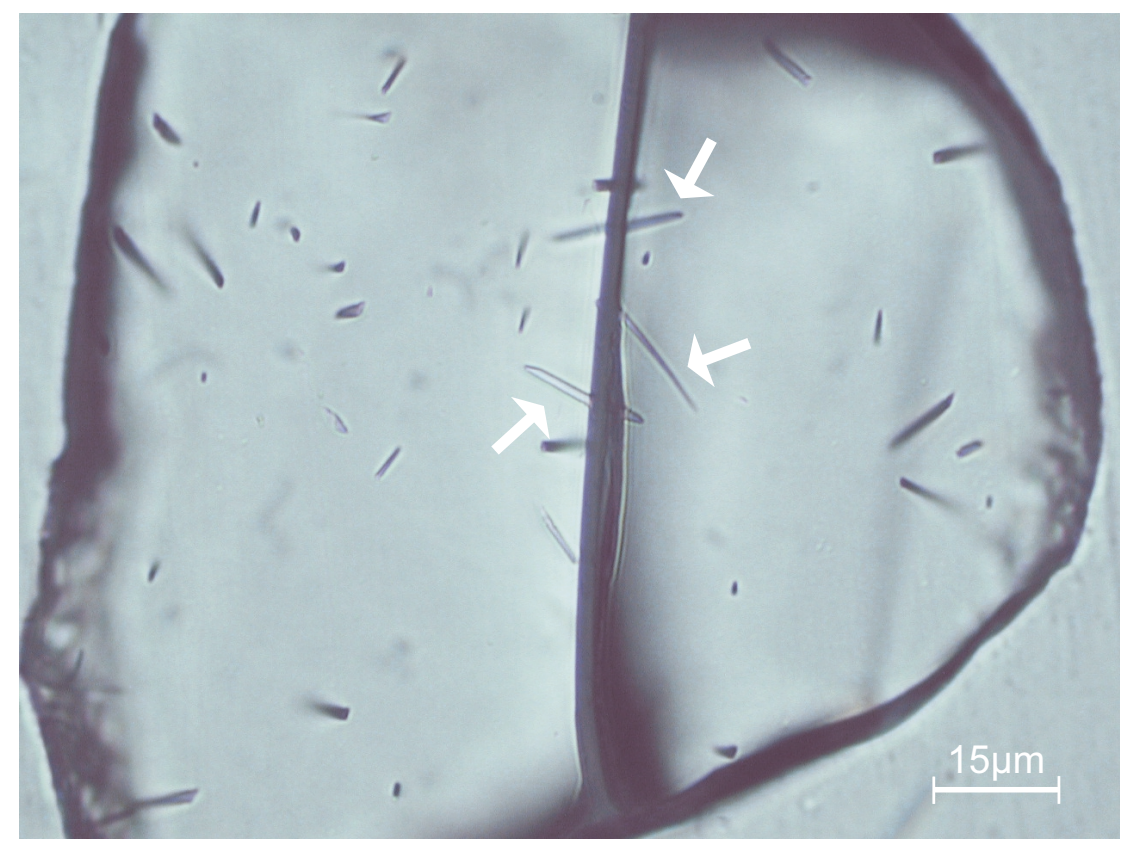

Figure 3.4: Apatite grain with three horizontal confined tracks (white arrows). Horizontal tracks are surface parallel and etchant has enlarged tracks through crack.

the major product of uranium decay, are so far below the critical mass that they cannot create tracks.

Price and Walker (1963) demonstrated that spontaneous fission of ${ }^{238} \mathrm{U}$ was the only significant source of tracks in most natural minerals (Table 3.1). Induced fission of ${ }^{235} \mathrm{U}$ by natural thermal neutrons can be ignored, as can cosmic rayinduced fission of uranium. The density of spontaneous fission tracks is a function of both the time over which the tracks are accumulated and the ${ }^{238} \mathrm{U}$ concentration. Several uranium-bearing minerals have been assessed for their potential use in fission track dating, but most are unsuitable due to their low uranium concentrations. Minerals that are commonly used over a wide range of geological conditions are: apatite, zircon, sphene and natural glasses (Fleischer et al. 1975, Ravenhurst and Donelick 1992).

\subsubsection{Track Annealing and the Effects of Temperature}

Fission tracks are not stable. They shorten progressively and irreversibly with increasing temperature over geological time scales of $10^{6}-10^{8} \mathrm{yrs}$. This recrystallisation process is referred to as annealing. Partial annealing reduces the lengths of individual tracks; total annealing erases all tracks completely.

At an early stage in the development of fission track dating, Fleischer et al. 


\begin{tabular}{cccc}
\hline & $\begin{array}{c}\text { Relative abundance } \\
\left.\text { (compared to }{ }^{238} \mathrm{U}\right)\end{array}$ & $\begin{array}{c}\text { Total half-life } \\
\text { (yrs) }\end{array}$ & $\begin{array}{c}\text { Spontaneous fission } \\
\text { half-life }(\mathrm{yrs})\end{array}$ \\
\hline${ }^{232} \mathrm{Th}$ & 4 & $1.40 \times 10^{10}$ & $1.0 \times 10^{21}$ \\
${ }^{234} \mathrm{U}$ & $5.44 \times 10^{-5}$ & $2.46 \times 10^{5}$ & $1.5 \times 10^{16}$ \\
${ }^{235} \mathrm{U}$ & $7.25 \times 10^{-3}$ & $7.04 \times 10^{8}$ & $1.0 \times 10^{19}$ \\
${ }^{238} \mathrm{U}$ & 1 & $4.47 \times 10^{9}$ & $8.2 \times 10^{15}$ \\
\hline
\end{tabular}

Table 3.1: Abundances and half-lives of the four major naturally occurring nuclides which undergo spontaneous fission after Wagner and van den Haute, 1992. The relative abundances and the spontaneous fission half-life suggest that most fission occurring in nature is due to ${ }^{238} \mathrm{U}$.

(1965) showed that of the various environmental parameters which could possibly affect the long term stability of fission tracks, temperature is by far the most dominant factor. Annealing experiments have shown that heating for ten times as long causes about the same increase in the degree of annealing as a temperature increase of $10^{\circ} \mathrm{C}$ (Green et al. 1986, Green et al. 1989b, Crowley et al. 1991).

Above temperatures of $\sim 60^{\circ} \mathrm{C}$ the annealing rate increases significantly until all tracks are completely annealed at temperatures greater than $\sim 110^{\circ} \mathrm{C}$. Therefore temperature decreases the measured apparent fission track age systematically, with progressive thermal annealing, until all tracks are fully annealed, and the apparent age is reduced to zero (Figure 3.5). Reduction in age occurs as a consequence of a decrease in the mean track length, which causes a proportional reduction in the measured spontaneous track density (Section 3.3) (Laslett et al. 1982 , Green 1988). The temperature range between $60^{\circ} \mathrm{C}$ and $110^{\circ} \mathrm{C}$ is generally referred to as the "partial annealing zone" (PAZ)(Gleadow and Fitzgerald 1987) (Figure 3.2). However, track shortening also occurs, albeit at very slow rates, at temperatures below $60^{\circ} \mathrm{C}$ (Green 1988, Donelick et al. 1990).

\subsubsection{Compositional Affects on Annealing}

The annealing behaviour of fission tracks in apatite $\left[\mathrm{Ca}_{5}\left(\mathrm{PO}_{4}\right)_{3}(\mathrm{~F}, \mathrm{Cl}, \mathrm{OH})\right]$ is also sensitive to chemical composition, especially to the ratio of chlorine to fluorine. Chlorine-rich apatites are more resistant to track annealing than fluorinerich apatites at temperatures above $\sim 60^{\circ} \mathrm{C}$, to temperatures of $\sim 110^{\circ} \mathrm{C}$ to $150^{\circ} \mathrm{C}$ at which all fission tracks in either type of grains are annealed (Gleadow and Duddy 1981, Green 1985, Green et al. 1986). For example, at temperatures between 90 and $120^{\circ} \mathrm{C}$, individual grain ages show a distinctive spread with some ages near zero and others approaching the original source age (Figure 3.5). This property suggests that the closure temperature for individual grains within a sample may vary significantly in response to variations in chlorine content (Green et 


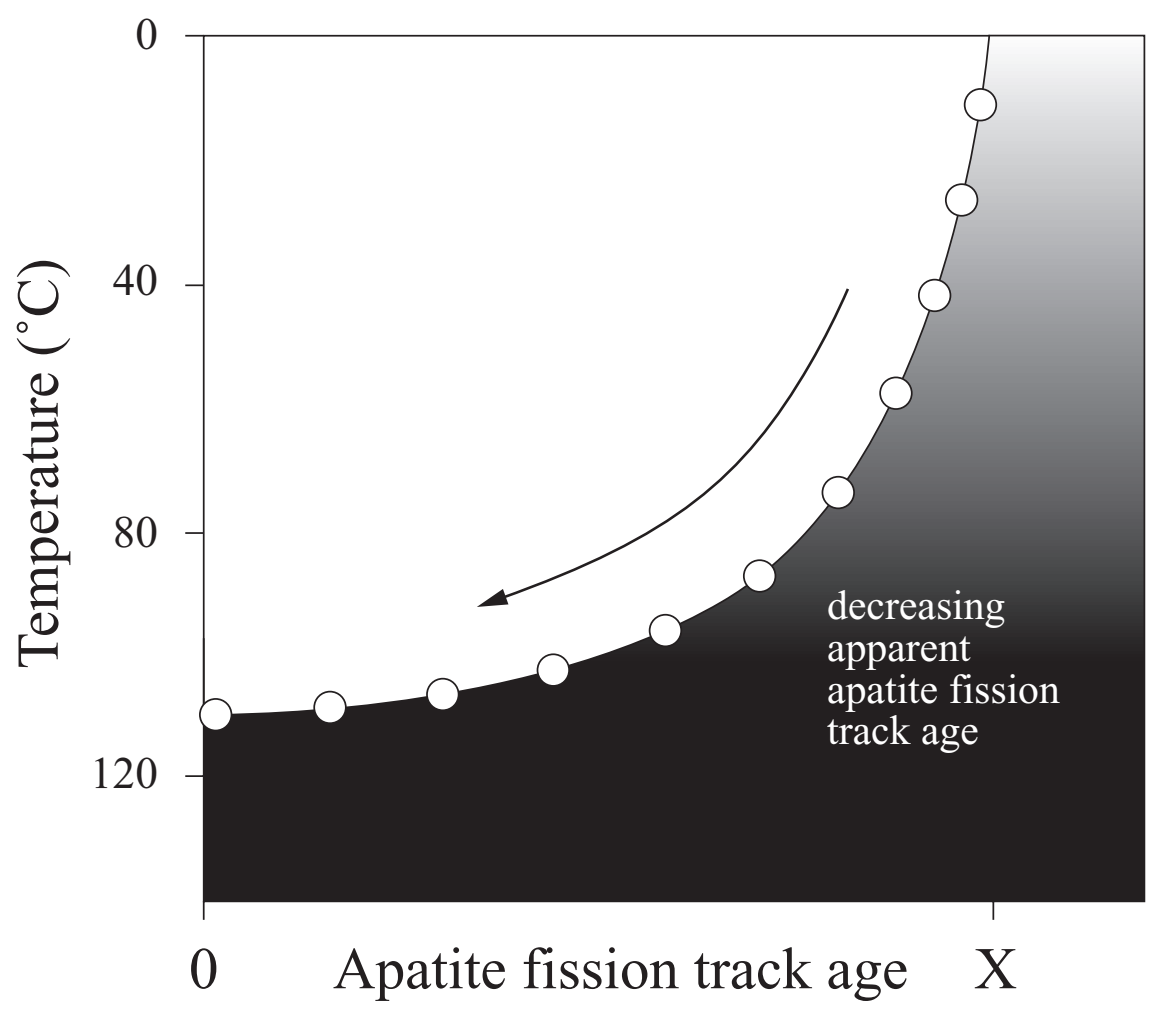

Figure 3.5: Apparent apatite fission track ages decrease from their original value $(X)$ to zero between 60 and $110^{\circ} \mathrm{C}$, because fission tracks anneal and the track density reduces to zero over the same time interval. Circles represent an array of samples exposed to different temperatures.

al. 1986, Carlson 1990, Carlson and Donelick 1993). Therefore, the measured apparent fission track age of a sample decreases systematically with progressive thermal annealing. This occurs because a decrease in the mean track length causes a proportional reduction in the measured spontaneous track density (Laslett et al. 1982, Green 1988). Relatively little is known about the influence of $\mathrm{OH}, \mathrm{Mn}$ and REE. In addition, the variation of track length with angle to the crystallographic caxis becomes progressively more anisotropic (with increasing temperatures). As the mean track length approaches zero, the only tracks left are aligned parallel to the c-axis (Green et al. 1986).

Constraining the chemical composition of individual grains within samples is an important step before interpreting thermal histories. Compositional differences do not produce significant annealing differences for samples with rapid cooling histories where the affects of the partial annealing zone are reduced. However, samples with protracted or multi-stage cooling histories may display significant differences in age and length distributions (Green et al. 1986, O'Sullivan and Parrish 1995). Fission track studies of sedimentary rocks have documented 
large spreads of individual grain ages within samples (Green et al. 1986, Green et al. 1989a). In most cases the spread is attributed to varying grain compositions sourced from multiple terrains. In previous studies (Arne 1994, Fitzgerald 1994) of plutonic terrains it is generally assumed that apatites from the same intrusive body, and subsequently within each rock sample, have similar chemistry. Therefore, different terrain provenance cannot be considered for plutonic rocks. The significance of variations in apatite chemistry within plutonic rock samples is described in O'Sullivan and Parrish (1995). The study illustrates that significant variations in apatite composition can occur in plutonic rock samples, which result in differences in the annealing behaviour between individual grains. This variation in annealing behaviour between single apatite grains thus provides important information about the maximum temperatures experienced by a sample (Section 3.4).

Several experiments have been conducted to constrain the annealing characteristics of track lengths in apatite (Green et al. 1986, Green et al. 1989a, Green et al. 1989b, Laslett et al. 1987, Carlson 1990, Crowley et al. 1991). It is still a matter of debate which annealing algorithm is most appropriate, as it is difficult to assess the apatite chemistry and crystal structure of each individual grain quantitatively. The Laslett et al. (1987) algorithm has been applied in this thesis, since microprobe analysis of selected grains showed chlorine concentrations being consistently below Durango apatite ( $0.4 \mathrm{wt} \%$ chlorine); and this was the upper chlorine concentration for the Laslett et al. (1987) models.

\subsection{Concepts behind Age Determination}

\subsubsection{Methods}

The fission track method is not substantially different from the other isotopic dating methods that are based on the decay of a naturally radioactive parent to stable daughter atom. The main difference is that the parent/daughter ratio is measured by counting the areal densities of fission tracks revealed through chemical etching. The daughter isotopic abundance is determined through counting the number of ${ }^{238} \mathrm{U}$ spontaneous tracks $\left(\mathrm{N}_{s}\right)$ formed in the mineral of interest. The parent isotopic concentration (the uranium concentration) is determined through counting the number of fission tracks produced from fission of ${ }^{235} \mathrm{U}$ induced by thermal neutron irradiation $\left(\mathrm{N}_{i}\right)$. Since the natural ratio of ${ }^{235} \mathrm{U} /{ }^{238} \mathrm{U}$ is well established the ${ }^{238} \mathrm{U}$ concentration can thereby be calculated (Section 3.3.4).

Two different laboratory procedures are in common use for determining fission track ages (Gleadow 1981, Wagner and van den Haute 1992). These are: 
1. The external detector method

2. The population method

The population method is used only on samples with a relatively homogeneous concentration of uranium between grains, and where a bulk average age of all the grains in a sample is desired. This is applicable e.g. to volcanic glasses or young volcanics, where only a simple cooling history is expected.

The external detector method makes it possible to date grains individually. It is used for samples with strongly heterogeneous concentrations of uranium between grains, and where different grains have different ages, such as can be caused by partial resetting of apatite grains by annealing. In practice, the fission track ages for the external detector method are calculated by (1) determining a personal calibration factor, (2) evaluating the spontaneous to induced fission track ratio, and (3) measuring the received thermal neutron fluence. The present study uses the external detector method to determine the parent to daughter track ratio for individual crystals (Gleadow and Lovering 1977). External muscovite detectors are attached to the surface of the prepared mineral mount, containing spontaneous fission tracks $\left(\mathrm{N}_{s}\right)$ to record the fission of ${ }^{235} \mathrm{U}$ induced by the bombardment of low energy neutrons $\left(\mathrm{N}_{i}\right)$ in the individual crystals. The ratio is then determined from the density of $\mathrm{N}_{s}$ to $\mathrm{N}_{i}$.

\subsubsection{Age Equations}

The age of a sample $(t)$ using the external detector method is calculated using the standard fission track age equation (Wagner and van den Haute 1992):

$$
t=\frac{1}{\lambda_{t}} \ln \left[1+\left(\frac{\lambda_{t}}{\lambda_{f}}\right)\left(g \frac{\rho_{s}}{\rho_{i}}\right) I \sigma \Phi\right]
$$

where:

$$
\begin{aligned}
& \rho_{s}=\text { the measured spontaneous track density (from natural fission of }{ }^{238} \mathrm{U} \text { ), typically in units of } \\
& \text { tracks } \cdot \mathrm{cm}^{-2} \text {. } \\
& \rho_{i}=\text { the measured induced track density (from induced fission of }{ }^{238} \mathrm{U} \text { ), typically in units of } \\
& \text { tracks } \cdot \mathrm{cm}^{-2} \text {. } \\
& \lambda_{t}=\text { the total (alpha plus fission) decay constant of }{ }^{238} \mathrm{U}\left(1.551 \cdot 10^{-10} \mathrm{a}^{-1}\right) . \\
& \left.\lambda_{f}=\text { the spontaneous fission decay constant of }{ }^{238} \mathrm{U} \text { (taken as } 8.46 \cdot 10^{-17} \mathrm{a}^{-1}\right)(\text { Hurford and } \\
& \quad \text { Green } 1982 \text {, Hurford } 1990 \mathrm{a} \text {, Wagner and van den Haute } 1992) . \\
& I=\text { the }{ }^{235} \mathrm{U} / 238 \mathrm{U} \text { isotopic ratio }\left(7.2527 \cdot 10^{-3}\right) \text {. } \\
& \sigma= \\
& \text { the thermal neutron capture cross sectional area of }{ }^{235} \mathrm{U} \text {, a measure of how likely a thermal } \\
& \text { neutron in the reactor is to induce fission track of a }{ }^{235} \mathrm{U} \text { nucleus }\left(584.25 \cdot 10^{-24} \mathrm{~cm}^{2} .\right. \\
& \text { neutron } \left.{ }^{-1}\right) .
\end{aligned}
$$


$\Phi=$ the thermal neutron dose received in the nuclear reactor (typically in units of neutrons $\left.\mathrm{cm}^{-1}\right)$.

$\mathrm{g}=\mathrm{a}$ geometry factor of 0.5 for the external detector method, which compensates for the fact that one-half of the U-bearing volume of the grain within one track range of the grain's internal surface has been removed by grinding and polishing of the internal surface before irradiation of the sample, so only 0.5 times as many induced tracks will form in the external detector.

and:

$$
\begin{aligned}
\rho_{i} & =\frac{N_{i}}{A_{i}} \\
\rho_{s} & =\frac{N_{s}}{A_{s}}
\end{aligned}
$$

with:

$N_{i}=$ number of induced fission tracks (in external detector).

$N_{s}=$ number of spontaneous fission tracks (in crystal).

$A=$ total area counted $\left(\mathrm{cm}^{2}\right)$.

Because of problems with both, the exact determination of the spontaneous fission decay constant $\lambda_{f}$, and in measuring the thermal neutron dose $\Phi$ received in the reactor, there are practical difficulties in using equation 3.1 directly (Hurford and Green 1982, Hurford 1990a). Whilst track densities are readily determinable, and the constants $\lambda_{t}, I$ and $\sigma$ are precisely known, the determination of the spontaneous fission decay constant $\lambda_{f}$ is nonetheless extremely difficult to quantify because of variations of the reaction rate of ${ }^{235} \mathrm{U}$ with thermal neutron fluence (Green and Hurford 1984). Combining these two problematic parameters to define a calibration constant evaluated against geological material of known age leads to the zeta-calibration factor, where the fission decay constant $\lambda_{f}$, the ${ }^{235} \mathrm{U} /{ }^{238} \mathrm{U}$ isotopic ratio $I$ and the ${ }^{235} \mathrm{U}$ nuclear fission cross section $\sigma$ are replaced by zeta $(\zeta)$ (Hurford and Green 1982, Hurford 1990a):

$$
\zeta=\frac{\Phi \sigma I}{\lambda_{f}}
$$

The neutron fluence is assessed by counting induced tracks in an uranium dosimeter glass, where the neutron-induced ${ }^{235} \mathrm{U}$ fission events are recorded in a mica detector. The track density is then represented by $\rho_{d}$ (in $\frac{\text { tracks }}{\mathrm{cm}^{2}}$ )(Hurford and Green 1982). Substituting $\zeta$ into equation 3.1 leads to:

$$
t=\frac{1}{\lambda_{t}} \ln \left[1+\lambda_{t} \zeta\left(g \frac{\rho_{s}}{\rho_{i}}\right) \rho_{d}\right]
$$

where:

$$
\rho_{d}=\frac{N}{A}
$$


A standard sample of known age $\left(t_{s t d}\right)$

$$
t_{s t d}=\frac{1}{\lambda_{t}} \ln \left[1+\lambda_{t} \zeta\left(g \frac{\rho_{s}}{\rho_{i}}\right) \rho_{d}\right]
$$

has to be analysed to determine $\zeta$ empirically by rearranging equation 3.7:

$$
\zeta=\frac{1}{\lambda_{t}}\left[\exp \left(t_{s t d} \lambda_{t}\right)-1\right]\left(\frac{\rho_{i}}{g \rho_{s}}\right)\left(\frac{1}{\rho_{d}}\right)
$$

The individual, operator related $\zeta$ is determined on a number of standard samples (15-20) of known isotopic age. A weighted mean of these determinations is used in equation 3.5. Some variations of the observational counting process will also be absorbed by using the $\zeta$-calibration.

The distribution of single grain ages is numerically assessed using the chisquare $\left(\chi^{2}\right)$ test (described in detail in Section A.2). If the $\chi^{2}$ probability $\left(\mathrm{P} \chi^{2}\right)$ is larger than $5 \%$, the single grain ages determined are considered to represent a normal Poissonian distribution (Green 1981a). The pooled age will then be considered since it assumes that all grains are related to a single age and fit within a Poissonian distribution. The sum of track counts from all grains counted is used to calculate the ratio of $\rho_{s} / \rho_{i}$ where:

$$
\begin{array}{r}
\rho_{s}=\frac{\sum_{j=1}^{n} N_{s j}}{\sum_{j=1}^{n} A_{s j}} \\
\rho_{i}=\frac{\sum_{j=1}^{n} N_{i j}}{\sum_{j=1}^{n} A_{i j}}
\end{array}
$$

will be substituted into equation 3.5.

The $\chi^{2}$ test is considered to have failed if the $\mathrm{P} \chi^{2}$ probability is smaller than $5 \%$, since the range in single grain ages or the variation in $\rho_{s} / \rho_{i}$ will be greater than expected for a Poissonian distribution. The assumption that is made in $\mathrm{P} \chi^{2}$ values smaller than $5 \%$, is that the grains belong to multiple age populations. The calculation of a mean age was introduced by Green (1981a), by thus calculating a mean of the $\rho_{s} / \rho_{i}$ ratio from the individual crystal ratios:

$$
\frac{\rho_{s}}{\rho_{i}}=\sum_{j=1}^{n} \frac{\left(\frac{\rho_{s}}{\rho_{i}}\right)_{j}}{n}
$$


which is then substituted into equation 3.5. $n$ is the number of grains.

Since the mean age depends only on the ratios $N_{s} / N_{i}$ and not on how large or small the actual track counts are, Galbraith and Laslett (1993) introduced the concept of "central age" as a more accurate assessment for mixed ages with a $\chi^{2}$ probability smaller than $5 \%$. The central age is essentially the weighted mean of the log normal distribution of single grain ages. The central age and the standard deviation can be calculated after Galbraith and Laslett (1993) by iteration of the following algorithm estimating $\eta$ as a weighted average of the variance $y_{j}$ with weights $w_{j} . \quad \sigma$ is then estimated by equating $\sum_{j=1}^{n} w_{j}^{2}\left(y_{j}-\eta\right)^{2}$ to its expected value: $\sum_{j=1}^{n} w_{j}$. The algorithm gives a precision for the central age estimate, but not for the age dispersion.

For $j=1,2 \ldots, n$ let

$$
\begin{gathered}
m_{j}=N_{s j}+N_{i j} \\
y_{j}=\frac{N_{s j}}{m_{j}} \\
z_{j}=\log \left(\frac{N_{s j}+\frac{1}{2}}{N_{i j}+\frac{1}{2}}\right)
\end{gathered}
$$

Set initial values of $\sigma$ and $\eta$. For example:

$\sigma=0.6 \cdot$ standard deviation of $\left\{z_{1}, z_{2} \ldots, z_{n}\right\}$,

$$
\eta=\frac{\sum_{j=1}^{n} N_{s j}}{\sum_{j=1}^{n} m_{j}}
$$

For $j=1,2, \ldots, n$ compute:

$$
w_{j}=\frac{m_{j}}{\left\{\eta(1-\eta)+\left(m_{j}-1\right) \eta^{2}(1-\eta)^{2} \sigma^{2}\right\}}
$$

Compute new values of $\sigma$ and $\eta$ as:

$$
\begin{gathered}
\sigma=\sigma\left(\frac{\sum_{j=1}^{n} w_{j}^{2}\left(y_{i}-\eta\right)^{2}}{\sum_{j=1}^{n} w_{j}}\right)^{\frac{1}{2}} \\
\eta=\frac{\sum_{j=1}^{n} w_{j} y_{j}}{\sum_{j=1}^{n} w_{j}}
\end{gathered}
$$


Recalculate equations 3.16, 3.17 and 3.18 until $\sigma$ and $\eta$ do not change; this is usually achieved within 20 iterations. The final value of $\sigma$ is the estimated age dispersion (variation). The final value for $\eta$ is substituted into the age equation 3.5 given the relationship:

$$
\frac{\eta}{(1-\eta)}=\frac{\rho_{s}}{\rho_{i}}
$$

The central age $t_{c}$ is then estimated from the age equation as:

$$
t_{c}=\frac{1}{\lambda_{t}} \ln \left[1+\frac{1}{2} \lambda_{t} \zeta \rho_{d} \frac{\eta}{1-\eta}\right]
$$

When the variation in the count population is consistent with a Poissonian distribution, then all three age estimations are essentially the same. Since the central age is more robust to outliers and non-Poissonian variations, it is the preferred sample age estimate (Gallagher et al. 1998).

\subsubsection{Error Calculation}

All measurements are inaccurate to some degree, depending as they do on several instrumental and operational uncertainties. As fission track dating is still a fully operator-controlled method, we therefore have as well to deal with the personal errors of the particular observer. Such errors can arise from many causes, as the operator's physical and mental conditions might vary during the observational process. These errors are due to the operator, and are often revealed by repeated observations. They are disordered in their incidence and variable in magnitude. To minimise the accidental or personal error in the behaviour of counting tracks with the microscope, the personal $\zeta$ calibration factor has been introduced and described in section 3.3. As mentioned earlier, the zeta factor absorbs some of the systematic errors introduced by the very process of observation itself.

Calculation of fission track errors for all three methods are shown below. The standard error (se) on the mean age $t_{m}$ is given by:

$$
s e\left(t_{m}\right)=\left[\left(\sum_{j=1}^{n} t_{j}^{2}-\frac{\sum_{j=1}^{n} t_{j}}{n}\right) \frac{1}{n(n-1)}\right]^{\frac{1}{2}}
$$

$t_{j}$ is the single grain age for $j$ number of grains. 
The standard error for the central age $t_{c}$ is estimated as:

$$
s e\left(t_{c}\right)=t_{c}\left[\frac{1}{\eta^{2}(1-\eta)^{2} \sum_{j=1}^{n} w_{j}}+\frac{1}{N_{d}}+\left(\frac{s e(\zeta)}{\zeta}\right)^{2}\right]^{\frac{1}{2}}
$$

If

$$
\frac{\eta}{1-\eta}=\frac{\sum_{j=1}^{n} N_{s j}}{\sum_{j=1}^{n} N_{i j}}
$$

then the central age $t_{c}$ becomes the pooled age, and its standard error becomes:

$$
s e\left(t_{p}\right)=t_{p}\left[\frac{1}{\sum_{j=1}^{n} N_{s j}}+\frac{1}{\sum_{j=1}^{n} N_{i j}}+\frac{1}{N_{d}}+\left(\frac{s e(\zeta)}{\zeta}\right)^{2}\right]^{\frac{1}{2}}
$$

with the standard error for the zeta value $(\zeta)$ :

$$
\operatorname{se}(\zeta)=\zeta\left[\frac{1}{\sum_{j=1}^{n} N_{s j}}+\frac{1}{\sum_{j=1}^{n} N_{i j}}+\frac{1}{N_{d}}+\left(\frac{s e\left(t_{s t d}\right)}{t_{s t d}}\right)^{2}\right]^{\frac{1}{2}}
$$

The error on the mean age is determined using the standard error of single grain ages. To estimate the error on the pooled and central ages, and the zeta value, raw track counts are used. The error on the zeta value also includes the error of the age standard, which is calculated during independent dating of the standard.

\subsubsection{Calculation of Uranium Content}

Dating single grain ages requires the knowledge of the uranium concentration in each individual grain. This is obtained by referencing to a dosimeter glass (CN5) of known uranium content using the following equation:

$$
U_{\text {conc }(u)}=\frac{\rho_{i}}{\rho_{d}} U_{\operatorname{conc}(s t d)}
$$

where: 
$U_{\text {conc }(u)}=$ unknown uranium concentration.

$U_{\text {conc }(s t d)}=$ uranium concentration of dosimeter glass $(\mathrm{CN} 5=12.5 \mathrm{ppm})$.

\subsection{Deriving Thermal Histories from Fission Track Data}

\subsubsection{Presentation of Fission Track Data}

After collection of all fission track information, the data can be displayed in various ways to show individual sample information (radial plots with individual grain ages, length distribution histograms). In order to visualise the fission track data, all measurements are presented in a graphical format (raw data are listed in this thesis in Appendix C).

Fission track age information is displayed in histograms and radial plots (Figure 3.6). Radial plots are constructed using the method of Galbraith (1990a). For a population of single grain ages, the radial plot is the most effective way to show the precision and spread around the central age. The age for a single crystal is found by extrapolating lines from the zero point to the age axis passing through the standard error of the sample (Figure 3.6c). The standard error is the same for all grains in a sample, and is indicated on the $y$-axis. The precision, or relative error, for each grain is indicated by the $x$-axis (Figure 3.6c). Grains that lie close to the $y$-axis are less precise (i.e. have a larger relative error) than those that lie to the right. The radial plot allows the visual recognition of distinct populations in a sample (O'Sullivan and Parrish 1995). The central age, $\chi^{2}$ probability, and variation (from the pooled age in \%), are all indicated on the right hand side of the radial plot. Confined track lengths data are plotted as histograms in $1 \mu \mathrm{m}$ intervals normalised to 100 tracks. The mean length, standard deviation, and number of tracks, are displayed on the right of the graph.

Regional trends can be observed when data are plotted, for example as age versus elevation, mean track length versus elevation, age versus mean track length and age versus standard deviation.

By assessing trends and relationships as shown it is possible to qualitatively extract the most important aspects of individual sample and regional thermal history information recorded in each sample. 
a

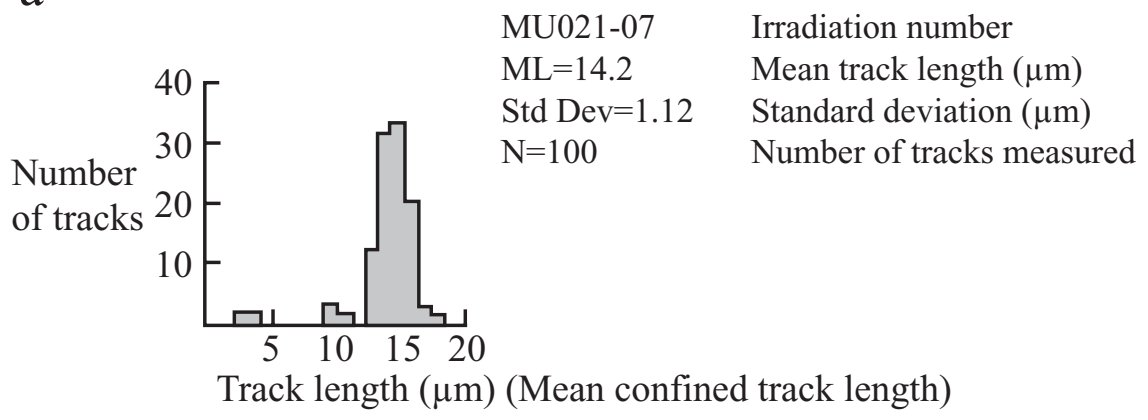

$\mathrm{b}$
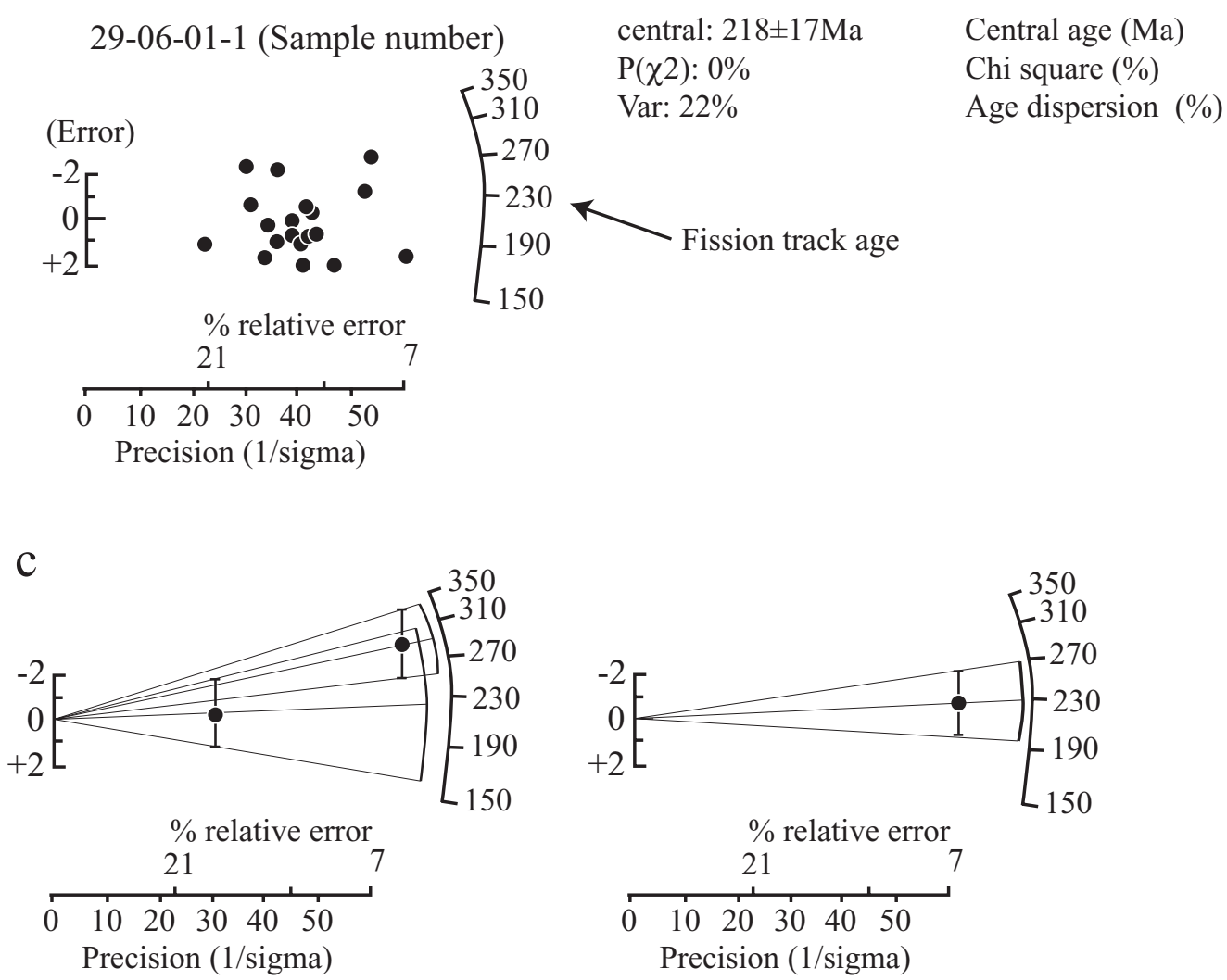

Figure 3.6: Fission track data are commonly plotted as track length histograms (a) and in radial plots of single grain ages (b). Relative error and precision of individual grains can be assessed. Ages on the right of the graph are more precise than those to the left. The size of the arc indicates the error spread for that grain (modified after Noble 1997). 


\subsubsection{Vertical Profiles}

In areas where crustal segments have been disrupted by faulting, the observed fission track profiles will show a different pattern due to the exposure of different crustal levels, since apparent ages form palaedepth markers which define an invisible fission track stratigraphy (Figure 3.7) (Gleadow 1990). Offsets in this stratigraphy can determine the relative uplift between different blocks. These discontinuities in the age patterns do not directly indicate the timing of the tectonic disruption. But, if not already determined by thermal modelling (Section 3.4.3), they do provide constraints on a maximum age for tectonic activity in that it must have occurred at, or after, the youngest apparent age in the disturbed sequence (Chapter 5). Notable examples of such offset fission track patterns have been observed in the Transantarctic Mountains (Gleadow and Fitzgerald 1987, Fitzgerald and Gleadow 1988), the East African Rift System (Foster and Gleadow 1996), the northeastern Brooke Range in Alaska (O'Sullivan et al. 1998) and southeastern Australia (Foster and Gleadow 1992b). The minimum offset to be visible in apparent fission track ages has been estimated to $300 \mathrm{~m}$ (Dumitru 2000).

A significant amount of thermal history information can be extracted if a suite of samples from a vertical profile is analysed. These profiles can be obtained from either deep boreholes or vertical relief profiles (Gleadow and Brown 2000).

The track length distribution in linear profiles forms a distinct concave-up curve (Figure 3.5 and 3.8), which indicates that each sample has experienced the same cooling history at slightly different times, at different temperatures (Naeser 1981, Brown et al. 1994b). The shape of the concave-up curves (Figure 3.8) implies very slow cooling rates (e.g. cratonic interiors), or slow heating, due to progressive burial in sedimentary basins (Gleadow and Brown 2000).

In tectonically stable regions with low denudation rates, the typical form of a vertical crustal profile is controlled primarily by the progressive increase of temperature with depth (Figure 3.8) (Brown et al. 1994b, Gleadow and Brown 2000). The resulting concave-up curves are interpreted as significant prolonged residence in the partial annealing zone. In this case the variation in apparent fission track age with elevation indicates progressive annealing due to increased temperatures. It is important to note that the gradient in these diagrams is not related in any way to cooling. Each individual sample in the profile has equilibrated at a slightly different temperature and will have a slightly different track length distribution. This indicates progressively greater degrees of track annealing (Gleadow and Brown 2000).

Typical examples of these concave-up partial annealing zone profiles are found in deep drillholes in sedimentary basins (Naeser 1981). They are also observed in epirogenetic uplifted zones such as the Transantarctic Mountains (Gleadow and Fitzgerald 1987, Fitzgerald and Gleadow 1988), and on basement relief as 
a Apatite age (Ma)

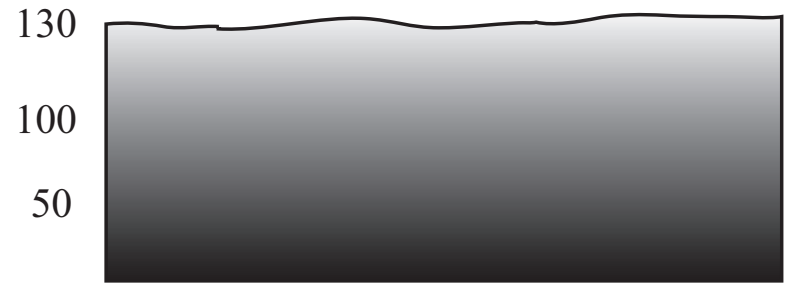

b

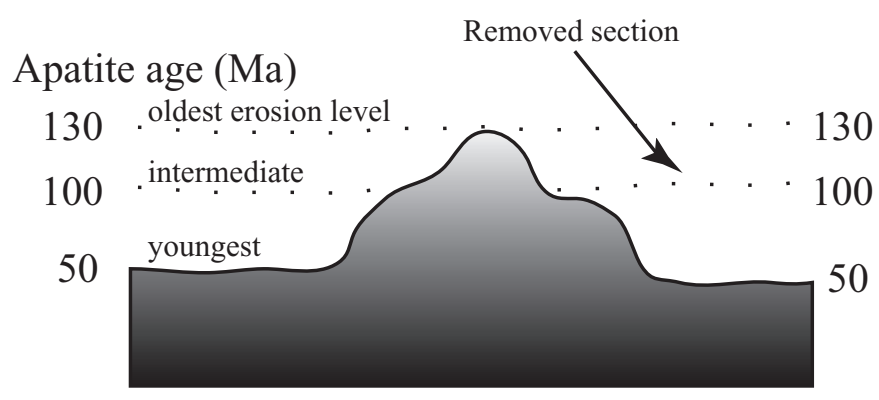

C

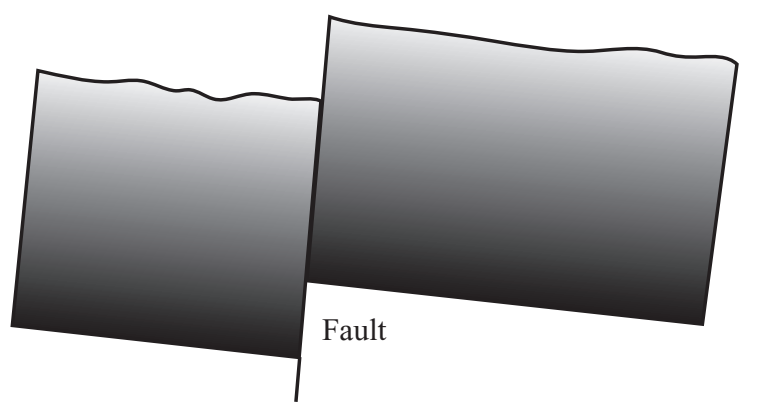

d

Apatite age (Ma)

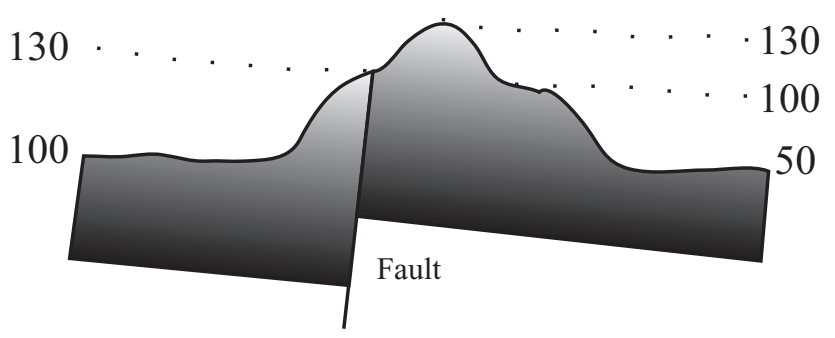

Figure 3.7: Rocks in the upper crust preserve a certain fission track age systematic due to temperature forced track shortening and the subsequent apparent age reduction (a). A simple erosional model is shown in (b). If faulting has occurred $(c)$ and the landscape was shaped in the same way as in b, different apatite fission track ages will be observed on either side of the fault line (d) (after Noble 1997). 
found on the flanks of active rift systems (Foster and Gleadow 1992a, Foster and Gleadow 1996), in active mountain ranges (Fitzgerald et al. 1995) or on passive margins (Johnson and Gallagher 2000).

In the case of more complex cooling histories in which prolonged periods of low denudation are followed by phases of accelerated denudation, a more complex fission track age and mean track length profile will also be observed. The base of the existing partial annealing zone for samples exposed to temperatures below $110^{\circ} \mathrm{C}$ (concave-up apparent age profile from Figure 3.5) will be shifted upwards towards a new topographic surface as denudation proceeds (Brown et al. 1994b). Apatite samples which were exposed to higher temperatures above $110^{\circ} \mathrm{C}$ prior to the onset of accelerated denudation did not accumulate tracks. Thus, these samples have zero apatite fission track ages up to the onset of (accelerated) denudation. They will begin to accumulate tracks after the initiation of cooling, once they have cooled below temperatures of $110^{\circ} \mathrm{C}$. This leads to the development of a new fission track age profile below the earlier (concave-up) profile (Figure 3.8). Most observed vertical profiles are made up of the concave-up curves and a linear relationship in the age elevation pattern (Gleadow and Brown 2000). This pattern is highly significant as it indicates a two stage cooling history. The upper partial annealing zone profile indicates a period of relative stability during which cooling rates were very low, followed by a period of accelerated cooling (Gleadow and Brown 2000).

The transition from the concave-up profile (preserved partial annealing zone, temperatures below $110^{\circ} \mathrm{C}$ ) to the new lower profile (temperature above $110^{\circ} \mathrm{C}$ ) is clearly marked by a break-in-slope. The break-in-slope marks the palaeoisotherm of $110^{\circ} \mathrm{C}$ prior to the initiation of rapid cooling. This too is highly significant in that the corresponding ages approximate the timing of the cooling event. Even though the lower part of the profile constrains the timing at which the accelerated cooling began, only limited temperature information can be extracted from these samples, because of the speed of their passage from the partial annealing zone into the field of track stability.

However maximum palaeotemperatures, prior to the onset of cooling, can be extracted from samples above the break-in-slope. Obtaining this information from vertical relief profiles is critical since it can be equated to the initial burial depth of the samples prior to cooling.

Because vertical relief profiles are collected across the geothermal gradient through which they have cooled, direct estimates of the palaeogeothermal gradient can be made, if the maximum palaeotemperature experienced at the time of onset of cooling is plotted versus the elevation from which the samples were collected. Information on the palaeogeothermal gradient is important to obtain for further quantification of the net amount of denudation that occurred since the onset of rapid cooling. It is also important to know whether significant changes in heat 


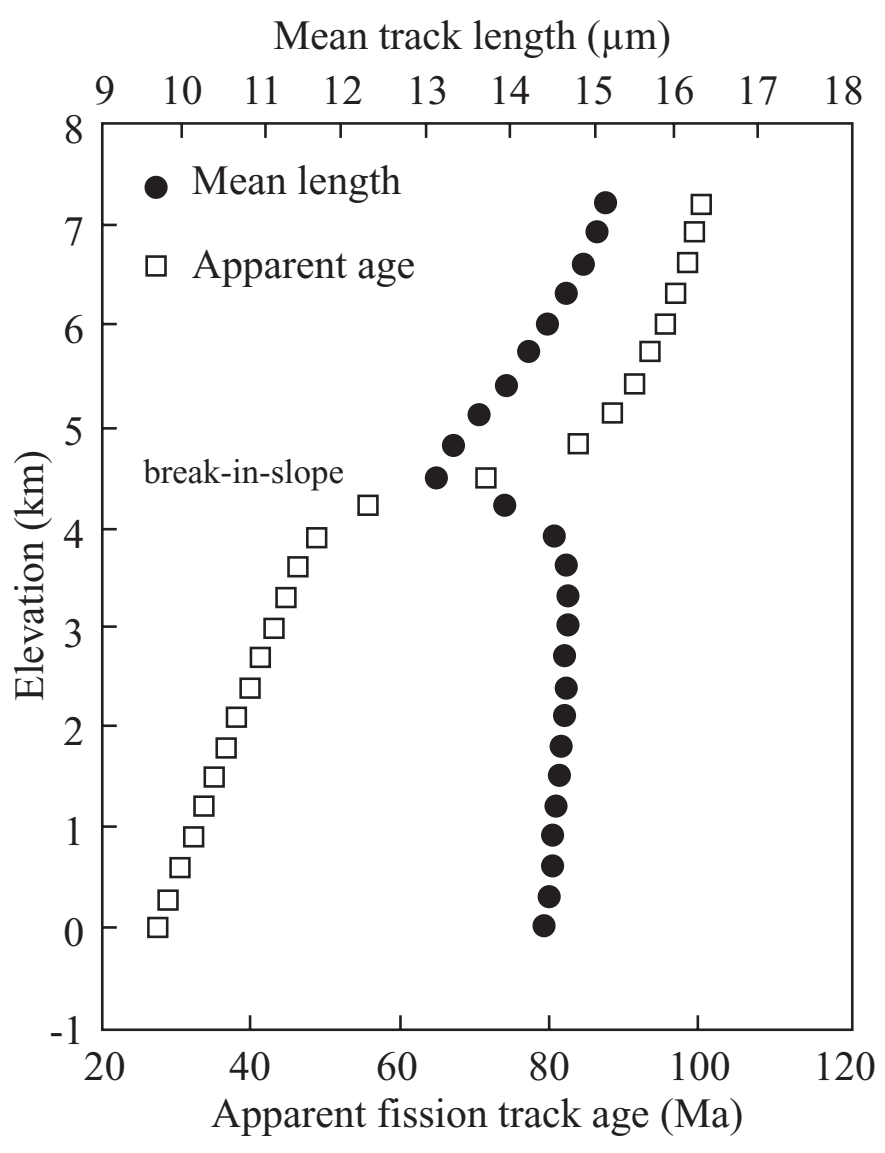

Figure 3.8: Fission track age and mean track length profile as observed in deep drill holes and vertical relief profiles. The break-in-slope separates the preserved partial annealing zone (upper part, concave-up) from the lower region of the curve where samples were totally annealed prior to the rapid cooling event and approximates the time of cooling (after Brown et al. 1994).

flow may have occurred over the same period of time.

\subsubsection{Thermal Modelling}

Following the qualitative interpretations, the thermal histories can now be quantified by forward modelling, integrating all fission track parameters.

Forward modelling has been introduced by Gallagher (1995) using a genetic algorithm (GA). The GA has been applied to test and quantify possible thermal histories from the apparent fission track age, single grain age distribution, track length distribution and mean confined track length.

For all samples with unknown apatite chemistry, the Laslett et al. (1987) an- 
nealing algorithm for Durango apatite $(0,4 \% \mathrm{Cl})$ was used to obtain the thermal histories. All annealing algorithms incorporated in Monte Trax (Laslett et al. 1987, Carlson 1990, Crowley et al. 1991) do not fully predict the annealing of fission tracks in apatite, for this reason the Laslett et al. (1987) algorithm was chosen; also it is in common use in the literature, and provides a reasonable match with most common apatite compositions. In general however the Laslett et al. model will slightly overestimate the timing of thermal histories for samples with low or no chlorine concentrations, and the inverse for samples with higher chlorine contents.

The model estimates the temperature and the timing required to achieve an equivalent degree of annealing for the observed measurements in a particular sample. It is important to note that forward modelling does not give a unique answer, it simply provides a best match to the data. However, the process of modelling is normally assisted by constraints based on the initial observations largely to proof possible thermal histories incorporating all available information. This is done by user defined time-temperature points. To fit a thermal history which maximises the probability of containing the measured data, the "maximum likelihood" approach has been applied to constrain the t-T path (Gallagher 1995), and can be summarised as:

$$
L=\sum_{j=1}^{N_{c}}\left(N_{s}^{j} \ln [\theta]+N_{i}^{j} \ln [1-\theta]\right)+\sum_{k=1}^{N_{j}} \ln \left[P\left(l_{k}\right)\right]
$$

with

$$
\theta=\frac{\rho_{s}}{\rho_{s}+\rho_{i}}
$$

$N_{s}^{j}$ and $N_{i}^{j}$ being the total number of spontaneous $(s)$ and induced $(i)$ tracks, with $j=1, N_{c} . P\left(l_{k}\right)$ being the probability of the track length measurements. $\rho_{s}$ and $\rho_{i}$ are the predicted spontaneous and induced track densities. For the maximum likelihood approach we used individual track counts and unbinned track length distribution. This approach also allows to map confidence regions around the best solution. These confidence regions represent the $95 \%$ confidence intervals $( \pm 2 \sigma)$, and were taken to obtain the time and temperature errors, with always the maximum $x, y$ error considered (the direct search method normally shows asymmetric errors). The $95 \%$ confidence level is the percentage of those estimates providing intervals that actually would contain the true value of the population parameter being estimated. 


\section{Chapter 4}

\section{Fission Track Results from Vertical Relief Profiles}

\subsection{Introduction}

Apatite fission track analysis can identify differential vertical movements of the crust by recording the cooling that results from the denudation that is caused by tectonic uplift, by local relief changes or by changing climate. This can be most tightly constrained and quantified if vertical relief profiles are available.

If a distinctive break-in-slope appears at a particular elevation on a graph of apparent fission track age plotted versus elevation, an excellent marker for the $110^{\circ} \mathrm{C}$ palaeoisotherm is found. This property of vertical fission track profiles is important for understanding the regional tectonics and geomorphic evolution of the study area, and is the focus of this chapter.

A break-in-slope marks the base of a fossil partial annealing zone (Section 3.4.2), provided the apparent apatite fission track ages decrease with increasing depth and temperature in relatively stable thermotectonic environments. This leads to a characteristic concave-up profile on the graph (Gleadow and Duddy 1981, Gleadow et al. 1983, Gleadow et al. 1986) (Section 3.2.2). The break-inslope, in general, is reached at a paleodepth between 3 - $5 \mathrm{~km}$ (Figure 3.8), depending on the palaeogeothermal gradient, and the chemical composition of the apatites (Green et al. 1986, O'Sullivan and Parrish 1995).

The age of the break-in-slope in such a characteristic profile approximates the onset of a phase of significant rapid cooling (Fitzgerald and Gleadow 1990, Brown et al. 1994b). Because samples physically residing at temperatures below the break-in-slope (in excess of $110^{\circ} \mathrm{C}$ ) do not retain any tracks, they therefore have zero age prior to the initiation of rapid cooling, and hence yield information 
about the timing. The form of the new apparent age profile that develops below the break-in-slope (Figure 4.3) therefore depends on the rate and duration of the accelerated period of denudation. It will be linear, if a sufficient section is removed (otherwise a new concave-up partial annealing zone profile will be formed) (Brown et al. 1994b).

Because samples above the break-in-slope retain tracks that formed prior to cooling, they can provide information about the maximum palaeotemperature experienced prior to the phase of accelerated denudation (Figure 3.8).

Thus, the qualitative information which can be derived from such a profile is: general information about the position of the $110^{\circ} \mathrm{C}$ palaeoisotherm and additional information about the thermal history in terms of discriminating between phases of tectonic stability (segment showing a concave-up profile) from phases of accelerated cooling, resulting in a linear array of apparent apatite fission track age with depth/elevation.

Knowledge of the palaeogeothermal gradient is crucial for further quantification of the denudation history (i.e. converting palaeotemperature information into palaeodepth information). The magnitude and timing of denudation can be directly derived if modelling techniques are applied, and information about the palaeogeothermal gradient can be extracted.

When samples are collected from an undisrupted vertical relief profile, the resulting data can be modelled to produce an internally consistent thermal history. The palaeogeothermal gradient at the time just prior to the rapid cooling phase can be reconstructed by plotting the maximum palaeotemperature versus present elevation of the sample. The gradient of this slope displays the palaeogeothermal gradient at that particular time. The gradient of the slope between apparent fission track age, and elevation below the break-in-slope, provides a direct estimate of the denudation rate over this time interval.

In this chapter the results of three vertical profiles - Brandberg, Okenyenya, and Windhoekgraben - will be discussed. Samples collected from vertical profiles from Spitzkoppe, Erongo and Spreetshoogte Pass did not yield sufficient apatites. Apatite mounts from the Okenyenya profile were provided by Roderick Brown.

The samples discussed in this chapter were collected from vertical profiles covering approximately $300-1800 \mathrm{~m}$ of relief. The resulting data were modelled to produce an internally consistent thermal history, and to further quantify the amount of section removed. 


\subsection{Thermal and Numerical Modelling}

Due to the fact that all vertical relief profiles discussed here are coherent crustal profiles, it is assumed that samples from deeper crustal levels were always hotter than the samples from shallower levels. Because all samples have experienced the same style of thermal history at slightly different times and temperatures, all data were modelled with a strong emphasis to find a common history which was compatible with all samples from the profile.

Two different modelling approaches were undertaken to obtain thermal histories consistent with the observed data. The first approach was to obtain timetemperature histories for each sample, using a genetic algorithm and a maximum likelihood function (Gallagher 1995), as described in Section 3.4.3. This approach calculates maximum palaeotemperatures at a certain time for each sample point (point temperatures). Raw track length and track counting data were entered in Contour Trax, an improved version of Monte Trax (Gallagher 1995). Errors on point temperatures are displayed at the $\pm 2 \sigma$ level. The second approach was to obtain a fit to the form of the age and length profiles defined by all samples using Thermotrack (Brown et al. 1994a). Thermotrack calculates apatite fission track parameters, using a one dimensional finite-difference thermal model. The model profiles (e.g. Figure 4.3 and 4.9) for apatite fission track age, and mean track length against elevation, were obtained by forward modelling; and the fit was determined by trial and error. This numerical modelling approach allows the entire apatite fission track age and mean track length profiles to be modelled, as well as the associated thermal histories. The annealing algorithm of Laslett et al. (1987) was used in both approaches.

\subsection{Calculation of Palaeogeothermal Gradient and Denudation}

To determine the maximum palaeogeothermal gradient and amount of section removed from vertical relief profiles, maximum palaeotemperatures derived from apatite fission track data are plotted versus present sample elevation. Maximum palaeotemperatures are derived by thermal modelling of individual samples (Section 3.4.3). The slope of the fitted linear relationship between maximum palaeotemperatures, and present elevation, provides a direct estimate of the maximum palaeogeothermal gradient $(\mathrm{G})$ at the time maximum palaeotemperatures were reached (e.g. Figure 4.5 and Section A.3).

If an estimate of the palaeogeothermal gradient can be made, the amount of removed section can be calculated by dividing the amount of cooling by the geother- 
mal gradient, using the following equation:

$$
D=\frac{\left(T-T_{s}\right)}{G}
$$

where $D$ is the denuded section $[\mathrm{km}], T$ is the modelled palaeotemperature $\left[{ }^{\circ} \mathrm{C}\right]$, $T_{s}$ is the surface temperature $\left[{ }^{\circ} \mathrm{C}\right]$ and $G$ the geothermal gradient $\left[\frac{{ }^{\circ} \mathrm{C}}{\mathrm{km}}\right]$.

The amount of cooling experienced by a particular sample is estimated by subtracting the maximum palaeotemperature from the estimated palaeo-surface temperature at that time. The palaeo-surface temperature is the surface temperature at the time when the subsurface section started to cool from maximum temperatures. It is therefore important to know whether the region has experienced significant changes in climate, since cooling from maximum palaeotemperatures occurred (O’Sullivan and Brown 1998).

Estimates for quantifying denudation rates can be made if a phase of accelerated erosion exhumed the total apatite annealing zone. This results in a linear segment of the age elevation profile below the break-in-slope (Figure 3.8). The slope of this linear segment is a direct measure of the denudation rate:

$$
R=\frac{\Delta E}{\Delta t}
$$

where $R$ is the denudation rate $\left[\frac{\mathrm{km}}{\mathrm{m} \cdot \mathrm{y}}\right], \Delta E$ is the difference in present elevation $[\mathrm{km}]$ and $\Delta t$ denotes the time interval [m.y.].

It should be noted that the denudation rate calculated this way is independent of assumptions about the geothermal gradient, because it records cooling of rock mass as it moves vertically through the effective closure isotherm (Foster and Gleadow 1996). However, estimates of the amount of denudation are only valid if a known depth for the $110^{\circ} \mathrm{C}$ isotherm can be assumed. According to Harrison and Clarke (1979), Parish (1983), Brown and Summerfield (1997), and Moore and England (2001), isotherms are not effected significantly by denudation for denudation rates below $0.5-0.3 \mathrm{~km} / \mathrm{m} . \mathrm{y}$. .

\subsection{The Brandberg Profile}

The Brandberg igneous complex in northwestern Namibia, with its summit at $2573 \mathrm{~m}$, is the highest mountain in Namibia. The isolated massif with a diameter of $25 \mathrm{~km}$ (areal extent of approximately $420 \mathrm{~km}^{2}$ ) rises approximately $1800 \mathrm{~m}$ above the plains of the Namib Desert. The Brandberg complex represents an intra-plate anorogenic ring-complex. It belongs to the Damaraland Alkaline Igneous Province (Section 2.2.5) and was emplaced into late Precambrian granites 


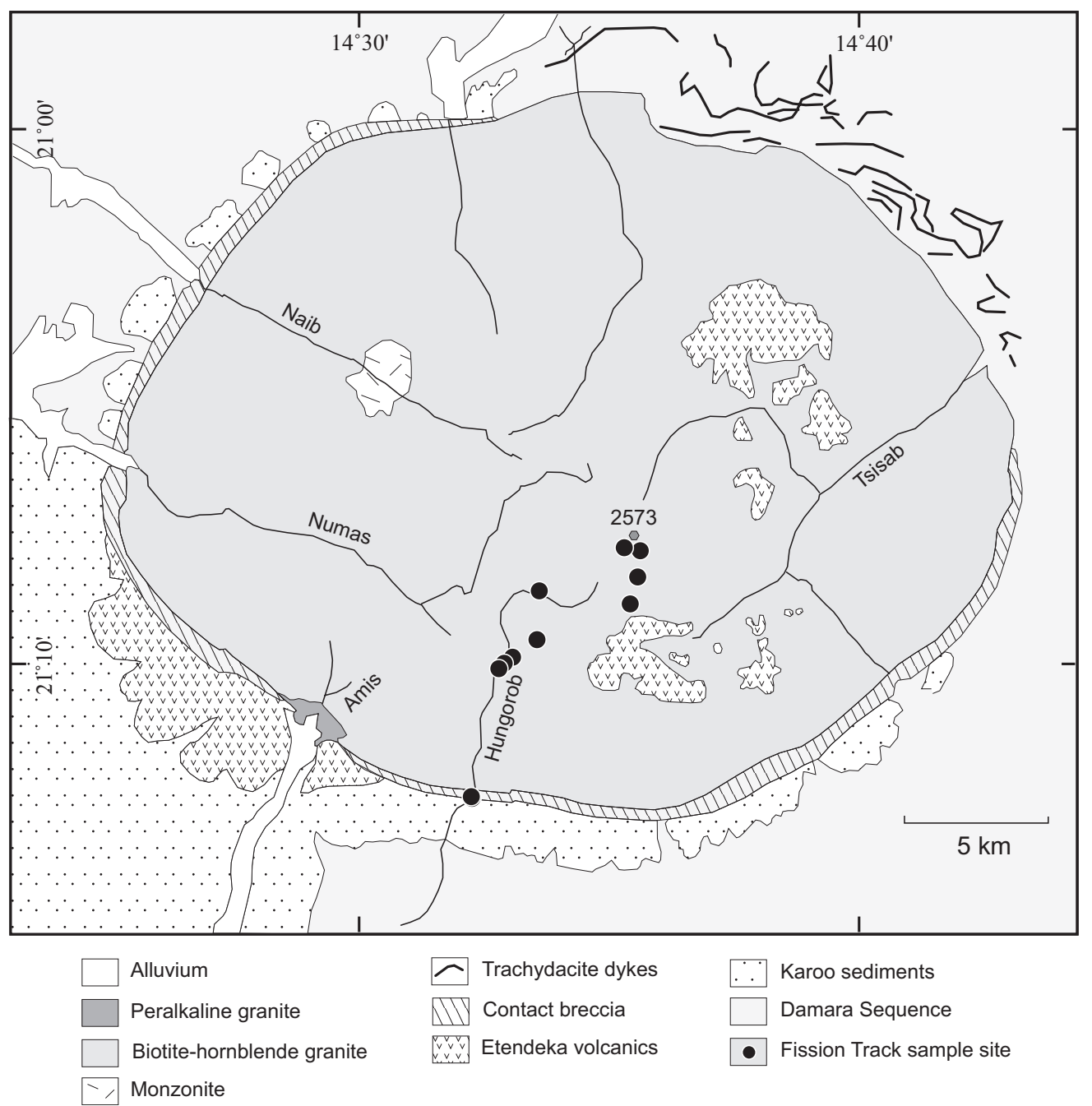

Figure 4.1: Simplified geological map of the Brandberg complex with fission track sampling sites (after Schmitt et al. 2000)

and metasedimentary rocks of the Damara sequence (Diehl 1990). Basically, the Brandberg igneous complex represents an exhumed granitic pluton with a very well constrained intrusion age of $132 \pm 1$ Ma (Watkins et al. 1994, Schmitt et al. 2000) (Section 2.2.5 and 2.3.2).

A number of subvolcanic, magmatic centers are exposed at the present level of erosion of the Brandberg. Detailed mapping by Diehl (1990) recognised eight cycles of magmatic/subvolcanic activity, expressed by different magmatic centers. Later studies by Schmitt et al. (2000) could not confirm this subdivision and they consider the Brandberg complex to consist of four essentially discrete and mappable intrusive units. However, alkali granite is by far the most abundant and characteristic rock type, with the vast majority of the massif formed by 

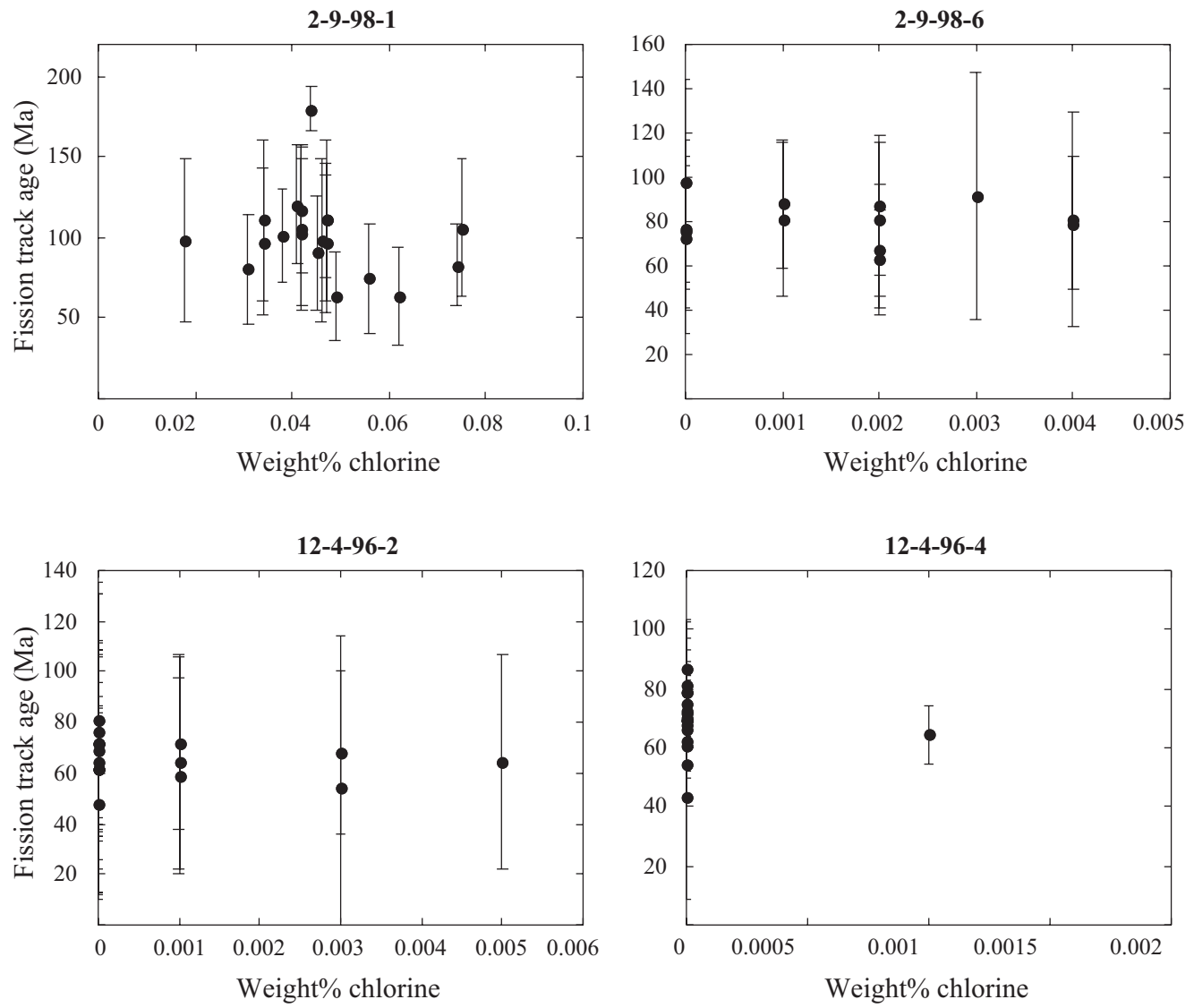

Figure 4.2: Chlorine content of four selected Brandberg samples. All samples are fluorapatites with less than $0.1 \%$ chlorine.

biotite-hornblende granite. An early quartz monzonite body, the Amis peralkaline granite, and peripheral felsic dykes make up the rest of the complex (Fig. 4.1).

The sampling rationale was to collect a full vertical profile covering the largest possible elevation range in order to obtain the utmost information about the timing and magnitude of cooling and subsequently denudation.

The Brandberg is difficult to access and two field campaigns were necessary to obtain a full profile. Fifteen samples were taken over a regular interval of approximately $100 \mathrm{~m}$, off the southern flank of the Brandberg, from the summit (2573 m) to the base of the Hongorob Gorge $(720 \mathrm{~m}$ ) (Figure 4.1). An early expedition in September 1996 had to be aborted at $1800 \mathrm{~m}$ altitude due to extreme climatic conditions. Rocks from the summit down to $2100 \mathrm{~m}$ were collected two years later by Klaus Weber on a helicopter flight provided by the German GeoForschungsZentrum Potsdam. Samples were collected from the main biotite-hornblende granite. Only the bottom sample belongs to the contact breccia, and was sampled for comparative purposes. 


\subsubsection{Fission Track Results}

Separation of apatite from the Brandberg samples was very difficult due to fluorite bearing granites. Fluorite has almost the same physical properties, and is indistinguishable from apatite applying standard mineral separation procedures (Appendix B) and is abundant compared to apatite if present. Apatites were successfully separated from eleven of this samples. Analytical details are displayed in Table 4.1. 20 grains could be counted in five out of eleven samples, and only the lowest two samples had 100 measurable lengths. Due to the very small number of apatite grains in most samples, horizontal confined track length information is very limited, and inferences based on a small number of confined tracks have to be treated with caution.

The apatite fission track ages range from $98 \pm 9$ Ma to $66 \pm 11 \mathrm{Ma}$ and decrease systematically with decreasing elevation. The systematic pattern in age reduction produces an asymptotic decrease of age from $2570 \mathrm{~m}$ altitude (2-9-98-1, $98 \mathrm{Ma}$ ) down to $2260 \mathrm{~m}$ altitude $(2-9-98-7,81 \mathrm{Ma})$, and an almost linear decrease below $2260 \mathrm{~m}$ altitude (2-9-98-6, $79 \mathrm{Ma}$ ) down to the base at $720 \mathrm{~m}$ altitude (12-4-96-5, $69 \mathrm{Ma})$. The mean confined track length distribution varies from $15.1 \pm 0.4 \mu \mathrm{m}$ to $12.2 \pm 1.1 \mu \mathrm{m}$ (Table 4.1). A characteristic of the mean track length profile for the upper section is the pronounced increase in mean track length that occurs from $2570 \mathrm{~m}$ down to $2120 \mathrm{~m}$ altitude (Figure 4.3). The mean track length in this part of the profile increases systematically from $14.3 \mu \mathrm{m}$ to $15.1 \mu \mathrm{m}(2-9-98$ 1 to 2-9-98-7). The associated standard deviation decreases systematically from values of 1.89 (2-9-98-1) to 1.19 (2-9-98-6). This systematic pattern results if palaeotemperatures above approximately $95^{\circ} \mathrm{C}$ were reached. As a result of such high palaeotemperatures the lengths of earlier formed tracks are dramatically reduced (Brown et al. 1994b). But the track length measuring procedure is strongly biased against measuring severely shortened tracks below $10 \mu \mathrm{m}$ (Laslett et al. 1982, Green 1988). This affects the mean track length distributions for these samples which become increasingly dominated by the long track length component. So, the resulting mean track length distribution begins to increase with a simultaneous decrease in standard deviation. As soon as maximum palaeotemperatures exceed $110^{\circ} \mathrm{C}$, none of the earlier formed tracks are preserved.

Microprobe data of all grains from four selected samples (2-9-98-1, 2-9-98-6, 12-4-96-2, 12-4-96-4) along the profile gave chlorine concentrations all less than $0.1 \mathrm{wt} \%$ chlorine (Figure 4.2). This indicates very little compositional variation in chlorine content, and because all compositions are more F-rich than the standard Durango apatite ( $0.4 \mathrm{wt} \%$ chlorine), estimated temperatures are maximum temperatures. Thus, the temperature at the base of the partial annealing zone that formed prior to approximately $80 \mathrm{Ma}$ did not exceed $110^{\circ} \mathrm{C}$ (Green et al. 1986). 

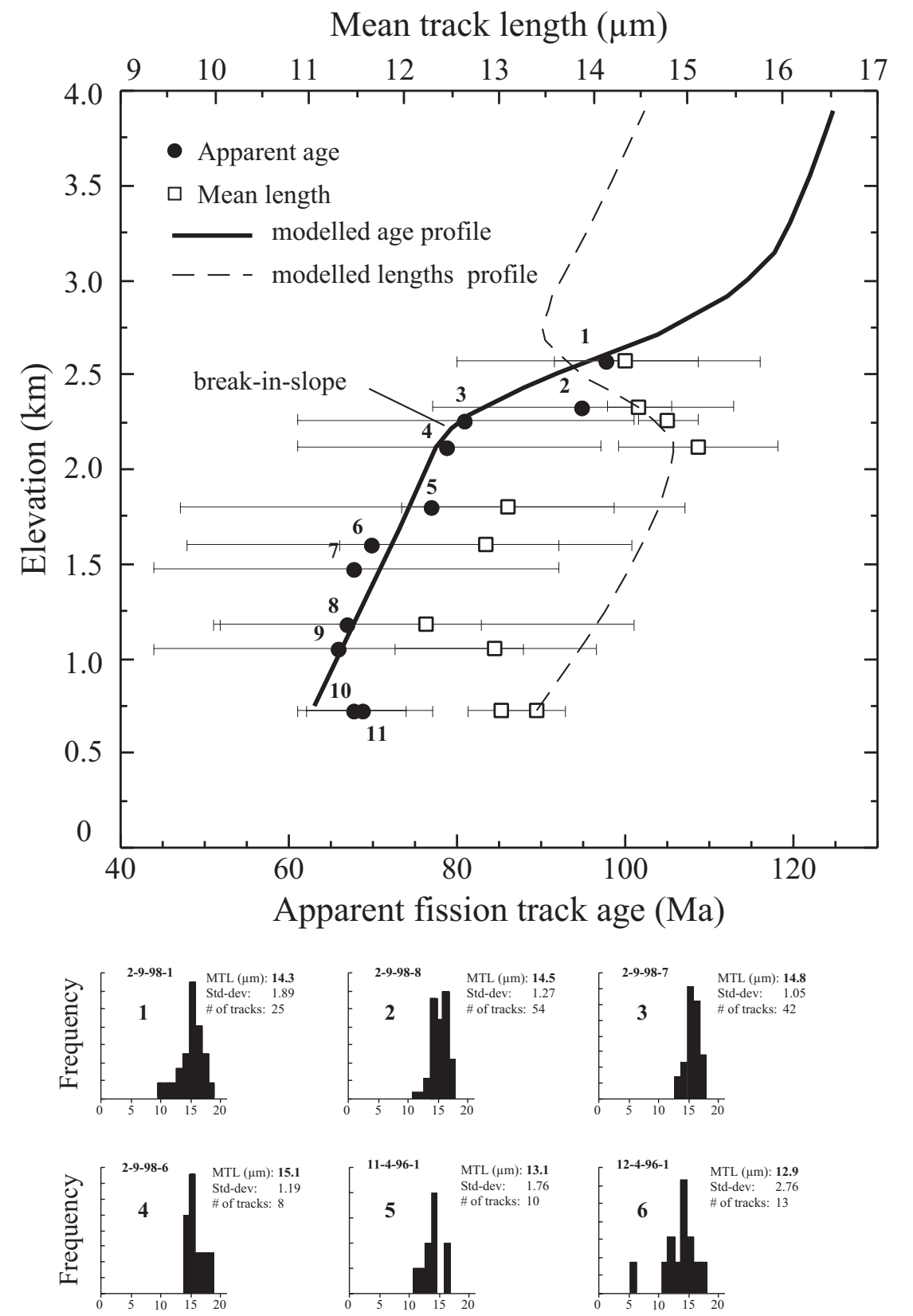

7) 12-4-96-2: no length data available

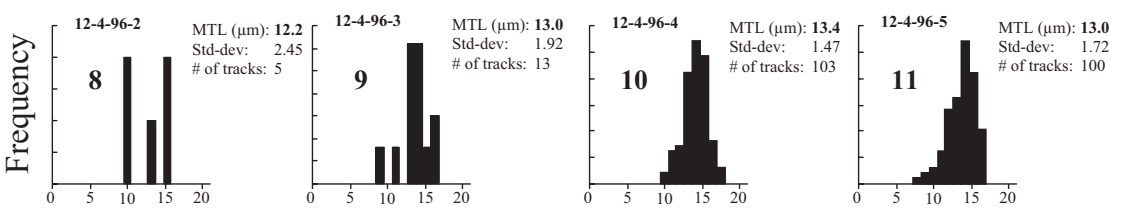

Figure 4.3: Apparent fission track ages and mean track lengths across the full height of the exposed Brandberg igneous complex. Number of tracks in histograms is normalised to 100. The pronounced inflection (at approximately $2100 \mathrm{~m}$ ) marks the break-in-slope at ca. $79 \mathrm{Ma}$. Errors are denoted at the $\pm 2 \sigma$. The solid and dashed lines represent the shapes of the 1-D Thermotrack models for apparent fission track ages and mean track lengths. 


\subsubsection{Discussion}

The vertical profile of the Brandberg exhibits the characteristic shape of the base of an exhumed partial and total annealing zone (Figure 4.3). The break-in-slope in the apparent apatite fission track age profile between 81 and 79 Ma marks the base of the partial annealing zone at $2260 \mathrm{~m}$ altitude, and this age approximates the timing of the initiation of a phase of rapid cooling. The mean track lengths for five samples below the break-in-slope (2-9-98-6, 11-4-96-1, 12-4-96-1, 12-4-96$2,12-4-96-3)$ are based on less than 20 track measurements, and should therefore only be regarded as indicative at this stage.

The fact that all ages between $2260 \mathrm{~m}$ and $720 \mathrm{~m}$ altitude are nearly concordant (Figure 4.3) with a weighted mean of $69 \pm 0.8 \mathrm{Ma}$, suggests that a phase of rapid cooling commenced at about that time.

The break-in-slope, and the change in apparent fission track ages from younger than 79 Ma below $2120 \mathrm{~m}$ to older than $79 \mathrm{Ma}$ above $2120 \mathrm{~m}$ altitude, mark the depth of the transition from the apatite partial annealing zone to the total annealing zone for the Late Cretaceous (Figure 4.3). In this interpretation, samples, which are at present above $2120 \mathrm{~m}$ altitude, were within the partial annealing zone for a protracted period of time before Late Cretaceous cooling. Samples below this elevation did not retain fission tracks, and would have recorded zero apatite fission track ages prior to this time (Gleadow and Fitzgerald 1987, Brown et al. 1994b).

Due to the different record preserved in samples above and below the breakin-slope, estimates of the palaeogeothermal gradient could be derived by thermal modelling from either part separately. This is because samples below the breakin-slope were exposed to temperatures in excess of $110^{\circ} \mathrm{C}$, and hence no tracks were accumulated at the time samples above the break-in-slope were exposed to temperatures close to and below $110^{\circ} \mathrm{C}$. In the case of the lower part of the Brandberg profile (Figure 4.3), no attempts to model palaeotemperatures were made, due to the lack of confined tracks.

The three samples from the highest elevation provided sufficient numbers of track lengths (2-9-98-1, 2-9-98-8, 2-9-98-7). Thermal histories were tested for a phase of accelerated cooling sometime in the Late Cretaceous. Histories derived by thermal modelling are shown in Figure 4.4. A coherent thermal profile was obtained for all three data, with increasing maximum temperatures with decreasing elevation (Figure 4.5).

All samples reflect an onset of quick cooling in the Late Cretaceous at about $83 \mathrm{Ma}$. Maximum palaeotemperatures at this time increase from $96 \pm 14$ to 105 $\pm 20^{\circ} \mathrm{C}$ (Figure 4.4). These model palaeotemperatures were plotted against present elevation in Figure 4.5. The gradient of the linear least square regression represents the palaeogeothermal gradient at this time. Linear regression was performed 

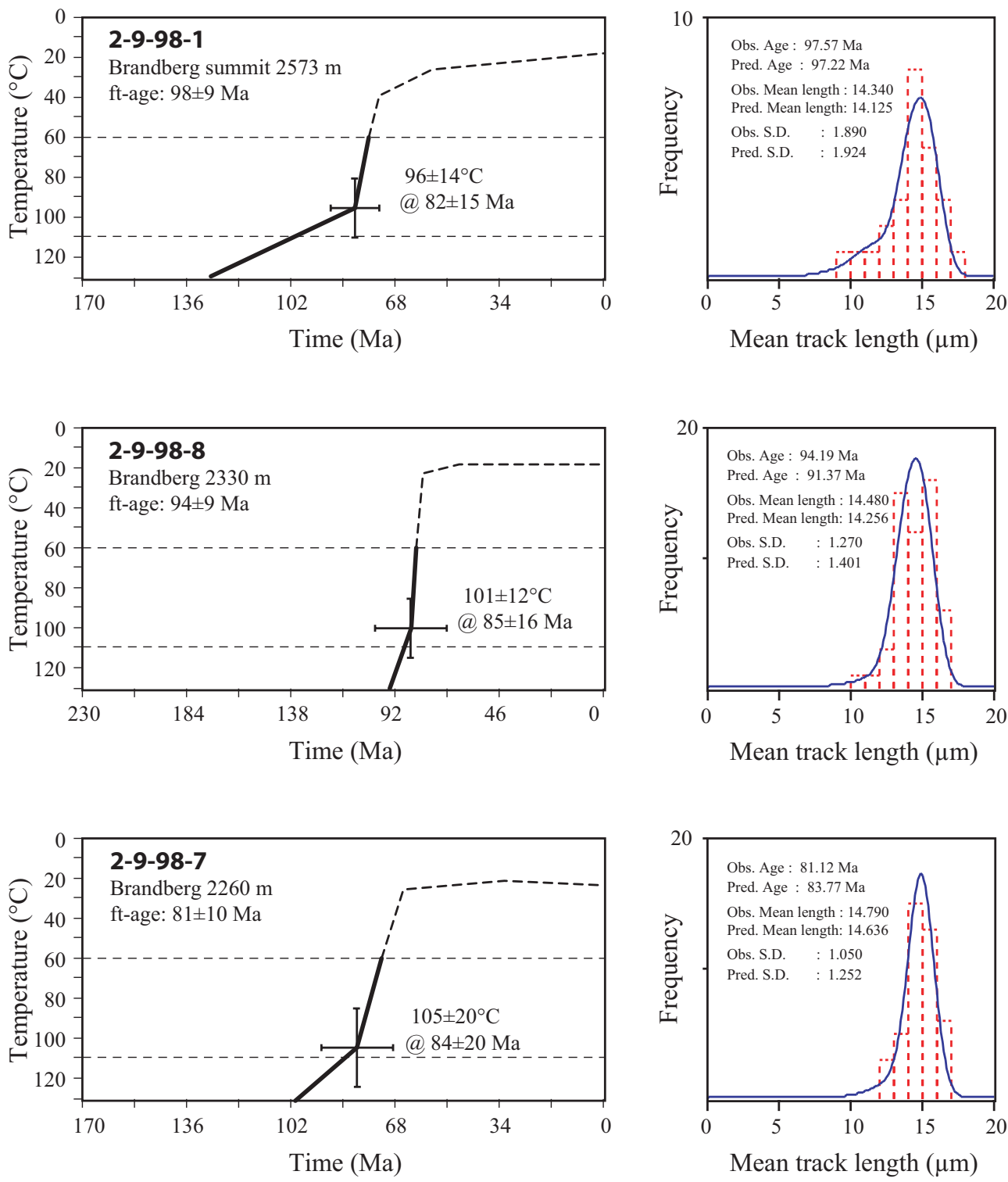

Figure 4.4: Thermal histories for the top three Brandberg samples. Error bars arise from the t-T-point where the thermal models suggest the onset of rapid cooling. These values were used to estimate the palaeogeothermal gradient in Figure 4.5. Errors are displayed as $\pm 2 \sigma$ errors. Horizontal dashed lines at 60 and $110^{\circ} \mathrm{C}$ bracket the partial annealing zone. Dashed lines extending thermal histories above $60^{\circ} \mathrm{C}$ mark a possible continuation of the thermal history since apatite fission track analysis is least sensitive to these temperatures.

twice in order to handle the errors in two different ways. The value of the palaeogeothermal gradient is $27 \pm 6^{\circ} \mathrm{C} / \mathrm{km}$ only if the dispersion of individually derived palaeotemperatures are considered to calculate the standard errors. Least square regression, which takes the $\pm 1 \sigma$ individual errors on the palaeotemperatures into 


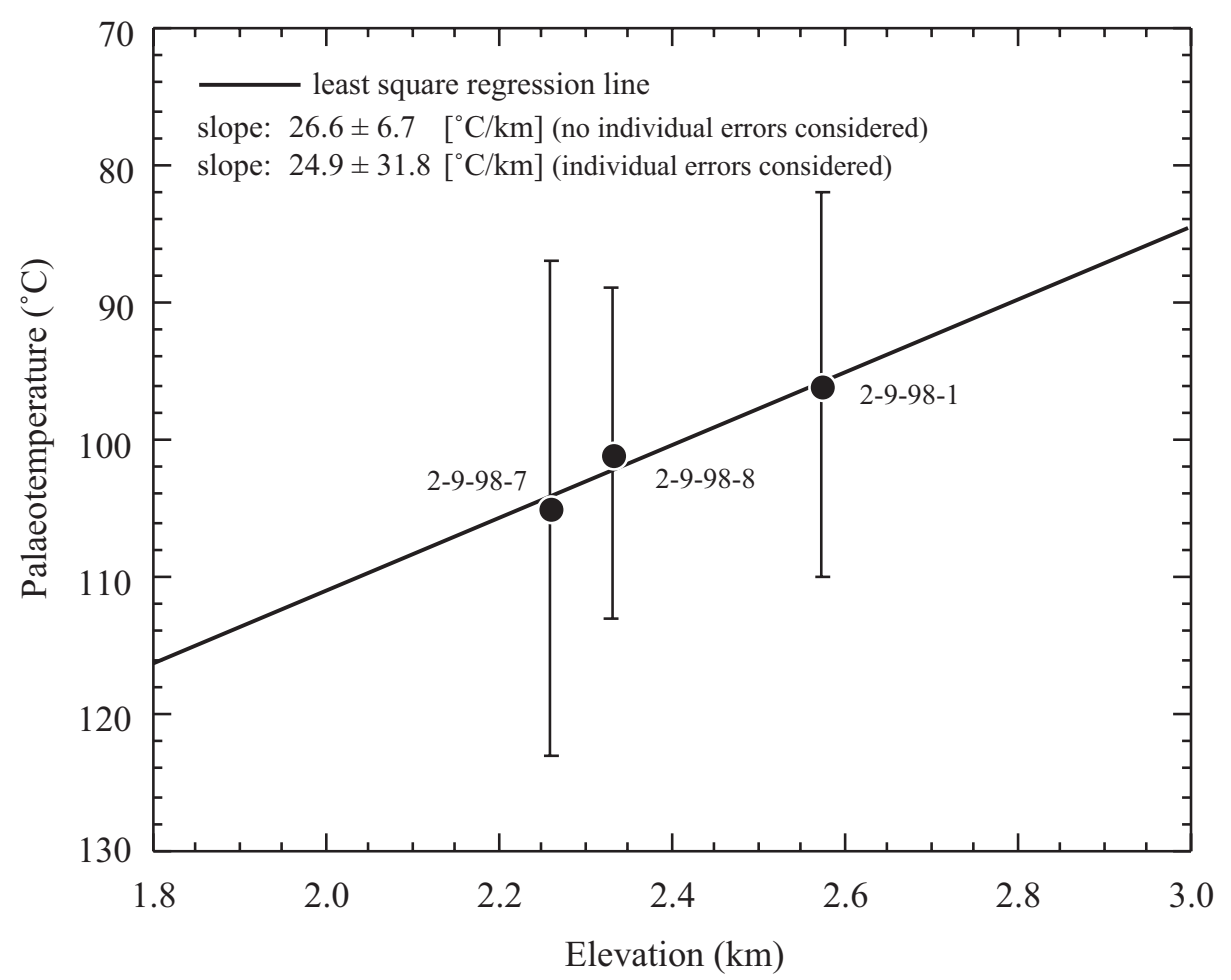

Figure 4.5: Palaeogeothermal gradient derived from thermal modelling for the top three Brandberg samples. Error bars are denoted as $\pm 2 \sigma$ errors.

account, reduces the palaeogeothermal gradient to $25^{\circ} \mathrm{C} / \mathrm{km}$ but significantly increases the error to $\pm 31^{\circ} \mathrm{C} / \mathrm{km}$. This large error results from large $1 \sigma$ errors, and the very narrow elevation interval from which the maximum palaeotemperatures were derived.

The error on the palaeogeothermal gradient could theoretically be minimised with more data. However, these data would be difficult to obtain. The three modelled samples are taken from the base of the partial annealing zone, which forms the highest elevation of the Brandberg. And, for reasons outlined above, the bottom part of the profile is not suitable for confident modelling.

Although the precision on the estimates of the gradient is low, it nevertheless provides a useful idea of what the Late Cretaceous gradient was. In fact, it appears that the Late Cretaceous palaeogeothermal gradient was not significantly elevated relative to the present day $\left(22^{\circ} \mathrm{C} / \mathrm{km}\right)$ (Ballard and Pollack 1987).

Using an estimate of the palaeogeothermal gradient of $26^{\circ} \mathrm{C}$, the amount of denudation can now be calculated using Equation 4.1. An annual mean surface temperature of $18^{\circ} \mathrm{C}$ was assumed for the calculation. The removed section for the Brandberg summit is then estimated to be approximately $3 \mathrm{~km}$. The preservation of the partial annealing zone is critical for gross estimates of the net amount of de- 
nudation if the removed section exceeds approximately $4 \mathrm{~km}$ (assuming a gradient of ca. $26^{\circ} \mathrm{C}$ ). This is because the difference in elevation to the remaining outcropping section, where palaeotemperatures were beyond $110^{\circ} \mathrm{C}$ (in this case from $2120 \mathrm{~m}$ altitude downwards), can be added to the denuded section where maximum palaeotemperatures could be derived by thermal modelling. Subsequently, the amount of removed section from the present regional landsurface at the base of the Brandberg is approximated to ca. $5 \mathrm{~km}$, since the difference in elevation from summit to base is ca. $1850 \mathrm{~m}$.

While the numerical modelling using Thermotrack requires some initial values for the geothermal gradient and the denudation rate, direct estimates of the denudation rate over time for the phase of accelerated denudation can be made by applying least square regression to the linear segment of near concordant ages below the break-in-slope of the profile (e.g. Brown et al. 1994b, Foster and Gleadow 1996). The least square regression from sample 2-9-98-7 to 12-4-96-5 estimates an apparent average denudation rate of $0.12 \pm 0.01 \mathrm{~km} / \mathrm{m} . \mathrm{y}$. over this particular time interval in the Late Cretaceous.

The numerical one-dimensional models for apparent fission track age and mean track length in Figure 4.3 were generated using Thermotrack (Brown et al. 1994a). Three episodes were postulated for the thermal history of the Brandberg samples: Assuming negligible denudation rates from 130 to $85 \mathrm{Ma}$; rapid denudation with average rates of $0.125 \mathrm{~km} / \mathrm{m}$.y. from 85 to $65 \mathrm{Ma}(2.5 \mathrm{~km})$ (see calculation above); followed by a phase of low denudation rates of $0.023 \mathrm{~km} / \mathrm{m}$.y. from $65 \mathrm{Ma}$ to present $(1.5 \mathrm{~km})$. An initial geothermal gradient of $26^{\circ} \mathrm{C}$ (see calculation above) and the annealing model of Laslett et al. (1987) were used. The resulting model is shown in comparison with the observed data in Figure 4.3.

While the model prediction for the apparent fission track ages forms an almost perfect fit to the measured apparent fission track ages, the mean track lengths predicted below the break-in-slope (between 1 and $2 \mathrm{~km}$ altitude) are significantly longer than the observed data (Figure 4.3). This misfit may be attributed to the small amount of measured lengths for these samples. Nevertheless, the mean track length in three out of four data (11-4-96-1, 12-4-96-2, 12-4-96-3) plot within the $2 \sigma$ error of the modelled curve. As soon as the number of measured confined track lengths reaches 100 tracks, as is the case with the two samples from the base of the Brandberg (12-4-96-4, 12-4-96-5), a perfect match with the model is obtained again.

Thermal histories displayed in Figure 4.6a represent the Thermotrack thermal history for the Brandberg profile, and reflect the simplest model that is able to predict the major features of the data. It is unreasonable to expect this model to satisfy all quantitative characteristics which have finally resulted from the "real" thermal history of the Brandberg. A limitation of these models is that the thermal effects of magmatic underplating, associated with rifting in the Early Cretaceous, 
a)

Time vs temperature

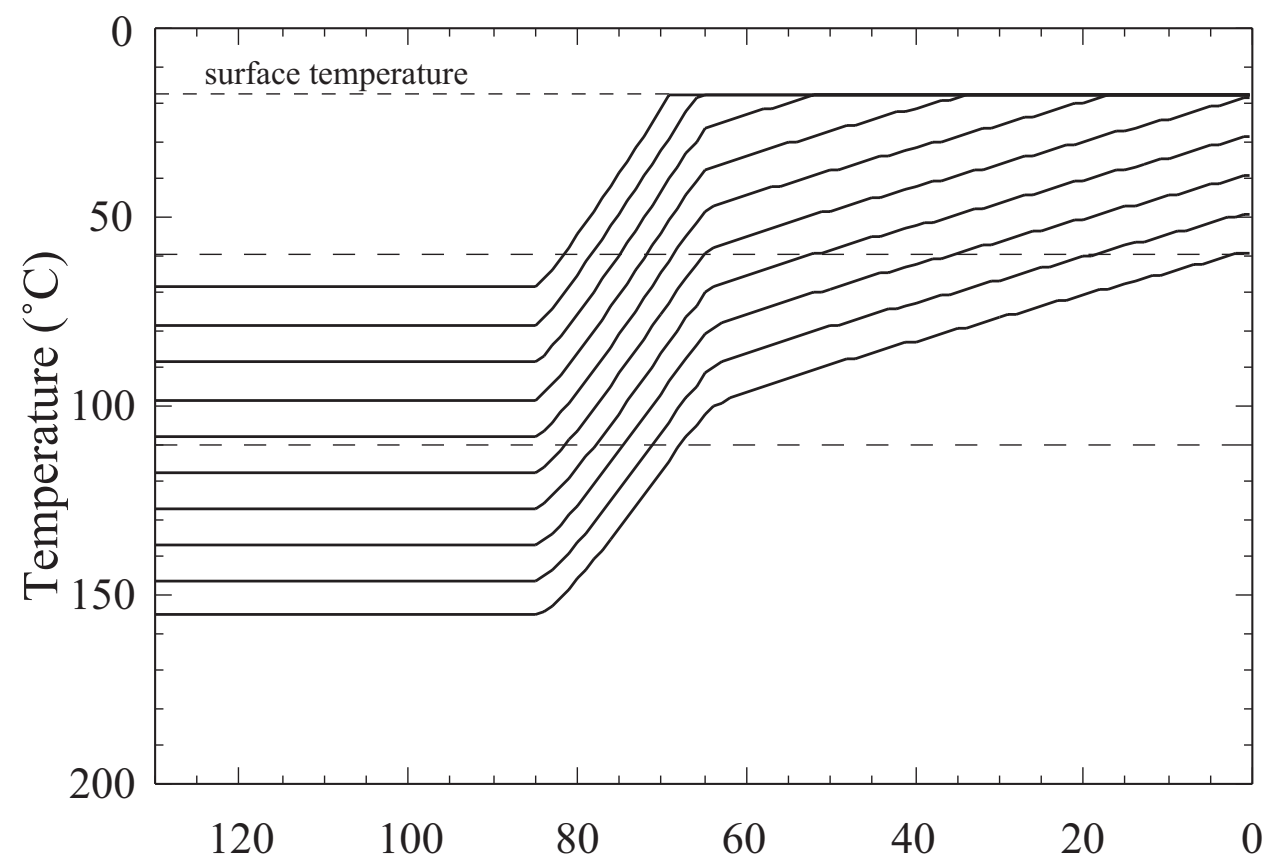

b)

Time vs depth

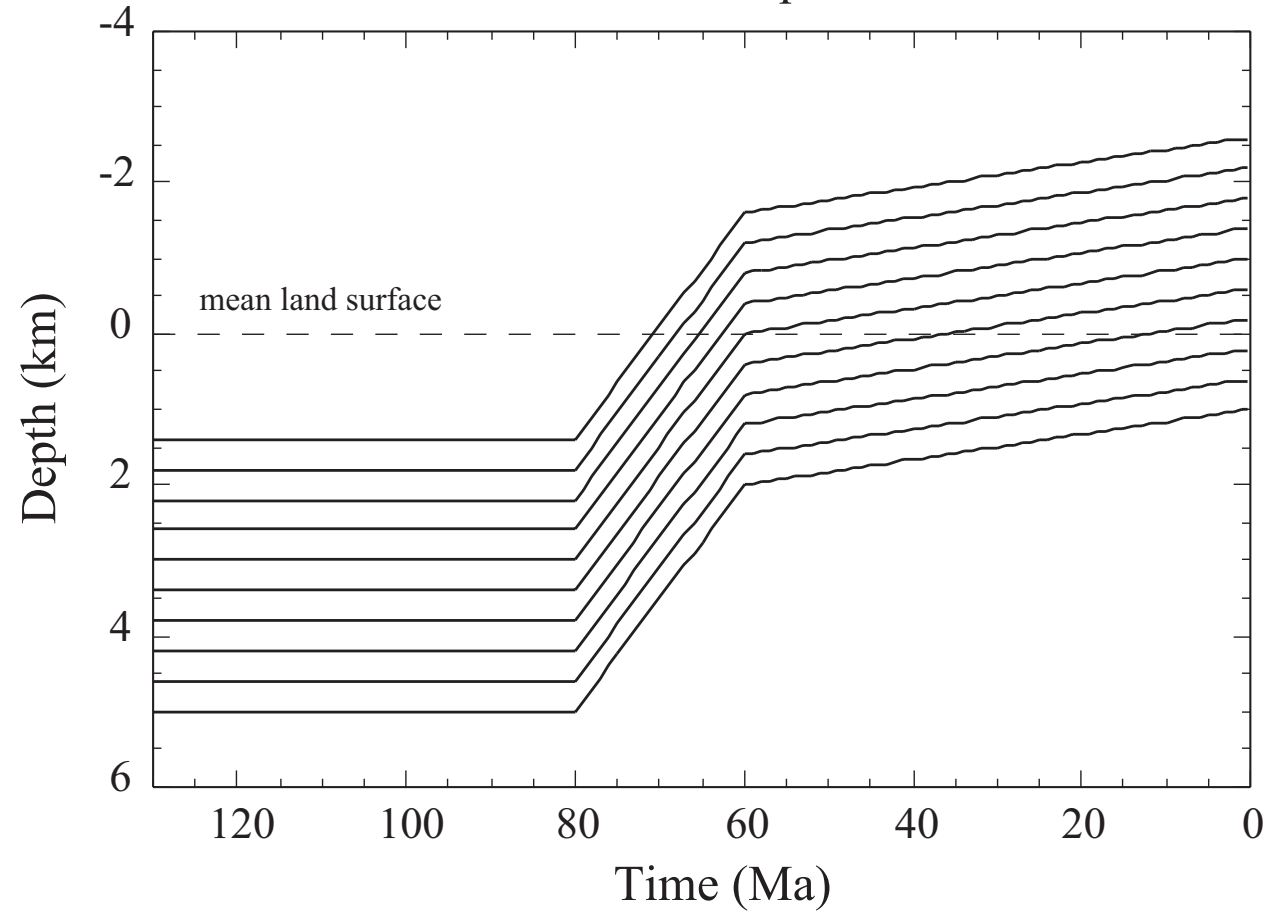

Figure 4.6: One-dimensional thermal histories for samples across the Brandberg. a) Dashed lines bracket the partial annealing zone between 60 and $110^{\circ} \mathrm{C} . \mathrm{b}$ ) Dashed line marks present mean land surface. 
are not included. However, magmatic underplating and cooling is unlikely to have affected the cooling history in the Late Cretaceous (Brown et al. 1994a). Despite the limitation, the one-dimensional models are capable of providing predictive model results which fit well with the observed data.

\subsubsection{Summary}

Several qualitative assumptions can now be placed on the thermal history of the present outcropping Brandberg igneous complex. The maximum palaeotemperatures experienced by rocks above $2120 \mathrm{~m}$ altitude, after initial cooling from intrusion, were less than $110^{\circ} \mathrm{C}$ (Figure 4.3 and 4.4). Figure 4.4 displays the point thermal histories for the three samples from the present highest exposures derived by thermal modelling after Gallagher (1995). Samples below $2120 \mathrm{~m}$ (below the break-in-slope) (Figure 4.3) were exposed to temperatures in excess of $110^{\circ} \mathrm{C}$ prior to their exhumation in the Late Cretaceous.

Rocks exposed by erosion that are now at the surface of plains surrounding the Brandberg (currently at approximately $700 \mathrm{~m}$ altitude) were at significantly elevated temperatures at least until the Late Cretaceous. This implies that several kilometers of denudation must have occurred on a regional scale during the Late Mesozoic-Early Cenozoic.

The amount of denudation that can be estimated since the time revealed by the break-in-slope provides good constraints on the position of the $110^{\circ} \mathrm{C}$ palaeoisotherm, which is currently at an altitude of approximately $2100 \mathrm{~m}$. Moreover, further quantitative constraints can be obtained by thermal and numerical models. These models were used to derive the simplest thermal history that could explain the quantitative and qualitative characteristics of the observed fission track results (Figure 4.3 and 4.6). The palaeogeothermal gradient was approximated by determination of point temperatures to ca. $26^{\circ} \mathrm{C}$ in the Late Cretaceous (Figure 4.5). Subsequently, the amount of removed section was estimated to be approximately $5 \mathrm{~km}$ from the present landsurface surrounding the Brandberg since the onset of rapid cooling in the Late Cretaceous.

The application of a combination of thermal and numerical modelling of fission track data has proved to be very useful in reconstructing thermal histories, as well as point temperatures and palaeogeothermal gradients, from the vertical relief Brandberg profile. 


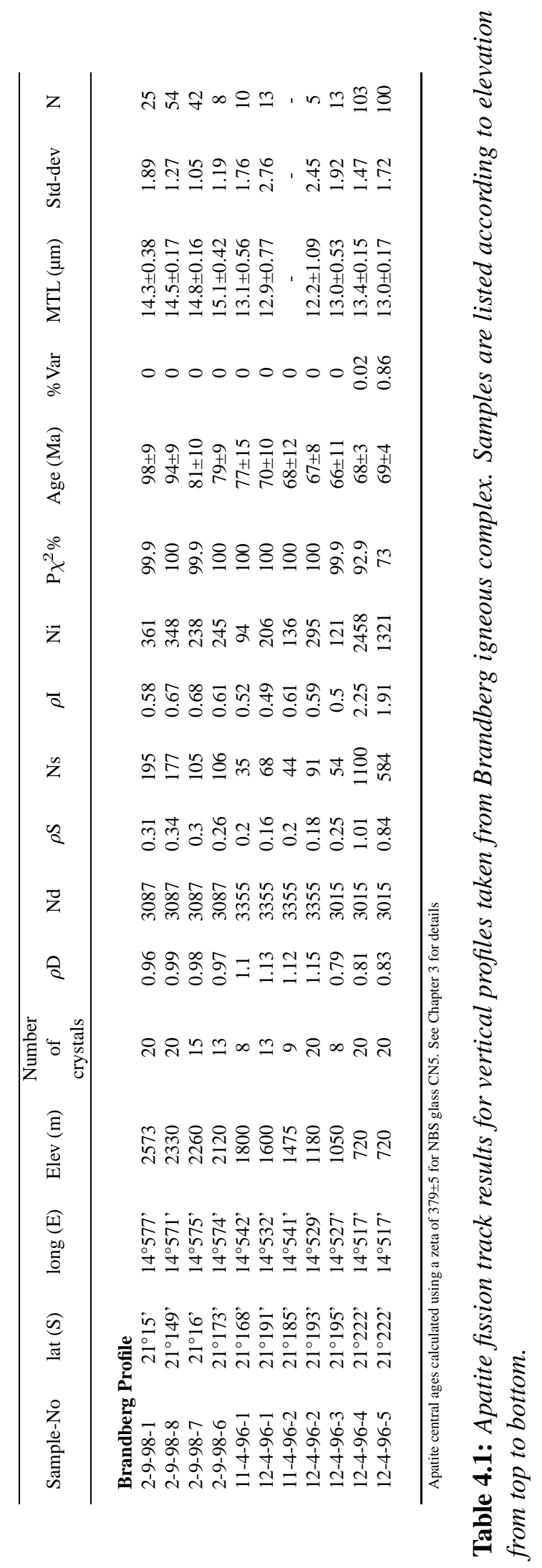




\subsection{The Okenyenya Profile}

The Okenyenya complex, only $70 \mathrm{~km}$ northeast of the Brandberg, is a much smaller complex, comprising approximately $20 \mathrm{~km}^{2}$. It rises almost $1 \mathrm{~km}$ above the surrounding plains. The Okenyenya complex, like the Brandberg, belongs to the anorogenic intraplate ring-complexes of the Damaraland Igneous Province (Section 2.2.5). It contains a wide range of rock types, from silica-undersaturated alkaline varieties and tholeiitic gabbros, to silica-oversaturated syenites (Fig. 4.7) (Watkins et al. 1994). Watkins et al. (1994) bracketed magmatic activity into a time interval of 132 to $128 \mathrm{Ma}$ (Section 2.2.5).

Being intruded in the Late Cretaceous into the Pan-African Damara Sequence (Figure 4.7), the Okenyenya complex forms the exposed and isolated remnants of several sequences of shallow intrusions. This profile was targeted, and nine samples were taken every $100 \mathrm{~m}$, to derive a detailed cooling history and the palaeogeothermal gradient for the Okenyenya-region, as demonstrated in the previous section for the Brandberg.

Because of the similarities to the Brandberg of emplacement age, exposure, and denudation history, only a brief description of the analytical results will be given here. Modelling was performed in the same fashion as for the Brandberg.

\subsubsection{Fission Track Results}

Samples over the full range of the Okenyenya profile were taken by Roderick Brown and Ron Watkins in 1995. Apatites were successfully separated from samples taken over vertical intervals of approximately $100 \mathrm{~m}$, from the summit at $1902 \mathrm{~m}$ down to the base at $980 \mathrm{~m}$, covering a difference in elevation of $920 \mathrm{~m}$.

The apatite fission track ages decrease from the summit with $103 \pm 9$ Ma systematically, and reach ages of $68 \pm 9 \mathrm{Ma}$ at the base. An asymptotic decrease in apparent apatite fission track age can be observed between $1902 \mathrm{~m}$ altitude (95N8 ) and $1400 \mathrm{~m}$ altitude $(95 \mathrm{~N}-13)$. This pattern is less pronounced in comparison with the Brandberg profile, as is the commencing linear decrease of apparent fission track age with elevation for the lower part of the profile $(95 \mathrm{~N}-14$ to $95 \mathrm{~N}-16$, 1310 to $980 \mathrm{~m}$ altitude).

The distribution of mean confined track lengths ranges from $14.1 \pm 0.18 \mu \mathrm{m}$ (95N-12) to $12.7 \pm 0.34 \mu \mathrm{m}(95 \mathrm{~N}-15)$, and the associated standard deviation varies from $1.53(95 \mathrm{~N}-15)$ to $1.06(95 \mathrm{~N}-9)$. Analytical results are displayed in Table 4.2.

Chlorine concentrations of four selected samples across the profile, determined by microprobe analysis, reach values for all grains below $0.15 \mathrm{wt} \%$ chlorine. All grains have less chlorine than the standard Durango apatite, and esti- 


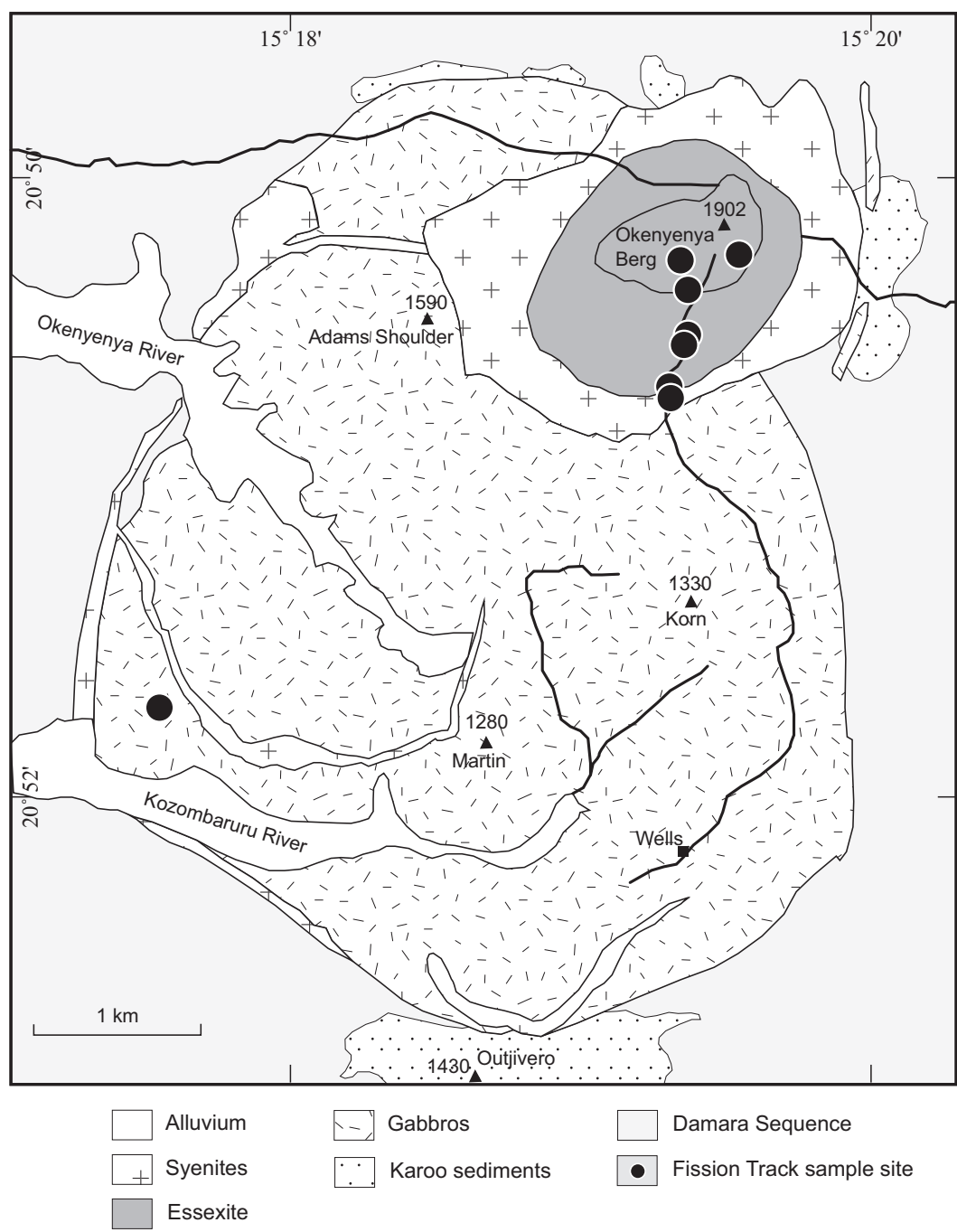

Figure 4.7: Simplified geological map of the Okenyenya complex with fission track sampling sites (after Watkins et al. 1994).

mated palaeotemperatures can be considered as maximum temperatures.

\subsubsection{Discussion}

The exposed Okenyenya profile displays the lower part of an apatite partial annealing zone, and the transition into the total annealing zone, similar to the Brandberg profile. The pronounced inflection in the apparent apatite fission track age profile at $73 \mathrm{Ma}$ places the break-in-slope at $1400 \mathrm{~m}$ altitude. The age of the break-inslope also approximates the timing of a phase of rapid cooling in the Late Cretaceous. 

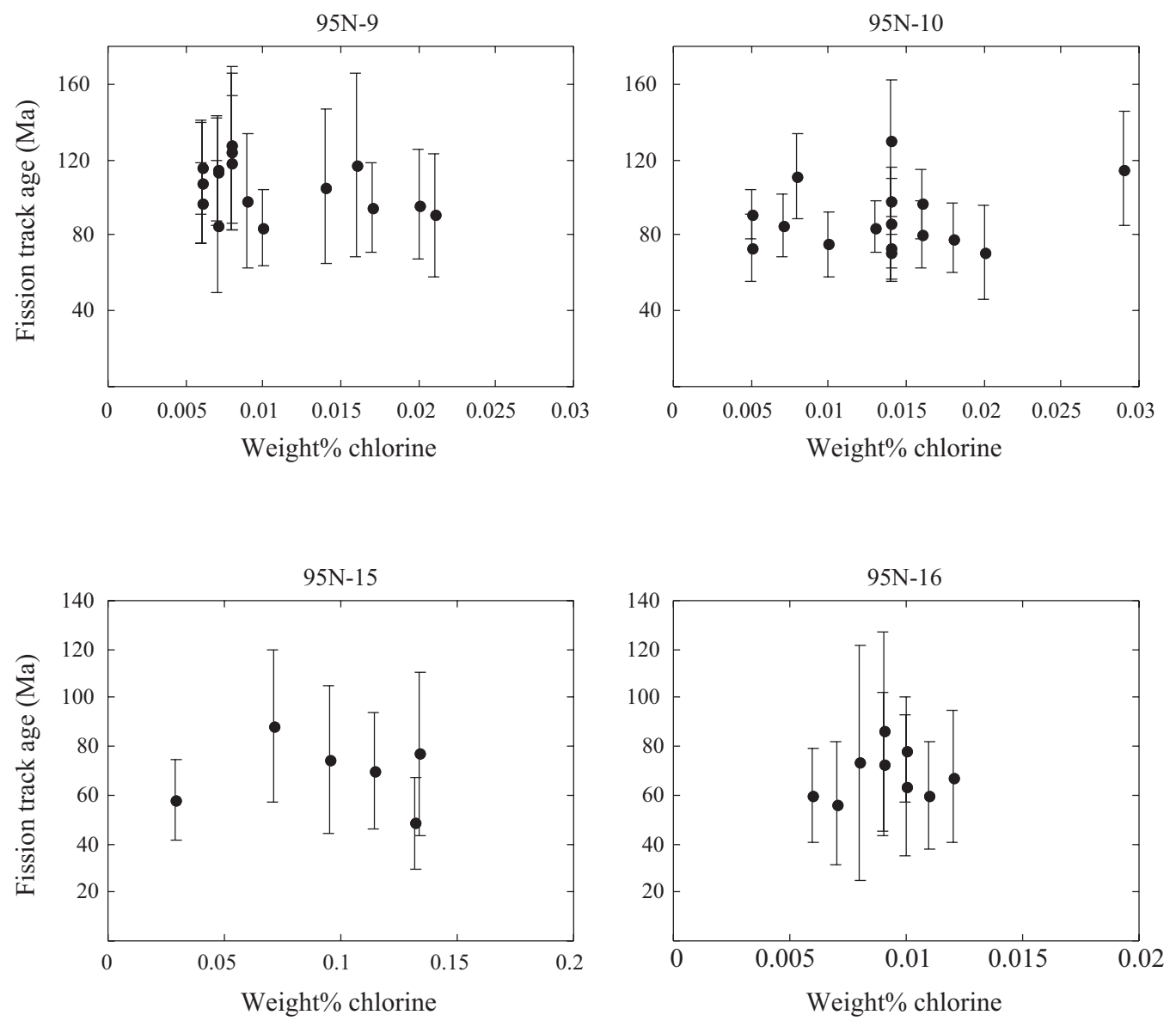

Figure 4.8: Chlorine content of four selected Okenyenya samples. All samples are fluorapatites with less than $0.2 \%$ chlorine.

The available track length information for samples $95 \mathrm{~N}-13$ to $95 \mathrm{~N}-15$ is limited to a maximum of twenty track lengths measurements. Consequently, these samples were not considered for thermal modelling.

Five samples above the break-in-slope $(95 \mathrm{~N}-8$ to $95 \mathrm{~N}-12)$ provide sufficient numbers of tracks, and thus were modelled with Contour Trax. Model-constraints were set to test for similar thermal histories to the Brandberg. The modelling results for all five samples are displayed in Figure 4.10.

The onset of a phase of accelerated denudation in the Late Cretaceous is consistent with the Brandberg results, and is reflected by all samples (Figure 4.10). They also show a consistent increase in maximum palaeotemperatures experienced, ranging from $94 \pm 12$ to $105 \pm 12^{\circ} \mathrm{C}$.

The palaeogeothermal gradient, obtained by applying linear least square regression, is $24 \pm 5^{\circ} \mathrm{C}$, if individual errors on palaeotemperatures are not considered. Performing linear least square regression with individual errors on palaeotemper- 


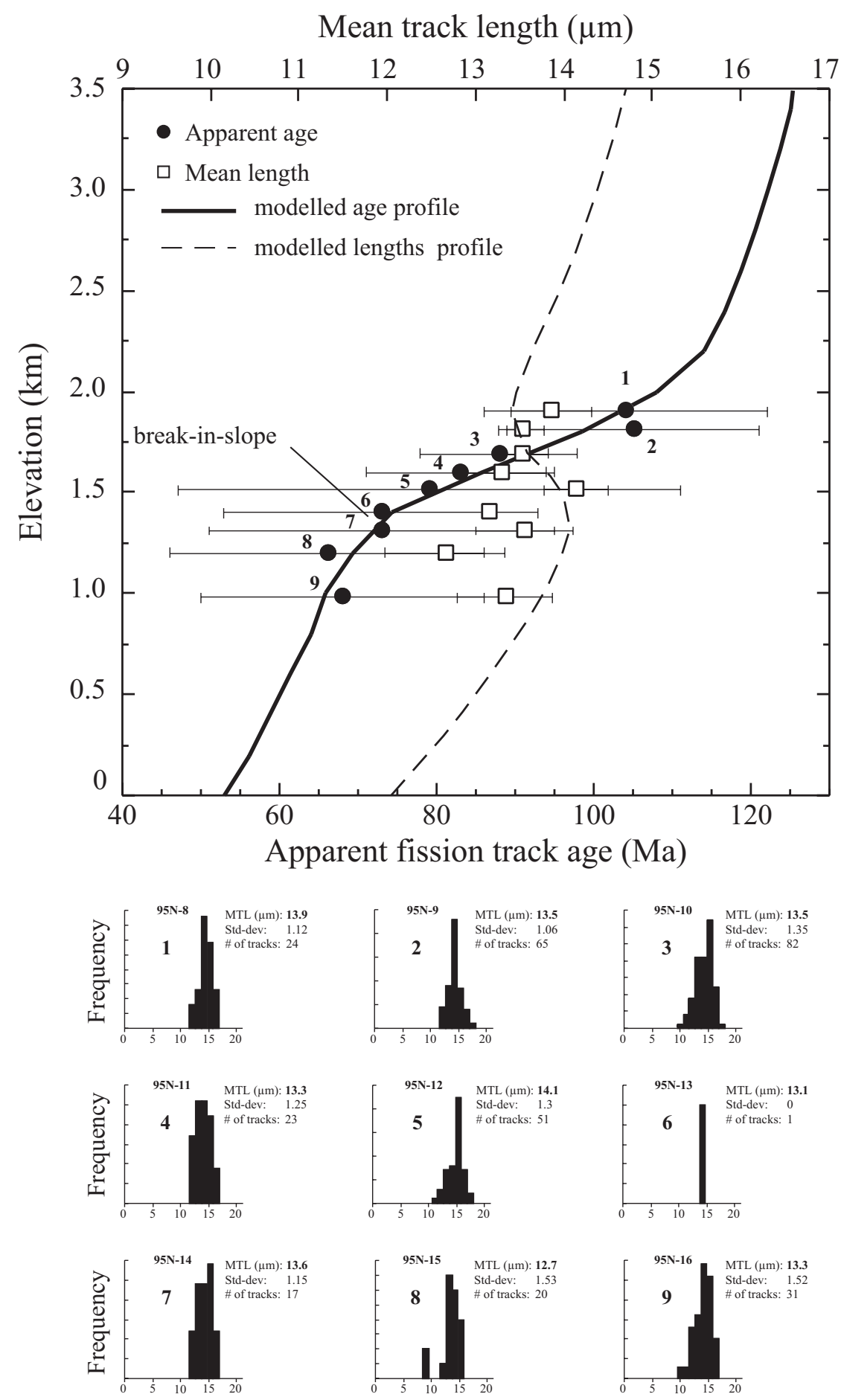

Figure 4.9: Apparent fission track ages and mean track lengths across the full height of the exposed Okenyenya igneous complex. Number of tracks in histograms is normalised to 100. The pronounced inflection between samples $95 \mathrm{~N}-13$ (6) and $95 \mathrm{~N}-14$ (7) marks the break-in-slope at $73 \mathrm{Ma}$. Errors are denoted on the $\pm 2 \sigma$ level. The solid and dashed lines represent the shapes of the 1-D Thermotrack models for apparent fission track ages and mean track lengths. 

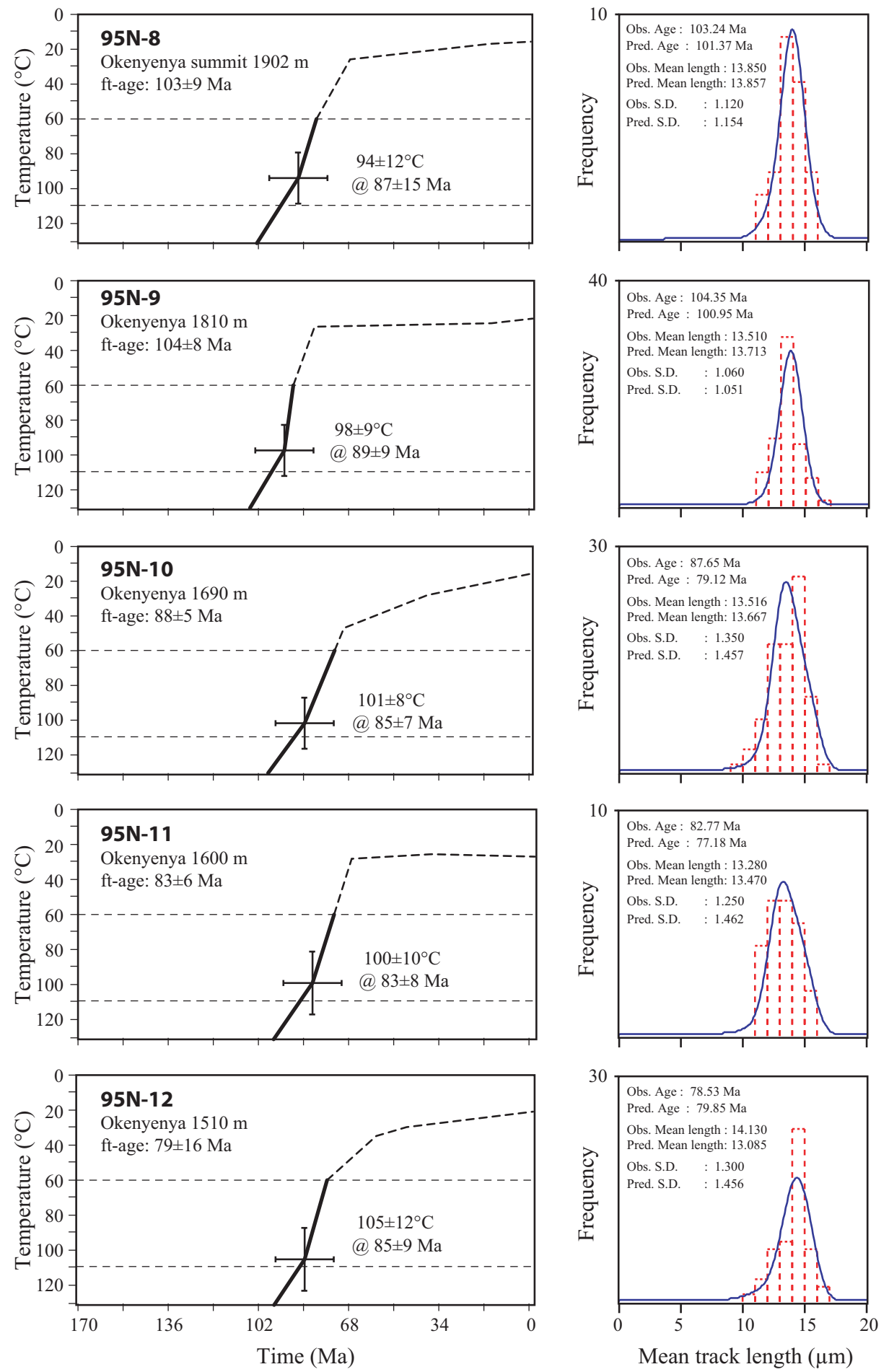

Figure 4.10: Thermal histories for the top five Okenyenya samples. Error bars are shown for the t-T-point where the thermal models suggest the onset of rapid cooling. These values were used to estimate the palaeogeothermal gradient in Figure 4.11. Errors are displayed as $\pm 2 \sigma$ errors. Horizontal dashed lines at 60 and $110^{\circ} \mathrm{C}$ bracket the partial annealing zone. Dashed lines extending thermal histories above $60^{\circ} \mathrm{C}$ mark a possible continuation of the thermal history since apatite fission track analysis is least sensitive to these temperatures. 
atures estimates a palaeogeothermal gradient of $23 \pm 34^{\circ} \mathrm{C}$ (Figure 4.11). The error treatment is discussed in Section 4.4.2 for the Brandberg, and is also applicable to the Okenyenya gradient.

The amount of removed section was calculated using Equation 4.1, and an estimate of the palaeogeothermal gradient of $24^{\circ} \mathrm{C}$ was used, as well as $18^{\circ} \mathrm{C}$ for the mean annual surface temperature. The amount of section removed from the summit of the Okenyenya since the Late Cretaceous can be approximated to ca. $3 \mathrm{~km}$, as observed for the Brandberg summit. Consequently, a removed section of approximately $4 \mathrm{~km}$ can be assumed for the present landsurface surrounding the Okenyenya complex.

Parameters for numerical modelling, to fit the observed data, were set to negligible denudation rates from 130 to $75 \mathrm{Ma}$, rapid denudation with average rates of $0.2 \mathrm{~km} / \mathrm{m}$.y. for the interval from 75 to $65 \mathrm{Ma}(2 \mathrm{~km})$, followed by low denudation rates of $0.015 \mathrm{~m} / \mathrm{m}$.y. from $65 \mathrm{Ma}$ to present. Because thermal histories have similar input parameters to the Brandberg histories, Thermotrack histories are not explicitly shown for the Okenyenya profile.

Numerical models for the apparent fission track ages show a near perfect fit with the observed data (Figure 4.9). The measured mean track length values deviate from the model results, particularly where only small numbers of confined tracks could be measured (Figure 4.9). Nevertheless, the mean track length in nine out of eleven data plot within the $\pm 2 \sigma$ error of the modelled curve.

\subsubsection{Summary}

The outcropping remnants of the Okenyenya igneous complex exhibit the lower part of an exhumed apatite partial annealing zone, and the transition into the total apatite annealing zone.

By analogy to the Brandberg profile, the $110^{\circ} \mathrm{C}$ palaeoisotherm is revealed by the break-in-slope, which is at a present elevation of approximately $1300 \mathrm{~m}$.

The palaeogeothermal gradient was estimated by thermal modelling to be ca. $24^{\circ} \mathrm{C} / \mathrm{km}$ in the Late Cretaceous.

The present landsurface surrounding the Okenyenya complex experienced denudation in the order of $4 \mathrm{~km}$ since the Late Cretaceous. Numerical modelling has shown that a discrete phase of accelerated denudation, beginning in the Late Cretaceous, is necessary to fit the observed data. 


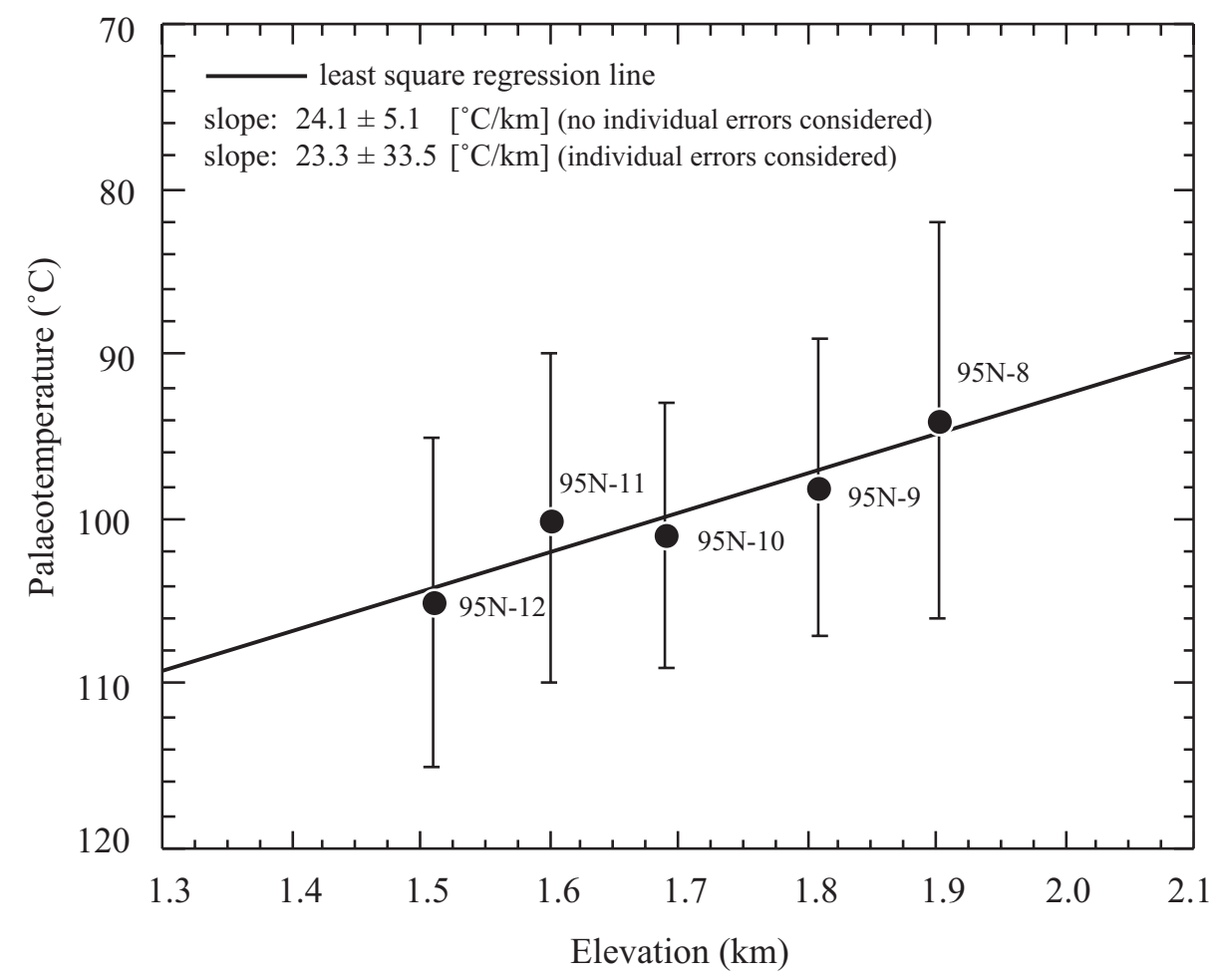

Figure 4.11: Palaeogeothermal gradient derived from thermal modelling for the top five Okenyenya samples. Error bars are denoted as $\pm 2 \sigma$ errors. 


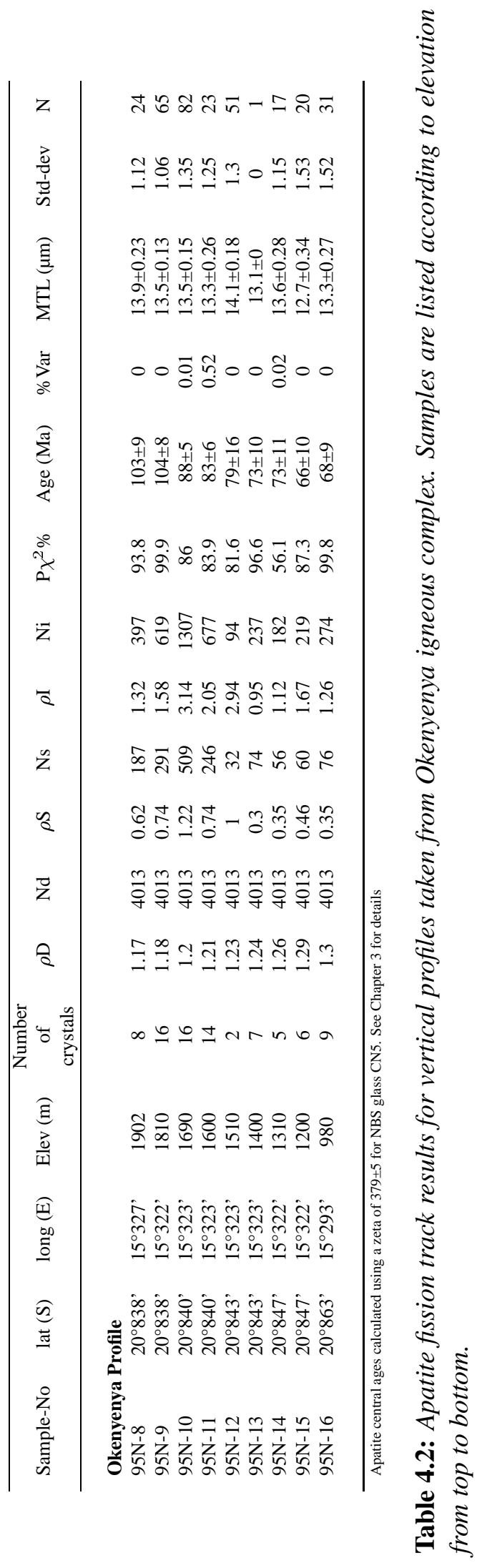




\subsection{The Windhoekgraben Profile}

The morphology of the Windhoekgraben reflects a northsouth striking graben structure through the Khomas Hochland from Windhoek to Okahandja. Peak elevations exceed $1950 \mathrm{~m}$ on both graben shoulders, while the ca. $15 \mathrm{~km}$ wide canyon has its lowest elevation along the main road B1 Windhoek-Okahandja, which decreases gently in elevation from $1800 \mathrm{~m}$ down to $1400 \mathrm{~m}$. The Windhoekgraben diminishes towards the Okahandja Lineament.

An east-west striking transect was sampled across both graben shoulders ca. $50 \mathrm{~km}$ north of Windhoek. The study area belongs to the Pan-African Kuiseb Formation, consisting of monotonous sequences of schistose pelitic and psammitic meta-turbidites with intercalations of graphitic schists and calc-silicate rocks. Peak metamorphism reached amphibolite facies during the Damara orogeny, and $\mathrm{K}-\mathrm{Ar}$ biotite cooling ages indicate temperatures of ca. $300^{\circ} \mathrm{C}$ at $481 \pm 25 \mathrm{Ma}$ (Haack 1983).

\subsubsection{Fission Track Results}

Four samples have been analysed from the Windhoekgraben profile, covering a vertical range of $300 \mathrm{~m}$ in elevation. The samples were collected at vertical intervals of $100 \mathrm{~m}$.

The apparent apatite fission track ages decrease systematically with decreasing elevation from $328 \pm 19 \mathrm{Ma}$ at the top down to $198 \pm 20 \mathrm{Ma}$ at the lowest point of the profile (Figure 4.12). The most notable feature in this particular profile is the significant age difference of ca. $100 \mathrm{Ma}$ occurring between the lowest samples

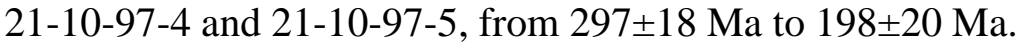

The mean track length distributions show little variation over the profile, and have significantly shortened mean values. They vary from $11.0 \pm 0.24 \mu \mathrm{m}(21-10-$ 97-4) to $10.8 \pm 0.17 \mu \mathrm{m}$ (21-10-97-2). Standard deviations range from 1.7 (21-1097-2) to $2.0(21-10-97-4)$.

\subsubsection{Discussion}

The shape of the apparent fission track age-elevation plot (Figure 4.12) is indicative of an exhumed part of an apatite partial annealing zone, with increased temperatures causing an exponential annealing of tracks and subsequently leading to an exponential reduction of the apparent apatite fission track age with depth. This is a characteristic feature of a profile, and occurs if samples are exposed to temperatures of approximately $95^{\circ} \mathrm{C}$ (Brown et al. 1994b). 

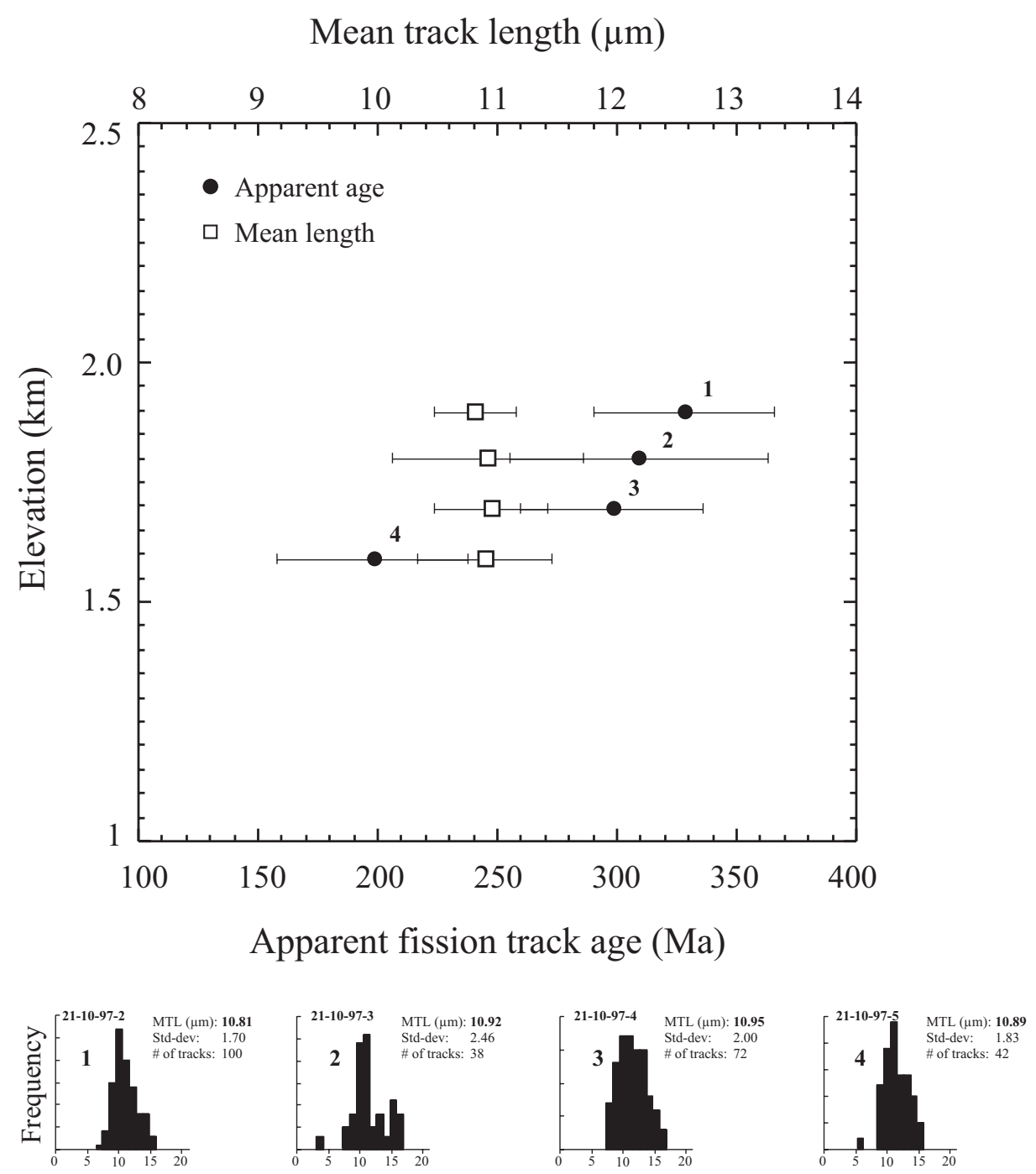

Figure 4.12: Apparent fission track ages and mean track lengths across the eastern graben shoulder of the Windhoekgraben. Number of tracks in histograms is normalised to 100. Errors are denoted at the $\pm 2 \sigma$ level. 

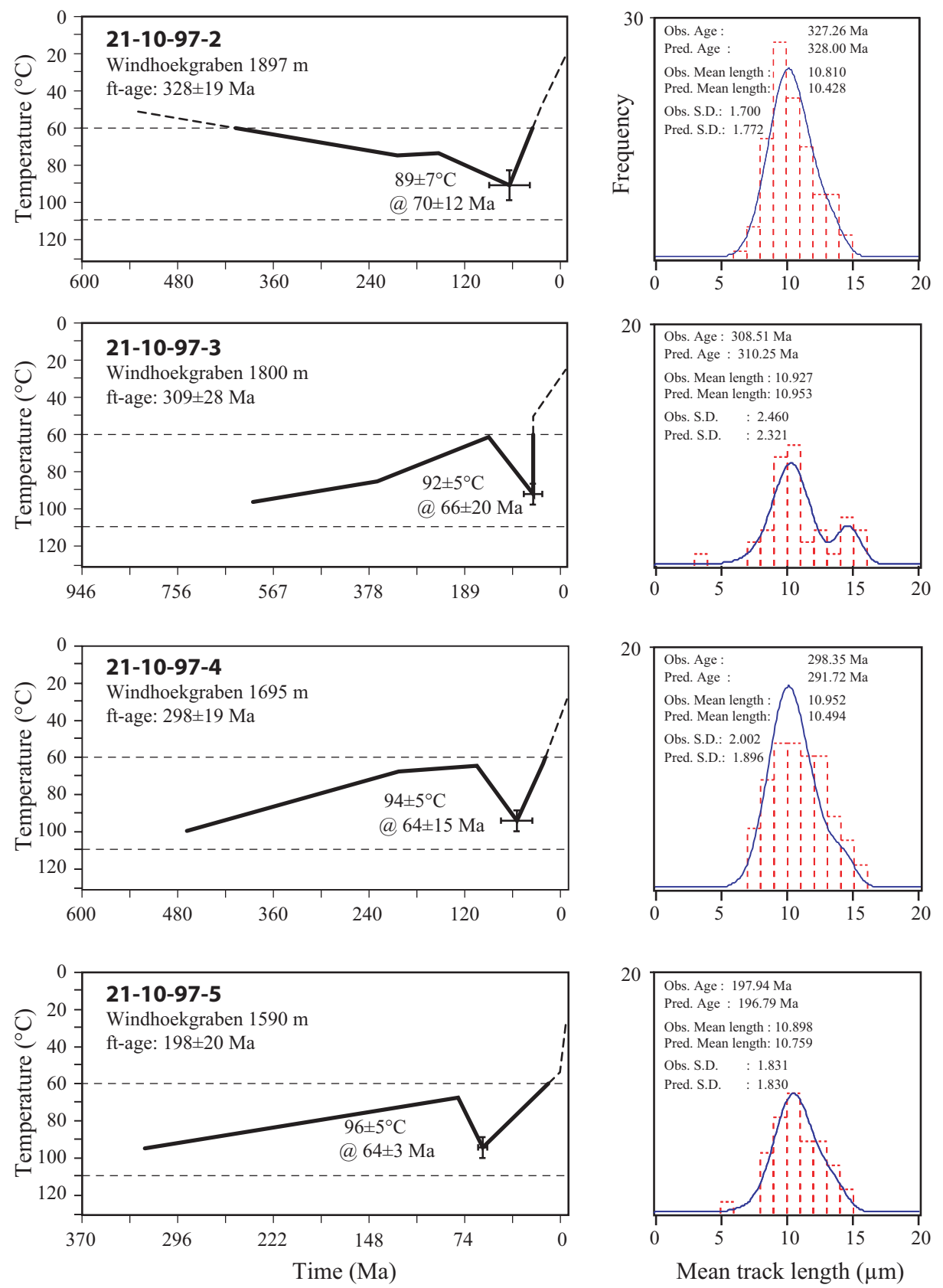

Figure 4.13: Thermal histories for all samples across the Windhoekgraben profile. Error bars are shown for the t-T-point where the thermal models suggest the onset of rapid cooling. These values were used to estimate the palaeogeothermal gradient in Figure 4.14. Errors are displayed as $\pm 2 \sigma$ errors. Horizontal dashed lines at 60 and $110^{\circ} \mathrm{C}$ bracket the partial annealing zone. Dashed lines extending thermal histories above $60^{\circ} \mathrm{C}$ mark a possible continuation of the thermal history since apatite fission track analysis is least sensitive to these temperatures. 


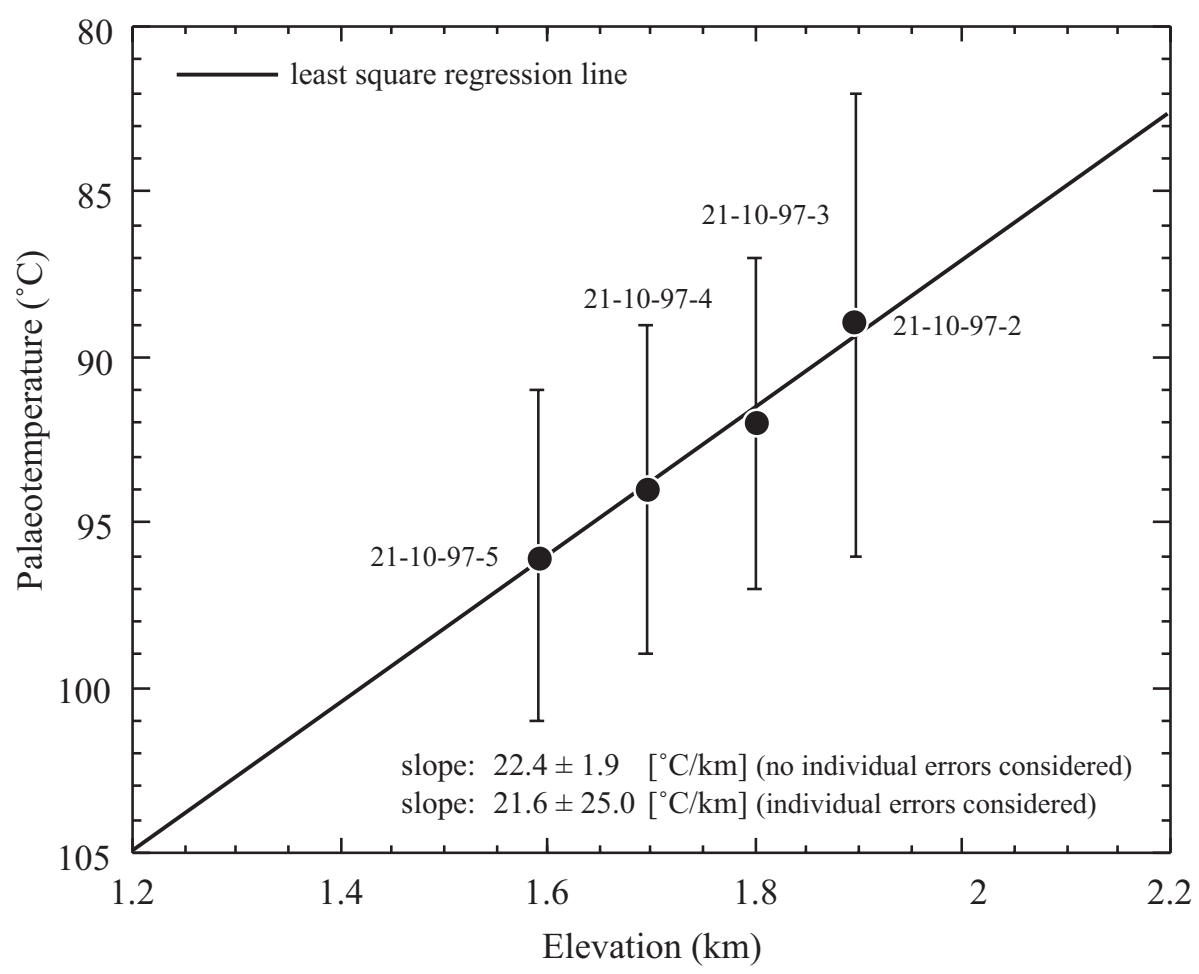

Figure 4.14: Palaeogeothermal gradient derived from thermal modelling for all samples across the Windhoekgraben profile. Error bars are denoted as $\pm 2 \sigma$ errors.

The generally old apparent fission track ages of these samples, and the very short mean track lengths, suggest that samples were exposed to elevated temperatures for a protracted period of time. The track length distribution (Figure 4.12 and 4.13) is indicative of the thermal history experienced. Although the mean track lengths are very short, the standard deviation is large and exceeds 1.7 in all samples. The ratio of annealed tracks to those that have experienced only a little annealing, provides crucial information about the timing of when samples passed through the partial annealing zone and reached the field of track stability; in other words, when they cooled to temperatures below $60^{\circ} \mathrm{C}$, where only very little annealing occurs.

This information was further quantified by thermal modelling. Thermal histories were tested for a phase of rapid cooling in the Late Cretaceous. Thermal modelling results are shown in Figure 4.13.

A consistent increase in experienced maximum palaeotemperature, with decreasing elevation, was obtained for all samples (Figure 4.14). Moreover, all the samples display protracted periods of residual in the partial annealing zone (at moderate temperatures), and a phase of accelerated cooling in the Late Cretaceous. The modelled palaeotemperatures for the Late Cretaceous increase from 
$89 \pm 7$ to $96 \pm 5^{\circ} \mathrm{C}$ (Figure 4.13 ).

The palaeogeothermal gradient was estimated to be $22 \pm 2^{\circ} \mathrm{C} / \mathrm{km}$ by linear regression, as shown in Figure 4.14. The error on the gradient increases to $22 \pm$ $25^{\circ} \mathrm{C} / \mathrm{km}$, if individual errors on the palaeotemperatures are considered (see Section 4.4.2 for error disussion).

The resulting denudation for the Windhoekgraben profile, with a palaeogeothermal gradient of $22^{\circ} \mathrm{C} / \mathrm{km}$ and $18^{\circ} \mathrm{C}$ for the mean annual surface temperature, can be inferred by using Equation 4.1. The thickness of the denuded section for the Windhoekgraben region can be estimated to $3-3.5 \mathrm{~km}$ (from top to bottom of the profile) since the Late Cretaceous.

\subsubsection{Summary}

The Kuiseb Schists, in the Khomas Hochland in the Windhoekgraben area north of Windhoek, represent a part of an exhumed fossil partial annealing zone. Qualitative inferences were made by interpreting the shape of the apparent apatite fission track age-elevation profile (Figure 4.12), and the individual track length distributions. Further quantitative information was extracted by thermal modelling. Derived point temperatures were used to estimate the palaeogeothermal gradient to $22^{\circ} \mathrm{C} / \mathrm{km}$ in the Late Cretaceous.

The resulting denudation inferred for this area ranges in the order of 3 to $3.5 \mathrm{~km}$ since the Late Cretaceous. 


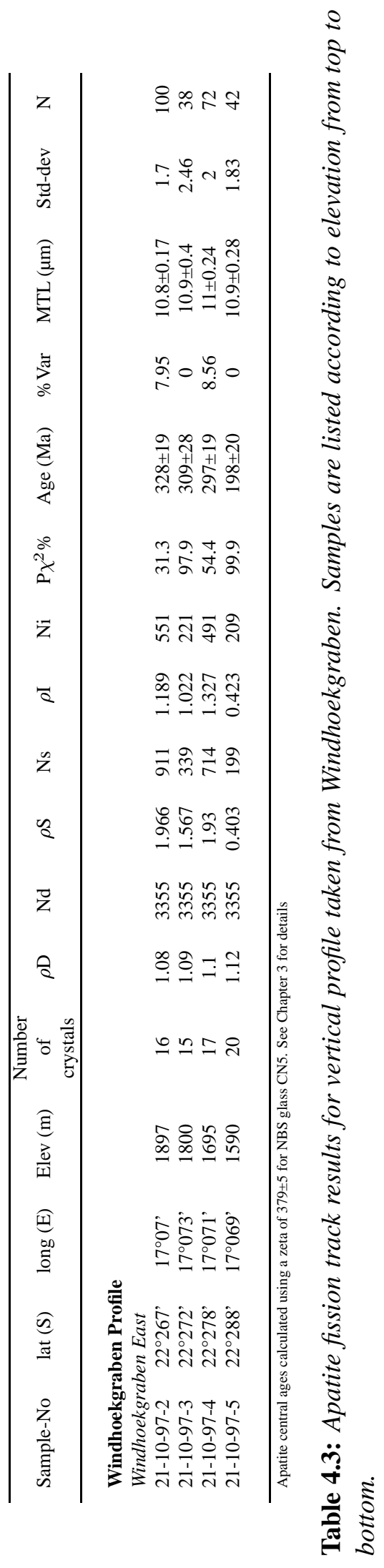




\subsection{Conclusions}

In order to obtain maximum information about the cooling pattern of three different regions of the study area, three vertical profiles from the Brandberg and Okenyenya igneous complexes, as well as the Windhoekgraben, have been analysed in detail.

The Brandberg and Okenyenya complexes are both key locations in northern Namibia. They form isolated massifs superimposed on the regional morphology, and exhibit vertical relief of $1800 \mathrm{~m}$ (Brandberg) and $900 \mathrm{~m}$ (Okenyenya) respectively. Both are anorogenic intra-plate complexes with well constrained intrusion ages in the Early Cretaceous (Section 2.2.5). The Windhoekgraben profile represents a key location for the Namibian highland.

The thermal histories, derived by different conceptual approaches, have been interpreted in terms of crustal cooling, discriminating between phases of tectonic stability and phases of accelerated denudation. Palaeotemperatures were determined by modelling and converted to equivalent depths to quantify denudation rates over the particular time interval of accelerated cooling. Qualitative interpretations were tested and further quantified by thermal and numerical modelling.

Estimations of the amount and rate of denudation from cooling histories require knowledge of the thermal gradient that prevailed in the geological environment from which the sample was obtained. This knowledge involves the presentday gradient as well as possible variations in the past.

Present-day geothermal gradients are normally obtained from surface heat flow measurements (e.g. Pollack et al. 1993). Extrapolating these gradients into the past introduces uncertainties. These uncertainties can be avoided if vertical apatite fission track profiles are available, and the gradients are estimated directly (Gleadow and Brown 2000).

Of the three analysed profiles the Brandberg profile is the most comprehensive in that the bottom of a fossil partial annealing zone is preserved as well as the transition into, and a substantial amount of the total apatite annealing zone is revealed (Figure 4.3). A palaeogeothermal gradient of approximately $26^{\circ} \mathrm{C} / \mathrm{km}$ was determined to have prevailed in the Late Cretaceous. The amount of cooling experienced since the Late Cretaceous was then converted into ca. $5 \mathrm{~km}$ of denudation from the present landsurface surrounding the Brandberg via the palaeogeothermal gradient and the mean annual surface temperature. The position of the $110^{\circ} \mathrm{C}$ palaeoisotherm for the Brandberg is presently at an altitude of approximately $2100 \mathrm{~m}$. The average denudation rate over this particular time interval (80 to $60 \mathrm{Ma}$ ) has been calculated to be $0.12 \pm 0.01 \mathrm{~km} / \mathrm{m}$.y.

The Okenyenya profile is similar to the Brandberg profile with the lower part of a fossil partial annealing zone preserved. An estimated palaeogeothermal gra- 
dient of $24^{\circ} \mathrm{C} / \mathrm{km}$ was determined for this profile and allows an estimated depth of denudation on the order of ca. $4 \mathrm{~km}$ for the base of the Okenyenya complex since the Late Cretaceous. The present position of the $110^{\circ} \mathrm{C}$ palaeoisotherm is at $1300 \mathrm{~m}$ altitude.

A palaeogeothermal gradient of $22^{\circ} \mathrm{C} / \mathrm{km}$ could be derived for the Windhoekgraben profile. The amount of the removed section for the presently exposed profile ranges from $3-3.5 \mathrm{~km}$.

Maximum palaeotemperatures for all samples analysed here were reached in the Late Cretaceous. A distinct phase of rapid cooling commenced during that time with average denudation rates of approximately $100 \mathrm{~m} / \mathrm{m} . \mathrm{y}$..

It is highly significant that the palaeogeothermal gradients derived from all three different vertical profiles are similar. The similarity of the three independent estimates suggests that the values are accurate, even though the precision on each measurement is low. Furthermore, the fact that the estimated palaeogeothermal gradients are similar to the present-day mean gradient for the region (ca. $22^{\circ} \mathrm{C} / \mathrm{km}$ ), is consistent with the interpretation that the observed cooling was caused by denudation, rather than by any sub-surface thermal mechanism.

It is important to note that the interpretation of cooling patterns and the subsequent estimated amount of denudation do not necessarily imply that the amount of denudation is matched by the same amount of surface uplift. This is because apatite fission track analysis pertains to cooling-denudational events, whereas constraining surface uplift in absolute terms requires independent geological evidence (Brown 1991, Fitzgerald et al. 1995, Summerfield and Brown 1998, Gleadow and Brown 2000). The isostatic response to denudation as well as sedimentation or tectonic activity can indeed lead to an absolute change in surface elevation (uplift or subsidence). However, such a change in surface elevation has no effect on the temperatures of rocks at shallow crustal levels, since in the absence of denudation they remain at their crustal depth relative to the surface (Brown 1991, Gleadow and Brown 2000). 


\section{Chapter 5}

\section{Late Cretaceous Reactivation of Major Shear Zones in Northern Namibia}

\subsection{Introduction}

Namibia's passive continental margin records a long history of tectonic activity since the Proterozoic. The orogenic belt, which was produced during the collision of the Congo and Kalahari Cratons in the Late Proterozoic, led to a zone of crustal weakness and became the preferred location for tectonism during the Phanerozoic. The Pan-African Damara mobile belt forms this intraplate boundary in Namibia, and its tectonostratigraphic zones are defined by ductile shear zones. The most prominent of these is described as the Omaruru Lineament-Waterberg Thrust.

The prominence of the continental margin escarpment is diminished in the area of the Central and Northern Zone of the Damara belt where the shear zones are located. This area has been targeted with a set of 66 outcrop samples over a $550 \mathrm{~km}$ long, $60 \mathrm{~km}$ broad, coast parallel transect from the top of the escarpment in the south, across the Damara sector to the Kamanjab Inlier in the north. Apatite fission track age and length data from all samples reveal a regionally consistent cooling event. Thermal histories derived by forward modelling bracket this phase of accelerated cooling in the Late Cretaceous. Maximum palaeotemperatures, immediately prior to the onset of cooling, range from ca. $120^{\circ} \mathrm{C}$ to ca. $60^{\circ} \mathrm{C}$, with the maximum occurring directly south of the Omaruru Lineament. Because different palaeotemperatures indicate different burial depth at a given time, the amount of denudation can be estimated, and thus used to constrain vertical displacements of the continental crust. This cooling pattern is interpreted as the geomorphic response to reactivation of basement structures caused by a change in spreading 

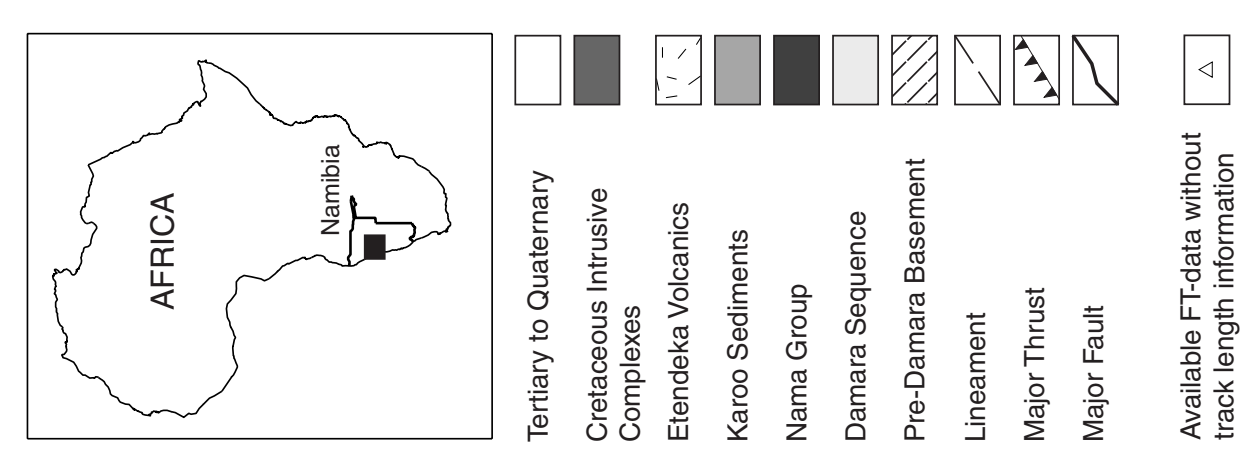

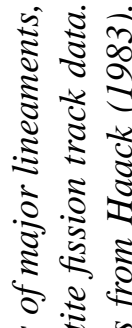

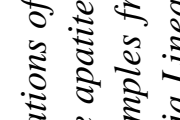
ปู ปี ป है इ 3.511 : र

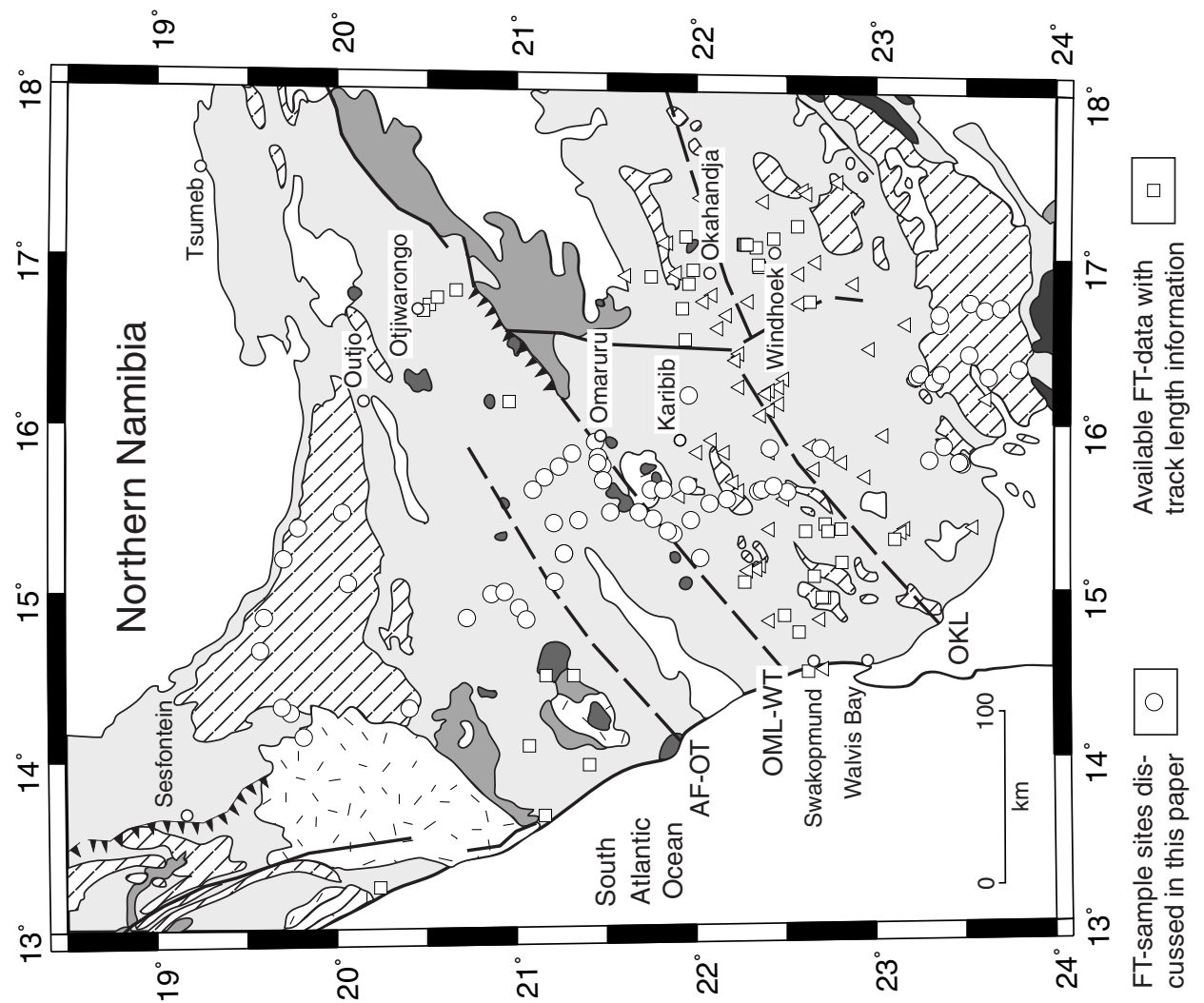

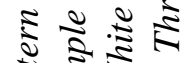
है इ

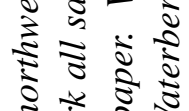
इ है ह

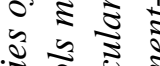
ำ क मे ह इ

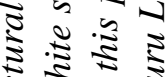

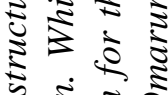
के ฐ ฐ

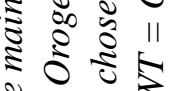
₹ 2 क इ 㲾 क्ष इ

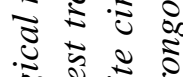
0
0
0
0
0
0

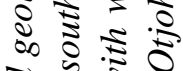

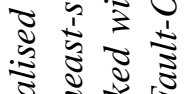
․ำ ปั

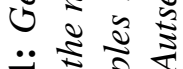
菂尖 10. है है

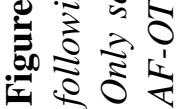




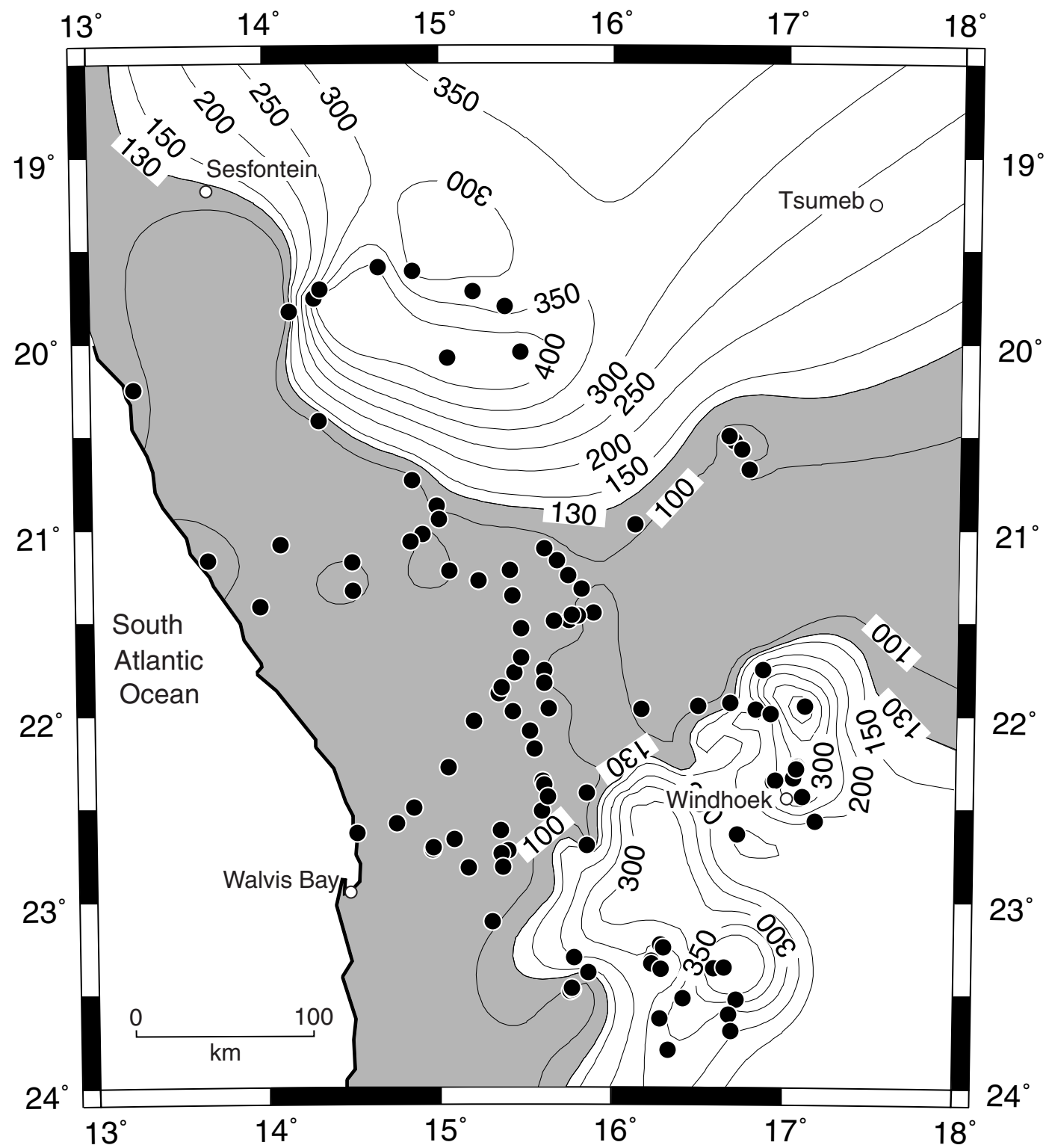

Figure 5.2: Contour-plot of all available fission track ages in northern Namibia. Cooling ages younger than 130 Ma (grey shaded area) occur coast-parallel, as well as in a welldefined northeast-southwest trend which is aligned with the regional tectonic fabric of the Damara mobile belt in this region, and coincides closely with the Central and Northern Zone. 
geometry in the South Atlantic and South West Indian Oceans.

The Pan-African mobile belts in southern (Tankard et al. 1982, Porada 1989) and west central Africa typically follow the margins of the Kalahari and Congo cratons. These belts strongly influenced the subsequent morphotectonic evolution of the continent by imposing a regional structural framework across Africa. The reactivation of pre-existing structures within these belts has long been recognised to be an important factor in the subsequent geological evolution of these regions (Rosendahl 1987, Unternehr et al. 1988, Versfelt and Rosendahl 1989). It is well known that old lineaments respond sensitively to later tectonic activity (e.g. Donath 1961, Handin 1969), but it is much more difficult to resolve and quantify multiple, discrete phases of reactivation, particularly where the amplitude of reactivation is relatively subtle.

In order to constrain and quantify the tectonically driven reactivation and the subsequent denudation history of the major structural entities in northern Namibia, 66 apatite fission track samples were collected over a ca. $60 \mathrm{~km}$-wide and $550 \mathrm{~km}$ long coast-parallel transect across the Great Escarpment, the Okahandja Lineament (OKL), the Omaruru Lineament-Waterberg Thrust (OML-WT) and the Autseib Fault-Otjohorongo Thrust (AF-OT) to the Kamanjab Inlier (see Figure 5.1). The area covers the Central and Northern Zone of the Damara Orogen. The stratigraphic ages of the samples range from Proterozoic (Kamanjab Inlier) over PanAfrican igneous and metasedimentary rocks, to Early Cretaceous igneous intrusive rocks.

By comparing the mean apparent apatite fission track age for the block with the regional age-elevation pattern, the relative vertical displacement between different tectonic blocks can be qualitatively assessed. For example, Foster and Gleadow (1992b) elucidated the existence and reactivation of important structures of the Kanmantoo Fold Belt and the Lachlan Fold Belt in southeastern Australia, on the basis of significant differences in the apparent apatite fission track age. Alternatively, relative vertical displacements can be estimated for any given time by comparing the modelled palaeotemperatures for the different blocks at that time. O'Sullivan et al. (1998) successfully applied forward modelling techniques to samples taken across structures along the Philip Smith Mountain front, Alaska, to reveal complex deformation sequences, where exposure is poor and the topography subdued. The latter approach has been applied in this thesis, and the result of this study shows that the area of the Damara Orogen experienced a kilometer-scale reactivation of an inherited basement structure along the Omaruru Lineament (Figure 5.1) with associated accelerated denudation during the Late Cretaceous. 


\subsection{Methodology}

66 outcrop samples were taken of a variety of Proterozoic to Damara sedimentary and igneous rocks, and of Cretaceous igneous rocks. Apatite fission track thermochronology is a powerful tool over a temperature range from ambient surface temperatures up to about $110^{\circ} \mathrm{C}$, the temperature that characterises the upper few kilometers of the Earth's crust. Denudation rates are most likely to control the cooling pattern of rocks at these relatively shallow depths for tectonically quiet settings (e.g. Gleadow and Brown 2000). A detailed overview of fission track thermochronology is provided in Chapter 3.

The track length distribution provides a direct record of the thermal history experienced, and together with the apparent fission track age, is used to derive the thermal history by forward modelling after Gallagher (1995) using the Laslett et al. (1987) model. It is important to note that an apatite fission track age will only record the time that a sample was last at a temperature of $\sim 110 \pm 10^{\circ} \mathrm{C}$ if the mean track length exceeds $14 \mu \mathrm{m}$. Otherwise a more complex cooling history must be considered, and the data are best interpreted using one of the available fission track annealing models (e.g. Laslett et al. 1987).

\subsection{Previous Fission Track Work}

The first fission track studies in Namibia were presented by Haack (1983). As the potential of confined track length information was not known at that time, only apparent apatite cooling ages are available from this earliest work. Haack interpreted the young $(<130 \mathrm{Ma})$ cooling ages north of the Okahandja Lineament as a very slow cooling of the Damara intrusives that were due to elevated heat production caused by the radioactive decay of U-enriched granites. However, these ages are not significantly different from the results from nearby samples that are presented in this thesis. Thus similar thermal histories for these samples can be assumed. Locations of Haack's samples are plotted as triangles in Figure 5.1, and calculated ages are contoured in Figure 5.2. A more comprehensive study was done by Brown (1992), integrating track length information and thermal modelling. These data have already been utilised to reveal a phase of accelerated denudation in the Late Cretaceous. that resulted from a change in plate kinematics in the South Atlantic (Brown 1992, Brown et al. 1997, Gallagher and Brown 1997, Gallagher and Brown 1999a, Gallagher and Brown 1999b, Brown et al. 2000). However, the raw data along the transect are reported here for the first time. 


\subsection{Fission Track Results}

A total number of almost 200 apatite fission track ages are now available for northern Namibia (see Figure 5.1 and Figure 5.2). To show the regional trend of cooling ages, all available ages are contoured in Figure 5.2. The youngest apatite fission track ages occur within a ca. $150 \mathrm{~km}$ wide coastal zone, and generally decrease systematically inland, a common trend in passive margins (Gallagher and Brown 1997). However, this regional pattern is modified by a well defined northeastsouthwest trending zone of cooling ages younger than $130 \mathrm{Ma}$, which cross-cuts the regional pattern, and coincides closely with the intracontinental arm of the Damara mobile belt (Figure 5.2). Cooling ages pre-dating the continental breakup were therefore obtained only from samples from the interior region that are more than $150 \mathrm{~km}$ inland of the coast. Ages younger than the approximate time of break-up have been shaded grey on Figure 5.2 to show the two overlapping zones of young ages. The northeast-southwest trend is aligned with the Central and Northern Zones of the Damara Belt (Miller 1983). This area is comprised of the pre-existing crustal structures.

66 samples over an approximately $550 \mathrm{~km}$-long, coast-parallel corridor have been chosen perpendicular to the major structures in this area. Samples were taken from at least $100 \mathrm{~km}$ inland of the current coastline. To avoid complexity with north-south striking fault zones further east, the profile has been kept relatively narrow at approximately $60 \mathrm{~km}$. Locations of the transect and individual samples are shown in Figure 5.3. The projected sample locations are shown along the transect versus elevation to indicate the spatial variation within the sampling corridor in Figure 5.4. The change in local relief is more variable at the southeastern end of the profile, as this area comprises the Gamsberg, the third highest mountain in Namibia (2343 m); and furthermore it is here that the profile crosses the margin of the Great Escarpment. The relief becomes more subdued to the northeast. The minimum and maximum elevation were extracted from the 30 arc second digital elevation model provided by the US Geological Survey using GMT (Wessel and Smith 1991). Samples were taken from elevations from ca. $600 \mathrm{~m}$ to $2300 \mathrm{~m}$ above sea level. Old ages (pre break-up) occur predominantly above $1000 \mathrm{~m}$, whereas ages younger than break-up occur between $600 \mathrm{~m}$ and $1500 \mathrm{~m}$ (Figure 5.5a).

The 66 apatite fission track ages from the profile range from $61 \pm 5$ Ma to $547 \pm 95 \mathrm{Ma}$, and most of the fission track ages are significantly younger than the corresponding stratigraphic ages of the host rocks. The mean track length varies from $14.3 \pm 0.7 \mu \mathrm{m}$ to highly annealed mean track lengths of $9.8 \pm 0.3 \mu \mathrm{m}$, with a range of standard deviations between 0.8 and $3.7 \mu \mathrm{m}$. The fission track ages postdating break-up at ca. $124 \mathrm{Ma}$ are mainly associated with unimodal track length distributions (standard deviation 0.8-1.8 $\mu \mathrm{m}$ ) and long mean track lengths from 


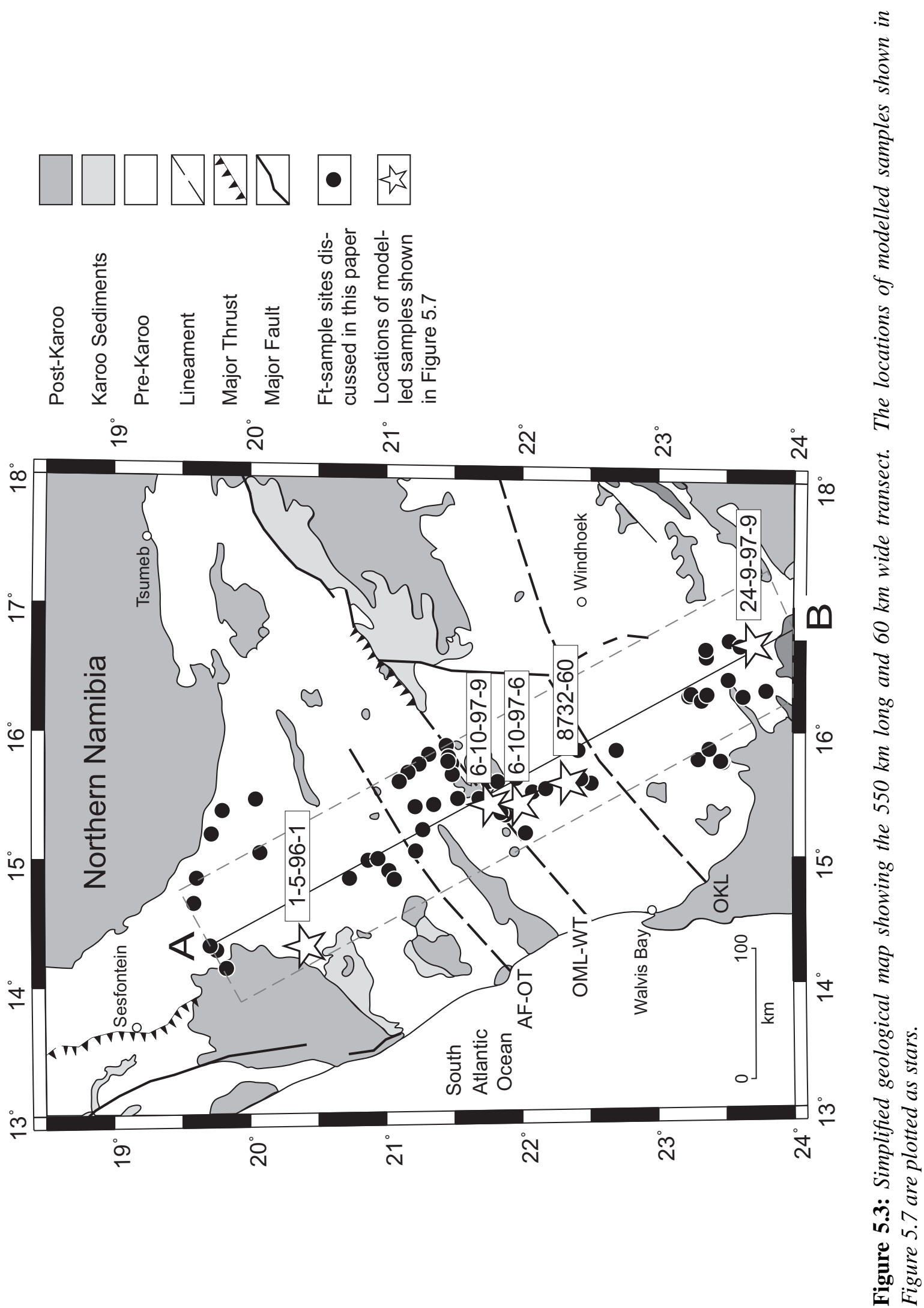




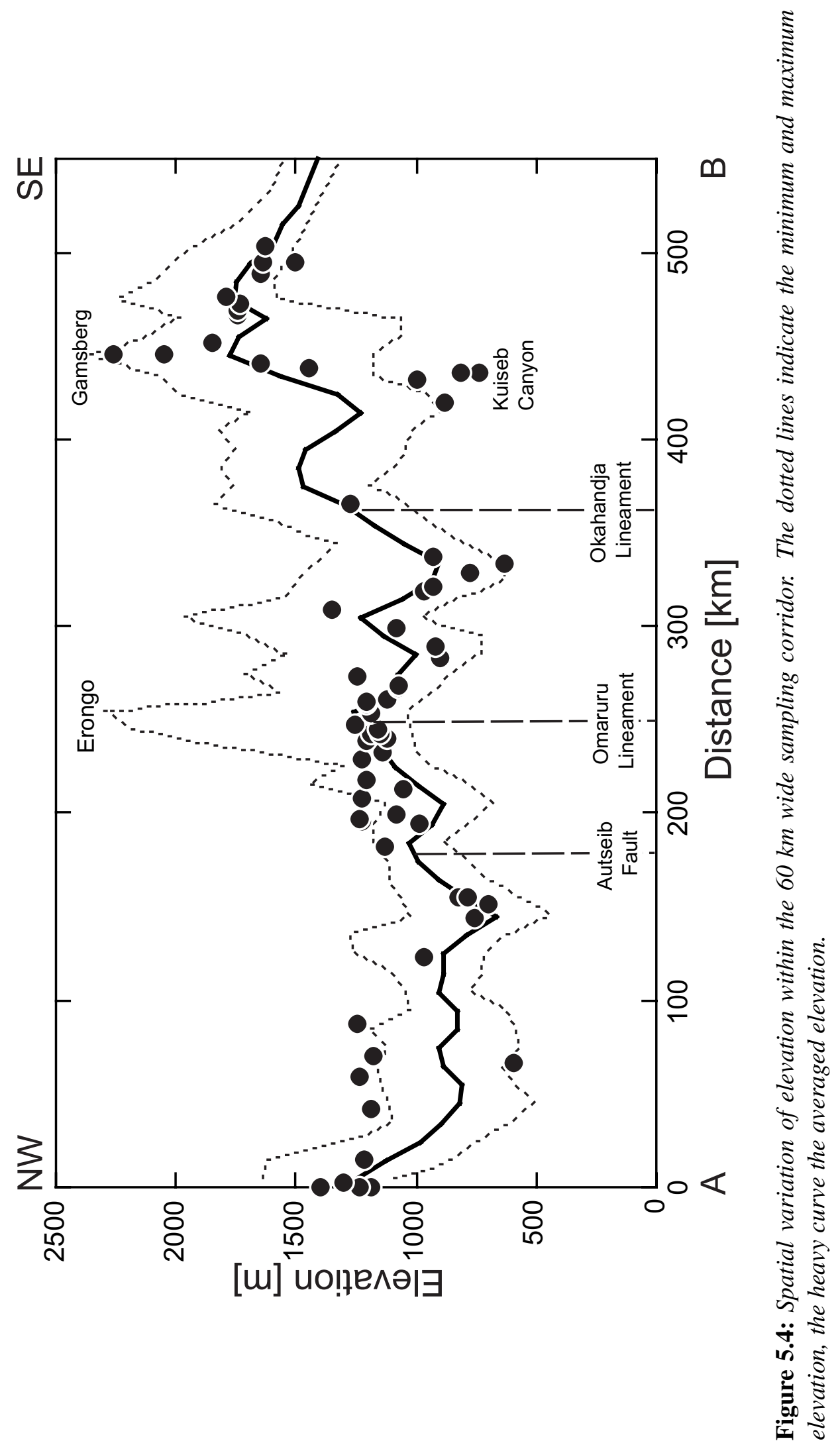



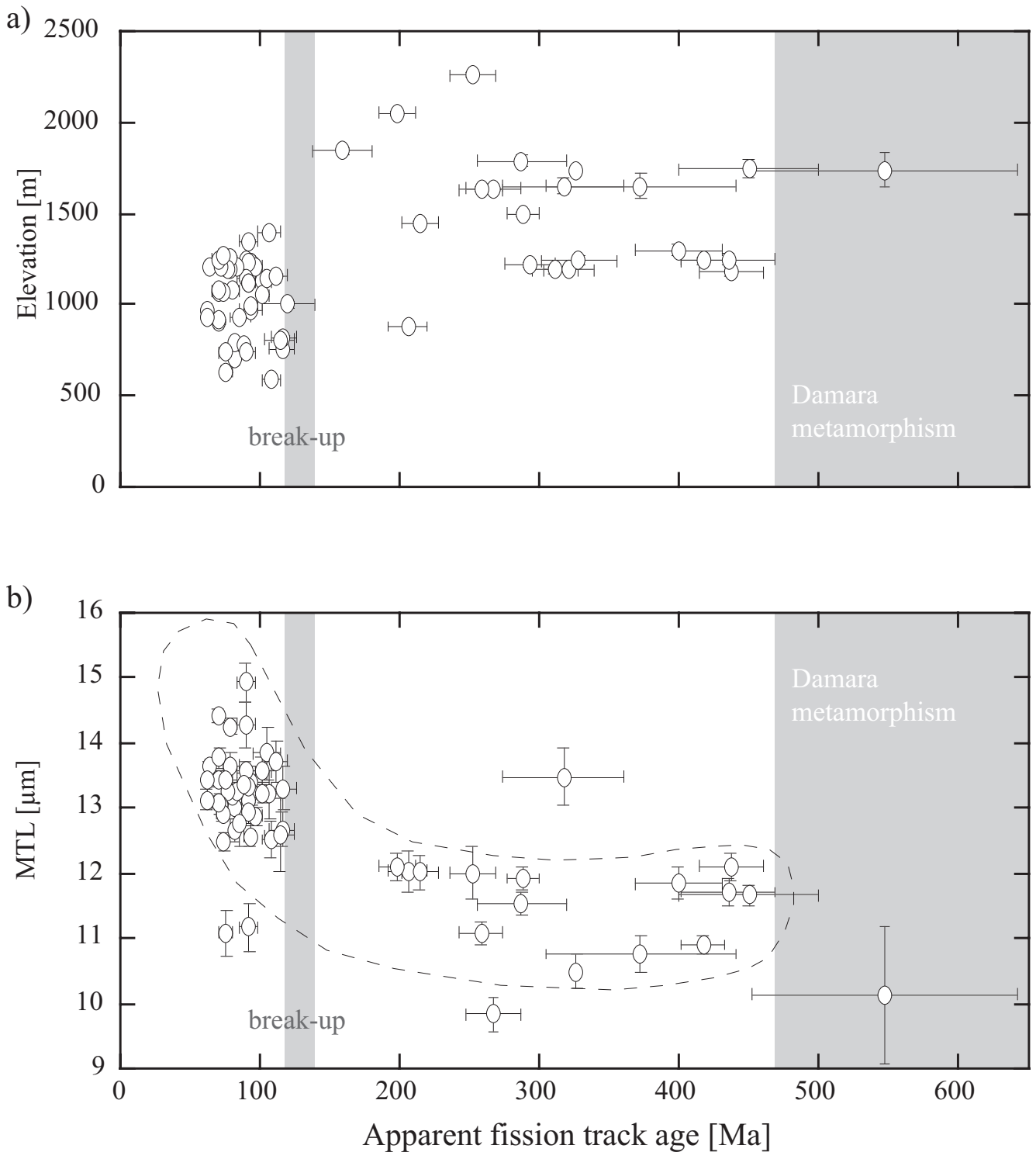

Figure 5.5: Relationship between the apatite fission track age with elevation (a) and mean track length $(b)$. The shaded bands represent the approximate time of Damara metamorphism and break-up. Boomerang shaped pattern is indicated by dashed line in $b$. 

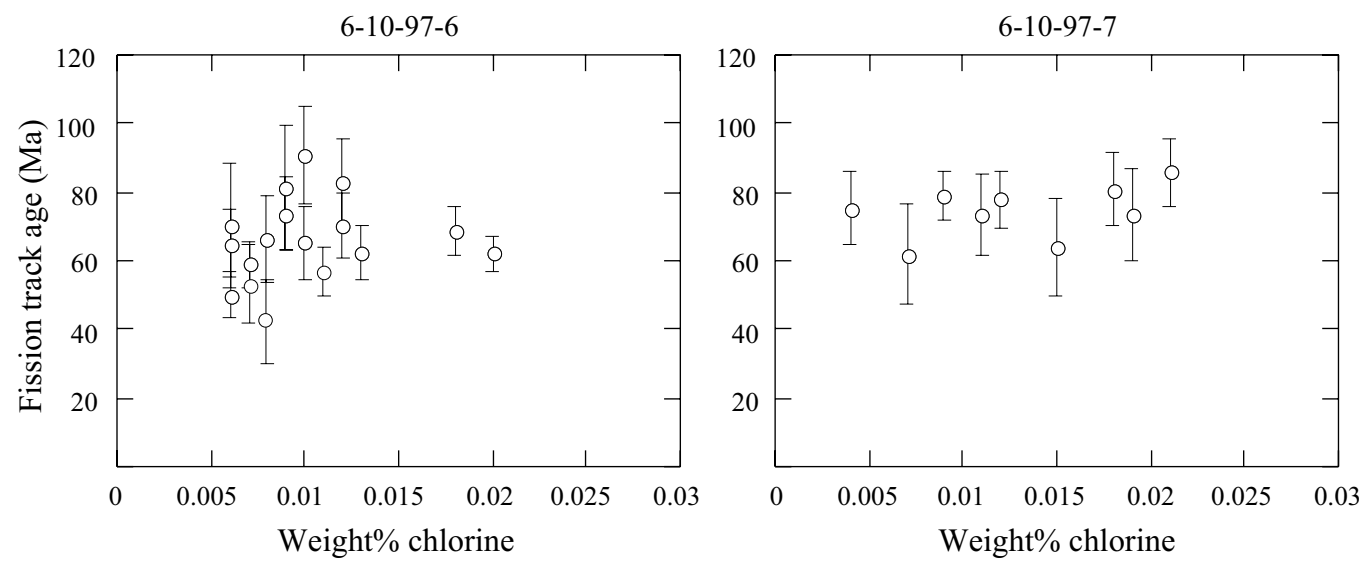

Figure 5.6: Chlorine concentration of individual grains from samples 6-10-97-6 and 610-97-7 on both sides of the Omaruru Lineament.

12.5-14.4 $\mu \mathrm{m}$. This indicates that most of these samples have been subjected to temperatures in excess of $110^{\circ} \mathrm{C}$ since the South Atlantic opening. Shorter mean track lengths from ca. 9.8-12.5 $\mu \mathrm{m}$ are associated with ages pre-dating break-up, and have broader track length distributions (standard deviations of 1.6-3.7 $\mu \mathrm{m}$ ). Figure 5.5 shows that effectively all apparent cooling ages post-date the Damara metamorphism at ca. $550 \mathrm{Ma}$.

The boomerang-shaped pattern of age, and mean track length, in Figure 5.5b, indicates that different samples cooled from different maximum palaeotemperatures (e.g. Gallagher and Brown, 1997). The progressive reduction of apparent apatite fission track age with decreasing elevation occurs because samples with older ages have experienced systematically lower maximum temperatures than samples with the younger apparent fission track ages prior to cooling. Therefore, older ages represent cooler rocks from shallower crustal levels, reflecting little annealing. Intermediate ages, with severely shortened tracks, represent rocks which cooled from deeper crustal levels. The tracks from samples with the youngest apparent fission track ages (to the left of the grey shaded 'break-up' band in Figure 5.5) were almost totally annealed prior to denudation and subsequent cooling in the Late Cretaceous. The majority of remaining tracks accumulated in these samples after the onset of cooling. The fission track ages of these younger samples (about $70 \mathrm{Ma}$ ) approximate the onset of accelerated denudation.

The track length distributions, and the single grain age distributions from representative samples, are shown in Figure 5.7. Radial plots show the single grain age distributions (Galbraith 1990a), with the \% relative error as a measure of the precision of each grain age. Precision increases towards the right. Grains belonging to a single age population scatter within the $\pm 2 \sigma$ age range shown on the y-axis. The five radial plots in Figure 5.7 show the variation in single grain ages for old (258 Ma, 24-9-97-9) and very young (61 Ma, 6-10-97-6) samples. 
While single grain ages in old samples scatter over a broad range in age (e.g. in sample 24-9-97-9 between 480 and $170 \mathrm{Ma}$ ), they are more confined in young samples, which were totally annealed and then rapidly cooled. Another way of measuring the spread in single grain ages is by applying the chi-square test. A chi-square probability of smaller than 5\% suggests a spread of ages larger than expected from a single poissonian population (Galbraith 1981). Analytical results are represented in Table 5.1.

Because the annealing behaviour of fission tracks is sensitive to the ratio of chlorine to fluorine (Green et al. 1986), the chlorine content of both samples (610-97-6, 6-10-97-7) on either side of the Omaruru Lineament was determined by microprobe analysis. All grains had chlorine concentrations between 0.0 and 0.02 $\mathrm{wt} \% \mathrm{Cl}$, indicating no evidence of significant compositional variation between the two samples across the shear zone (Figure 5.6).

\subsection{Thermal Modelling}

The maximum likelihood approach outlined in Gallagher (1995) has been applied to test and quantify possible thermal histories, using single grain age distributions and track length distributions. The annealing algorithm of Laslett et al. (1987) for Durango apatite $(0.4 \mathrm{wt} \% \mathrm{Cl})$ has been used. To find a thermal history which maximises the probability of obtaining the measured data, the maximum likelihood approach has been applied to constrain the time-temperature path. For this approach the raw track length and track counting data has been utilised. This approach also allows the mapping of confidence regions around the best solution. These confidence regions were taken to derive the time and temperature errors as listed in Table 5.2, the maximum x,y error was always considered (the direct search method normally shows asymmetric errors).

\subsection{Constraining Reactivation and Denudation}

As mentioned earlier, samples with the youngest age, and the longest mean track length, provide some constraints on the time of initiation of cooling. Therefore, the thermal history models were run to test whether samples show a distinct cooling signal in the Late Cretaceous. 26 representative samples were chosen to present an equidistant distribution along the transect (Table 5.2). After significant differences in maximum palaeotemperatures became apparent, more samples in the vicinity of the major shear zones were modelled. In order to obtain the best fit thermal histories, five time-temperature bounding boxes were set. Because tracks are partly annealed to a different degree in all samples, the above samples were 

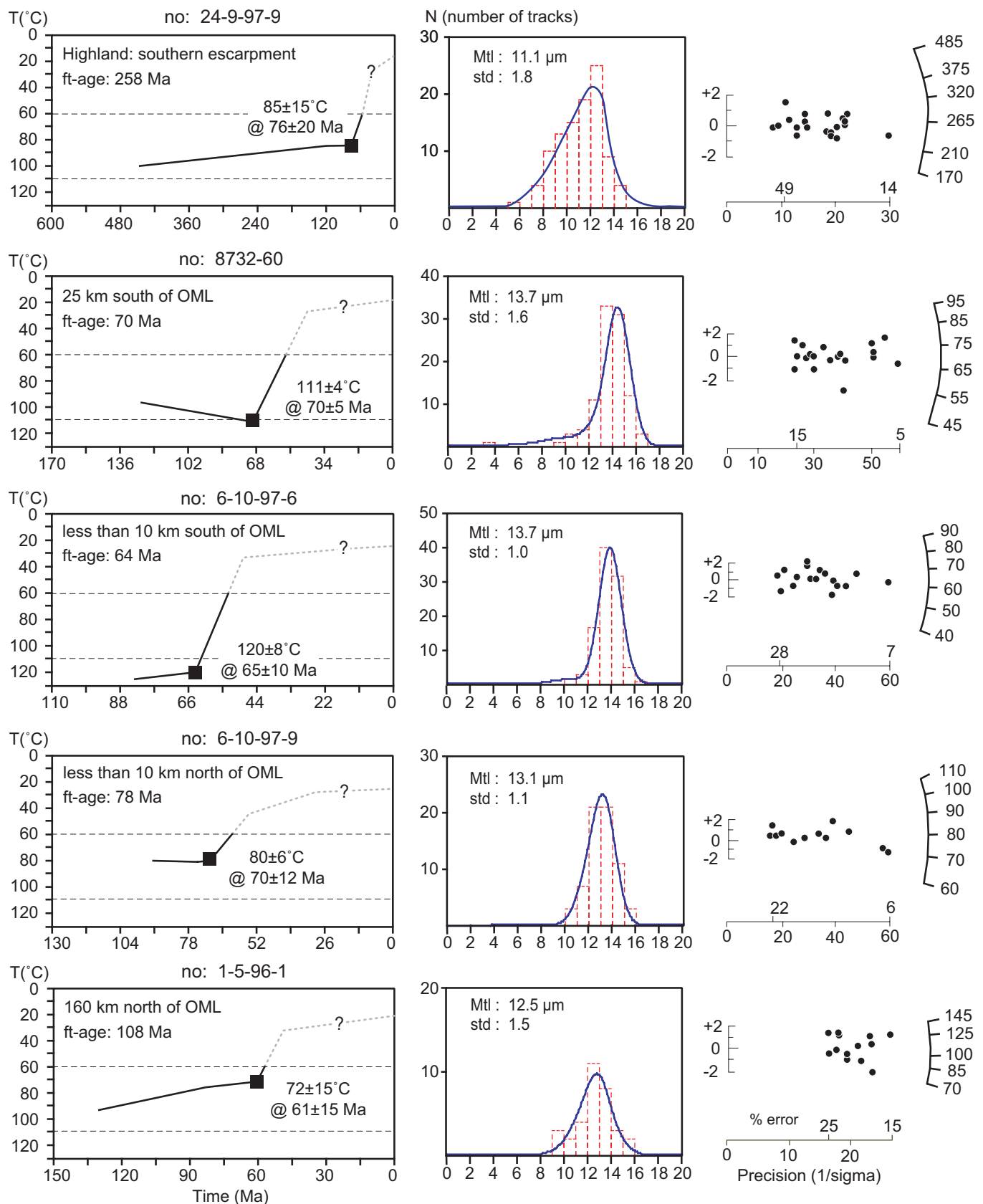

Figure 5.7: Left column: Black lines are the thermal histories derived by forward modelling which best fit the observed data. The black squares show the time-temperature points which constrain the timing and the temperature of the onset of denudation. Dashed lines at 60 and $110^{\circ} \mathrm{C}$ approximate the partial annealing zone. Mid column: The binned horizontal confined track lengths distributions are shown in histograms, the model predictions as continuous lines. Right column: Single grain age distribution is shown in radial plots. Perimeter scale is in Ma. Precision increases towards the right. 
modelled individually. In Figure 5.7, the thermal histories best fitting the data obtained with the full likelihood ratio test (Gallagher 1995) are shown. The results are listed in Table 5.2. In Figure 5.7, five models of those samples are presented to show the time-temperature constraints for temperatures greater than $60^{\circ} \mathrm{C}$. The time-temperature points marking the initiation of denudation are shown as black squares, and labelled with their values and errors. As the method is less sensitive to temperatures below $60^{\circ} \mathrm{C}$, the continuation of the model $\mathrm{t}-\mathrm{T}$ path below this temperature is shown by a dashed line labelled with a question-mark.

The amount of removed section can be estimated by dividing the amount of cooling by the geothermal gradient (Equation 4.1). Because it is not known how heat flow might have varied over time, the average present geothermal gradient for this region of $22\left[\frac{{ }^{\circ} \mathrm{C}}{\mathrm{km}}\right]$ is used (Ballard and Pollack 1987). There are no indicators for an increased heat flow in the Late Cretaceous (Chapter 4). Although the average value of the geothermal gradient appears to be appropriate, estimates for gradients of 30 and $50^{\circ} \mathrm{C} / \mathrm{km}$ are also shown for comparison. A constant surface temperature of $20^{\circ} \mathrm{C}$ has been used. The values of denudation are listed in Table 5.2.

\subsection{Discussion}

Apparent apatite fission track ages are shown plotted against distance along the transect in Figure 5.8a. Owing to a strong relationship between apatite fission track age and elevation (Figure 5.5), ages are highly variable $(<100 \mathrm{Ma}$ to $>$ $500 \mathrm{Ma}$ ) in the southeast of the profile, as the local relief and sample elevation vary significantly in this sector. In contrast, only minor variations in age are observed within the vicinity of the shear zones, and the observed ages are generally less than ca. $100 \mathrm{Ma}$ (between the Okahandja Lineament and the Autseib Fault (Figure 5.8a)).

Northwest of the Autseib Fault, approaching the Etendeka province and Kamanjab Inlier, apparent fission track ages appear to form two discrete groups, and are either about $110 \mathrm{Ma}$ or older than $\sim 290 \mathrm{Ma}$. It is likely that the younger ages from this area record cooling subsequent to heating associated with the Etendeka magmatic episode, as samples from this region were taken from the Etendeka basalts or closely underlying lithologies. Similarly, since the older ages were obtained from Proterozoic basement rocks, it is likely that they record partially reset 'mixed ages' after their reburial since the Carboniferous and subsequent exhumation in the Late Cretaceous.

Although the observed apatite fission track ages along the transect vary significantly between 62 to $549 \mathrm{Ma}$, the modelled thermal histories suggest that all samples experienced a common episode of accelerated cooling during the Late 

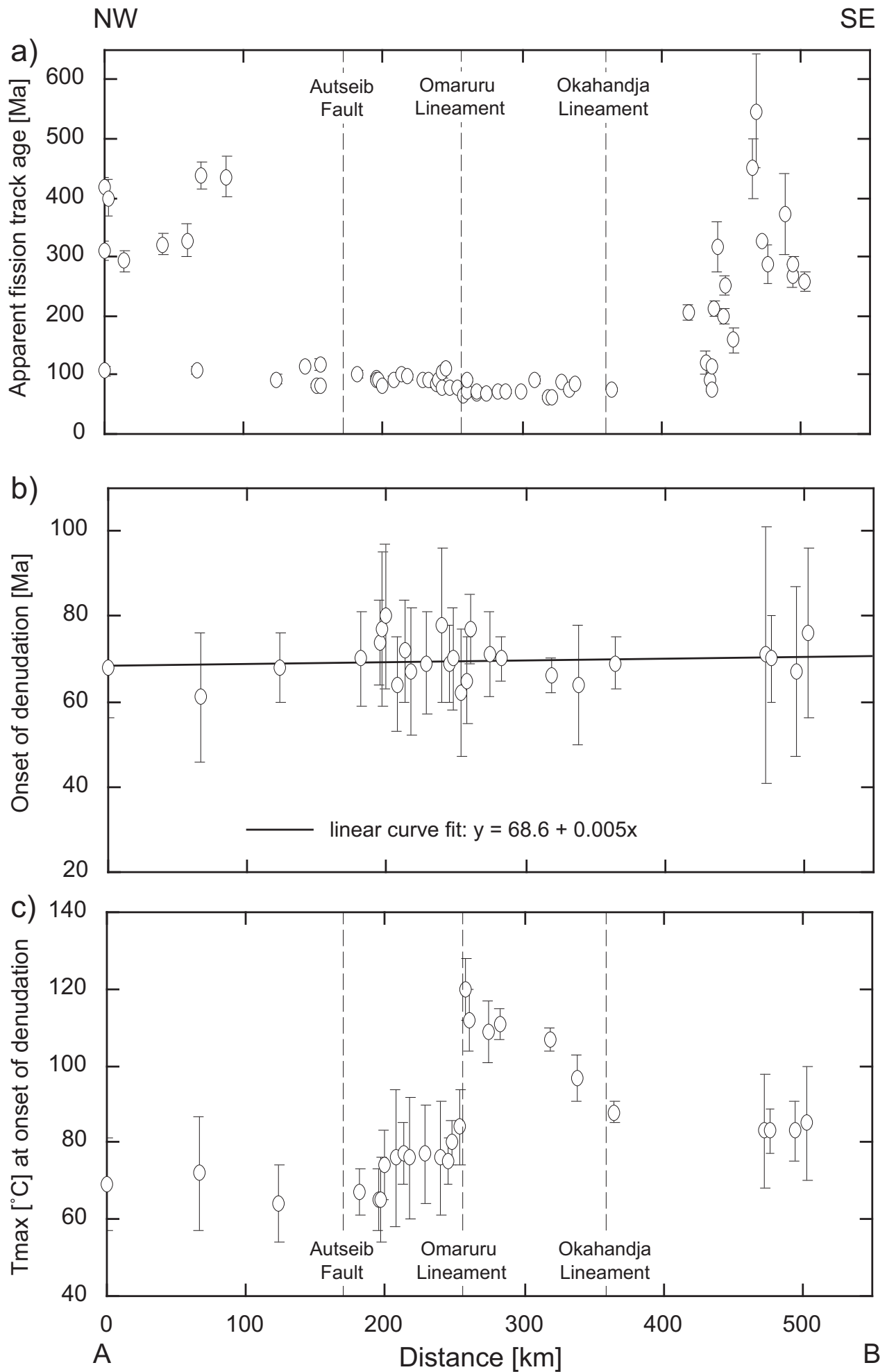

Figure 5.8: Plots showing apparent apatite fission track ages (a), onset of denudation (b) and maximum palaeotemperatures (c) across the transect. Error bars are $2 \sigma$ on the apparent fission track ages (a) and were graphically derived from thermal models for onset of denudation (b) and maximum palaeotemperature at onset of denudation (c). 
Cretaceous. The onset of accelerated cooling for each of the modelled samples is shown plotted against sample distance along the transect in Figure 5.8b. Least squares linear regression of the onset of cooling versus distance along the transect produces a best fit line with minimal gradient (Figure 5.8b). This is consistent with all samples along the transect experiencing a discrete cooling event at ca. $70 \mathrm{Ma}$, and an indication of the timing of this event $(69 \pm 1 \mathrm{Ma})$ is given by the weighted mean age of cooling (Table 5.2).

A contrasting pattern is obtained if the estimated Late Cretaceous maximum palaeotemperatures is plotted with distance along the transect for each of the modelled samples (Figure 5.8c). Samples in the southeast sector of the transect have experienced similar palaeotemperatures of about $85^{\circ} \mathrm{C}$. North of the Okahandja Lineament, palaeotemperatures increase gradually to a maximum of $120^{\circ} \mathrm{C}$ immediately southeast of the Omaruru Lineament. A significant, and apparently discontinuous, decrease in palaeotemperature occurs from southeast to northwest across the Omaruru Lineament, where the palaeotemperature drops steeply from $120^{\circ} \mathrm{C}$ to ca. $80^{\circ} \mathrm{C}$ (Figure $5.8 \mathrm{c}$ ).

Between the Omaruru Lineament and the Autseib Fault, palaeotemperatures appear to decrease slightly towards the north, from around $80^{\circ} \mathrm{C}$ to $65^{\circ} \mathrm{C}$, with a mean of ca. $76^{\circ} \mathrm{C}$. A possible minor offset occurs at approximately $200 \mathrm{~km}$ from the northwest end of the transect, where the modelled palaeotemperatures appear to vary rapidly by ca $10^{\circ} \mathrm{C}$. No significant variations in temperature are visible for the rest of the profile.

Consequently, the apparently discontinuous offset of almost $40^{\circ} \mathrm{C}$ in the estimated palaeotemperatures across the Omaruru Lineament can be interpreted as evidence for tectonic reactivation of that lineament during and/or since the Late Cretaceous. The difference in temperature can be used to estimate the net amount of vertical displacement across the Omaruru Lineament, and, using the present average gradient of $22^{\circ} \mathrm{C} / \mathrm{km}$ (Ballard and Pollack 1987), an offset of $40^{\circ} \mathrm{C}$ indicates approximately $2 \mathrm{~km}$ of differential vertical movement (Figure 5.9).

The palaeotemperature estimates also provide constraints on the amount of denudation which accompanied the tectonic reactivation of this structural zone in the Late Cretaceous. The estimated pattern of denudation along the transect since the Late Cretaceous is shown in Figure 5.9 for three different palaeothermal gradients: 22,30 and $50{ }^{\circ} \mathrm{C} / \mathrm{km}$. The amount of denudation ranges from a maximum of between 4.5 and $2 \mathrm{~km}$, and a minimum of between 2 and less than $1 \mathrm{~km}$, for the selected thermal gradients.

The interpretation that the Omaruru-Waterberg structural zone was tectonically reactivated at around $70 \mathrm{Ma}$ is consistent with recent analysis of the offshore seismic stratigraphy within the Walvis Basin (Clemson et al. 1997). These studies demonstrated that the continental margin offshore of northern Namibia 


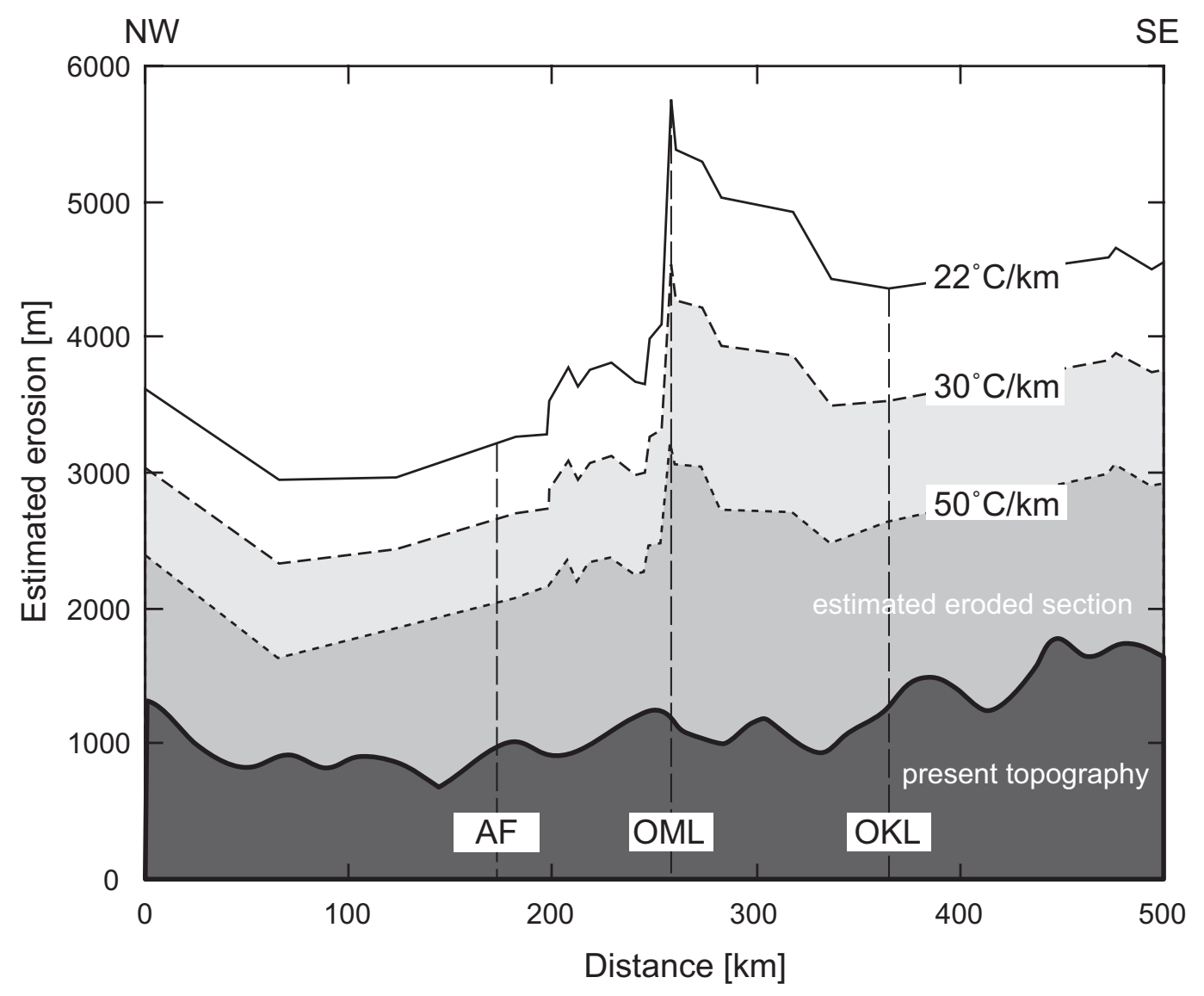

Figure 5.9: Estimated erosion since 70 Ma based on three geothermal gradients with 20, 30 and $50^{\circ} \mathrm{C} / \mathrm{km}$ relative to the present day topography.

is segmented along its length into discrete zones, with different rifting histories, by major structurally defined segment boundaries which are roughly orthogonal to the rift axis. The most important of these, the Cape Cross segment boundary (CCSB), is a complex zone approximately $80 \mathrm{~km}$ wide separating the Lüderitz Basin to the south from the Walvis Basin to the north, and accommodating an eastward offset (dextral) of the rift axis of around $50 \mathrm{~km}$. The southern boundary of the CCSB is approximately co-linear with the offshore extrapolation of the Omaruru Lineament, as is the northern boundary with the extrapolation of the Autseib Lineament. Offshore extrapolation of these crustal lineaments to the southwest is also indicated by the apparent continuation of magnetic anomalies associated with these lineaments (Clemson et al. 1997).

Both the Omaruru and Autseib structures were reactivated during the Triassic, and possibly also during the Early Cretaceous (Hegenberger 1988, Clemson et al. 1997). However, the chronology of the seismic stratigraphy within the Walvis Basin is not well-constrained, as it is based on extrapolation of the chronology de- 
termined from the Kudu wells within the Orange Basin more than $800 \mathrm{~km}$ to the south (Hoal 1990). Many of the seismic sequence boundaries pinch-out across the major basement arches/segment boundaries separating the Orange, Lüderitz and Walvis Basins (Maslanyj et al. 1992, Light et al. 1993), and the age of rifting and break-up youngs towards the north, with break-up occurring in the early Aptian along the Walvis Basin segment of the margin (Clemson et al. 1997). In light of the apatite fission track evidence for significant reactivation of the Omaruru structure within the onshore region during the late Cretaceous given here, it seems possible that the current offshore seismic sequence chronology within the Walvis Basin over estimates the age of reactivation; and that the major sequence boundaries are 10-20 Ma younger than the current seismic chronozones suggest. Alternatively, it is possible that the offshore segments of the Omaruru and Autseib structures remained inactive during the Late Cretaceous.

\subsection{Conclusions}

Although the measured apatite fission track ages across the Damara sector of the Namibian margin range between about 62 and $549 \mathrm{Ma}$, the apatite fission track data for all samples are consistent with a discrete period of accelerated cooling beginning at about $70 \mathrm{Ma}$. The variation of modelled Late Cretaceous palaeotemperatures along the study transect shows a distinct discontinuity across the Omaruru Lineament, with the maximum palaeotemperatures changing abruptly from approximately $120^{\circ} \mathrm{C}$ to $80^{\circ} \mathrm{C}$, from south to north across the lineament. This temperature difference indicates a net vertical displacement of approximately $2 \mathrm{~km}$ for a thermal gradient of $22^{\circ} \mathrm{C} / \mathrm{km}$ (the present average thermal gradient for this region).

A range of geological and geophysical observations have indicated that the major northeast-southwest oriented structures within the Damara mobile belt have been reactivated at various times in the Phanerozoic. However, the timing of the most recent of these episodes has been enigmatic, since there is no substantial stratigraphy younger than Early Cretaceous preserved within the onshore region of the Damara sector of the margin. The new apatite fission track data provide strong evidence that a major period of tectonic reactivation of the Omaruru LineamentWaterberg Thrust occurred at approximately $70 \mathrm{Ma}$, and was expressed by about $2 \mathrm{~km}$ of net vertical displacement (south-side up).

This new evidence is consistent with the available onshore geological information, which suggests that a major period of reactivation occurred during the Early Cretaceous or later. The apatite fission track data presented here are not inconsistent with structural interpretations of the offshore seismic data (Clemson et al. 1997). However, it is possible that the current chronozones within the Walvis 
Basin may be over-estimating the age of the major sequence boundaries by 10-20 Ma; but resolution of this issue must await publication of new chronozone estimates based on wells drilled within the Walvis Basin sequences. 


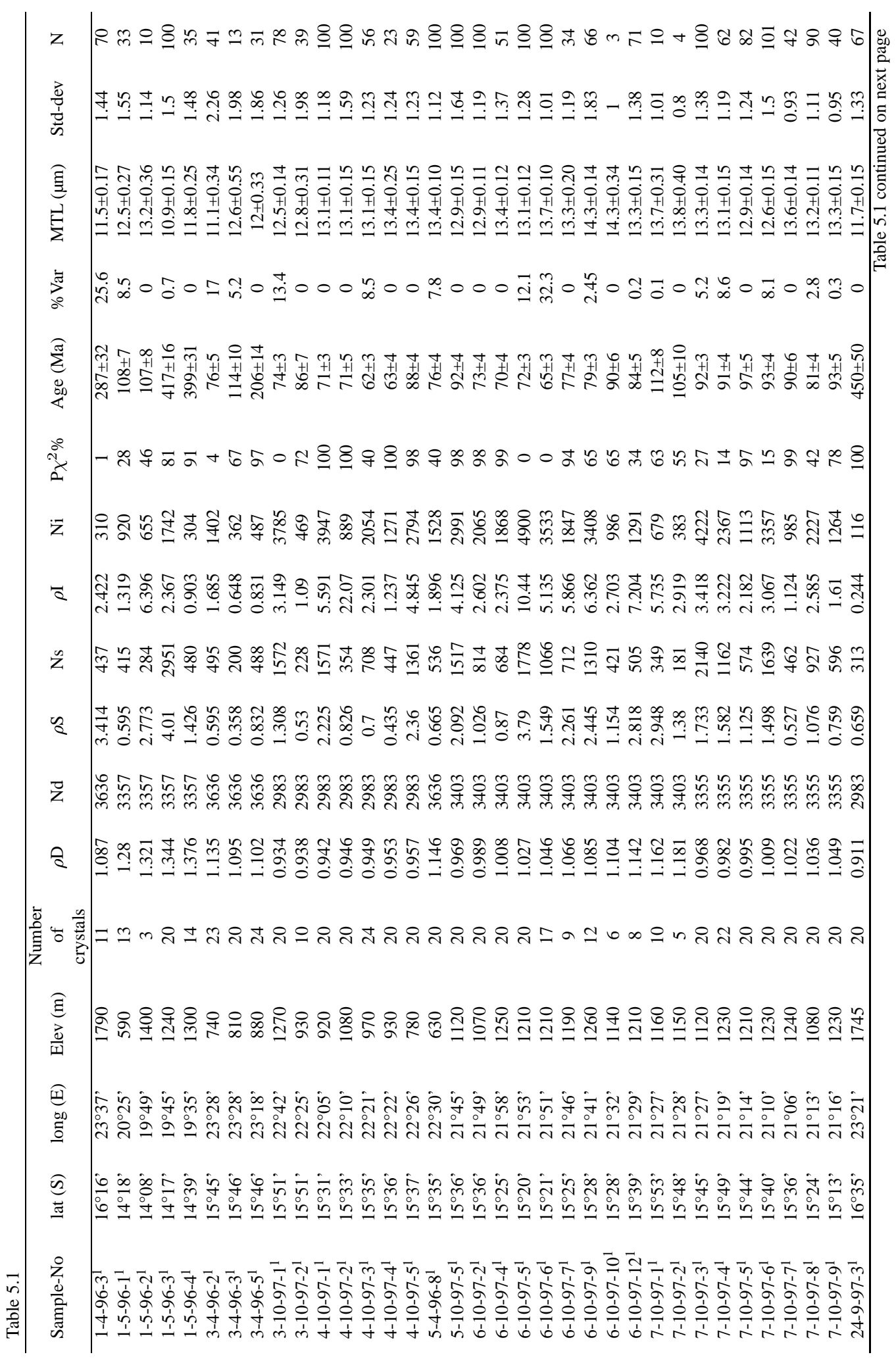




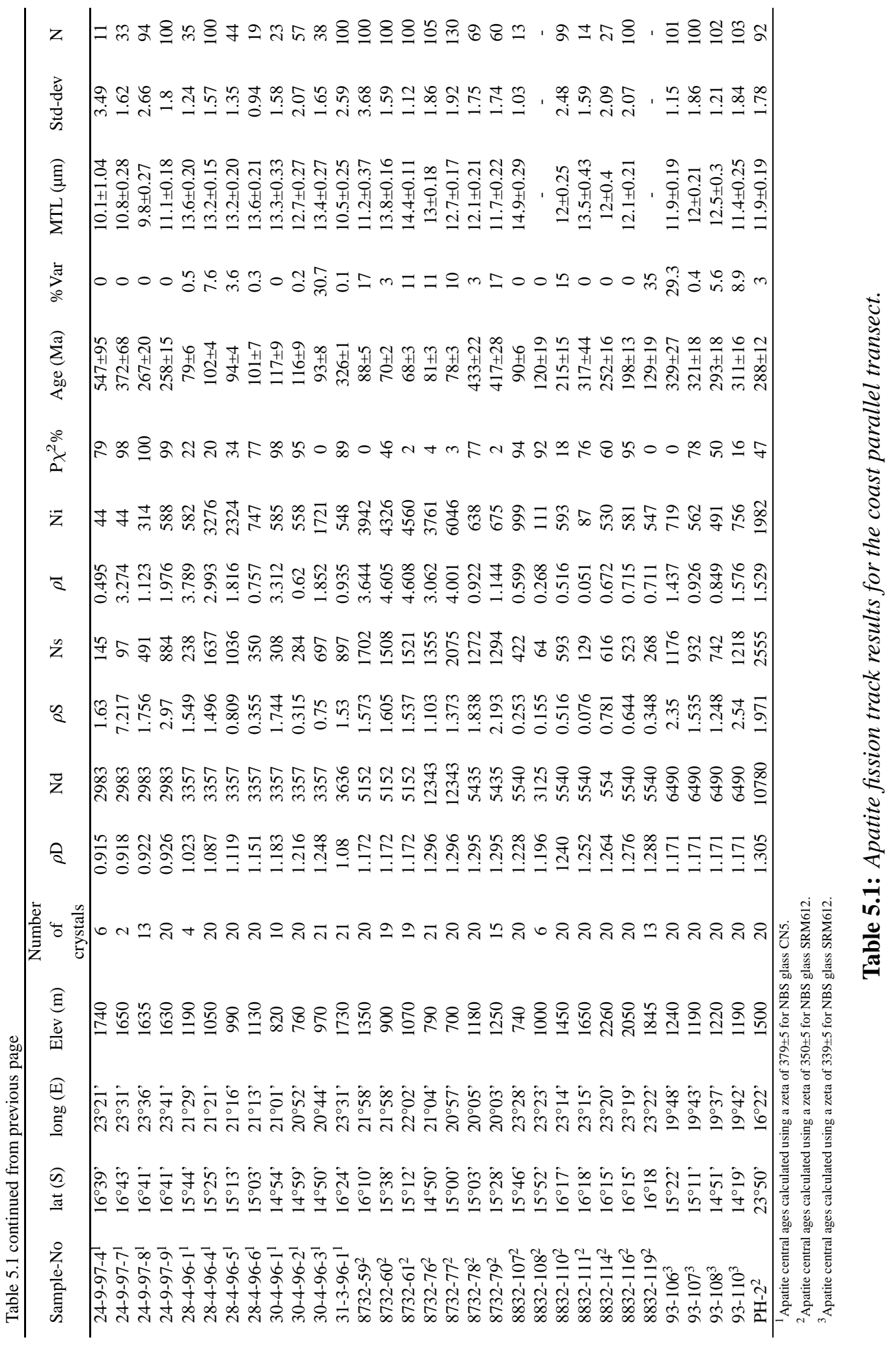




\begin{tabular}{cccccc}
\hline Sample-No & Tmax $\left[{ }^{\circ} \mathrm{C}\right]$ & Onset [Ma] & $\begin{array}{c}\text { Denuded section [m] } \\
\text { at } \\
22^{\circ} \mathrm{C} / \mathrm{km}\end{array}$ & $\begin{array}{c}\text { Denuded section }[\mathrm{m}] \\
\text { at } \\
30^{\circ} \mathrm{C} / \mathrm{km}\end{array}$ & $\begin{array}{c}\text { Denuded section }[\mathrm{m}] \\
\text { at } \\
50^{\circ} \mathrm{C} / \mathrm{km}\end{array}$ \\
\hline $1-5-96-2$ & $69 \pm 12$ & $68 \pm 12$ & 2200 & 1600 & 1000 \\
$1-5-96-1$ & $72 \pm 15$ & $61 \pm 15$ & 2300 & 1700 & 1000 \\
$30-4-96-3$ & $64 \pm 10$ & $68 \pm 8$ & 2000 & 1500 & 900 \\
$28-4-96-6$ & $67 \pm 6$ & $70 \pm 11$ & 2100 & 1600 & 900 \\
$7-10-97-9$ & $65 \pm 8$ & $74 \pm 10$ & 2000 & 1500 & 900 \\
$7-10-97-7$ & $65 \pm 11$ & $77 \pm 18$ & 2000 & 1500 & 900 \\
$7-10-97-8$ & $74 \pm 9$ & $80 \pm 17$ & 2500 & 1800 & 1100 \\
$7-10-97-6$ & $76 \pm 18$ & $64 \pm 11$ & 2500 & 1900 & 1100 \\
$28-4-96-4$ & $77 \pm 8$ & $72 \pm 12$ & 2600 & 1900 & 1100 \\
$7-10-97-5$ & $76 \pm 16$ & $67 \pm 15$ & 2500 & 1900 & 1100 \\
$7-10-97-4$ & $77 \pm 13$ & $69 \pm 12$ & 2600 & 1900 & 1100 \\
$7-10-97-3$ & $76 \pm 15$ & $78 \pm 18$ & 2500 & 1900 & 1100 \\
$7-10-97-1$ & $75 \pm 6$ & $69 \pm 9$ & 2500 & 1800 & 1100 \\
$6-10-97-9$ & $80 \pm 6$ & $70 \pm 12$ & 2700 & 2000 & 1200 \\
$6-10-97-7$ & $84 \pm 10$ & $62 \pm 15$ & 2900 & 2100 & 2000 \\
$6-10-97-6$ & $120 \pm 8$ & $65 \pm 10$ & 4500 & 3300 & 1800 \\
$6-10-97-5$ & $112 \pm 8$ & $77 \pm 8$ & 4200 & 3100 & 1800 \\
$6-10-97-4$ & $109 \pm 8$ & $71 \pm 10$ & 4000 & 3000 & 1800 \\
$8732-60$ & $111 \pm 4$ & $70 \pm 5$ & 4100 & 3000 & 1700 \\
$4-10-97-3$ & $107 \pm 3$ & $66 \pm 4$ & 4000 & 2900 & 1500 \\
$3-10-97-2$ & $97 \pm 6$ & $64 \pm 14$ & 3500 & 2600 & 1400 \\
$3-10-97-1$ & $88 \pm 3$ & $69 \pm 6$ & 3100 & 2300 & 1300 \\
$31-3-96-1$ & $83 \pm 15$ & $71 \pm 30$ & 2900 & 2100 & 1300 \\
$1-4-96-3$ & $83 \pm 6$ & $70 \pm 10$ & 2900 & 2100 & 1300 \\
$24-9-97-8$ & $83 \pm 8$ & $67 \pm 20$ & 2900 & 2100 & 1300 \\
$24-9-97-9$ & $85 \pm 15$ & $76 \pm 20$ & 3000 & 2200 & \\
\hline
\end{tabular}

Table 5.2: Modelled palaeotemperatures at the time of onset of denudation and total amount of denudation for different palaeogeothermal gradients of $22^{\circ} \mathrm{C} / \mathrm{km}, 30^{\circ} \mathrm{C} / \mathrm{km}$ and $50^{\circ} \mathrm{C} / \mathrm{km}$. 


\section{Chapter 6}

\section{Denudation Chronology of Northern Namibia}

\subsection{Introduction}

Significant advances in modelling apatite fission track data, to derive thermal history information, make it possible to reconstruct regional denudation patterns. These denudation patterns are based on extracted palaeotemperatures at particular times. Palaeotemperatures in turn can be plotted as maps on a regional scale (Gallagher and Brown 1999a, Gallagher and Brown 1999b, Brown et al. 2000). Palaeotemperatures can be equated to crustal depth, if information about the palaeogeothermal gradient or heat-flow data are available. This leads to estimates about the section removed, and regional denudation maps can be constructed based on this data. Moreover, estimates of palaeotopography can be made by loading the present-day topography with the estimated denudation.

This chapter is dedicated to using the thermal history information from apatite fission track data on a regional scale, and to introducing palaeotemperature, denudation, as well as palaeotopography maps to achieve and visualise quantitative information of the denudation chronology of the passive continental margin of northern Namibia.

Although a large data set of apatite fission track data is available for the southwest African margin (Haack 1983, Brown 1992), the coverage is still sparse over this large area. The modelled denudation chronology presented in this chapter aims to provide improved constraints on the pre-existing long-term chronologies from Gallagher and Brown (1999a), Gallagher and Brown (1999b), and Brown et al. (2000), for northern Namibia in particular. In contrast to the previous models, the new results were derived by incorporating the raw track length data, rather than just the mean track length values. This is an important difference, since the shape 
of the confined track length distribution allows a more sensitive interpretation of the observed data than the mean value on its own.

The extracted thermal history information was used to construct maps of palaeotemperature, denudation, and palaeotopography in time intervals of 1 m.y. since the Permian (300 Ma to present). The individual maps were combined into computer animations to view the cooling history from the perspective of palaeotemperature, denudation, and palaeotopography. Computer animated movies, as well as all maps (900), and the full dataset (model data), are on the CD attached to this thesis (Appendix E).

Denudation, and the spatial variation of denudation in particular, is a key issue for distinguishing between different passive margin evolution models. Three different geodynamic models considering the formation of long-term passive margin topography are discussed in Section 2.3.3. The process of denudation normally removes the record of palaeoelevation and the evidence for vertical motion onshore (Chapter 5). In order to understand long-term denudation and passive margin evolution, it is important to provide direct and quantitative estimates of what was being eroded at a particular time. This can be constrained on geological time-scales with apatite fission track analysis.

\subsection{Previous Work in Low Temperature Thermo- chronology}

An extensive regional fission track data set, by Brown (1992), for South Africa and Namibia has indicated substantial crustal cooling for the entire western margin of southern Africa (Brown et al. 1990, Brown 1992, Gallagher and Brown 1997, Gallagher and Brown 1999a, Gallagher and Brown 1999b, Brown et al. 2000). Brown (1992) also suggested that reactivation of pre-existing crustal structures in response to a change in the spreading geometry between South America and Africa implies a model of rapid denudational response to tectonic reactivation of major shear zones in Namibia.

The margin was subjected to low amounts of syn-rift denudation on the order of less than $1 \mathrm{~km}$, but large amounts of post-rift dendudation on the order of 3 to $5 \mathrm{~km}$ have occurred since $118 \mathrm{Ma}$ (Brown et al. 2000, Cockburn et al. 2000). The total depth of denudation since rifting is greatest for the coastal area, and decreases towards the continental interior, a common trend for passive margins (Brown 1992, Gallagher and Brown 1997). Fission track data also revealed that denudation is not uniform through time, and the majority of denudation had occurred prior to the beginning of the Tertiary. An accelerated phase of crustal cooling from ca. 80 to $60 \mathrm{Ma}$ in the Late Cretaceous has been inferred for many 
sites and the data have been broadly correlated with offshore seismic and borehole data from Rust and Summerfield (1990). The data are consistent with further stratigraphic evidence which implies low denudation rates for the Tertiary (Ward 1987). The fission track data also suggest that the timing and magnitude of denudation vary geographically, in particular along the strike of the margin.

\subsection{Quantifying Long-Term Denudation}

Utilising apatite fission track thermochronology for quantifying long-term denudation requires thermal modelling of the apatite fission track data by extracting the temperature history for every sample for any given time, since they provide information on timing and temperature respectively. The temperature information in turn needs to be converted into an equivalent depth as a function of time.

Extraction of thermal histories for large regional data sets is accomplished using forward modelling techniques after Gallagher (1995) (Section 3.4.3), where the palaeotemperature value for a particular time interval is estimated. Data from across a region can then be contoured and placed over the topography, enabling the creation of a contoured image of the predicted palaeotemperature for any given time in the past.

In order to convert the thermal history information extracted from apatite fission track data into estimates of denudation (Equation 4.1), some constraints on the palaeogeothermal gradient are required. This information can be obtained from a series of selected samples over a range of topographic elevations, as demonstrated for the Brandberg, Okenyenya and Windhoekgraben profile in Chapter 4.

The assessment of the palaeogeothermal gradient for three key locations in northern Namibia (Chapter 4) has shown that the geothermal gradient in the Late Cretaceous was not different to the present-day geothermal gradient (Pollack et al. 1993). Although it is not known how heat-flow might have varied over time, it appears to be highly unlikely that the geothermal gradient was significantly elevated after continental break-up. Brown et al. (1994a) and Gallagher et al. (1994) have demonstrated that the increased heat-flow during rifting does not significantly effect the rift-flanks and the shallow crustal levels less than ca. $10 \mathrm{~km}$ of depth.

Present-day heat-flow data, as well as the three palaeogeothermal gradients $\left(26,24\right.$ and $\left.22^{\circ} \mathrm{C} / \mathrm{km}\right)$, suggest that the variation in thermal gradients for Namibia is relatively restricted to values between 20 and $30^{\circ} \mathrm{C} / \mathrm{km}$ (Pollack et al. 1993, Gallagher and Brown 1999a) (Chapter 4).

Based on this data, it was assumed for the models that the heat-flow was constant over time. To allow the model some spatial variation in heat-flow, the present-day heat-flow data from Pollack et al. (1993) were used. 
If heat-flow data are used for the conversion of palaeotemperatures into denudation, then values for the thermal conductivity of the eroded section need to be assumed, since the geothermal gradient represents the ratio of heat-flow (Q) and thermal conductivity $(\mathrm{k})$. The equivalent amount of denudation $(\mathrm{Z})$ is then given as:

$$
Z=\frac{k}{Q}\left(T-T_{s}\right)
$$

where $T$ is the modelled palaeotemperature $\left[{ }^{\circ} \mathrm{C}\right]$, and $T_{s}$ is the surface temperature $\left[{ }^{\circ} \mathrm{C}\right]$ (Gallagher and Brown 1999a, Gallagher and Brown 1999b). For the models presented here a constant thermal conductivity of $2.2 \mathrm{Wm}^{-1} \mathrm{~K}^{-1}$ was assumed for the eroded material and a surface temperature of $20^{\circ} \mathrm{C}$.

As shown in Chapter 4, calculated rates for phases of accelerated denudation after contintal break-up were on the order of 100-200 m/m.y.. Consequently it can be assumed that advective heat transfer due to fast exhumation was not significant, and is unlikely to have affected the palaeogeothermal gradient.

The thermal histories for rocks analysed are therefore primarily controlled by their vertical displacement relative to the surface along a near steady-state geotherm. Hence denudation can be considered as the major controlling process, and the rate of cooling is determined by the rate of denudation (Gallagher et al. 1994, Brown et al. 1994a, Brown and Summerfield 1997, Gallagher et al. 1998).

The bulk-modelling of all data was performed by Kerry Gallagher, University College, London. Further data processing and map generation was done using GMT (Wessel and Smith 1991), and GMT-scripts developed by Roderick Brown (Appendix D.5).

\subsection{Denudation Chronology}

Due to the sparse data coverage in some places, an additional data set of 158 samples has been analysed (Figure 6.2). One of the most striking features of the fission track data in Namibia is that fission track ages within $200 \mathrm{~km}$ of the present-day coast are consistently young (50 to $80 \mathrm{Ma}$ ), and far younger than the time of break-up (Haack 1983, Brown 1992, Brown et al. 1994b, Gallagher and Brown 1997, Gallagher and Brown 1999a, Gallagher and Brown 1999b, Brown et al. 2000) (Figure 6.3).

Figure 6.1 shows the association of samples with long mean track lengths and unimodal track length distributions, in comparison with old ages and more annealed length distributions. Because all fission track ages are younger than the stratigraphic age of the host rock, it can be inferred that these samples have all 


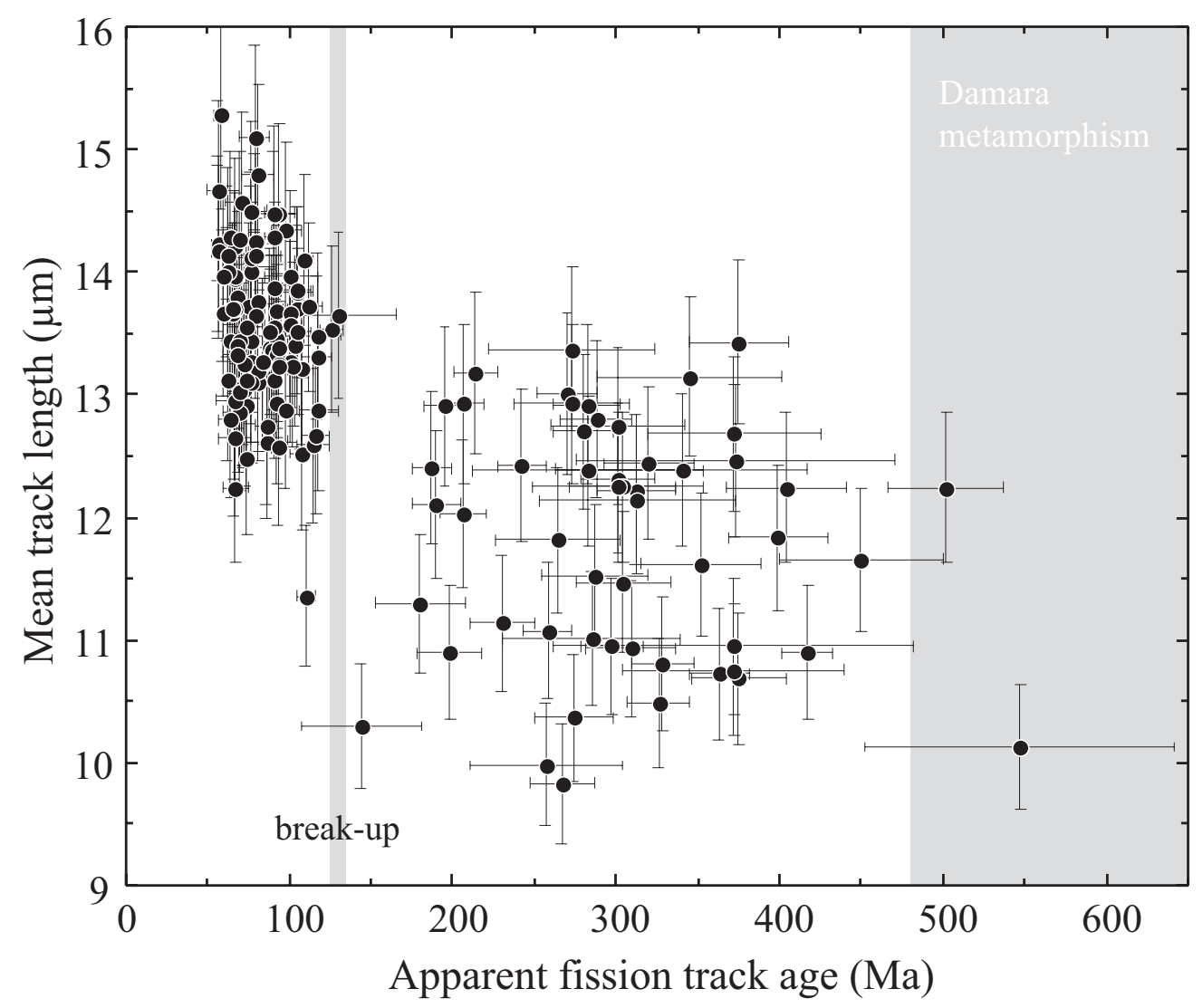

Figure 6.1: Relationship between the apparent apatite fission track age and the mean track length. The shaded bands represent the Damara metamorphism and the approximate time of continental break-up.

been exposed to increased temperatures in the past, in particular that the youngest samples have experienced temperatures in excess of $110^{\circ} \mathrm{C}$.

Another characteristic fission track age pattern for the study area is the age distribution defining a distinct northeast trending corridor of apparent apatite fission track ages younger than $100 \mathrm{Ma}$. The alignment of this corridor coincides with the regional structural trend of the Northern and Central Zone of the Pan-African Damara Orogen. This area has been investigated in detail, and the results are described in Chapter 5. The structural architecture is described in Section 2.2.2. The reactivation of major structures in this area caused differential vertical movements of the crust, resulting in a relative offset of at least $2 \mathrm{~km}$ in the Late Cretaceous (Chapter 5). 


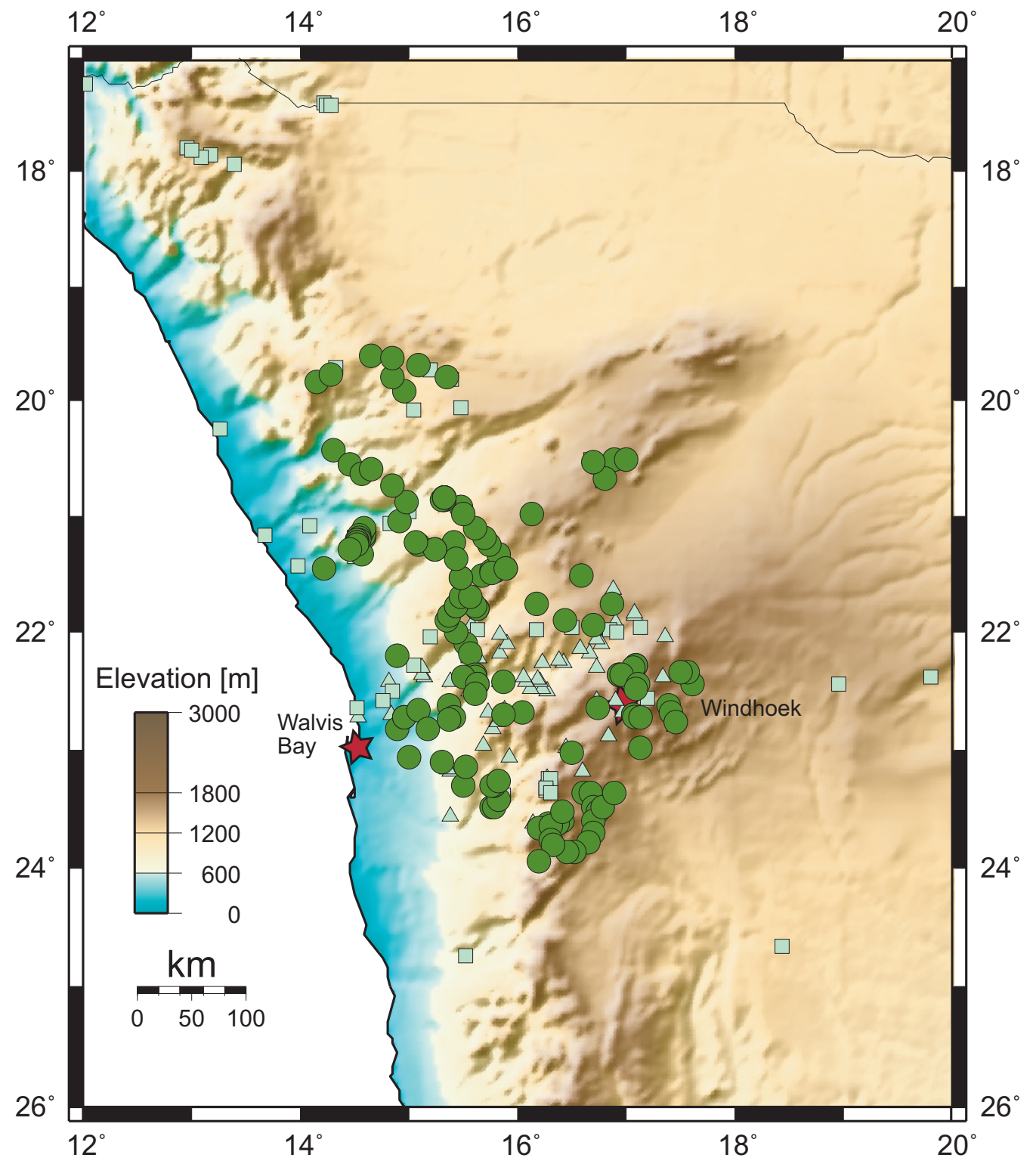

Figure 6.2: Sample location map of all available fission track ages. Dark green circles are sample locations for samples processed for this thesis. Light green triangles indicate samples from Haack (1983). Light green squares mark sample locations from Brown (1992). 


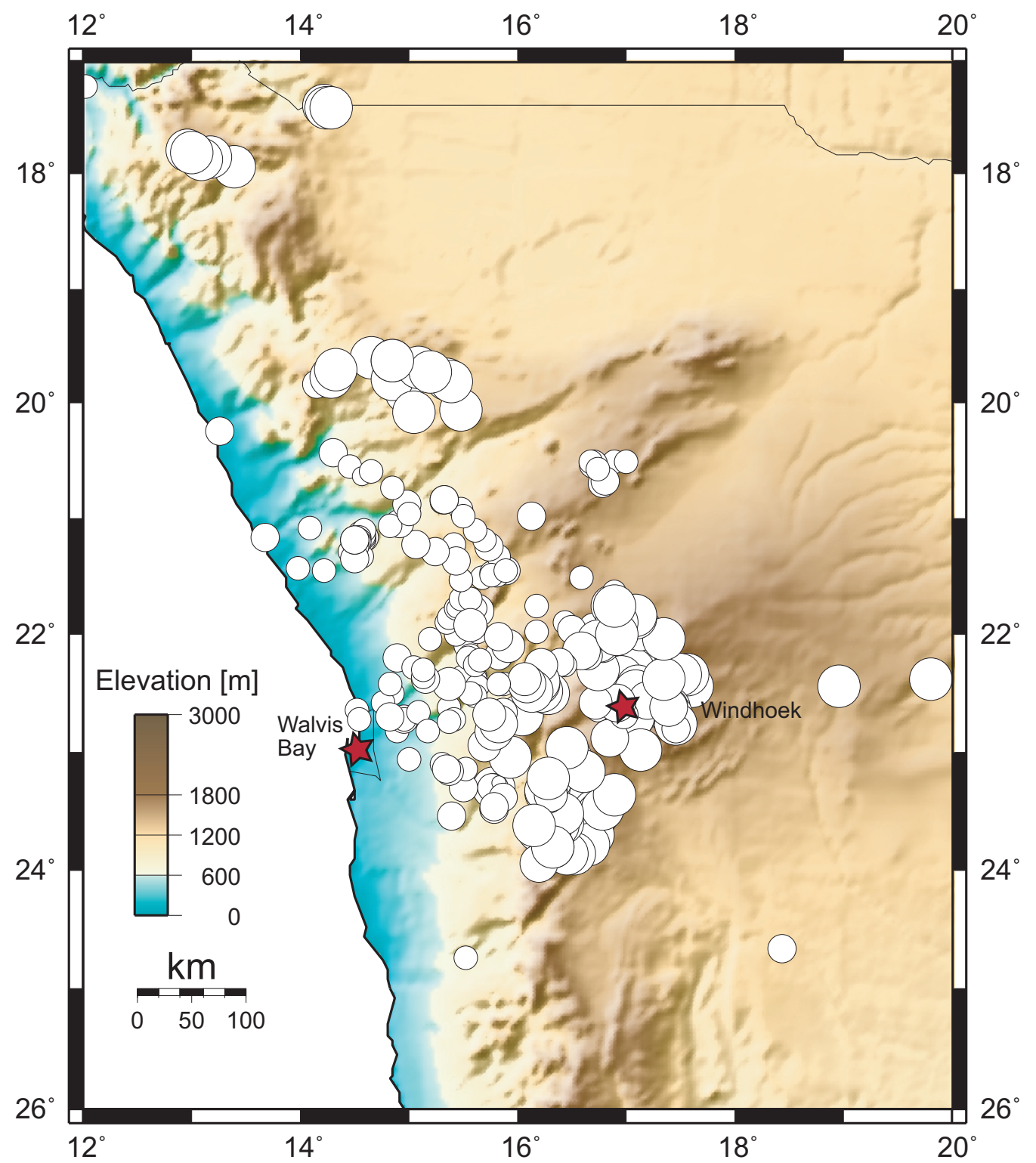

Figure 6.3: Sample location map of all available fission track ages. Circles are indicative of the apatite fission track age: circle radius increases with increasing age. Note the well-defined northeast to southwest trending intracontinental zone of younger apparent apatite fission track ages (higher maximum palaeotemperatures), which is aligned with the regional tectonic fabric of the Damara mobile belt in this region, and coincides closely with the Central and Northern Zone (Miller 1983). 


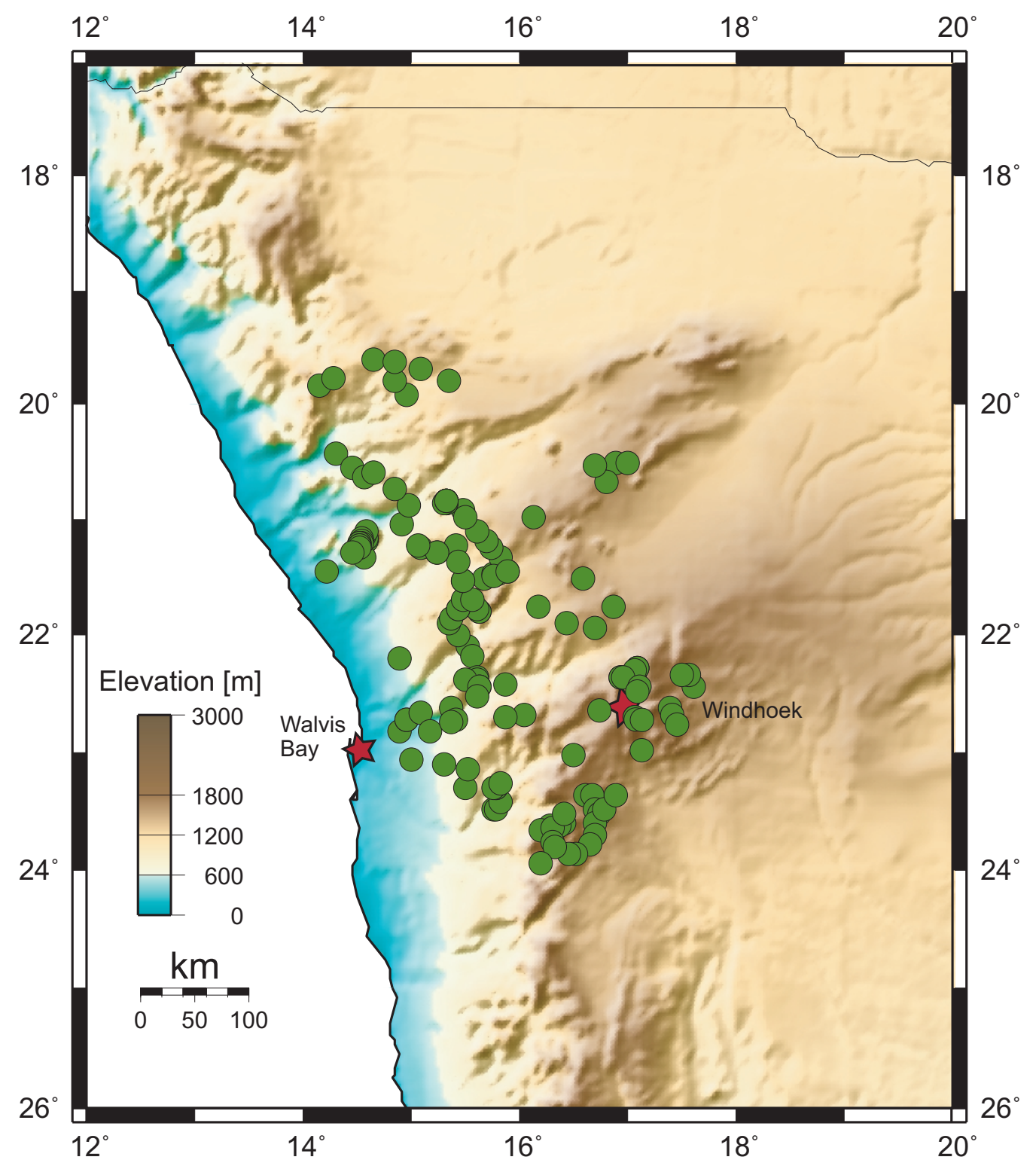

Figure 6.4: Sample location map of all fission track data considered for thermal modelling in this thesis. 


\section{Temperature Evolution}

The evolving temperature history of samples from the study area since the Early Cretaceous is shown in Figure 6.5 and 6.6. The temperature values for any particular area reflect the amount of cooling which is required to cool the rocks to surface temperatures since the time indicated.

Samples considered for modelling are exclusively from this study. This is largely because no track length information is available from Haack's study 1983. The data set of Brown (1992) has only mean track length values available at this stage, and this particular modelling approach was designed deliberately to incorporate individual track length information, rather than just a mean value. The temperature evolution based on Brown's data for the southwestern margin of Africa as a whole has been published by Gallagher and Brown (1999a), Gallagher and Brown (1999b), and Brown et al. (2000).

Merging the modelled data sets from Brown and data from this study presented difficulties due to the slightly different input parameters. A combined and consistent temperature evolution model of all available fission track data, with track length information, must await further reseach.

A location map with all samples incorporated into the bulk-modelling is shown in Figure 6.4.

The interpolation radius was generously set to $3^{\circ}$ for samples without neighbours. Consequently edge-effects increase significantly in interpolated areas without samples. This is particularly obvious in the northwestern and southeastern part of the study area (Kaoko-Veld and Highland respectively), where samples from Brown add improved constraints for these regions (compare with contoured fission track data map in Figure 5.2).

Although the temperature evolution has been extracted since the Permian (300 Ma, see Movies in Appendix E), only the evolution since initial rifting is discussed here.

The regional modelling suggests that samples within $100 \mathrm{~km}$ of the coast and in the area of the Northern and Central Damara Zone were at temperatures in excess of $110^{\circ} \mathrm{C}$ during the Late Creataceous. Samples from the cratonic interiors and the highlands respectively, were exposed to lower temperatures in the Early Cretaceous (Figure 6.5, $130 \mathrm{Ma}$ ). Little cooling occurred in the period between 130 and $90 \mathrm{Ma}$. The cooling history from the Late Cretaceous to the Early Tertiary (90 to $50 \mathrm{Ma}$, Figure 6.5 and 6.6) is dominated by more dramatic cooling for the coastal region and the Northern and Central Damara Zone. The majority of samples cooled in this period from temperatures in excess of $110^{\circ} \mathrm{C}$ to temperatures below $70^{\circ} \mathrm{C}$. Samples in the region underwent only subdued cooling from the Middle Tertiary to present (Figure 6.6, Appendix E). 


\section{Denudation History}

The palaeotemperature information has been converted into equivalent amounts of denudation by using Equation 6.1, and the present-day heat-flow data. Because the amount of denudation is derived directly from the palaeotemperature data, the pattern of denudation is slightly different from the cooling histories shown in Figure 6.5 and 6.6. This is because the heat-flow varies spatially across the area. Lower heat-flow results in higher estimates of the amount of denudation, and the inverse for higher heat-flow values.

The resulting maps of the denudational history are shown in Figure 6.7 and 6.8 respectively. It is important to note that thermal modelling data can only determine cooling for a particular sample below $110^{\circ} \mathrm{C}$.

\section{Palaeotopography}

The palaeotopography maps shown in Figure 6.9 and 6.10 were calculated using a simple thin elastic plate model of the lithosphere with an effective elastic thickness of $25 \mathrm{~km}$. The palaeotopography for each time slice was calculated by backstacking the eroded section (as indicated in Figure 6.7 and 6.8) onto the present topography (Brown 1991), and allowing for isostasy.

It is important to note that the resulting palaeotopography does not include any transient changes in topography that have since dissipated (such as that caused by thermal boyancy along the early rifted margin). Nonetheless the reconstructed palaeotopography does provide some broad constraints of the style of past landscapes within the study area. 
Palaeotemperature $\left({ }^{\circ} \mathrm{C}\right)$
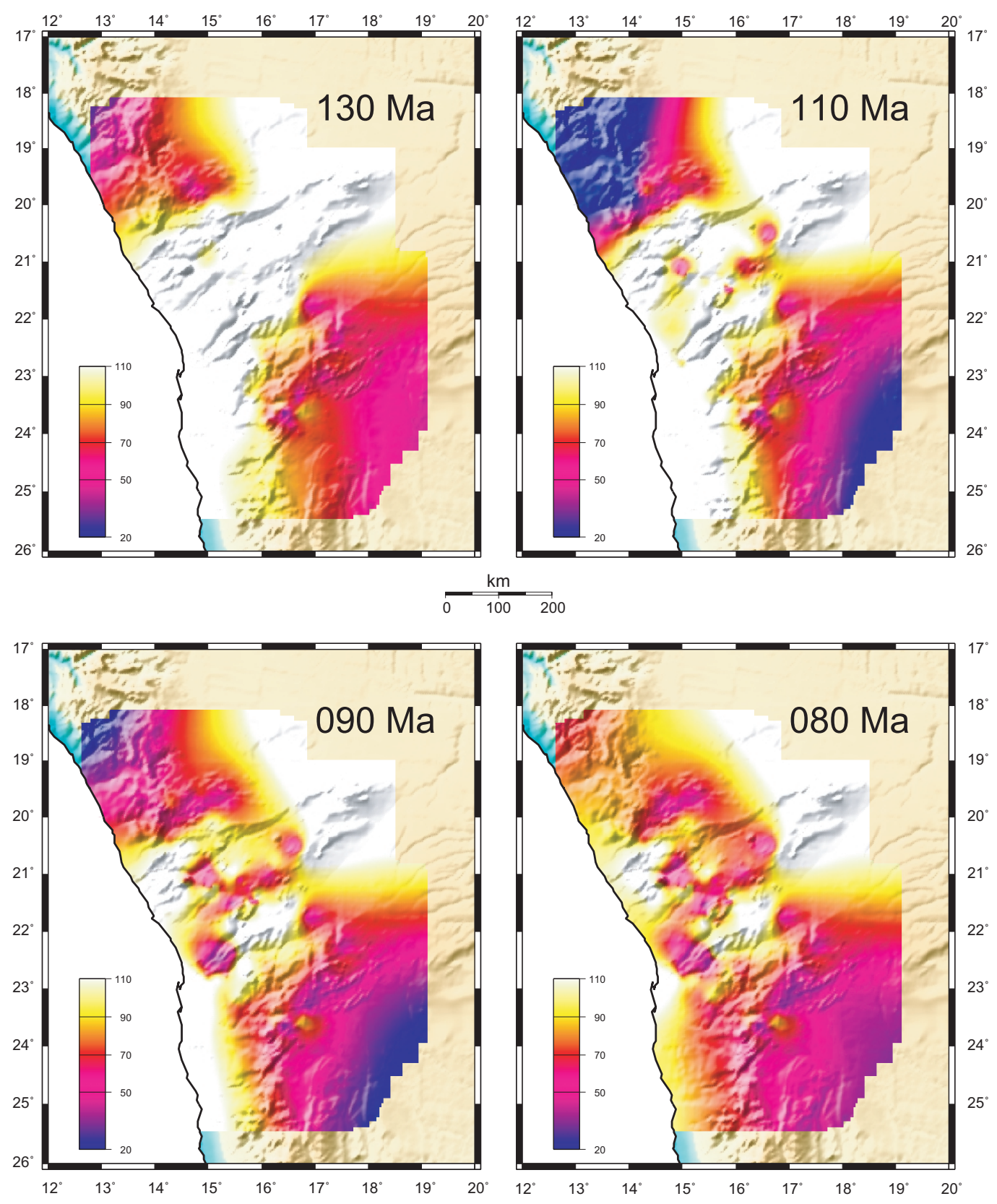

Figure 6.5: Reconstructed palaeotemperature maps for 130, 110, 90 and $80 \mathrm{Ma}$, based on the temperature history models derived from the apatite fission track data of this thesis. 
Palaeotemperature $\left({ }^{\circ} \mathrm{C}\right)$
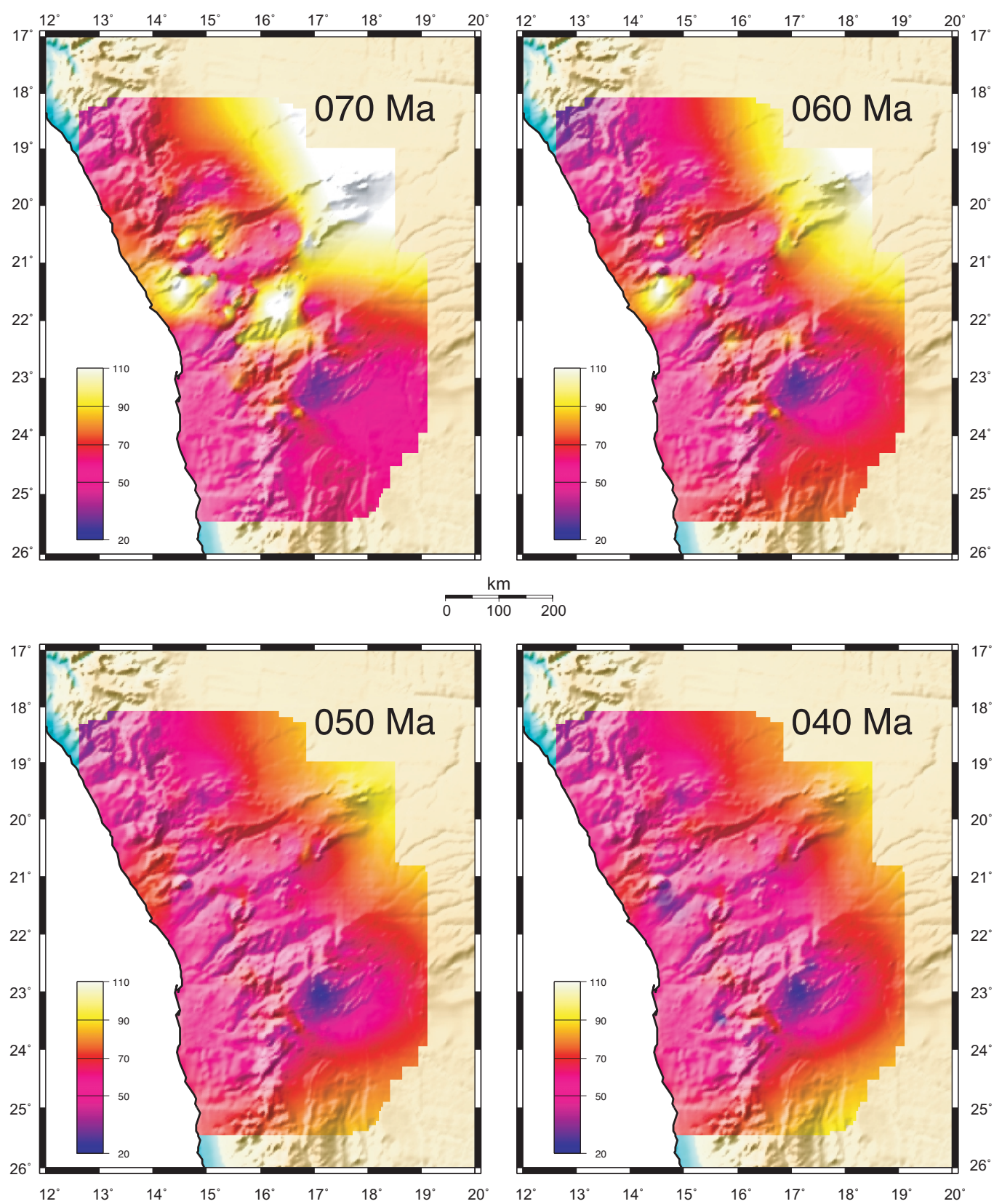

Figure 6.6: Reconstructed palaeotemperature maps for 70, 60, 50 and $40 \mathrm{Ma}$, based on the temperature history models derived from the apatite fission track data of this thesis. 


\section{Denudation $(\mathrm{km})$}
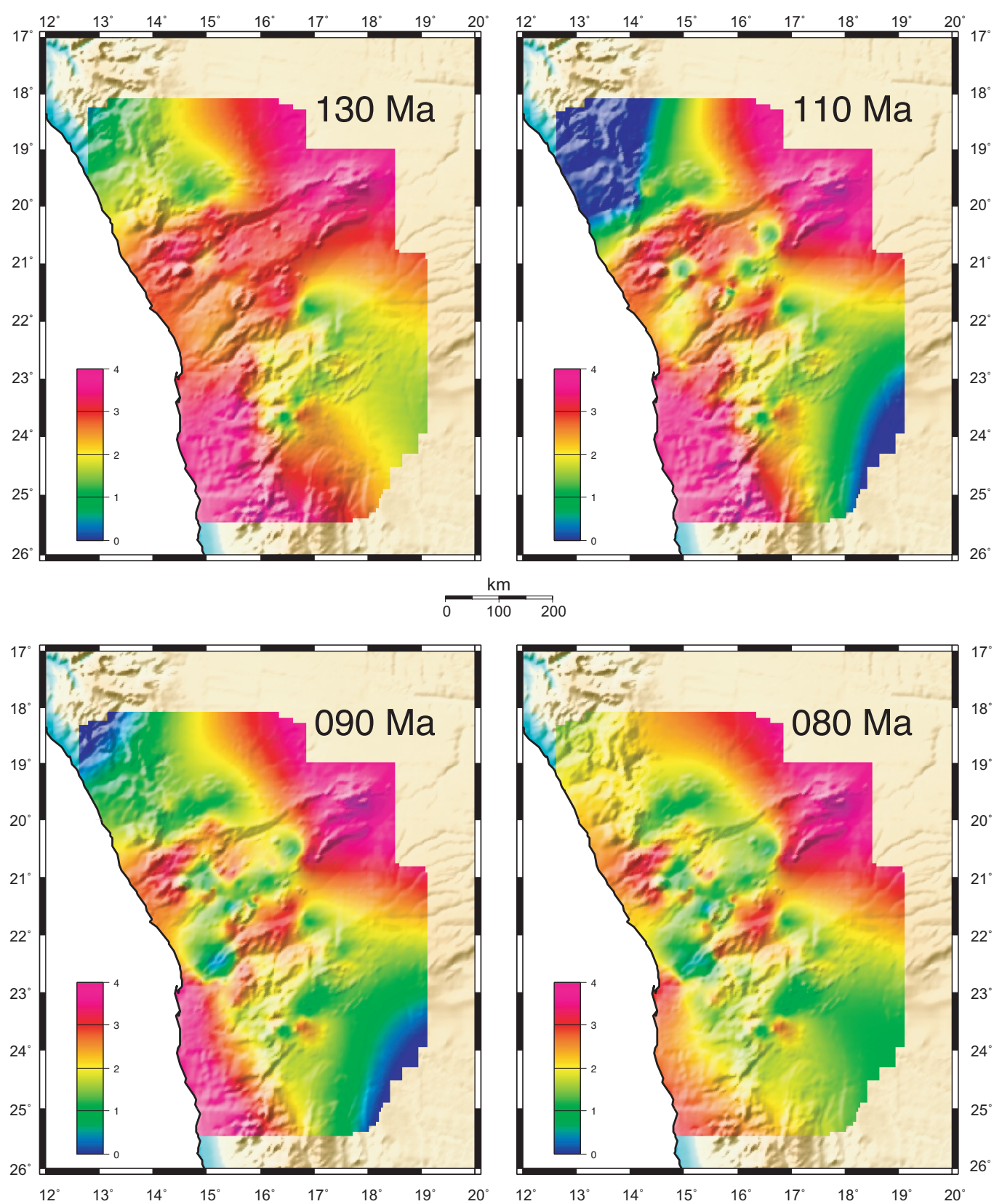

Figure 6.7: Reconstructed denudation maps for 130,110, 90 and $80 \mathrm{Ma}$, derived from the palaeotemperature maps, using the present-day heat-flow data of Namibia (Pollack et al. 1993). 


\section{Denudation $(\mathrm{km})$}
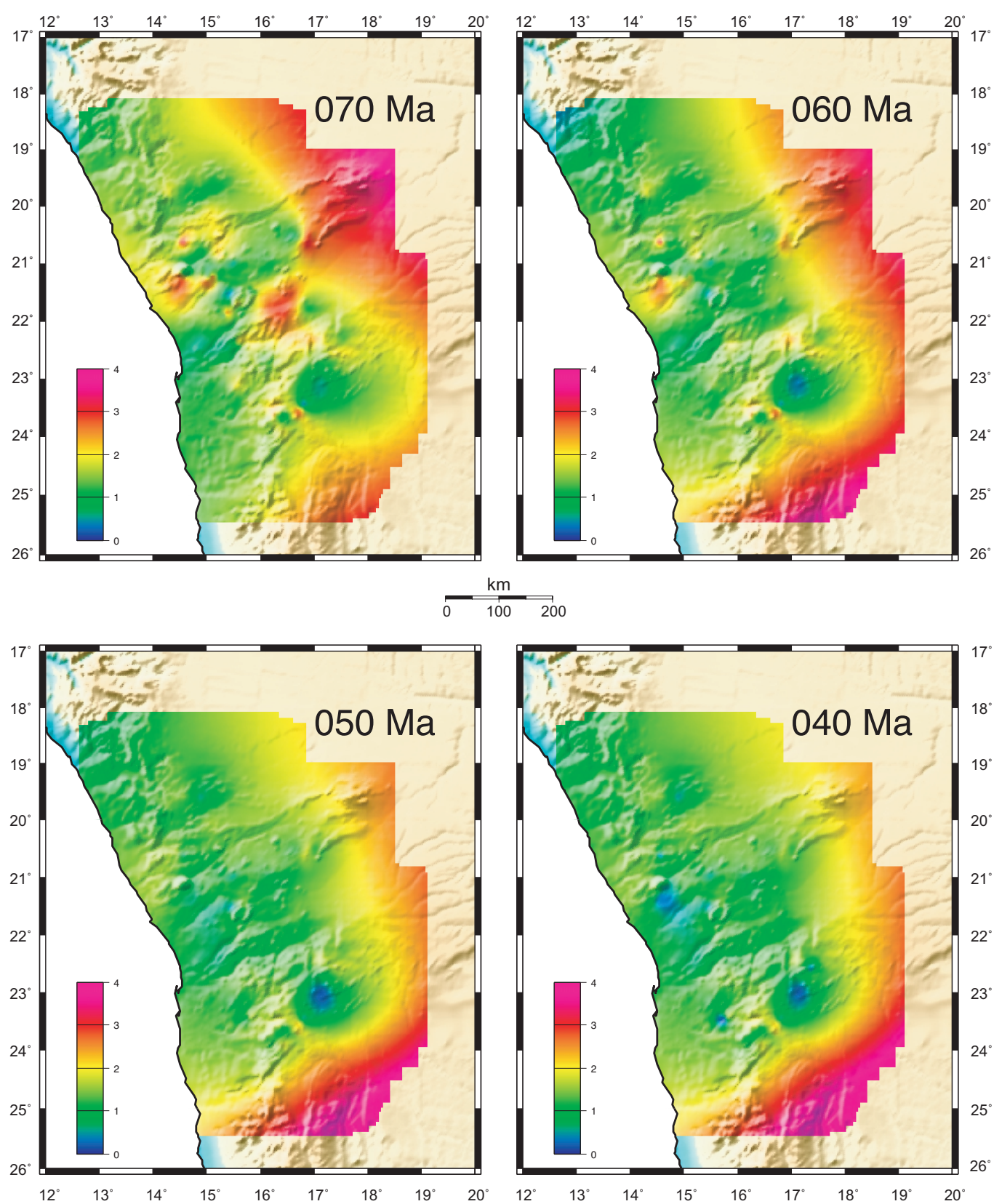

Figure 6.8: Reconstructed denudation maps for 70, 60, 50 and $40 \mathrm{Ma}$, derived from the palaeotemperature maps, using the present-day heat-flow data of Namibia (Pollack et al. 1993). 
Palaeotopography (Te=25 km)
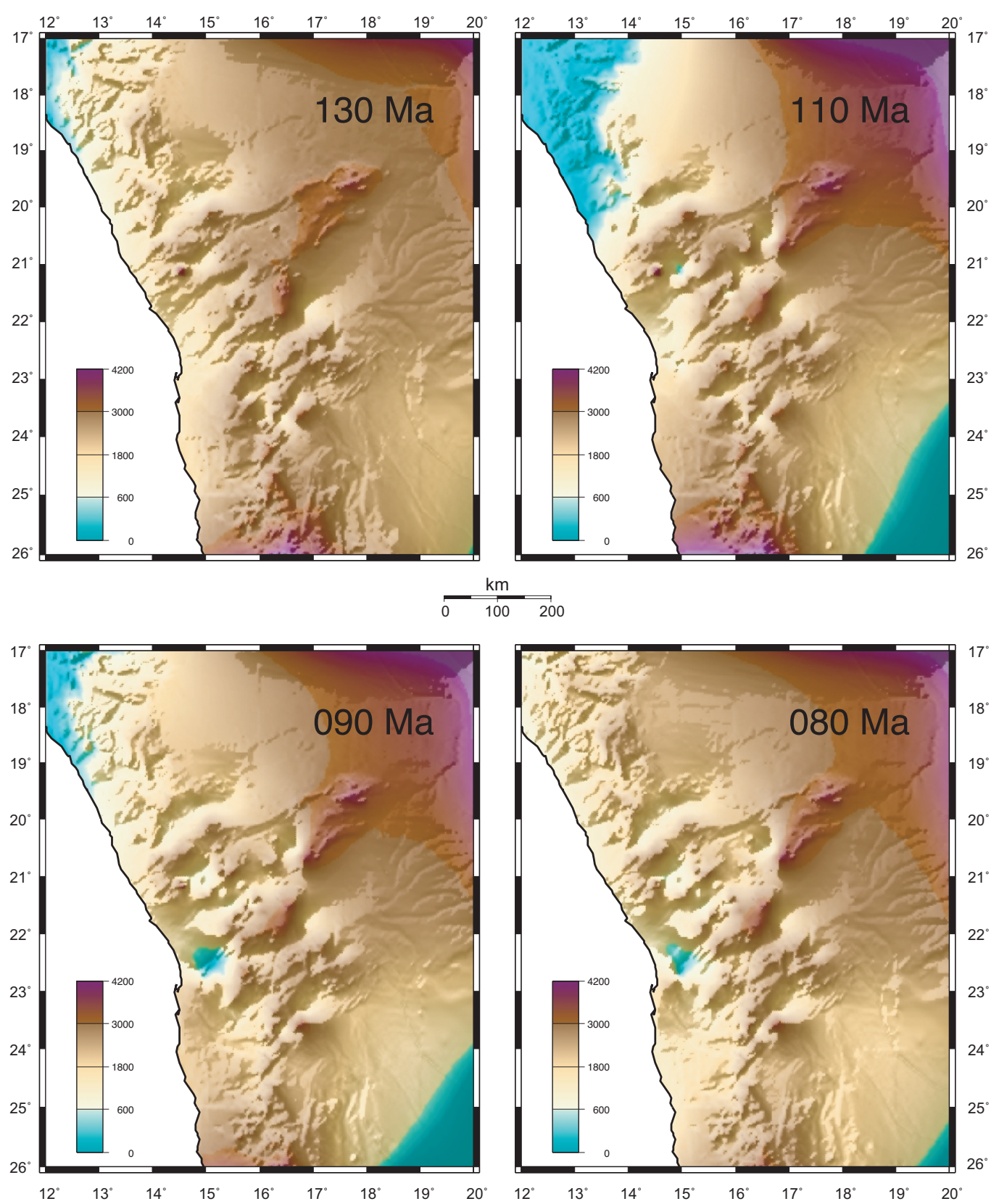

Figure 6.9: Reconstructed denudation maps for 130, 110, 90 and $80 \mathrm{Ma}$, calculated by loading the present-day topography with the estimated denudation, and adjusting for isostasy assuming $T e=25 \mathrm{~km}$. 
Palaeotopography (Te=25 km)
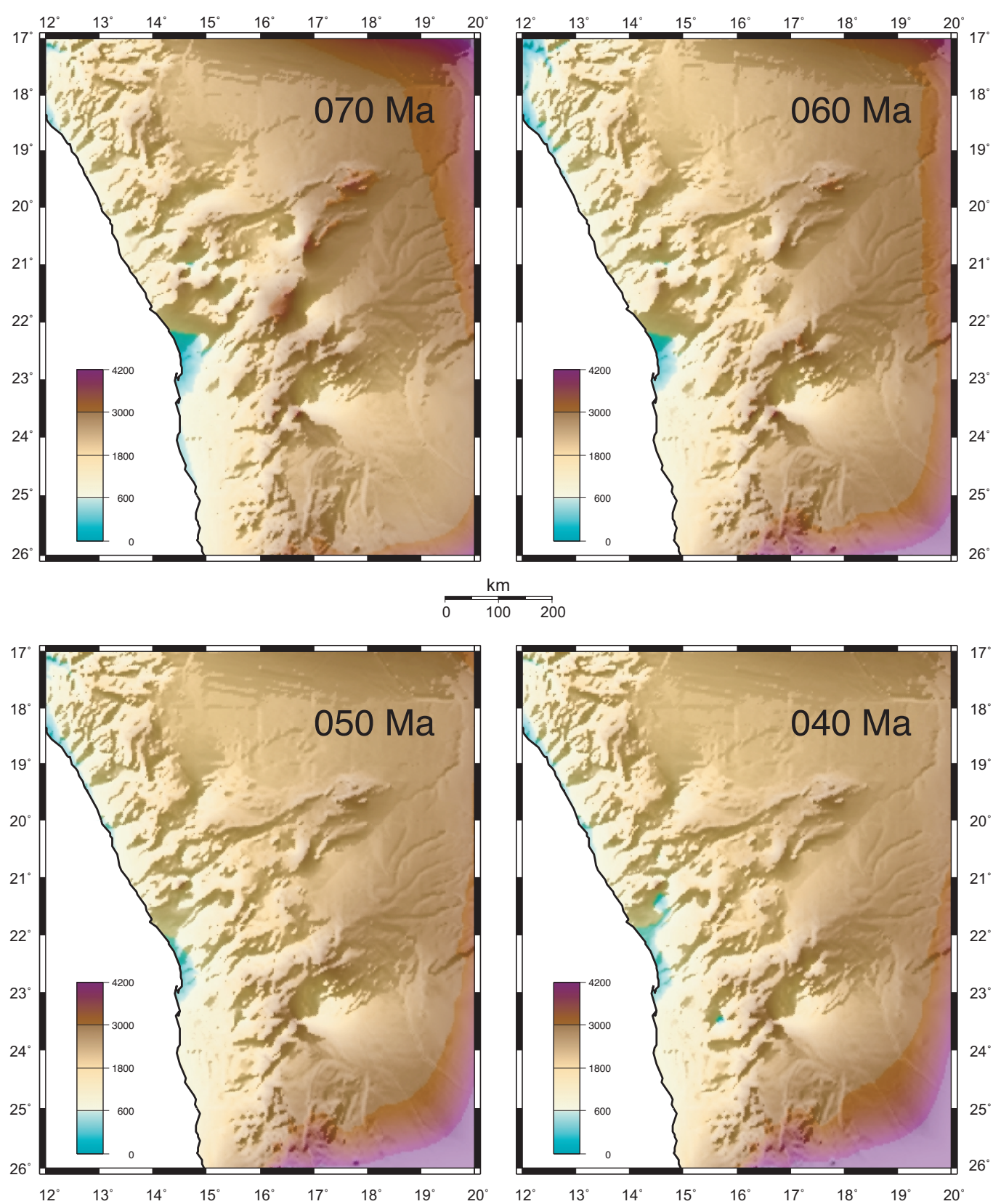

Figure 6.10: Reconstructed denudation maps for 70, 60, 50 and $40 \mathrm{Ma}$, calculated by loading the present-day topography with the estimated denudation, and adjusting for isostasy assuming $T e=25 \mathrm{~km}$. 


\subsection{Summary}

Denudation plays an important role in the evolution of the onshore regions of passive margins. Furthermore it represents a primary means of providing sediments to basins. Also, the structural history onshore, often manifested as discrete periods of locally enhanced denudation (Chapter 5), is likely to be reflected to a variable degree in the offshore basin (Clemson et al. 1997, Clemson et al. 1999). Consequently, denudation chronologies are of major importance for hydrocarbon exploration strategies. The record of this process, revealed by low temperature thermochronology data, has clearly shown that levels of denudation vary widely within and between different margins (Gallagher and Brown 1997). As shown above, apatite fission track analysis is an ideal methodology for determining the pattern of denudation through time across the onshore region of passive margins. These estimates can then be used to reconstruct the history of the onshore margin through time using thermal modelling techniques and transferring thermal history information into a denudational record (Gallagher and Brown 1997, Gallagher and Brown 1999a, Gallagher and Brown 1999b, Brown et al. 2000).

Because the youngest fission track ages in no way coincide with the timing of rifting or break-up, the reflection of the complex interaction between the generation of topography and the associated geomorphic response, later tectonic reactivation of major structures, and their influence on local denudation, can be inferred directly from apatite fission track data (Chapter 5).

Although these figures are extremely useful in visualising the overall trends in large regional data sets, they can only show the general trend of the data, and are not intended to replace the careful interpretation of samples on a local scale, such as discussed in Chapter 4 and 5. Nevertheless, the results from bulk-modelling clearly show typical passive margin signature (Gallagher and Brown 1997) for northern Namibia. They also demonstrate the complexity of denudation where reactivated structures are superimposed over the regional geomorphology.

These histories are best viewed using the animations provided in Appendix E. 


\section{Chapter 7}

\section{Concluding Statements and Ideas for Future Work}

Apatite fission track thermochronology data provide an independent and direct constraint on the spatial and temporal variations of denudation in onshore regions. The method allows the identification of major eroding source areas over time. With this information, a record of the cooling history can be established, potentially identifying offsets across major structures, as well as important periods of accelerated denudation and their distribution along the continental margin. Moreover, if vertical relief profiles are available, a palaeogeothermal gradient can be reconstructed.

This thesis has successfully contributed to understanding of the low temperature thermotectonic evolution of the passive margin of northern Namibia using apatite fission track thermochronology. The study presents a detailed regional examination with a new set of 158 apatite fission track ages which reveal temperature and denudation evolution since continental break-up. Samples were selected to analyse the cooling pattern of the crust in one- (Chapter 4), two- (Chapter 5), and three-dimensional space (Chapter 6).

In order to obtain site specific information about the cooling history in particular regions, three vertical relief profiles have been analysed. The thermal histories extracted from these profiles allowed the calculation of denudation rates, the net amount of denudation which occurred locally, and the determination of palaeogeothermal gradients (Chapter 4). The significance of this chapter is that palaeogeothermal gradients could successfully be revealed $\left(22-26^{\circ} \mathrm{C} / \mathrm{km}\right)$, and hence eliminates uncertainties in extrapolating present-day gradients into the past. This information is very important in that it provides a highly needed and so far unknown input parameter for the calculation of denudation. The net amount of denudation calculated for the Central Damara Zone is 4 to 5 kilometers, since the Late Cretaceous, for the Okenyenya and Brandberg complex respectively. De- 
nudation affecting the Highland in the Windhoekgraben area could also be tightly constrained to be on the order of 3.5 kilometers.

A key finding in applying apatite fission track analysis along a $550 \mathrm{~km}$ long transect across the major structures in northern Namibia was the determination of timing and magnitude of a vertical offset across the Omaruru Lineament-Waterberg Thrust (Chapter 5). The net vertical displacement of the crust could be calculated to be on the order of at least 2 kilometers. A particularly valuable outcome of this reseach was applying thermal modelling techniques to confidently quantify the uniform effect of a phase of accelerated denudation in the Late Cretaceous over the transect.

Advanced modelling procedures proved to be ideally suited to reveal the large scale trends, rates, and patterns of denudation in three-dimensions across northern Namibia (Chapter 6). The modelling results have not only shown the typical signature expected for passive margins, but they also revealed the complexity of denudation in the Central Damara Zone, where deep seated shear zones dominate the regional basement structure. Animations provide an optimum way of viewing the overall temperature and denudation evolution over time (Appendix E).

The information and ideas formulated and presented in this thesis represent a significant advance in our understanding of passive margin evolution of northern Namibia. They highlight the importance of considering the impact of pre-existing structures on the architecture and magnitude of denudation events.

Overall, the thesis highlights a number of opportunities for further research relating to both the specific study of northern Namibia and to the broader topic of linking tectonics with low temperature thermochronology.

Independent geological evidence suggests crustal reactivation post-dating rifting in northernmost Namibia particularly in the Kaokoveld area. However, the timing and magnitude of this is at present unknown. Research in this area is important because it may reveal structural control on the widely observed coast parallel cooling pattern at least in this area. Other areas that would benefit from the approach adopted in this thesis include southern Angola where the margin development is largely unconstrained.

Apatite fission track analysis is undoubtedly a useful tool for identifying large scale crustal offsets, but lower magnitude structural signatures may require greater resolution. U-Th/He apatite thermochronometry can provide complementary information on cooling histories below approximately $70^{\circ} \mathrm{C}$. Therefore it should be possible to reveal more subtle crustal offsets in northern Namibia as for example expected for the Autseib Fault (Section 2.2.2) by using a combined U-Th/He and apatite fission track approach.

For a fully comprehensive understanding of the thermotectonic and geomorphic evolution of passive margins it appears to be appropriate to combine the 
use of fission track analysis as demonstrated here with complementary techniques such as U-Th/He thermochronometry and cosmogenic isotope analysis. These techniques would help support the fission track results by providing site specific and shorter term information on denudation. This combination would lead to an improved conceptual model of margin development based on the insights into the complex interplay of tectonics and topography provided by fission track analysis. 


\section{Appendix A}

\section{Applied Statistics}

\section{A.1 Introduction}

The interpretation of fission track data is based on the statistical assessment of several different random samples, as there are, for example, the spontaneous and induced track densities, single grain ages, the track length distribution, the weighted mean of all zeta calibrations, the calculation of gradients (slopes of a regression line) as well as the estimates of timing and magnitude of cooling. The precision of these measurements has been calculated, and the assumption of a common true value has been tested, by standard methods, such as the $\chi^{2}$ test. This section reviews the applied statistics and error assessment used in this thesis. Further statistical reviews are given by (Galbraith 1981, Green 1981a, Galbraith 1985, Galbraith 1990b, Galbraith 1990c, Galbraith 1990a, Galbraith and Laslett 1993).

\section{A.2 The Chi-Square Test}

To test the presence of multiple populations in single grain ages, it is important that some measure of the dispersion of count data is given. For the external detector method the chi-square $\left(\chi^{2}\right)$ test detects the presence of uncertainty, additional to that allowed by Poisson variation in track counts (Galbraith 1981, Hurford 1990a). The chi-square distribution represents a random variable that is the sum of the squares of several independent normal random variables. This means that using the chi-square distribution to represent the sampling distribution for $s^{2}$ (sample variance) is theoretically valid only when the individual sample observations are taken from a normally distributed population. The chi-square serves as an approximation to the true sampling distribution, even when the population is not normal. 
The sampling distribution of sample variance $s^{2}$ is simplest to obtain by transforming the random variable into the chi-square statistic:

$$
\chi^{2}=\frac{(n-1) s^{2}}{\sigma^{2}}
$$

The chi-square distribution is specified by the number of degrees of freedom (df). When it is applied to making probability statements about $s^{2}, d f=n-1$. There are only $n-1$ degrees of freedom because in addition to the $n$ observed $X$ 's, $\bar{X}$ is used in calculating $s^{2}$, and 1 degree of freedom is lost in specifying the level for $\bar{X} . \sigma^{2}$ is the population variance. The chi-square test densities are positively skewed, with upper tails extending indefinitely, but the degree of skewness becomes less pronounced as the degrees of freedom increase (Laplin 1990).

The equation used to test the distribution of single grain ages with the chisquare test is given by Green (1981a):

$$
\chi^{2}=\sum_{j=1}^{n} \frac{\left(N_{s j}-\bar{N}_{s j}\right)^{2}}{\bar{N}_{s j}}+\sum_{j=1}^{n} \frac{\left(N_{i j}-\bar{N}_{i j}\right)^{2}}{\bar{N}_{i j}}
$$

where:

$$
\begin{aligned}
& \bar{N}_{s j}=\frac{N_{s}}{N_{s}+N_{i}}\left(N_{s j}+N_{i j}\right) \\
& \bar{N}_{i j}=\frac{N_{i}}{N_{s}+N_{i}}\left(N_{s j}+N_{i j}\right)
\end{aligned}
$$

with $N_{s j}$ and $N_{i j}$ are the total number of tracks $N_{j}$ of the $j$ th crystal and denote the measurements in crystals containing spontaneous and induced tracks respectively.

\section{A.3 Method of Least Squares}

To achieve a best curve fit with a line through a set of $n$ data points, the method of least squares normally applies. The principle of the least squares may be expressed as: the most probable value of any observed quantity is such that the sum of the squares of the deviations of the observations from this value is least (Topping 1972). If a model is assumed of the form of $y=a+b x$ with numbering the values $y_{i}$ and $x_{i}$ from $i=1$ to $n$, there will:

$$
y_{i}=a+b x_{i}+e
$$

where $e$ denotes random errors. The random errors are assumed to be independent and normally distributed with mean zero and constant variance $\sigma^{2}$. 
The parameters a and b are (usually) estimated by the method of least squares, such that the sum of the squared deviations from the line is as small as possible. That is, given if:

$$
\sum_{i=1}^{n}\left(y_{i}-a-b x_{i}\right)^{2}
$$

is a minimum. This gives:

$$
a=y-b x
$$

and:

$$
b=\frac{\sum\left(x_{i}-\bar{x}\right)\left(y_{i}-\bar{y}\right)}{\sum\left(x_{i}-\bar{x}\right)^{2}}
$$

It is also necessary to estimate the variance, given as:

$$
\sigma^{2}=\frac{\sum\left(y_{i}-a-b x_{i}\right)^{2}}{n-2} .
$$

\section{A.4 Weighted Mean}

Because observations occur with frequencies $f_{1}, f_{2}, \ldots, f_{n}$ respectively, the most probable value of a measured quantity is the weighted mean of the observations:

$$
\left(f_{1} x_{1}+f_{2} x_{2}+\ldots+f_{n} x_{n}\right) /\left(f_{1}+f_{2}+\ldots+f_{n}\right)
$$

In such an expression $f_{s}$ is known as the weight of the observation $x$. If:

$$
\bar{x}_{w}=\frac{\sum_{s=1}^{n} f_{s} x_{s}}{\sum_{s=1}^{n} f_{s}}
$$

is written, then $\bar{x}_{w}$ is the weighted mean of the observations with each value weighted according to the frequency of its occurrence.

In the above derivation the weight equals the frequency of occurrence of the observation, but in other cases the weight is attributed by the accuracy of the observation. Thus, each observation $x_{j}$ can be given a weight proportional to the reciprocal of the square of the standard error $\alpha$ of the individual measurements:

$$
\bar{x}_{w}=\frac{\sum_{j=1}^{j} x_{j} / \alpha_{j}^{2}}{\sum_{j=1}^{j} 1 / \alpha_{j}^{2}}
$$


The standard error $\alpha$ of the weighted mean itself is given as:

$$
\alpha=\frac{\sigma}{\sqrt{n}}
$$

with the variance $\sigma^{2}$ :

$$
\sigma^{2}=\sum_{s=1}^{n}\left(x_{s}-\bar{x}\right)^{2} /(n-1)
$$

and subsequently the standard deviation $\sigma$ as:

$$
\sigma=\left[\frac{\sum\left(x_{s}-\bar{x}\right)^{2}}{(n-1)}\right]^{\frac{1}{2}}
$$




\section{Appendix B}

\section{Sample Preparation and Experimental Conditions}

\section{B.1 Introduction}

All samples were collected from the study area in central and northern Namibia. Core samples were selected to maximise apatite yields where possible. A global positioning system (GPS) was used in conjunction with geological (1:250000) and topographic (1:250000 and 1:50000) maps. Sample elevations were determined using a barometric altimeter with an estimated error of $\pm 50 \mathrm{~m}$. Samples were prepared for apatite fission track dating, using conventional mineral separation and preparation techniques (Green 1985, Green et al. 1986, Ravenhurst and Donelick 1992).

To obtain individual apatite grain ages the external detector method (Gleadow and Lovering 1977) was used. Twenty crystals and one hundred horizontal confined track lengths were dated and measured per sample when possible. Samples were send to the Australian HIFAR reactor for neutron irradiation. An automated stage system was used in conjunction with a Zeiss Axiotron microscope at 1250x magnification to determine track densities and measure horizontal confined track length. Chlorine concentration of apatite grains was determined using a JEOL JXA-5A microprobe. Thermal history modelling was accomplished using the approach described by Gallagher (1995). The entire process from mineral separation, data analysis, modelling and interpretation was carried out with the Fission Track Research Group at La Trobe University, Bundoora, Australia (1998 - 1999) and The University of Melbourne, Australia (1999 - 2001). 


\section{B.2 Sample Preparation}

Rock samples of ca. $5 \mathrm{~kg}$ were chosen from predominantly granitic rocks since they normally yield abundant apatite of reasonable uranium concentration. After applying jawcrusher and discmill, a Wilfley mineral separation table was used to remove the very fine fraction of dust and clay to obtain a pre-selection of heavy minerals and to reduce the amount of material used in following separation procedures. Samples were dried usually over night in an oven at ca. $54^{\circ} \mathrm{C}$. Magnetic and heavy liquid techniques were used to finally concentrate apatites in the 63-250 $\mu \mathrm{m}$ size range. If necessary, separates were further purified in a centrifuge using sodium polytungstate at $3,0 \mathrm{~g} / \mathrm{cm}^{3}$. Apatite yields were highly variable from very few grains to in excess of $10 \mathrm{~g}$, whereas less than $50 \mathrm{mg}$ of apatite were required for the mounting procedure (Fig. B.1).

Apatite grains were mounted on a glass slide in a drop of epoxy (Petropoxy ${ }^{\mathrm{TM}}$ ). A very fine film of epoxy was spread over a marked area of about $1 \cdot 1,5 \mathrm{~cm}$ before a small fraction of apatite grains $(\sim 10 \mathrm{mg})$ were poured over the epoxy. To enable the grains to be in an optimal distribution and separated from each other, they were distributed evenly by using a binocular and a clean needle. After curing a few minutes over a hotplate $\left(120^{\circ} \mathrm{C}\right)$, a thicker layer of epoxy was spread on top of the previous, hardened layer, so that a greater area was covered. For curing completely the samples were left for another $\sim 15$ minutes on the hotplate.

To expose a maximum area of internal apatite crystal surfaces from a maximum number of grains, the mounted slides were ground gradually and polished in water. For grinding, 600 and 1200 grade silicon carbide papers were used. The slides were polished with $1,0 \mu \mathrm{m}$ and with $0,3 \mu \mathrm{m}$ alumina powder for $\sim 2$ minutes. The polished mounts were then etched in $5 \mathrm{M} \mathrm{HNO}$ for $20 \mathrm{~s}$ at $20^{\circ} \mathrm{C}$, rinsed in water to stop etching and washed, first in water plus detergent, and then with alcohol. Each mount was examined after etching to ensure suitability for fission track dating and confined track length measurements. The apatite mounts were cut and ground down to $1 \cdot 1,5 \mathrm{~cm}$ rectangles. Low uranium muscovite external detectors (Brazilian Ruby Clear muscovite precut to $0,4 \cdot 1,4 \mathrm{~mm}$ ) were attached in close contact to apatite mounts using plastic shrink wrap. To monitor induced fission of ${ }^{235} \mathrm{U}$ during irradiation, muscovite detectors were also attached to standard glasses of known uranium content. This is necessary to calculate $\rho D$, uranium concentration of grains, and a possible flux gradient within each can during irradiation.

Samples (10 - 15) were packed into aluminum irradiation cans with two CN5 standard glasses $(12,5 \mathrm{ppm} \mathrm{U})$ at the top and bottom of the pile. Neutron irradiations were carried out in the well-thermalised X7 position of the Hi Flux Australian Reactor (HIFAR) at Lucas Heights, New South Wales, Australia. A nominal neutron fluence of $1,6 \cdot 10^{16} \mathrm{n} / \mathrm{cm}^{2}$ was requested for each can.

After irradiation, samples were given two to three months time to 'cool down' 
in order to reach acceptable radiation levels. Before unwrapping, pin pricks were placed through muscovite detector and mount, to enable later stage alignment and identification of adjacent tracks in print. Muscovite sheets (from mount and standard glasses) were etched, using $40 \%$ hydrofloric acid (HF) for 20 minutes at room temperature $\left(23^{\circ} \mathrm{C}\right)$. Both samples and muscovite detectors were mounted on a 2,5 $\cdot 7,5 \mathrm{~cm}$ glass microscope slide, using Petropoxy ${ }^{\mathrm{TM}}$. Standard glass muscovite external detectors were etched and mounted accordingly (Fig. B.2).

\section{B.3 Experimental Conditions}

\section{B.3.1 Fission Track Dating}

Spontaneous and induced fission tracks were counted using a Zeiss Axiotron optical microscope at $1250 \mathrm{x}$ magnification with dry lenses. The microscope was equipped with a computer controlled automated stage system. The FT-Stage ${ }^{\mathrm{TM}}$ system matches grains with their prints on the external detector. All fission tracks were counted under the same conditions, using $100 \mathrm{x}$ dry objectives, an optovar set at $1.25 \mathrm{x}$ and $10 \mathrm{x}$ oculars, giving a total magnification of $1250 \mathrm{x}$. The Zeiss Axiotron microscope had transmitted and reflected light capabilities. The accuracy of the FT-Stage system to move from grain to print was approximately $\pm 5 \mu \mathrm{m}$. Manual adjustments were made when necessary.

After aligning the slide, the mount was scanned for countable grains. Before counting a grain, the quality was reassessed in observing the grain in transmitted and reflected light, to ensure that the grain's surface was oriented parallel to the crystallographic c-axis, and free of dislocations. Parallelity to c-axis is indicated by sharp polishing scratches and parallel track etch pits. Grains were counted in order of occurrence of good quality grains during scanning, to avoid an operatorcaused bias in the random selection of countable grains. If possible, twenty grains were dated, and identical areas were counted on the grain and its print. This was monitored with a $10 \times 10$ grid of $1 \mathrm{~mm}$ squares fitted to one eye piece of the microscope. Spontaneous tracks were counted in transmitted light; reflected light was only used to aid in track identification. In the case of very high induced track densities in mica, etch pits were counted under reflected light, and if in doubt transmitted light was used to aid identification.

Standard glass external detectors were counted under the same conditions to determine $\rho D$ for an irradiation package. Twentyfive fields of the full $10 \cdot 10$ grid were counted across each standard glass external detector. Flux gradients were assumed to be linear, and $\rho D$ values were calculated for each mount.

Ages were calculated with MacTrack and represented by the central age with percentage variation. MacTrack output files with raw track counts $\left(\mathrm{N}_{s}\right.$ and $\left.\mathrm{N}_{i}\right)$, 
$\rho D, \rho_{s}$ and $\rho_{i}$ values, individual grain ages and summary plots, are shown in Appendix C.

\section{B.3.2 Track Length Measurements}

Horizontal confined track lengths were measured following the recommendations by Laslett et al. (1982), the most important being that only horizontal confined tracks are to be measured. Such tracks can easily be identified by the strong reflection obtained from them when viewed in reflected light, or by the constancy of focus along their lengths, using a high power objective in transmitted light. Therefore, all measured confined track lengths for this thesis were taken exclusively from grains parallel c-axis. This is of great importance because of the anisotropy of the annealing process in apatite, whereby tracks oriented parallel to the c-axis are more resistant to annealing, and are therefore longer than tracks perpendicular to c-axis (Laslett et al. 1984, Green 1981b).

Track lengths were measured by recording the position of each end of a confined track using a mouse with LED attachment, based on a Zeiss drawing tube attached to the microscope and a CalComp ${ }^{\mathrm{TM}}$ DrawingBoard ${ }^{\mathrm{TM}}$ connected with the FT-Stage system. Magnification for length measurements was the same for track counting.

In each sample the length of at least 100 confined tracks were measured wherever possible. No distinction has been drawn between tracks-in-track (TINT) and tracks-in-crack (TINC) (Laslett et al. 1982).

\section{B.3.3 Calibration}

Microscope calibration was carried out by counting the number of lines on an accurately ruled diffraction grating for the $10 \cdot 10$ eye grid.

Track length calibration was accomplished by measuring unannealed Fish Canyon, Durango, Mount Dromedary apatites, and test samples from different operators of known length distribution. A personal correction parameter was obtained by repeatedly measuring the distance of $20 \mu \mathrm{m}$ on the accurately ruled diffraction grating.

The personal zeta $(\zeta)$ calibration factor was established by counting age standards and substituting $\rho_{s}, \rho_{i}$ and $\rho D$ into equation 3.8. As age standards served (in Ma): Fish Canyon Tuff (27.8 \pm 0.1 ), Durango (31.4 \pm 0.5$)$ and Mount Dromedary (98.7 \pm 0.6$)$. The weighted mean of $378.8 \pm 5.5$ was calculated for 22 zeta determinations on standards. Prior to calculation of zeta, numerous apatite samples and standard glass micas were counted to perfect track recognition and grain selection 
techniques. After completion of zeta calibration, numerous real samples from different operators were counted for final training.

\section{B.3.4 Microprobe Analysis}

Microprobe analyses were done by Geotrack International, Vic., Australia, to determine the weight percent chlorine of apatite. Analyses were carried out on selected samples on grains of known fission track age. All grains considered for fission track dating were probed if a sample was chosen. Microprobe results are quoted as weight percent chlorine. 


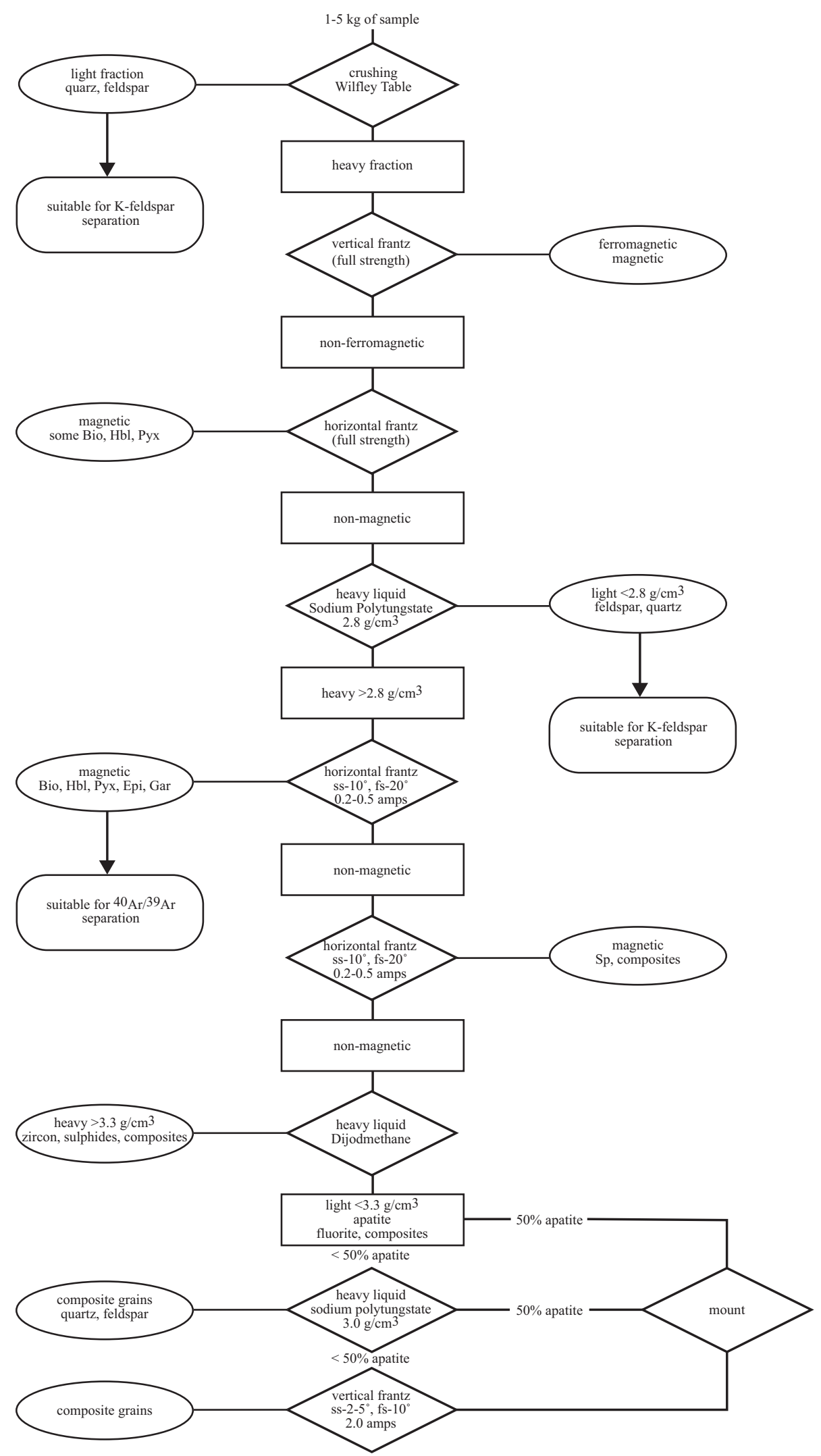

Figure B.1: Flow chart of apatite separation after Tingate 1990 and Noble 1997. 


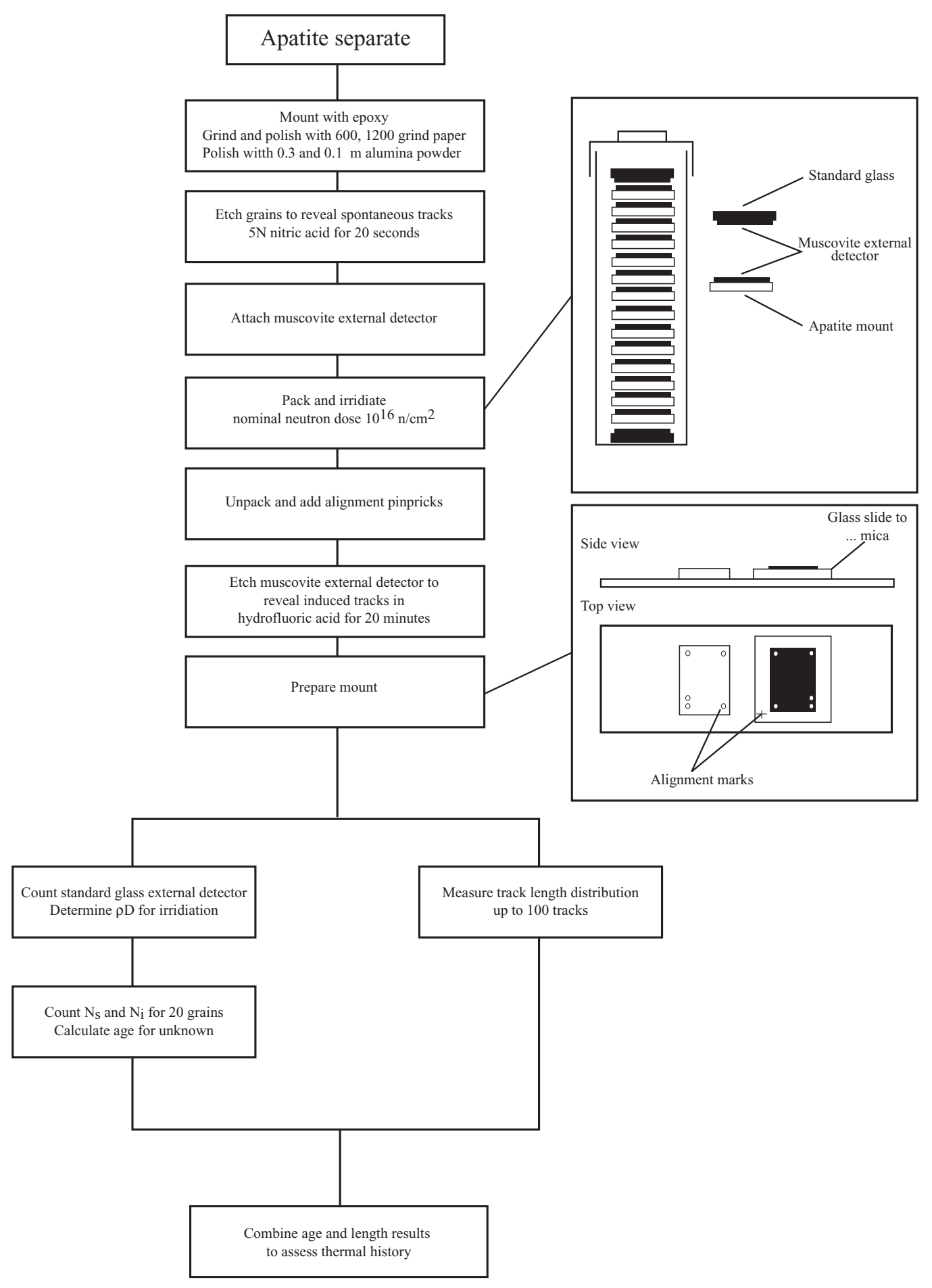

Figure B.2: Flow chart of mounting procedure for apatite fission track dating (after Noble 1997). 


\section{Appendix C}

\section{Fission Track Data Files}

Samples in this appendix are arranged in two different ways: Data in Table C.1 are listed in order of sampling date (sample number equals sampling date plus order of samples taken). Irradiation code, localities (in decimal latitude longitude values), description of samples plus stratigraphic units and stratigraphic age are also listed in Table C.1.

Section C. 3 contains the fission track raw data for each sample, single grain ages, statistics and summary plots as described in Section 3.4.1. Samples are ordered according to their irradiation code. 


\section{C.1 Sample Localities and Descriptions}

Table C.1: Sample locations and descriptions

\begin{tabular}{|c|c|c|c|c|c|}
\hline Sample-No & Irrad-code & latitude & longitude & Sample description & Stratigraphic age \\
\hline $22-9-94-7^{1}$ & MU024-01 & & & Apatite crystals & $(?)$ \\
\hline $95 \mathrm{~N}-8^{2}$ & LU 436-03 & $20^{\circ} 838^{\prime}$ & $15^{\circ} 327^{\prime}$ & Oligoclase, Okenyenya & Cretaceous \\
\hline $95 \mathrm{~N}-9^{2}$ & LU 436-04 & $20^{\circ} 838^{\prime}$ & $15^{\circ} 322^{\prime}$ & Oligoclase, Okenyenya & Cretaceous \\
\hline $95 \mathrm{~N}-10^{2}$ & LU 436-05 & $20^{\circ} 84^{\prime}$ & $15^{\circ} 323^{\prime}$ & Oligoclase, Okenyenya & Cretaceous \\
\hline $95 \mathrm{~N}-11^{2}$ & LU 436-06 & $20^{\circ} 84$ & $15^{\circ} 323^{\prime}$ & Nepheline syenite, Okenyenya & Cretaceous \\
\hline $95 \mathrm{~N}-12^{2}$ & LU 436-07 & $20^{\circ} 843^{\prime}$ & $15^{\circ} 323^{\prime}$ & Evolved gabbro? Okenyenya & Cretaceous \\
\hline $95 \mathrm{~N}-13^{2}$ & LU 436-08 & $20^{\circ} 843^{\prime}$ & $15^{\circ} 323^{\prime}$ & Nepheline syenite, Okenyenya & Cretaceous \\
\hline $95 \mathrm{~N}-14^{2}$ & LU 436-09 & $20^{\circ} 847^{\prime}$ & $15^{\circ} 322^{\prime}$ & Syenite, Okenyenya & Cretaceous \\
\hline $95 \mathrm{~N}-15^{2}$ & LU 436-10 & $20^{\circ} 847^{\prime}$ & $15^{\circ} 322^{\prime}$ & Coarsed grained gabbro, Okenyenya & Cretaceous \\
\hline $95 \mathrm{~N}-16^{2}$ & LU 436-11 & $20^{\circ} 863^{\prime}$ & $15^{\circ} 293^{\prime}$ & Fayalite syenite (ring dyke), Okenyenya & Cretaceous \\
\hline $31-3-96-1$ & LU 570-01 & $23^{\circ} 523^{\prime}$ & $16^{\circ} 415^{\prime}$ & Dacitic gneiss & Proterozoic \\
\hline $1-4-96-3$ & LU 570-02 & $23^{\circ} 632^{\prime}$ & $16^{\circ} 283^{\prime}$ & Pixteel granite & Proterozoic \\
\hline $3-4-96-2$ & MU024-03 & $23^{\circ} 482^{\prime}$ & $15^{\circ} 76^{\prime}$ & Quartzite Gaub-Valley-Formation & Proterozoic \\
\hline $3-4-96-3$ & LU 570-03 & $23^{\circ} 476^{\prime}$ & $15^{\circ} 772^{\prime}$ & Quartzite Gaub-Valley-Formation & Proterozoic \\
\hline $3-4-96-4$ & MU024-04 & $23^{\circ} 422^{\prime}$ & $15^{\circ} 825^{\prime}$ & Rostock orthogneiss & Proterozoic \\
\hline $3-4-96-5$ & LU 570-04 & $23^{\circ} 302^{\prime}$ & $15^{\circ} 781^{\prime}$ & Quartzite Kuiseb-Schists & Proterozoic \\
\hline $3-4-96-6$ & MU024-05 & $23^{\circ} 304^{\prime}$ & $15^{\circ} 774^{\prime}$ & Quartzite Kuiseb-Schists & Proterozoic \\
\hline $3-4-96-7$ & MU024-06 & $23^{\circ} 302^{\prime}$ & $15^{\circ} 763^{\prime}$ & Quartzite mica-rich & Proterozoic \\
\hline $3-4-96-8$ & MU024-07 & $23^{\circ} 31^{\prime}$ & $15^{\circ} 505^{\prime}$ & Quartzite mica-rich & Proterozoic \\
\hline $5-4-96-1$ & MU024-08 & $22^{\circ} 811^{\prime}$ & $14^{\circ} 893^{\prime}$ & Pegmatite & Cretaceous (?) \\
\hline $5-4-96-2$ & LU 570-05 & $22^{\circ} 724^{\prime}$ & $14^{\circ} 957^{\prime}$ & Orthogneiss pre-Damara basements & Proterozoic \\
\hline $5-4-96-3$ & LU 570-06 & $22^{\circ} 712^{\prime}$ & $14^{\circ} 961^{\prime}$ & Abbabis-Gneiss & Proterozoic \\
\hline $5-4-96-4$ & LU 570-07 & $22^{\circ} 667^{\prime}$ & $15^{\circ} 086^{\prime}$ & Pegmatite & Cretaceous (?) \\
\hline $5-4-96-5$ & LU 570-08 & $22^{\circ} 619^{\prime}$ & $15^{\circ} 356^{\prime}$ & Salem-Granite & Prot.-Camb. \\
\hline $5-4-96-6$ & LU 570-09 & $22^{\circ} 379^{\prime}$ & $15^{\circ} 494^{\prime}$ & Etusis-Sandstone & Proterozoic \\
\hline $5-4-96-7$ & MU024-09 & $22^{\circ} 44^{\prime}$ & $15^{\circ} 622^{\prime}$ & Salem-Granite & Prot.-Camb. \\
\hline $5-4-96-8$ & LU 570-10 & $22^{\circ} 514^{\prime}$ & $15^{\circ} 593^{\prime}$ & Salem-Granite & Prot.-Camb. \\
\hline $7-4-96-1$ & LU 570-11 & $22^{\circ} 82^{\prime}$ & $15^{\circ} 167^{\prime}$ & Salem-Granite & Prot.-Camb. \\
\hline $7-4-96-2$ & LU 570-12 & $22^{\circ} 728^{\prime}$ & $15^{\circ} 399^{\prime}$ & Salem-Granite & Prot.-Camb. \\
\hline $7-4-96-3$ & LU $570-13$ & $22^{\circ} 744^{\prime}$ & $15^{\circ} 357^{\prime}$ & Salem-Granite & Prot.-Camb. \\
\hline $7-4-96-4^{3}$ & LU 570-14 & & & Salem-Granite & Prot.-Camb. \\
\hline 7-4-96-5 & MU024-10 & $23^{\circ} 146^{\prime}$ & $15^{\circ} 517$ & Donkerhoek-Granite & Proterozoic \\
\hline $7-4-96-6$ & LU 570-15 & $23^{\circ} 111^{\prime}$ & $15^{\circ} 305^{\prime}$ & Donkerhoek-Granite & Proterozoic \\
\hline $7-4-96-7$ & MU024-11 & $23^{\circ} 057^{\prime}$ & $14^{\circ} 99^{\prime}$ & Salem-Granite & Prot.-Camb. \\
\hline $11-4-96-1$ & MU024-12 & $21^{\circ} 185^{\prime}$ & $14^{\circ} 542^{\prime}$ & Brandberg-Granite & Cretaceous \\
\hline $11-4-96-2$ & MU024-13 & $21^{\circ} 185^{\prime}$ & $14^{\circ} 541^{\prime}$ & Brandberg-Granite & Cretaceous \\
\hline $12-4-96-1$ & MU024-14 & $21^{\circ} 191^{\prime}$ & $14^{\circ} 532^{\prime}$ & Brandberg-Granite & Cretaceous \\
\hline $12-4-96-2$ & MU024-15 & $21^{\circ} 193^{\prime}$ & $14^{\circ} 529^{\prime}$ & Brandberg-Granite & Cretaceous \\
\hline $12-4-96-3$ & MU025-01 & $21^{\circ} 195^{\prime}$ & $14^{\circ} 527^{\prime}$ & Brandberg-Granite & Cretaceous \\
\hline $12-4-96-4$ & MU025-02 & $21^{\circ} 222^{\prime}$ & $14^{\circ} 517^{\prime}$ & Brandberg-Granite & Cretaceous \\
\hline $12-4-96-5$ & MU025-03 & $21^{\circ} 222^{\prime}$ & $14^{\circ} 517^{\prime}$ & Brandberg-Granite & Cretaceous \\
\hline $13-4-96-1$ & MU025-04 & $21^{\circ} 233^{\prime}$ & $14^{\circ} 511^{\prime}$ & Brandberg-Granite & Cretaceous \\
\hline $13-4-96-6$ & LU 575-10 & $21^{\circ} 435^{\prime}$ & $14^{\circ} 206^{\prime}$ & Syenite & Cretaceous \\
\hline $22-4-96-2$ & MU025-06 & $23^{\circ} 662^{\prime}$ & $16^{\circ} 18^{\prime}$ & Gneiss & Proterozoic \\
\hline $26-4-96-1$ & MU025-07 & $20^{\circ} 68^{\prime}$ & $16^{\circ} 794^{\prime}$ & Granite & Proterozoic \\
\hline $26-4-96-2$ & LU 571-01 & $20^{\circ} 529^{\prime}$ & $16^{\circ} 699^{\prime}$ & Granite & Proterozoic \\
\hline $26-4-96-4$ & LU 571-02 & $20^{\circ} 976^{\prime}$ & $16^{\circ} 129^{\prime}$ & Granite & Proterozoic \\
\hline $27-4-96-1$ & MU025-08 & $21^{\circ} 687^{\prime}$ & $15^{\circ} 552^{\prime}$ & Intermediate igneous rock & Cretaceous \\
\hline $28-4-96-1$ & LU 571-03/04 & $21^{\circ} 491^{\prime}$ & $15^{\circ} 749^{\prime}$ & Egls granodiorite, syntectonic & Proterozoic \\
\hline $28-4-96-2$ & MU025-09 & $21^{\circ} 448^{\prime}$ & $15^{\circ} 885^{\prime}$ & Granite & Proterozoic \\
\hline $28-4-96-3$ & MU025-10 & $21^{\circ} 535^{\prime}$ & $15^{\circ} 484^{\prime}$ & Granite & Proterozoic \\
\hline $28-4-96-4$ & LU 571-05 & $21^{\circ} 36^{\prime}$ & $15^{\circ} 423^{\prime}$ & Granite & Proterozoic \\
\hline $28-4-96-5$ & LU 571-06 & $21^{\circ} 277^{\prime}$ & $15^{\circ} 225^{\prime}$ & Granite & Proterozoic \\
\hline
\end{tabular}


Table C. 1 continued from previous page

\begin{tabular}{|c|c|c|c|c|c|}
\hline Sample-No & Irrad-code & latitude & longitude & Sample description & Stratigraphic age \\
\hline $28-4-96-6$ & LU 571-07 & $21^{\circ} 227^{\prime}$ & $15^{\circ} 056^{\prime}$ & Granite & Proterozoic \\
\hline $30-4-96-1$ & LU 571-08 & $21^{\circ} 029^{\prime}$ & $14^{\circ} 902^{\prime}$ & Granite & Proterozoic \\
\hline $30-4-96-2$ & LU 571-09 & $20^{\circ} 877^{\prime}$ & $14^{\circ} 984^{\prime}$ & Granite & Proterozoic \\
\hline $30-4-96-3$ & LU 571-10 & $20^{\circ} 738^{\prime}$ & $14^{\circ} 845^{\prime}$ & Granite & Proterozoic \\
\hline $1-5-96-1$ & LU 571-11 & $20^{\circ} 418^{\prime}$ & $14^{\circ} 312^{\prime}$ & Granite & Proterozoic \\
\hline $1-5-96-2$ & LU 571-12 & $19^{\circ} 833^{\prime}$ & $14^{\circ} 144^{\prime}$ & Basalt & Cretaceous \\
\hline $1-5-96-3$ & LU 571-13 & $19^{\circ} 759^{\prime}$ & $14^{\circ} 284^{\prime}$ & Granite & Proterozoic \\
\hline $1-5-96-4$ & LU 571-14 & $19^{\circ} 595^{\prime}$ & $14^{\circ} 652^{\prime}$ & Granite & Proterozoic \\
\hline $5-5-96-1$ & MU025-11 & $21^{\circ} 897^{\prime}$ & $16^{\circ} 434^{\prime}$ & Granite & Proterozoic \\
\hline $5-5-96-2$ & LU 571-15 & $21^{\circ} 934^{\prime}$ & $16^{\circ} 685^{\prime}$ & Granite & Proterozoic \\
\hline $11-8-97-1^{1}$ & LU 572-01 & $22^{\circ} 639^{\prime}$ & $16^{\circ} 729^{\prime}$ & & \\
\hline $17-9-96-9$ & LU 575-09 & $22^{\circ} 196^{\prime}$ & $14^{\circ} 896^{\prime}$ & Granite & Proterozoic \\
\hline 20-9-97-1 & MU025-12 & $22^{\circ} 434^{\prime}$ & $17^{\circ} 597^{\prime}$ & Basement gneiss, Seeisinlier & Proterozoic \\
\hline $20-9-97-2$ & MU025-13 & $22^{\circ} 337^{\prime}$ & $17^{\circ} 552^{\prime}$ & Basement gneiss, Seeisinlier & Proterozoic \\
\hline $20-9-97-3$ & MU025-14 & $22^{\circ} 341^{\prime}$ & $17^{\circ} 496^{\prime}$ & Basement gneiss, Seeisinlier & Proterozoic \\
\hline 21-9-97-1 & MU025-15 & $22^{\circ} 624^{\prime}$ & $17^{\circ} 377^{\prime}$ & Basement gneiss, Rietfonteininlier & Proterozoic \\
\hline $21-9-97-2$ & MU026-01 & $22^{\circ} 679^{\prime}$ & $17^{\circ} 415^{\prime}$ & Basement gneiss, Rietfonteininlier & Proterozoic \\
\hline $21-9-97-3$ & MU026-02 & $22^{\circ} 756^{\prime}$ & $17^{\circ} 443^{\prime}$ & Basement gneiss, Rietfonteininlier & Proterozoic \\
\hline 24-9-97-1 & LU 572-02 & $23^{\circ} 441^{\prime}$ & $16^{\circ} 56^{\prime}$ & Granite & Proterozoic \\
\hline $24-9-97-3$ & LU 572-03 & $23^{\circ} 361^{\prime}$ & $16^{\circ} 597^{\prime}$ & Basement rhyolite & Proterozoic \\
\hline 24-9-97-4 & LU 572-04 & $23^{\circ} 354^{\prime}$ & $16^{\circ} 658^{\prime}$ & Basement mylonite & Proterozoic \\
\hline $24-9-97-6$ & MU026-03 & $23^{\circ} 482^{\prime}$ & $16^{\circ} 691^{\prime}$ & Basement tuff & Proterozoic \\
\hline 24-9-97-7 & LU 572-05 & $23^{\circ} 529^{\prime}$ & $16^{\circ} 73^{\prime}$ & Basement gneiss & Proterozoic \\
\hline $24-9-97-8$ & LU 572-06 & $23^{\circ} 608^{\prime}$ & $16^{\circ} 686^{\prime}$ & Basement granite & Proterozoic \\
\hline $24-9-97-9$ & LU 572-07 & $23^{\circ} 696^{\prime}$ & $16^{\circ} 699^{\prime}$ & Basement granite & Proterozoic \\
\hline $24-9-97-10$ & MU026-04 & $23^{\circ} 775^{\prime}$ & $16^{\circ} 636^{\prime}$ & Basement pyroclast & Proterozoic \\
\hline 24-9-97-11 & MU026-05 & $23^{\circ} 855^{\prime}$ & $16^{\circ} 512^{\prime}$ & Basement Quartzite & Proterozoic \\
\hline $24-9-97-12$ & MU026-06 & $23^{\circ} 858^{\prime}$ & $16^{\circ} 457^{\prime}$ & Basement pyroclast & Proterozoic \\
\hline 25-9-97-1 & MU026-07 & $23^{\circ} 598^{\prime}$ & $16^{\circ} 405^{\prime}$ & Basement pyroclast & Proterozoic \\
\hline $25-9-97-2$ & MU026-08 & $23^{\circ} 614^{\prime}$ & $16^{\circ} 361^{\prime}$ & Basement granite & Proterozoic \\
\hline $25-9-97-3$ & MU026-09 & $23^{\circ} 648^{\prime}$ & $16^{\circ} 302^{\prime}$ & Basement granite & Proterozoic \\
\hline $25-9-97-5$ & MU026-10 & $23^{\circ} 767^{\prime}$ & $16^{\circ} 293^{\prime}$ & Basement granite & Proterozoic \\
\hline $25-9-97-6$ & MU026-11 & $23^{\circ} 794^{\prime}$ & $16^{\circ} 324^{\prime}$ & Pegmatite & $(?)$ \\
\hline $25-9-97-8$ & MU026-12 & $23^{\circ} 941^{\prime}$ & $16^{\circ} 192^{\prime}$ & Basement granite & Proterozoic \\
\hline $25-9-97-9$ & MU026-13 & $23^{\circ} 479^{\prime}$ & $16^{\circ} 769^{\prime}$ & Biotite schist, Kuiseb Formation & Proterozoic \\
\hline $25-9-97-10$ & MU026-14 & $23^{\circ} 255^{\prime}$ & $15^{\circ} 826^{\prime}$ & Rostock Granite & Proterozoic \\
\hline $25-9-97-12$ & MU026-15 & $23^{\circ} 343^{\prime}$ & $16^{\circ} 013^{\prime}$ & Sandstone & Proterozoic \\
\hline $26-9-97-3$ & MU027-01 & $23^{\circ} 364^{\prime}$ & $16^{\circ} 893^{\prime}$ & Sandstone & Proterozoic \\
\hline $26-9-97-6$ & MU027-02 & $22^{\circ} 985^{\prime}$ & $17^{\circ} 126^{\prime}$ & Quarzite & Proterozoic \\
\hline $28-9-97-1 \mathrm{~A}$ & MU027-03 & $22^{\circ} 47^{\prime}$ & $17^{\circ} 079^{\prime}$ & Biotite quarzite, Kuiseb Formation & Proterozoic \\
\hline $28-9-97-2$ & LU 572-08 & $22^{\circ} 436^{\prime}$ & $17^{\circ} 106^{\prime}$ & Biotite quarzite schist, Kuiseb Formation & Proterozoic \\
\hline $2-10-97-1$ & MU027-04 & $23^{\circ} 025^{\prime}$ & $16^{\circ} 487^{\prime}$ & Hartelust-Rhyolite & Proterozoic \\
\hline $2-10-97-2$ & LU 575-08 & $22^{\circ} 675^{\prime}$ & $16^{\circ} 046^{\prime}$ & Quartzite Kuiseb Formation & Proterozoic \\
\hline 3-10-97-1 & LU 572-09 & $22^{\circ} 701^{\prime}$ & $15^{\circ} 855^{\prime}$ & Donkerhoek granite & Cambrian \\
\hline $3-10-97-2$ & LU 572-10 & $22^{\circ} 418^{\prime}$ & $15^{\circ} 854^{\prime}$ & Pegmatite & Cretaceous (?) \\
\hline 4-10-97-1 & LU 572-11 & $22^{\circ} 088^{\prime}$ & $15^{\circ} 523^{\prime}$ & Salem monzogranite & Proterozoic \\
\hline $4-10-97-2$ & LU 572-12 & $22^{\circ} 181^{\prime}$ & $15^{\circ} 551^{\prime}$ & Metavolcanic rock & Proterozoic \\
\hline $4-10-97-3$ & LU 572-13 & $22^{\circ} 354^{\prime}$ & $15^{\circ} 599^{\prime}$ & Kubas-Granite & Cambrian \\
\hline $4-10-97-4$ & LU 572-14 & $22^{\circ} 375^{\prime}$ & $15^{\circ} 607^{\prime}$ & Kubas-Granite & Cambrian \\
\hline $4-10-97-5$ & LU 572-15 & $22^{\circ} 44^{\prime}$ & $15^{\circ} 63^{\prime}$ & Salem-Granite & Prot-Camb. \\
\hline $5-10-97-3$ & LU 575-11 & $21^{\circ} 788^{\prime}$ & $15^{\circ} 627^{\prime}$ & Granite & Cretaceous \\
\hline $5-10-97-4$ & LU 573-02 & $21^{\circ} 788^{\prime}$ & $15^{\circ} 627^{\prime}$ & Granite & Cretaceous \\
\hline $5-10-97-5$ & LU 573-03 & $21^{\circ} 76^{\prime}$ & $15^{\circ} 607^{\prime}$ & Damara granite, post-tectonic & Cambrian \\
\hline $6-10-97-2$ & LU 573-04 & $21^{\circ} 831^{\prime}$ & $15^{\circ} 604^{\prime}$ & $\mathrm{NgSAs}$ granite, syntectonic & Proterozoic \\
\hline $6-10-97-4$ & LU 573-05 & $21^{\circ} 983^{\prime}$ & $15^{\circ} 424^{\prime}$ & Eglp granite, posttectonic & Cambrian \\
\hline $6-10-97-5$ & LU 573-06 & $21^{\circ} 886^{\prime}$ & $15^{\circ} 343^{\prime}$ & Pegmatite & Cretaceous (?) \\
\hline $6-10-97-6$ & LU 573-07 & $21^{\circ} 855^{\prime}$ & $15^{\circ} 361^{\prime}$ & Eglp granite, posttectonic & Cambrian \\
\hline $6-10-97-7$ & LU 573-08 & $21^{\circ} 775^{\prime}$ & $15^{\circ} 432^{\prime}$ & Eglp granite, posttectonic & Cambrian \\
\hline
\end{tabular}


Table C. 1 continued from previous page

\begin{tabular}{|c|c|c|c|c|c|}
\hline Sample-No & Irrad-code & latitude & longitude & Sample description & Stratigraphic age \\
\hline $6-10-97-8$ & MU027-05 & $21^{\circ} 769^{\prime}$ & $15^{\circ} 435^{\prime}$ & Eglp granite, posttectonic & Cambrian \\
\hline $6-10-97-9$ & LU 573-09 & $21^{\circ} 694^{\prime}$ & $15^{\circ} 471^{\prime}$ & Eglp granite, posttectonic & Cambrian \\
\hline $6-10-97-10$ & LU 573-10/11 & $21^{\circ} 535^{\prime}$ & $15^{\circ} 473$ & KgEGg granite & Cretaceous \\
\hline $6-10-97-12$ & LU 573-12 & $21^{\circ} 496^{\prime}$ & $15^{\circ} 662^{\prime}$ & Egls granite, syntectonic & Proterozoic \\
\hline 7-10-97-1 & LU 573-13 & $21^{\circ} 451^{\prime}$ & $15^{\circ} 892^{\prime}$ & KgEGg granite & Cretaceous \\
\hline $7-10-97-2$ & LU 573-14 & $21^{\circ} 469^{\prime}$ & $15^{\circ} 802^{\prime}$ & Volcanic rock & Cretaceous (?) \\
\hline $7-10-97-3$ & LU 574-01 & $21^{\circ} 463^{\prime}$ & $15^{\circ} 765^{\prime}$ & Egls, syntectonic granite & Proterozoic \\
\hline $7-10-97-4$ & LU 574-02 & $21^{\circ} 323^{\prime}$ & $15^{\circ} 819^{\prime}$ & Egls, syntectonic granite & Proterozoic \\
\hline $7-10-97-5$ & LU 574-03 & $21^{\circ} 249^{\prime}$ & $15^{\circ} 742^{\prime}$ & OgSAS, late tectonic granite & Ordovician \\
\hline $7-10-97-6$ & LU 574-04 & $21^{\circ} 172^{\prime}$ & $15^{\circ} 68^{\prime}$ & OgSAS, late tectonic granite & Ordovician \\
\hline $7-10-97-7$ & LU 574-05 & $21^{\circ} 107^{\prime}$ & $15^{\circ} 604^{\prime}$ & OgSAS, late tectonic granite & Ordovician \\
\hline $7-10-97-8$ & LU 574-06 & $21^{\circ} 223^{\prime}$ & $15^{\circ} 407^{\prime}$ & Ogl, late-posttectonic granite & Ordovician \\
\hline 7-10-97-9 & LU 574-07 & $21^{\circ} 277^{\prime}$ & $15^{\circ} 226^{\prime}$ & OgTSgd, posttectonic Granodiorite & Ordovician \\
\hline $7-10-97-10$ & MU027-06 & $21^{\circ} 24^{\prime}$ & $15^{\circ} 086^{\prime}$ & OgSAs, posttectonic granite & Ordovician \\
\hline $8-10-97-2$ & MU027-07 & $21^{\circ} 315^{\prime}$ & $14^{\circ} 558^{\prime}$ & Pegmatite & Cretaceous \\
\hline $9-10-97-3$ & MU027-08 & $20^{\circ} 916^{\prime}$ & $15^{\circ} 463^{\prime}$ & Granite & Proterozoic \\
\hline $9-10-97-4$ & MU027-09 & $20^{\circ} 983^{\prime}$ & $15^{\circ} 49^{\prime}$ & Rhyolite, Karoo-Sequence & Jurassic \\
\hline $10-10-97-2$ & MU027-10 & $20^{\circ} 542^{\prime}$ & $14^{\circ} 462^{\prime}$ & Damara granite & Proterozoic \\
\hline $10-10-97-3$ & MU027-11 & $20^{\circ} 631^{\prime}$ & $14^{\circ} 568^{\prime}$ & Damara granite & Proterozoic \\
\hline $10-10-97-4$ & MU027-12 & $20^{\circ} 59^{\prime}$ & $14^{\circ} 638^{\prime}$ & Damara granite & Proterozoic \\
\hline $11-10-97-1$ & MU027-13 & $19^{\circ} 917^{\prime}$ & $14^{\circ} 95^{\prime}$ & Feldspar Augengneiss, Kamanjab Inlier & Proterozoic \\
\hline $11-10-97-2$ & MU027-14 & $19^{\circ} 785^{\prime}$ & $14^{\circ} 844^{\prime}$ & Feldspar Augengneiss, Kamanjab Inlier & Proterozoic \\
\hline $11-10-97-3$ & MU027-15 & $19^{\circ} 616^{\prime}$ & $14^{\circ} 85^{\prime}$ & Meta volcanic rock, Kamanjab Inlier & Proterozoic \\
\hline $11-10-97-4$ & MU028-01 & $19^{\circ} 687^{\prime}$ & $15^{\circ} 092^{\prime}$ & Gneiss, Kamanjab Inlier & Proterozoic \\
\hline $11-10-97-5$ & MU028-02 & $19^{\circ} 796^{\prime}$ & $15^{\circ} 333^{\prime}$ & Gneiss, Kamanjab Inlier & Proterozoic \\
\hline $17-10-97-1$ & MU028-03 & $21^{\circ} 759^{\prime}$ & $16^{\circ} 873^{\prime}$ & Salem-Granite & Prot.-Camb. \\
\hline $17-10-97-2$ & MU028-04 & $20^{\circ} 514^{\prime}$ & $16^{\circ} 886^{\prime}$ & Quartzite & Proterozoic \\
\hline $17-10-97-3$ & MU028-05 & $20^{\circ} 512^{\prime}$ & $16^{\circ} 985^{\prime}$ & Granite & Proterozoic \\
\hline $18-10-97-4$ & MU028-06 & $21^{\circ} 755^{\prime}$ & $16^{\circ} 165^{\prime}$ & Granite & Proterozoic \\
\hline $21-10-97-1$ & LU 574-08 & $22^{\circ} 338^{\prime}$ & $17^{\circ} 053^{\prime}$ & Biotite schist, Kuiseb Formation & Proterozoic \\
\hline $21-10-97-2$ & LU 574-09 & $22^{\circ} 267^{\prime}$ & $17^{\circ} 07^{\prime}$ & Biotite schist, Kuiseb Formation & Proterozoic \\
\hline $21-10-97-3$ & LU 574-10 & $22^{\circ} 272^{\prime}$ & $17^{\circ} 073$ & Biotite schist, Kuiseb Formation & Proterozoic \\
\hline $21-10-97-4$ & LU 574-11 & $22^{\circ} 278^{\prime}$ & $17^{\circ} 071^{\prime}$ & Biotite schist, Kuiseb Formation & Proterozoic \\
\hline $21-10-97-5$ & LU 574-12 & $22^{\circ} 288^{\prime}$ & $17^{\circ} 069^{\prime}$ & Biotite schist, Kuiseb Formation & Proterozoic \\
\hline $21-10-97-6$ & LU 575-01 & $22^{\circ} 358^{\prime}$ & $16^{\circ} 936^{\prime}$ & Quartz-biotite schist, Kuiseb Formation & Proterozoic \\
\hline $21-10-97-7$ & LU 575-02 & $22^{\circ} 357^{\prime}$ & $16^{\circ} 937^{\prime}$ & Biotite schist, Kuiseb Formation & Proterozoic \\
\hline $21-10-97-8$ & LU 575-03 & $22^{\circ} 351^{\prime}$ & $16^{\circ} 95^{\prime}$ & Quartz-biotite schist, Kuiseb Formation & Proterozoic \\
\hline $22-10-97-1$ & LU 575-04 & $22^{\circ} 709^{\prime}$ & $17^{\circ} 061^{\prime}$ & Auas Quartzite & Proterozoic \\
\hline $22-10-97-2$ & LU 575-05 & $22^{\circ} 707^{\prime}$ & $17^{\circ} 057^{\prime}$ & Auas Quartzite & Proterozoic \\
\hline $22-10-97-3$ & LU 575-06 & $22^{\circ} 702^{\prime}$ & $17^{\circ} 061^{\prime}$ & Greenschist & Proterozoic \\
\hline $22-10-97-4$ & LU 575-07 & $22^{\circ} 691^{\prime}$ & $17^{\circ} 063$ & Blueschist & Proterozoic \\
\hline $2-9-98-1$ & MU028-07 & $21^{\circ} 15^{\prime}$ & $14^{\circ} 577^{\prime}$ & Brandberg-Granite & Cretaceous \\
\hline $2-9-98-6$ & MU028-08 & $21^{\circ} 173^{\prime}$ & $14^{\circ} 574^{\prime}$ & Brandberg-Granite & Cretaceous \\
\hline $2-9-98-7$ & MU028-09 & $21^{\circ} 16^{\prime}$ & $14^{\circ} 575^{\prime}$ & Brandberg-Granite & Cretaceous \\
\hline $2-9-98-8$ & MU028-10 & $21^{\circ} 149^{\prime}$ & $14^{\circ} 571^{\prime}$ & Brandberg-Granite & Cretaceous \\
\hline $3-9-98-1$ & MU028-11 & $21^{\circ} 105^{\prime}$ & $14^{\circ} 584^{\prime}$ & Quartz norite (?) & Cretaceous \\
\hline $14-9-98-6$ & MU028-12 & $21^{\circ} 514^{\prime}$ & $16^{\circ} 573^{\prime}$ & Salem-Granite & Prot.-Camb. \\
\hline
\end{tabular}

${ }^{1}$ Samples provided by Prof. K. Weber, Georg-August-Universität Göttingen, Germany. No further information available

2 Apatite mounts supplied by Dr. R. Brown, The University of Melbourne, Australia

${ }^{3}$ No GPS reception 


\section{C.2 Analytical Results}

This section contains a tabular summary of the analytical apatite fission track results. Samples are ordered according to their sample code. 


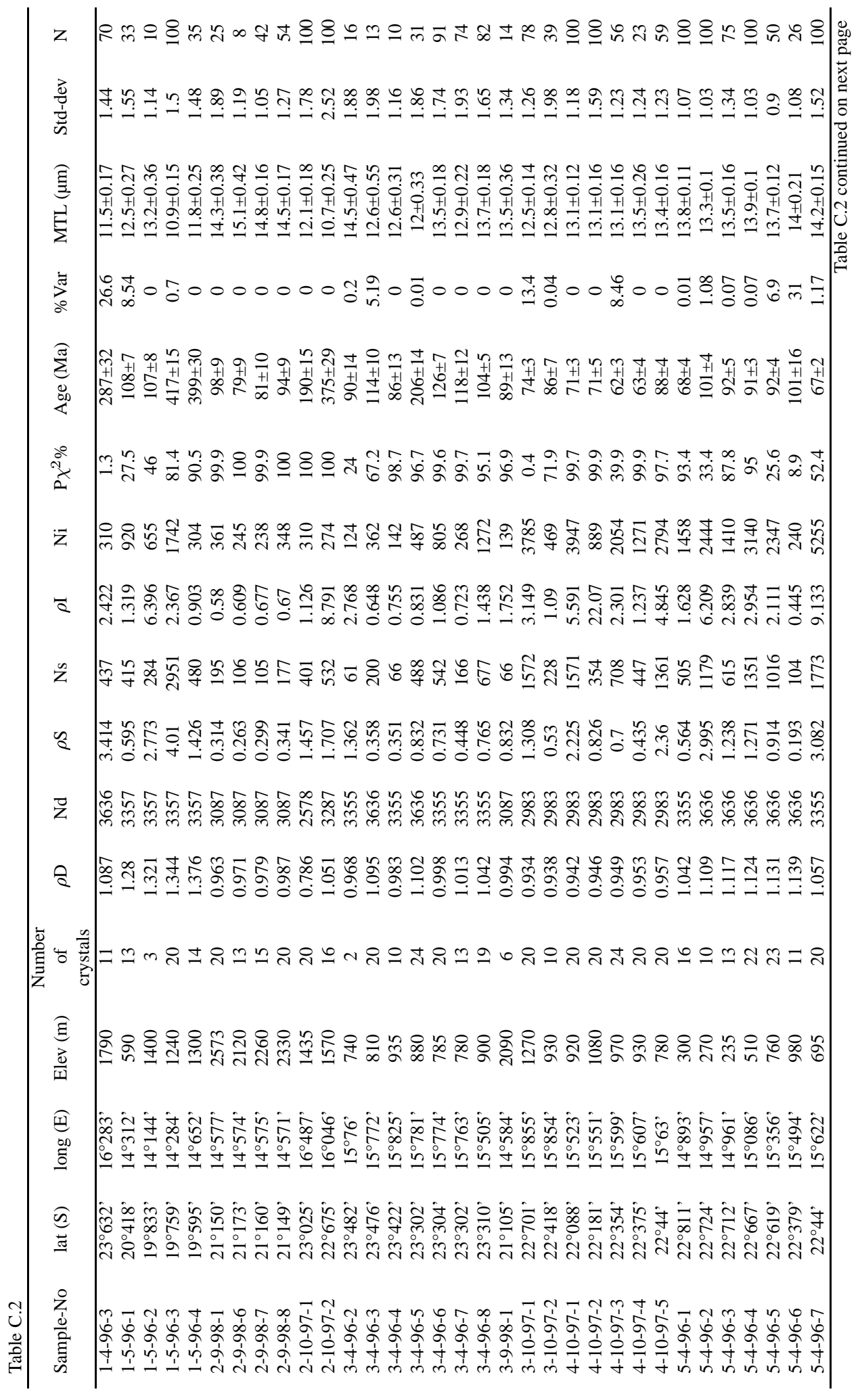




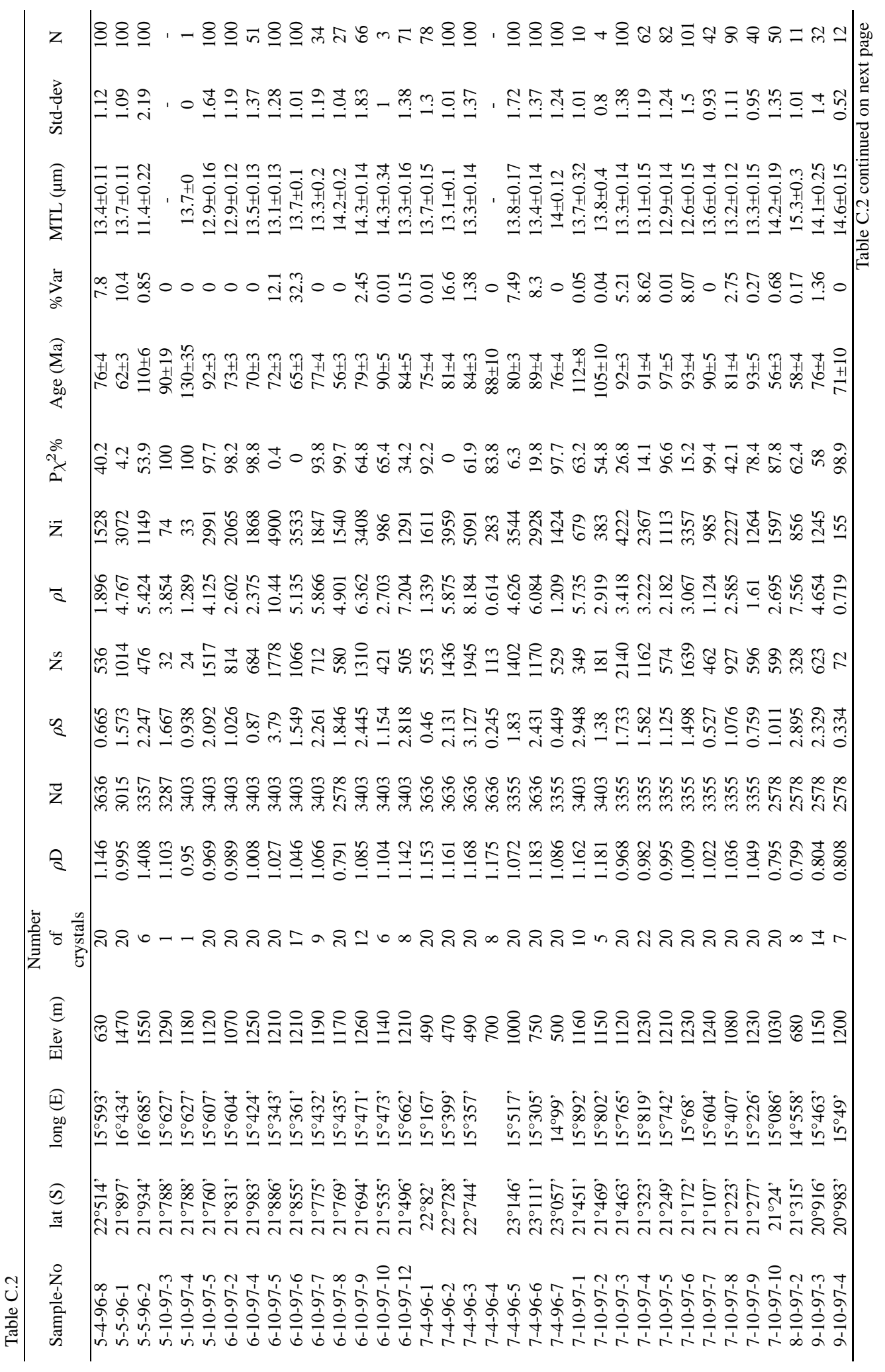




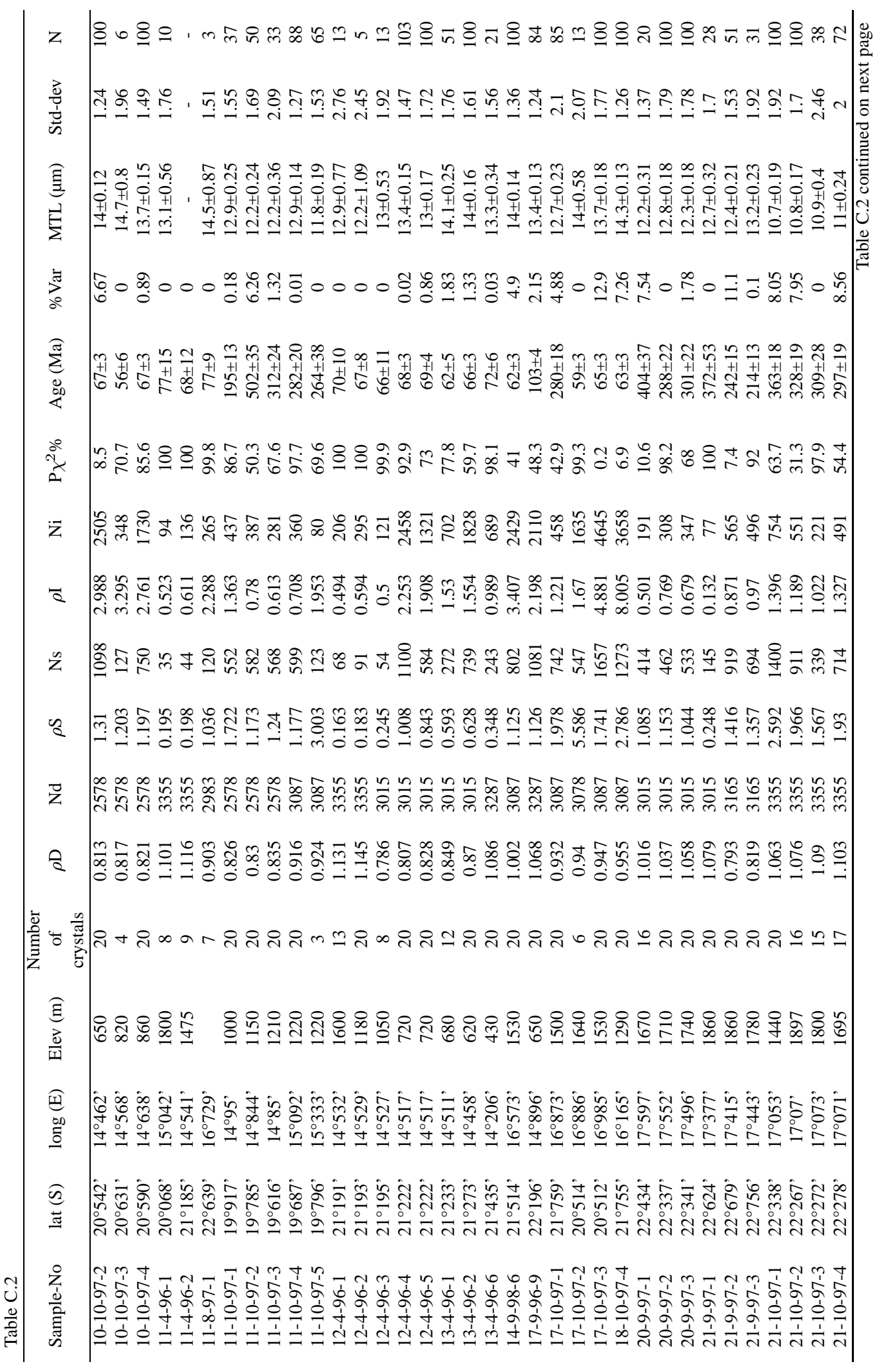




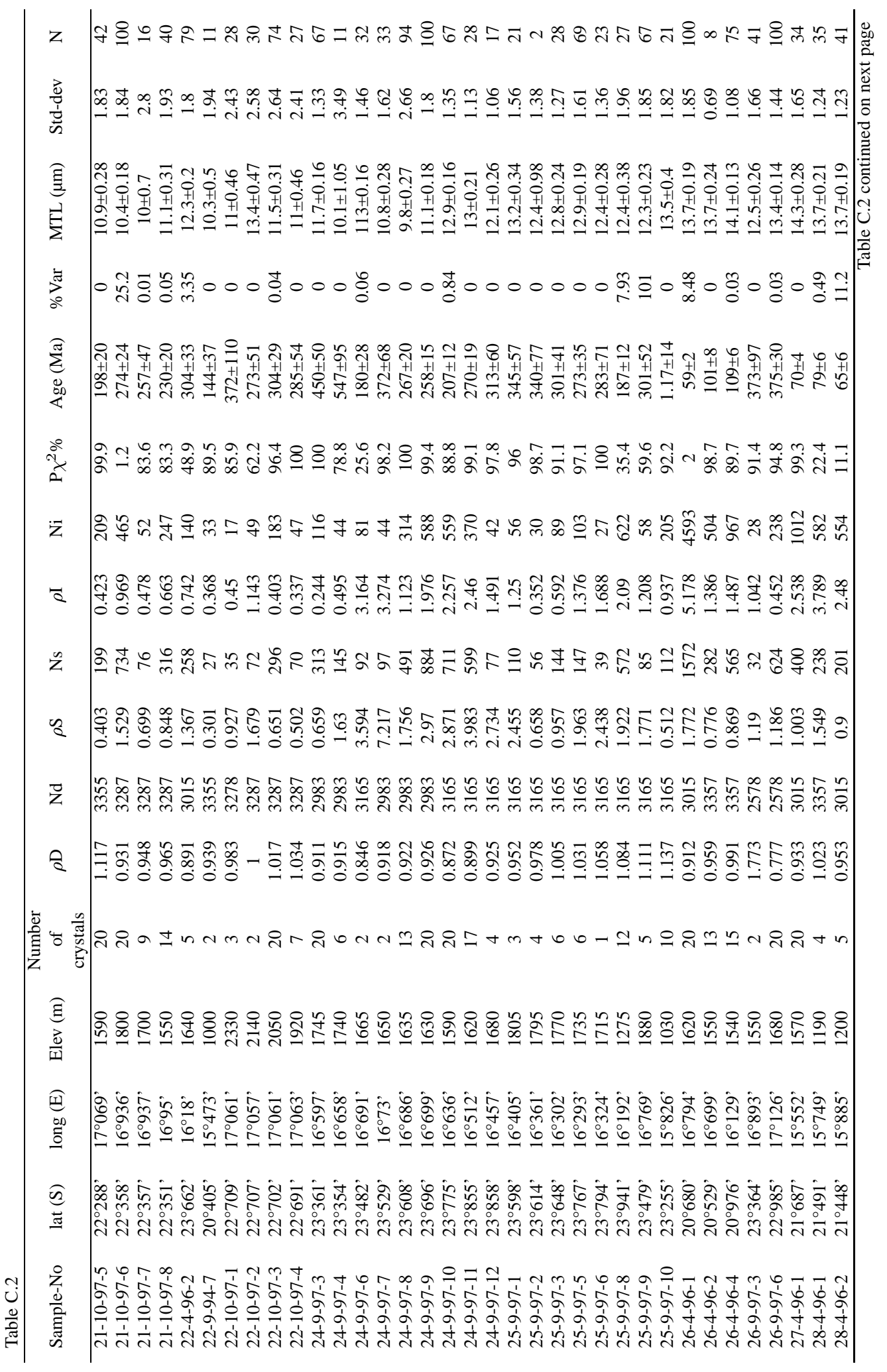




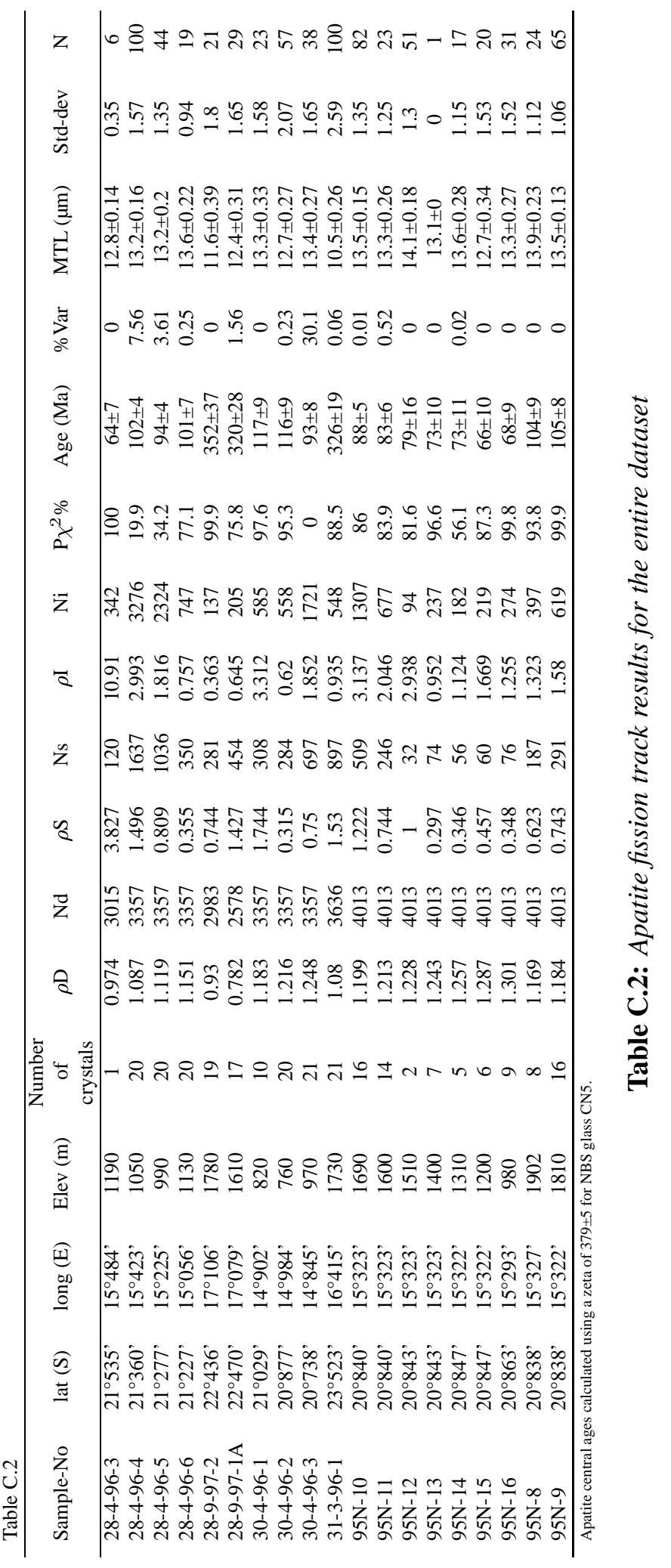




\section{C.3 Raw Data Files}

Raw data are ordered according to their irradiation code:
HB016
LU 570
LU 571
LU 572
LU 573
LU 574
LU 575
MU 024
MU 025
MU 026
MU 027
MU 028
LU 436 

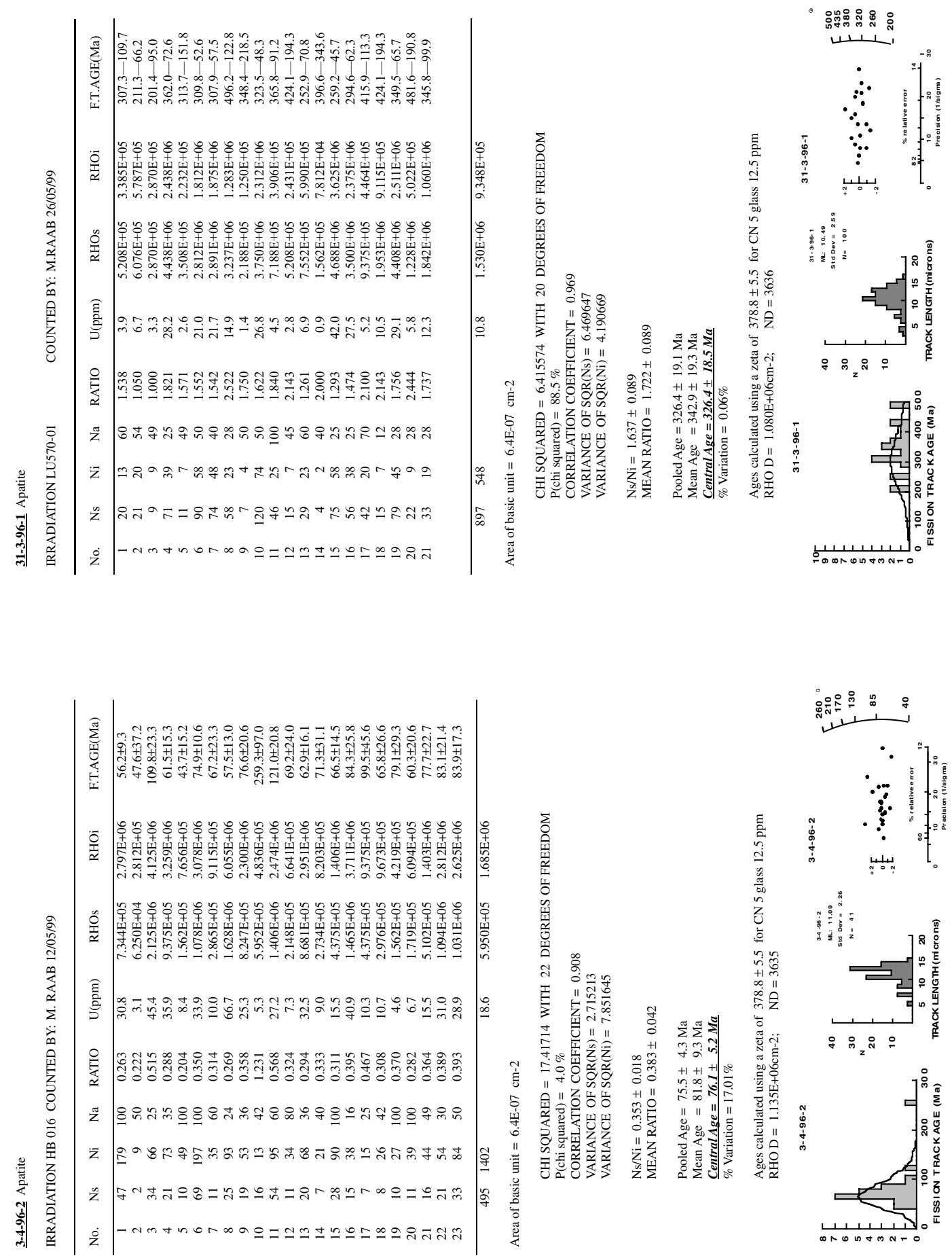

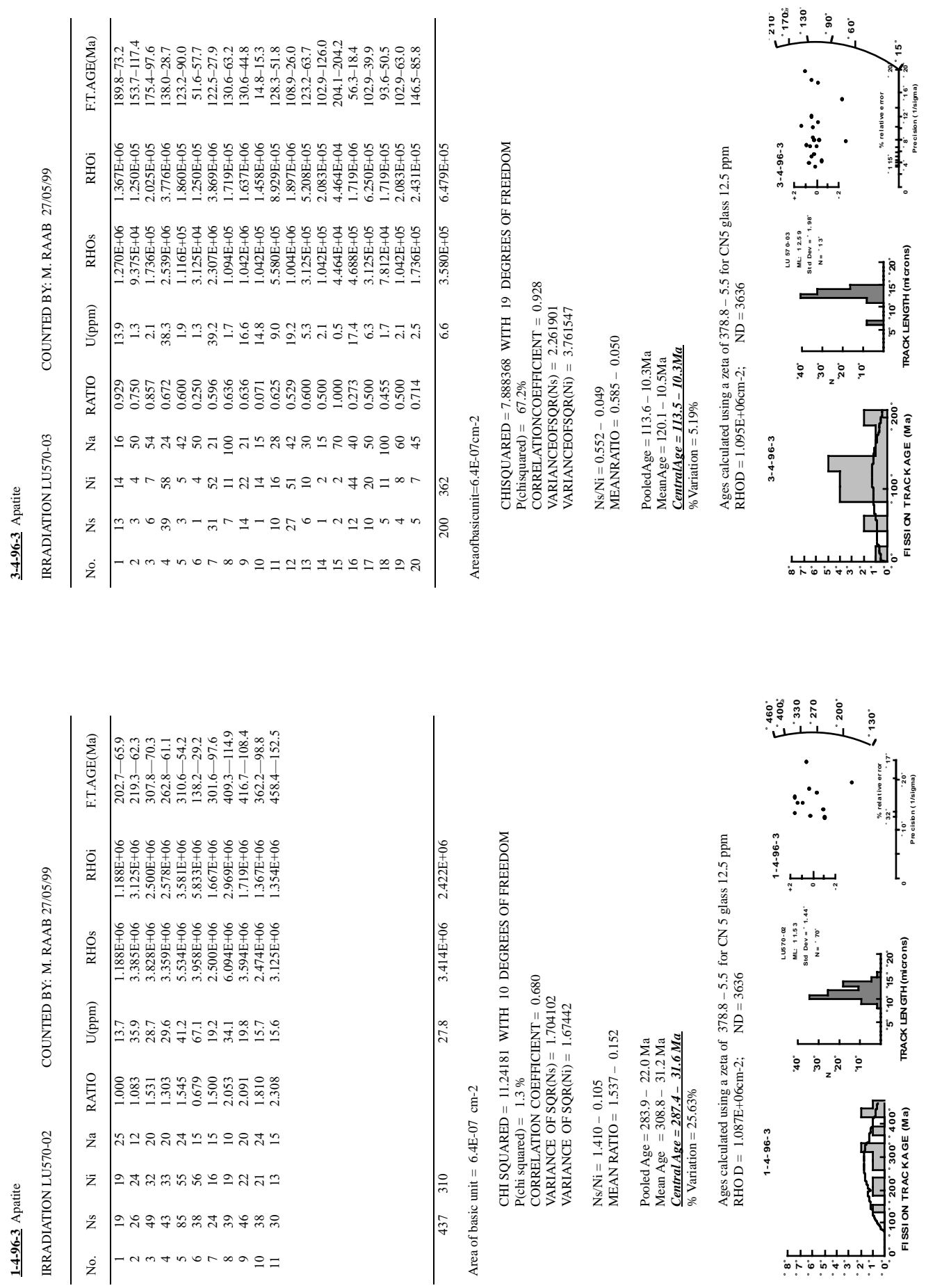

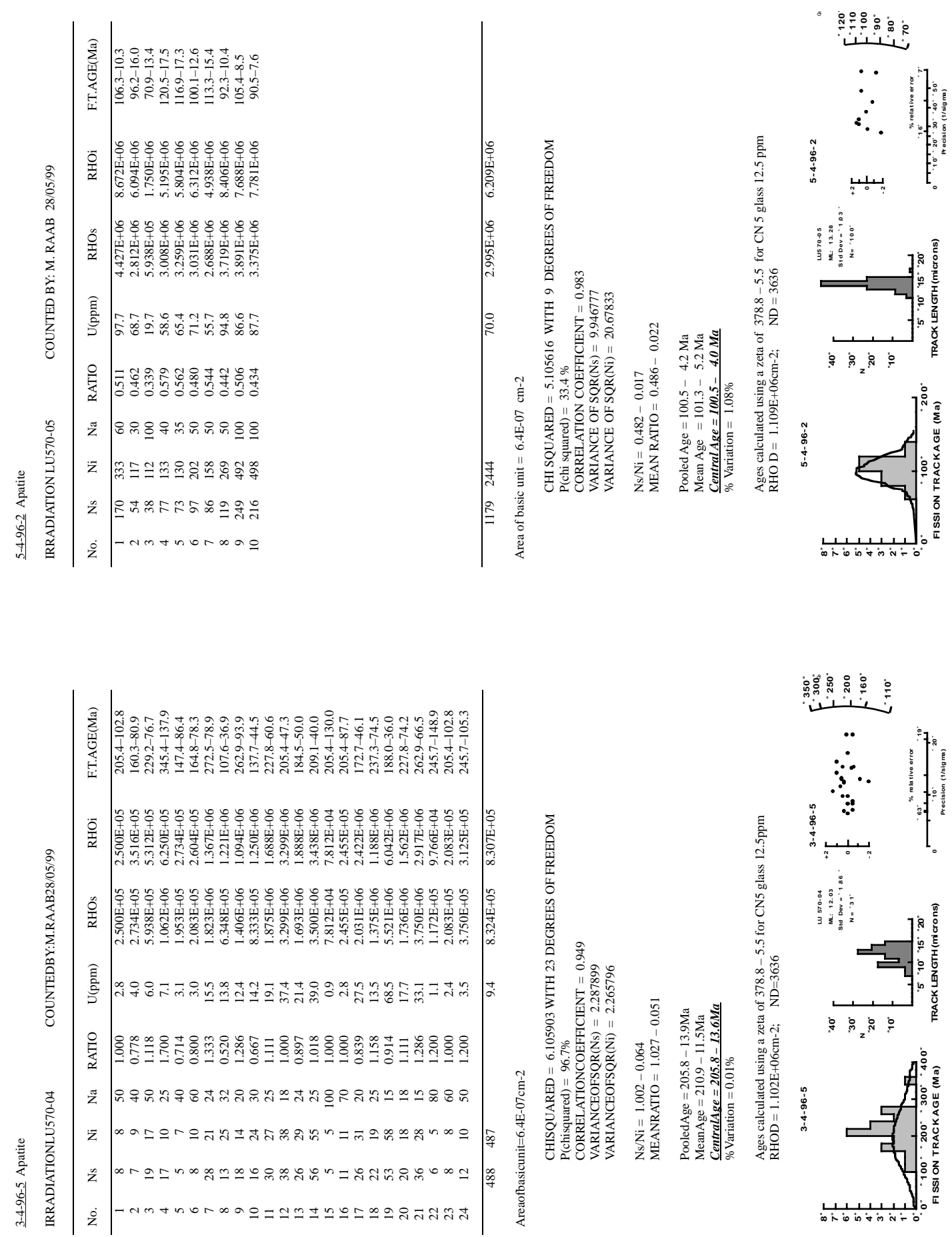

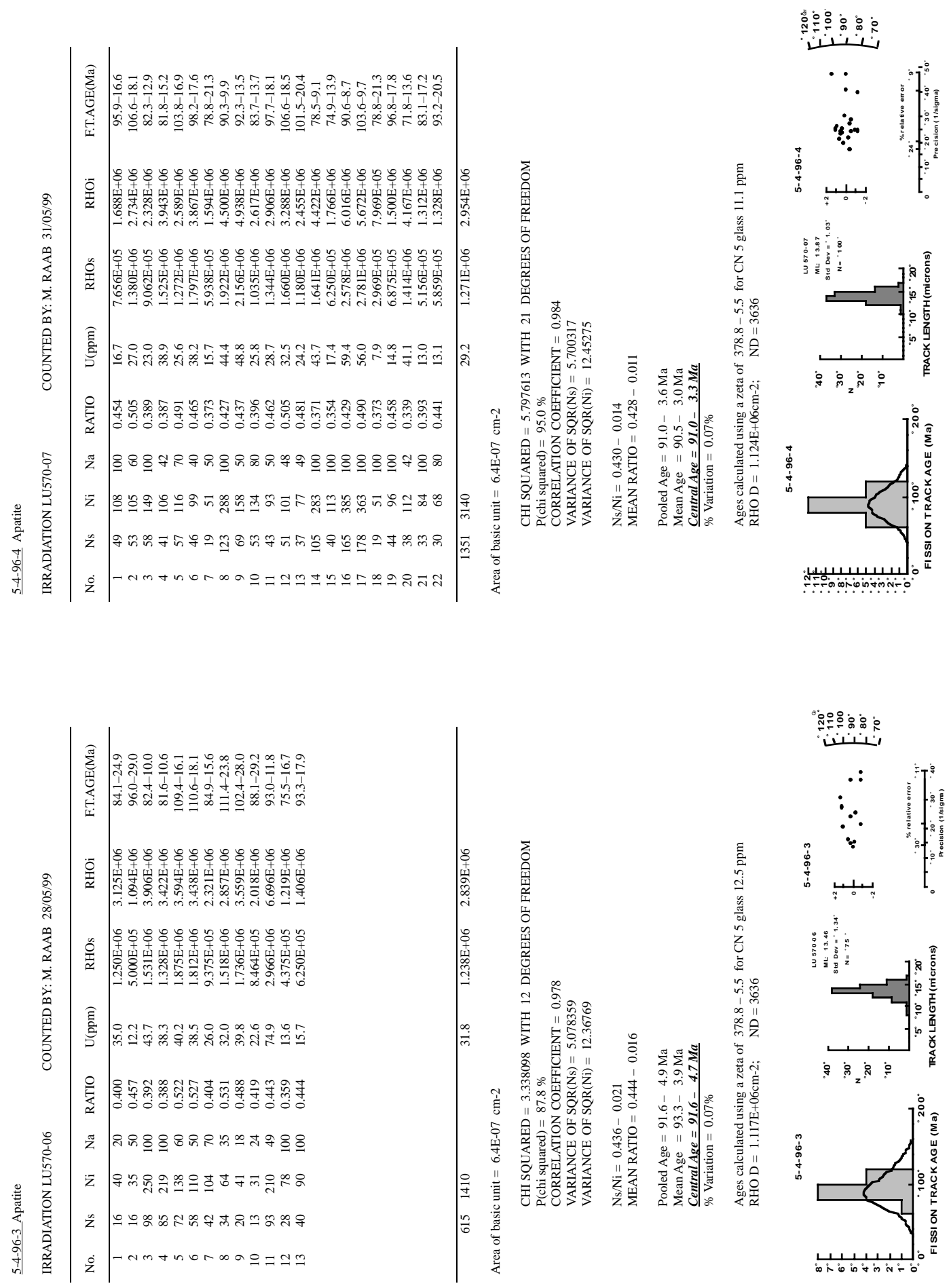

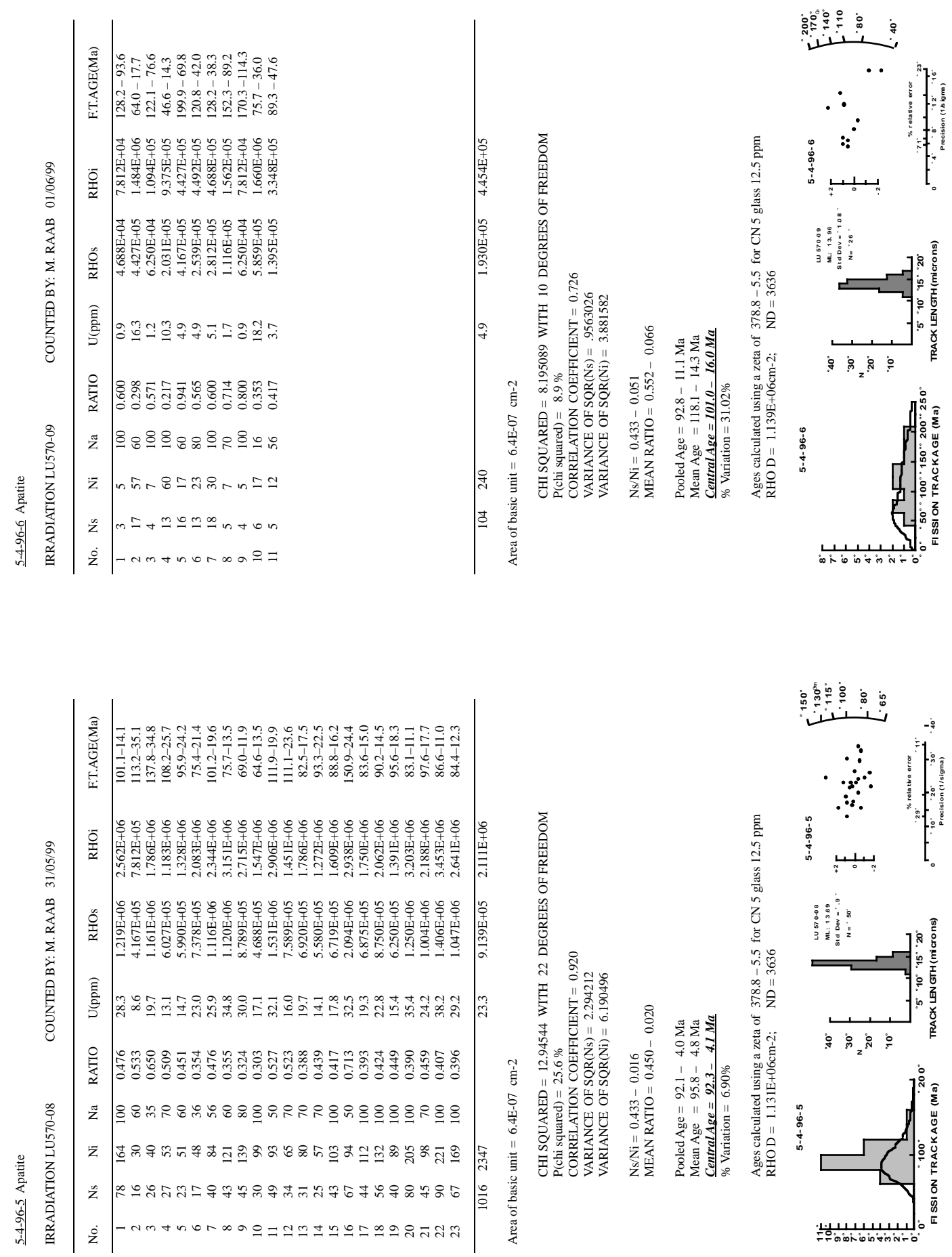

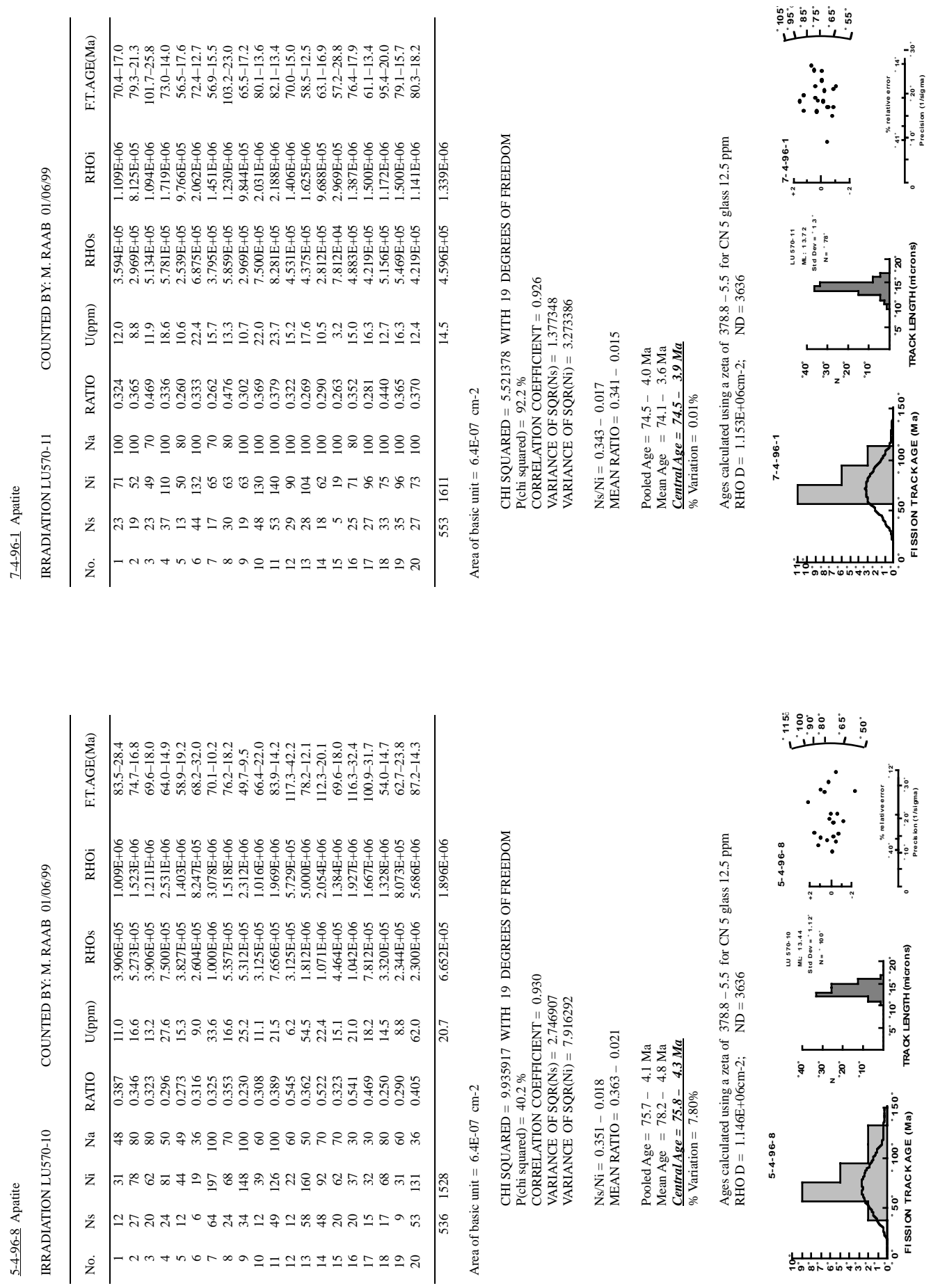

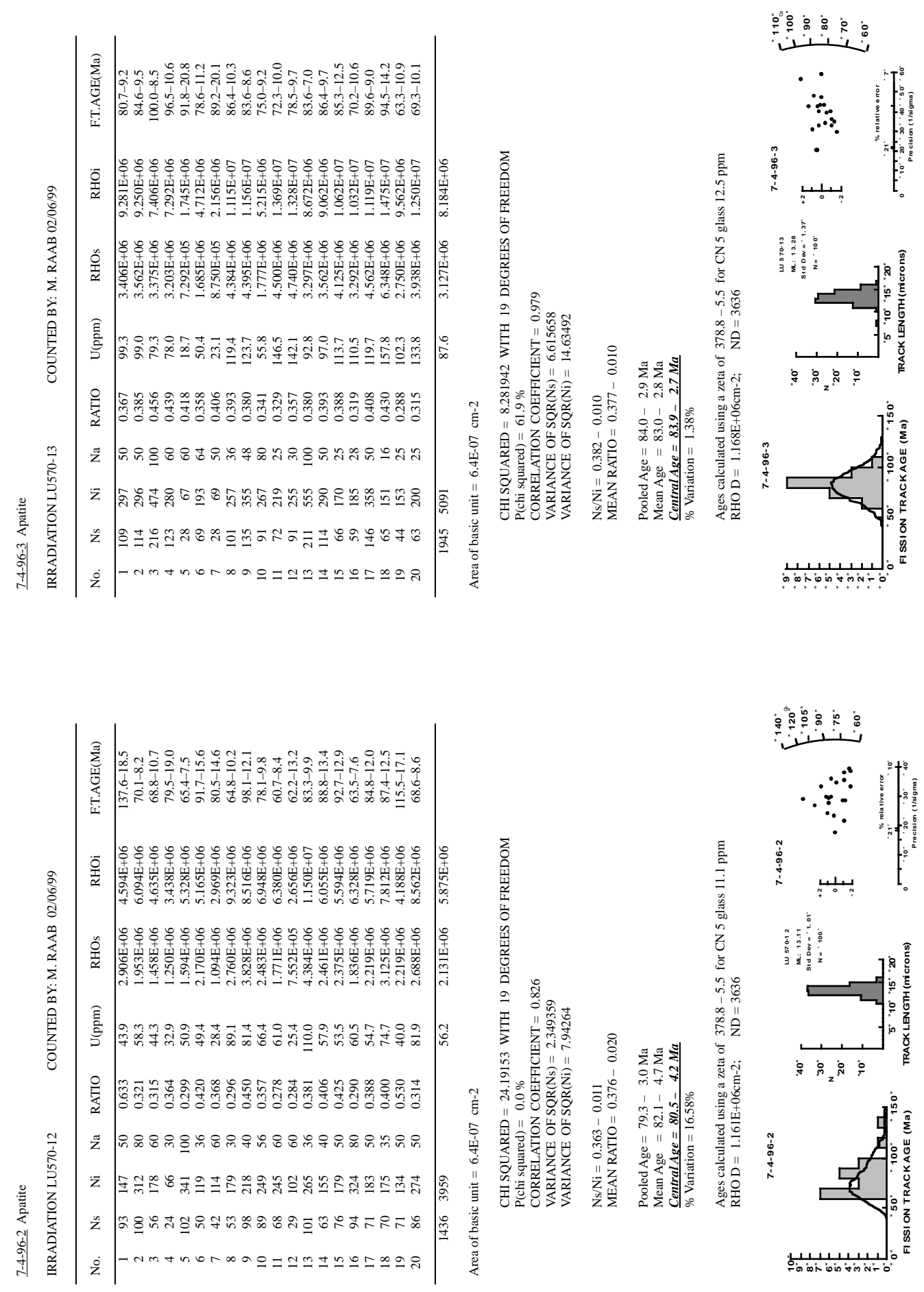

웅

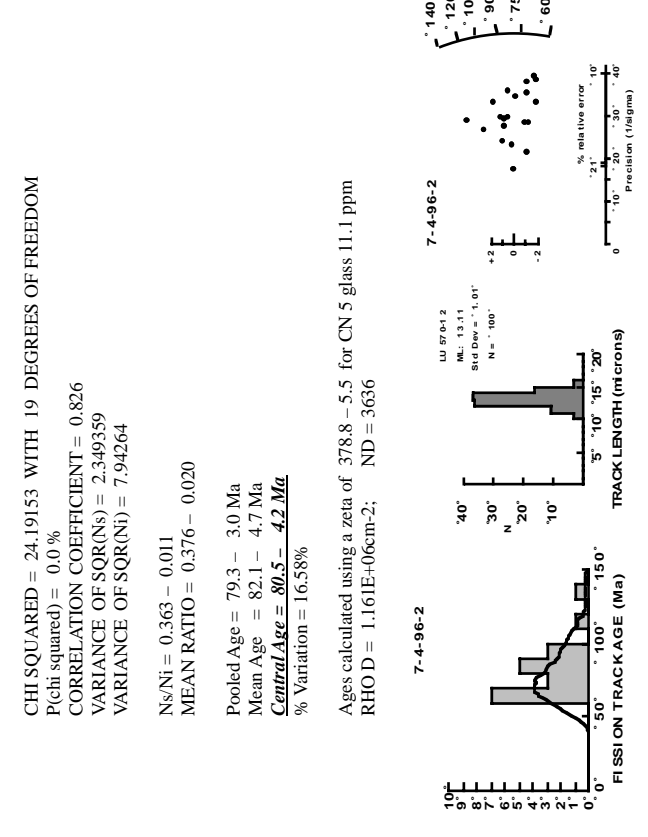



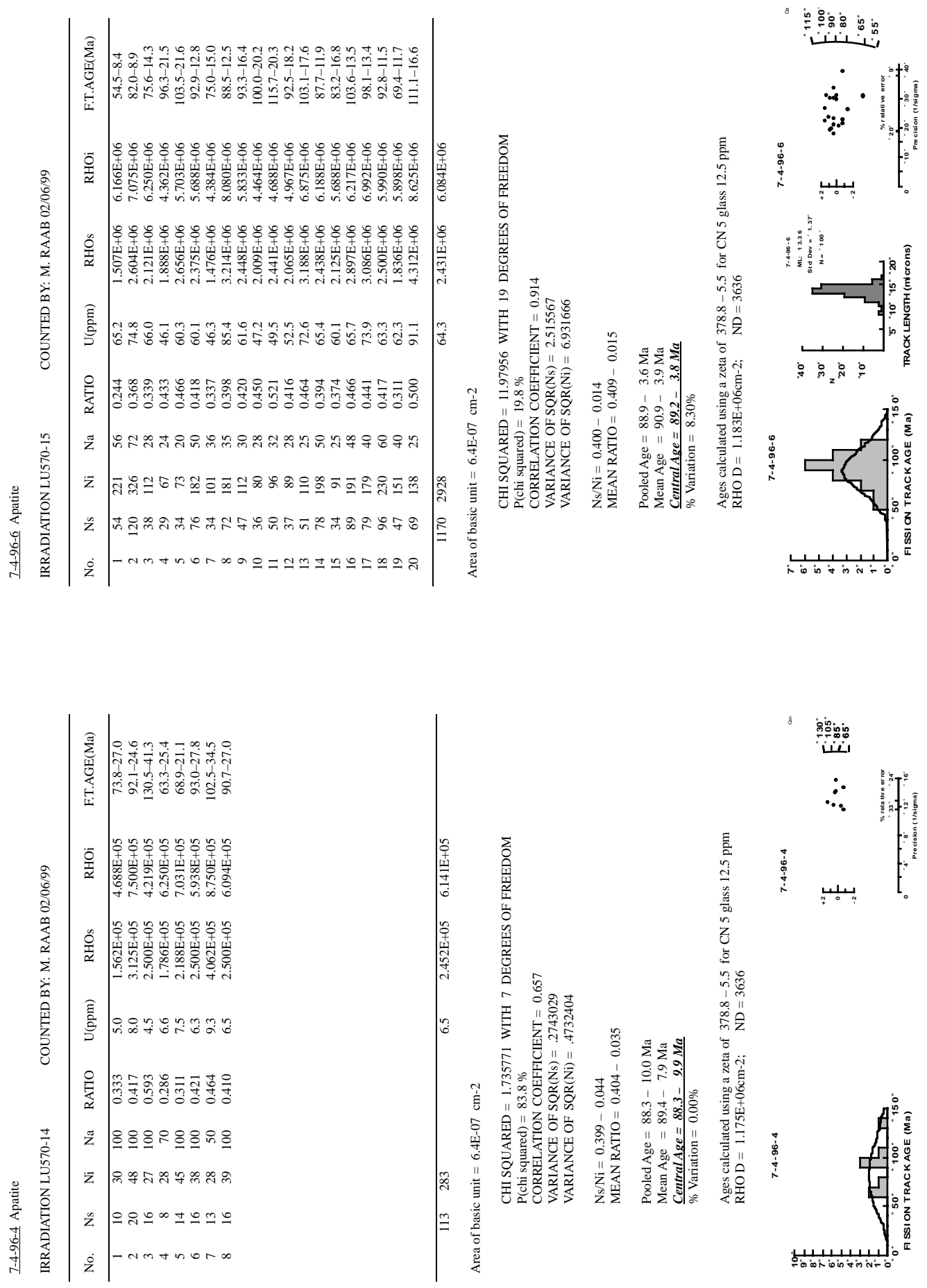

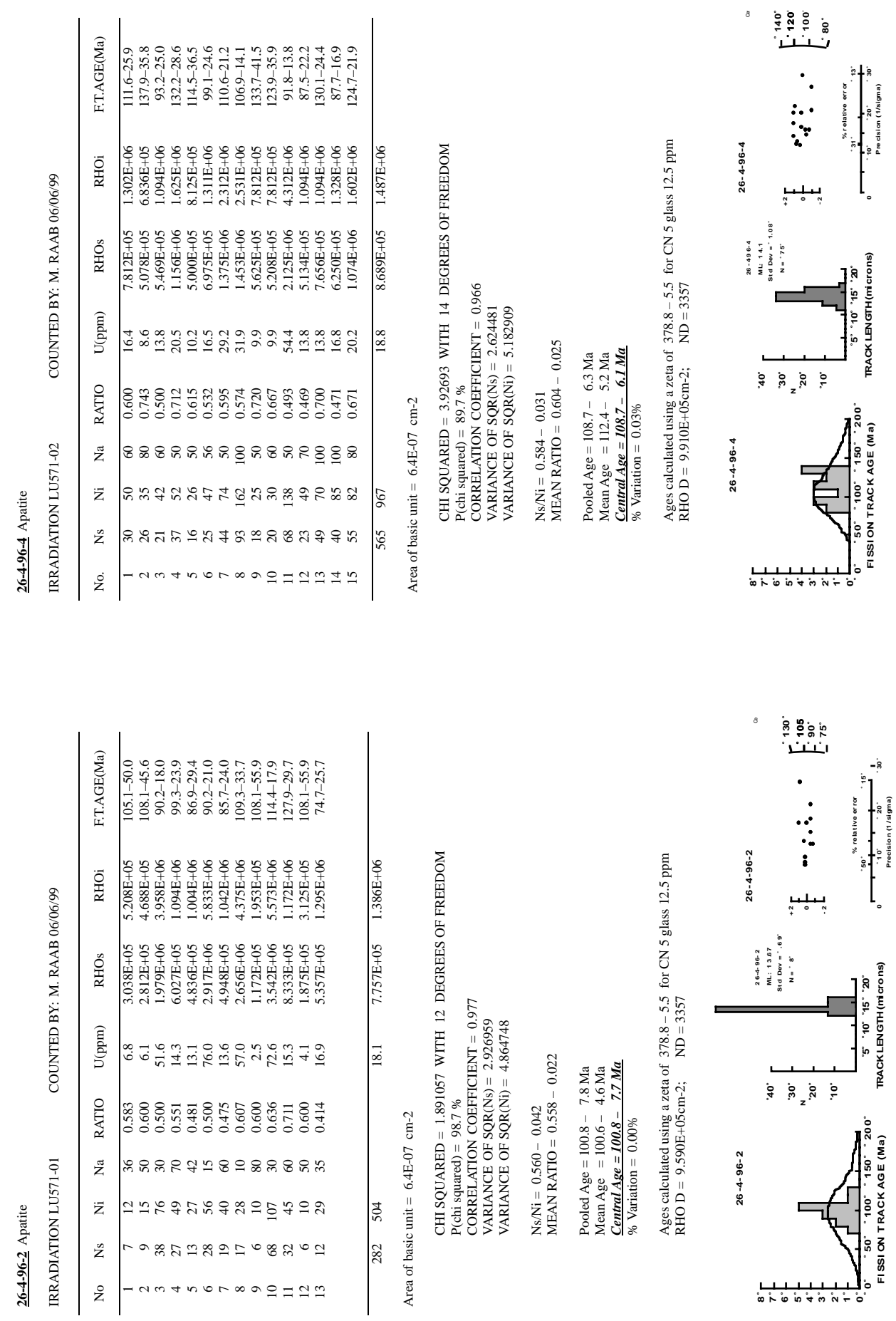

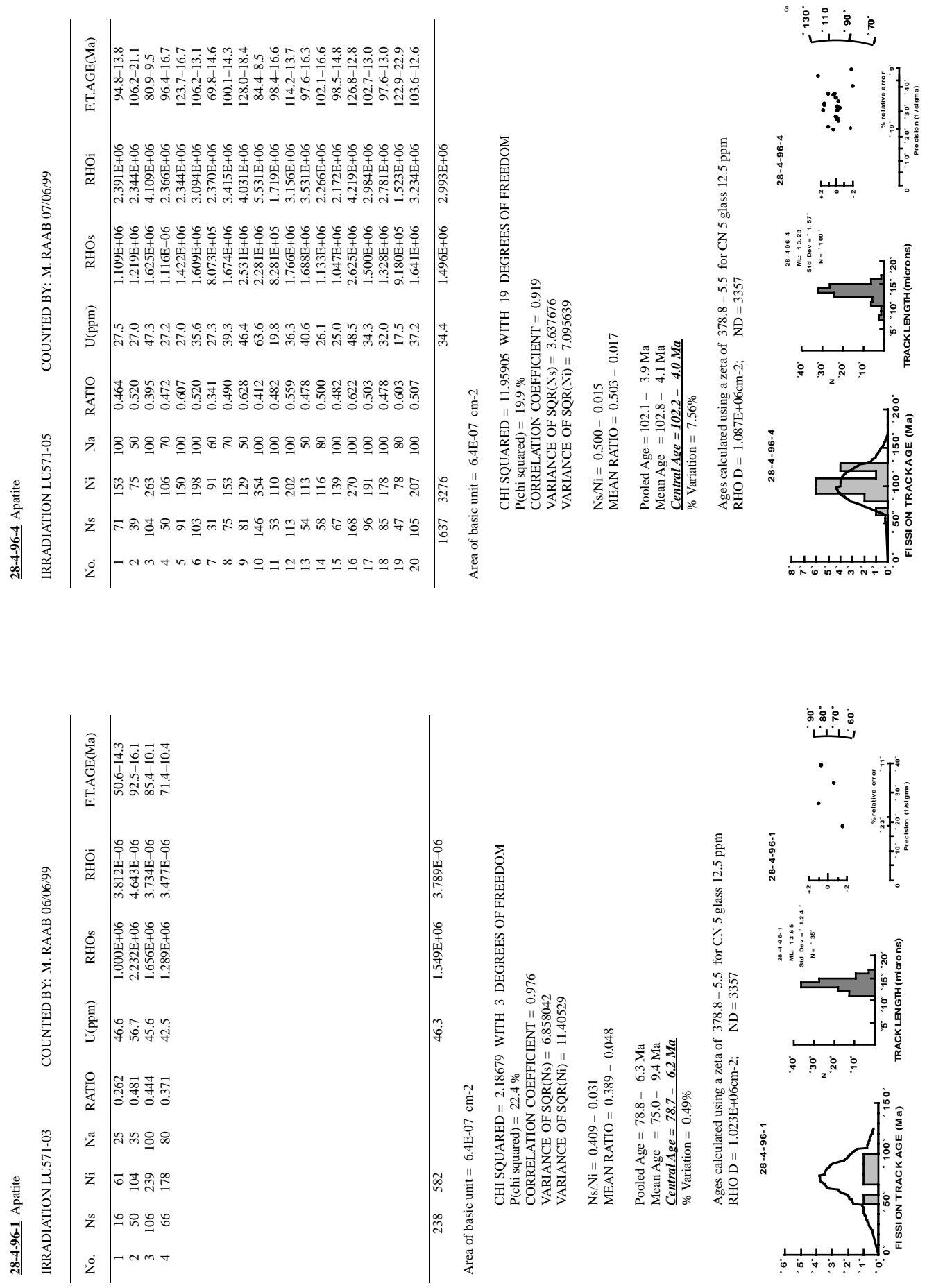

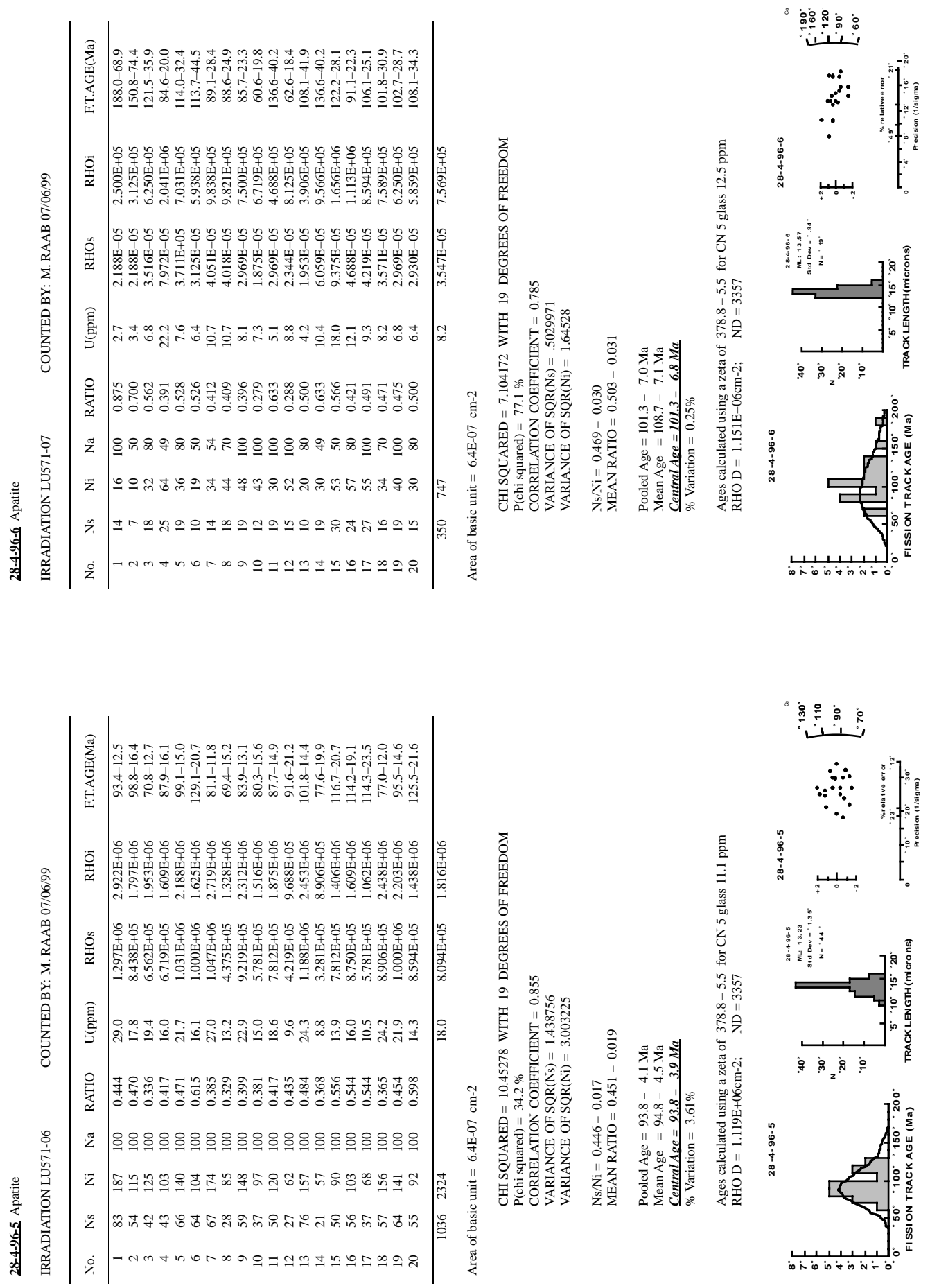

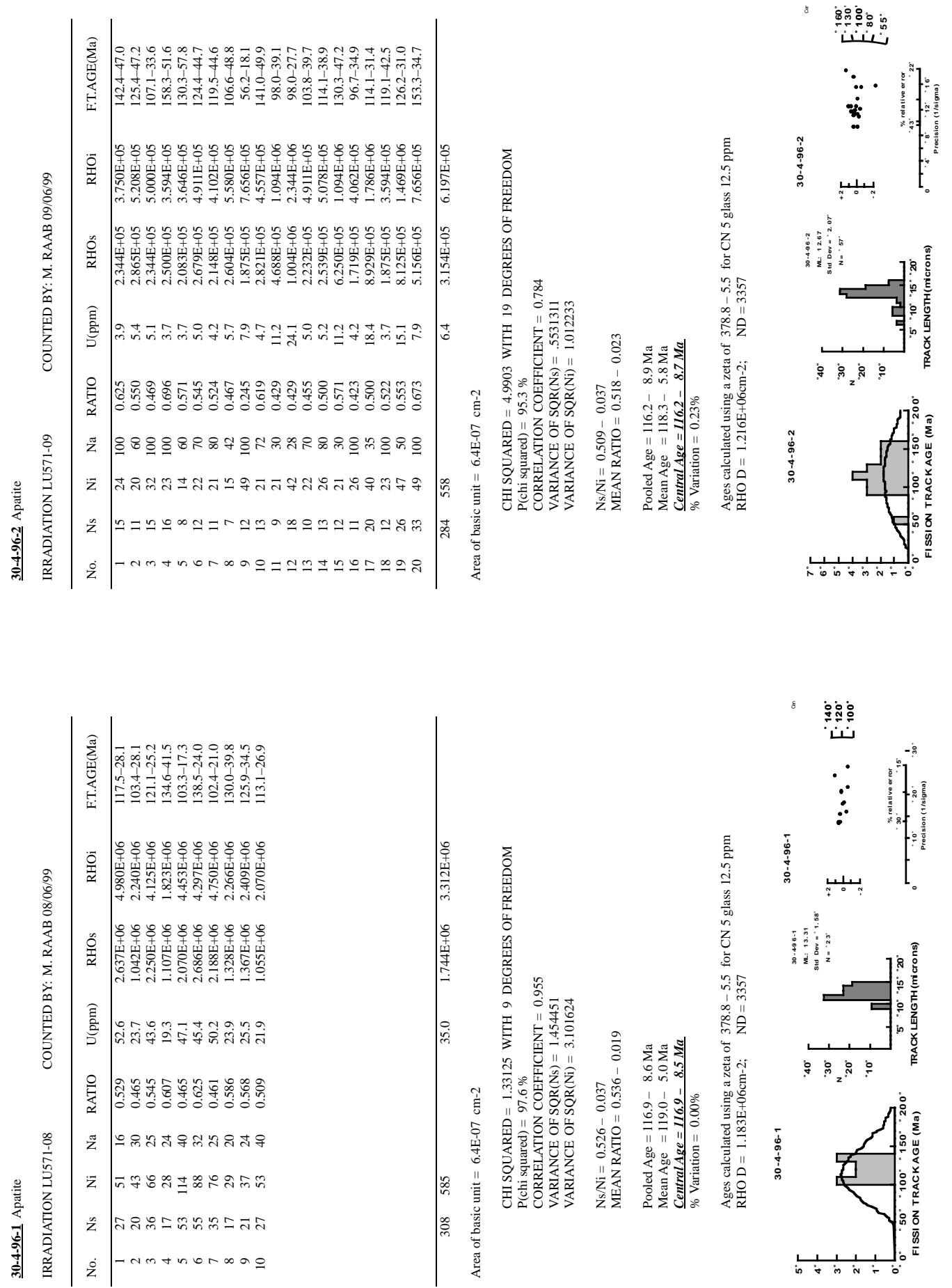

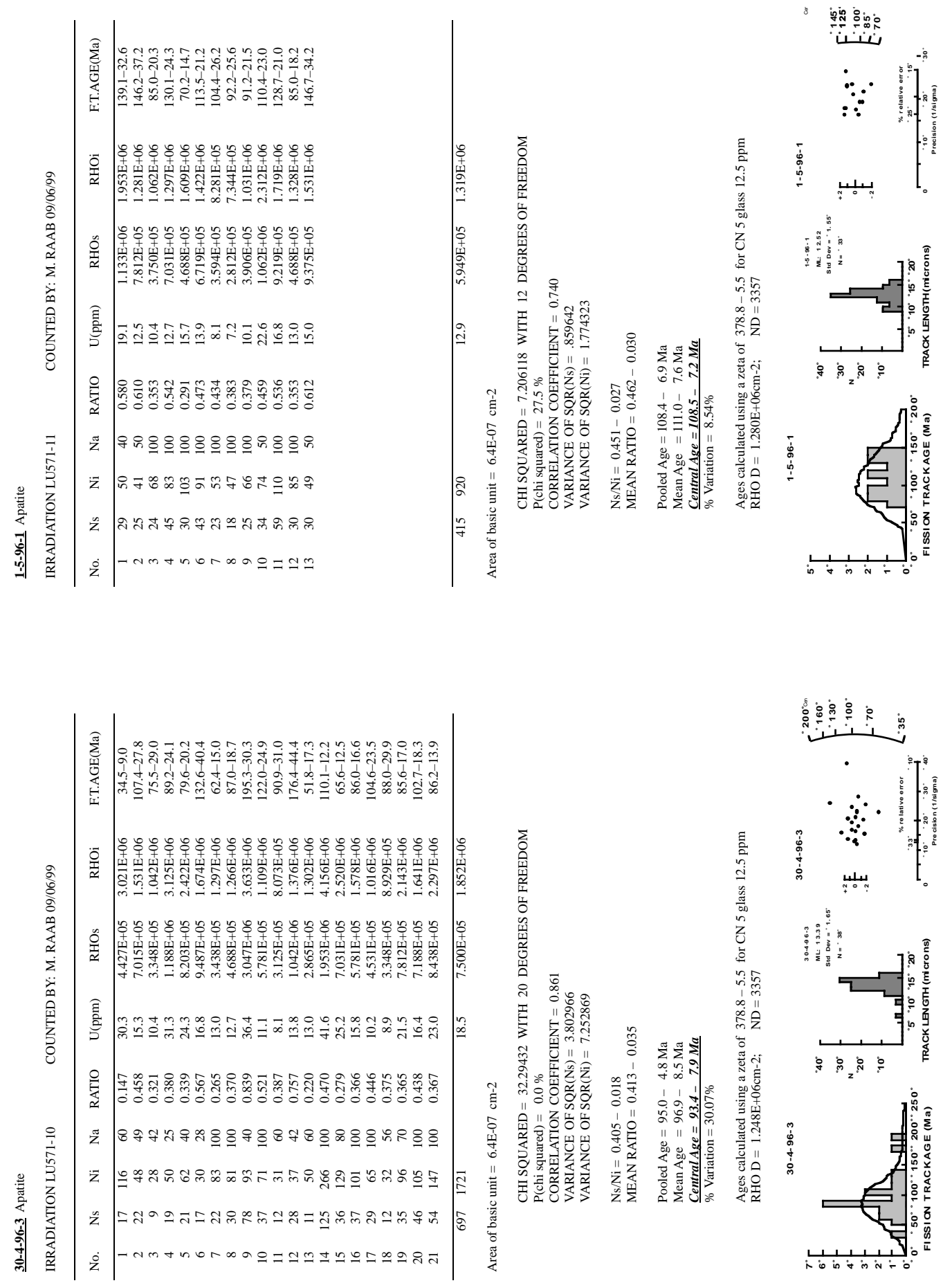


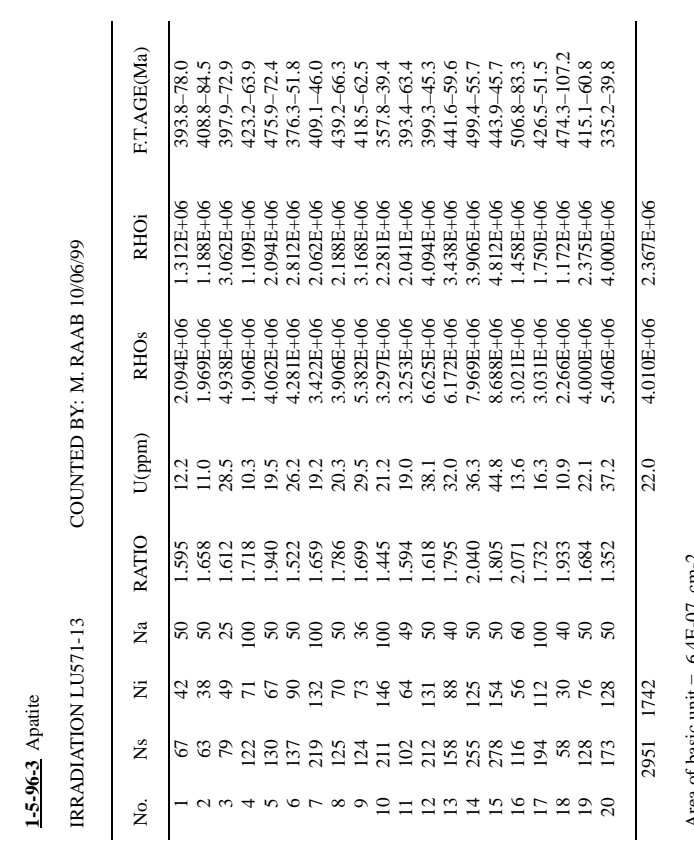

8 일
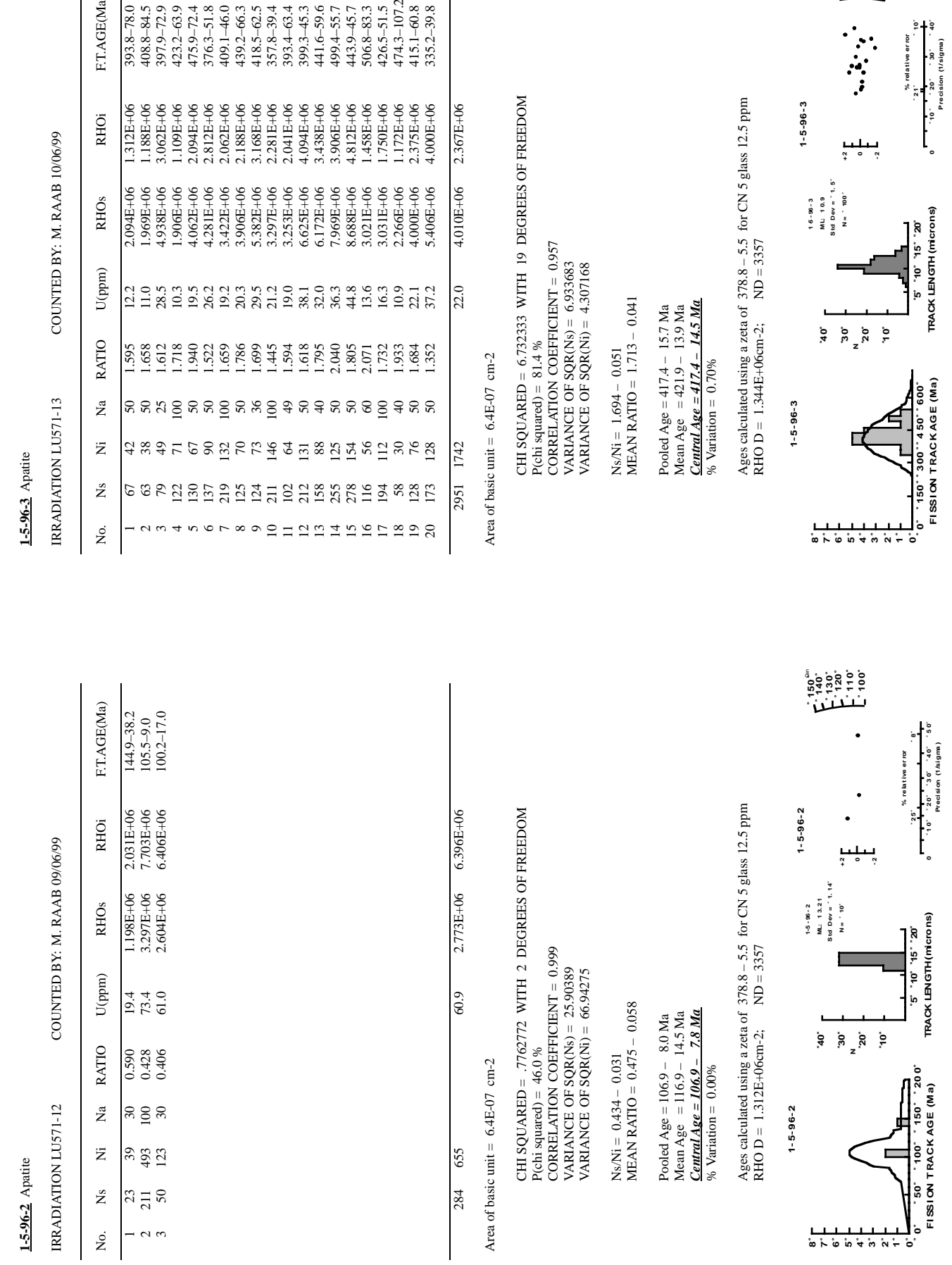

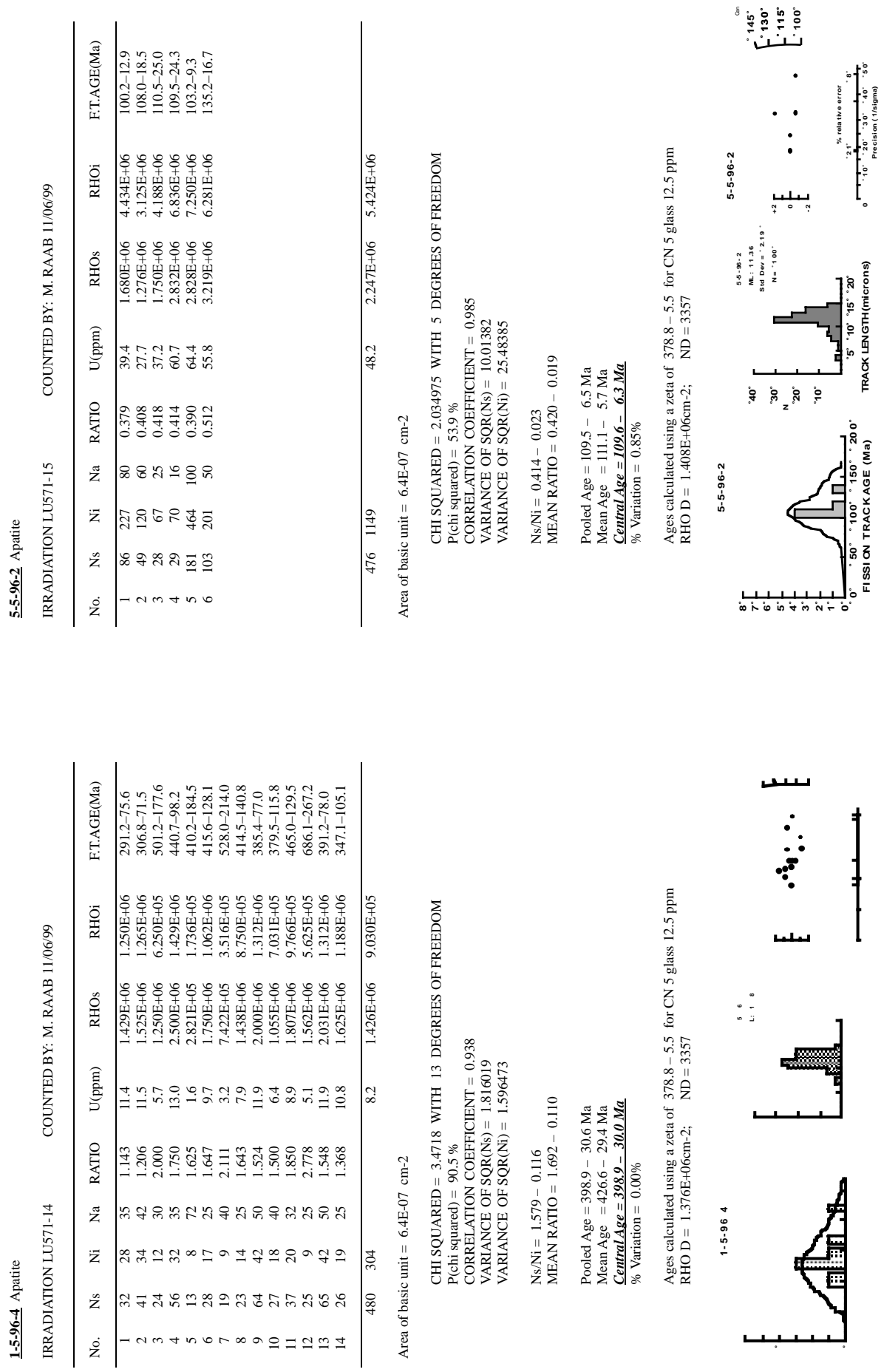

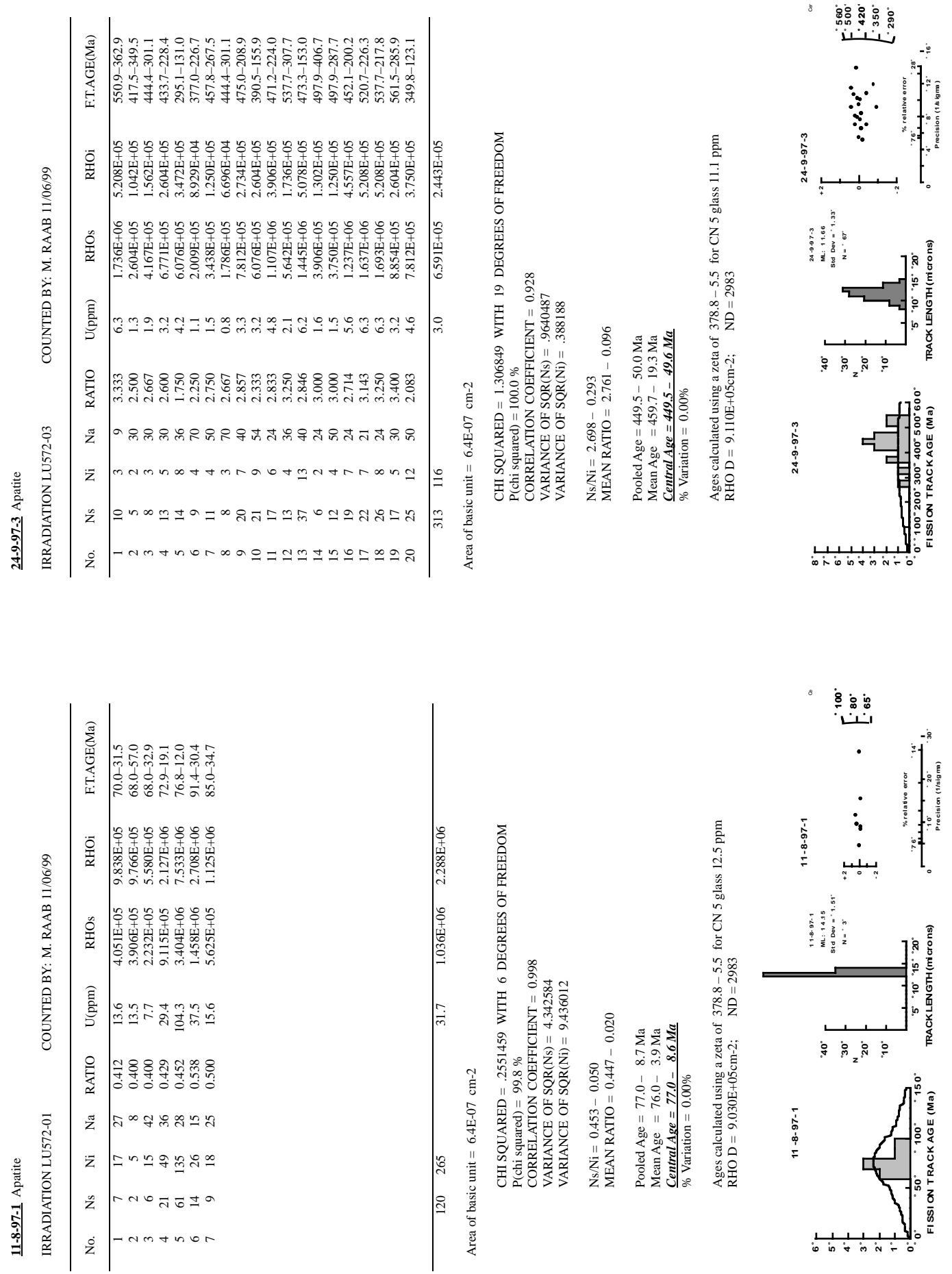

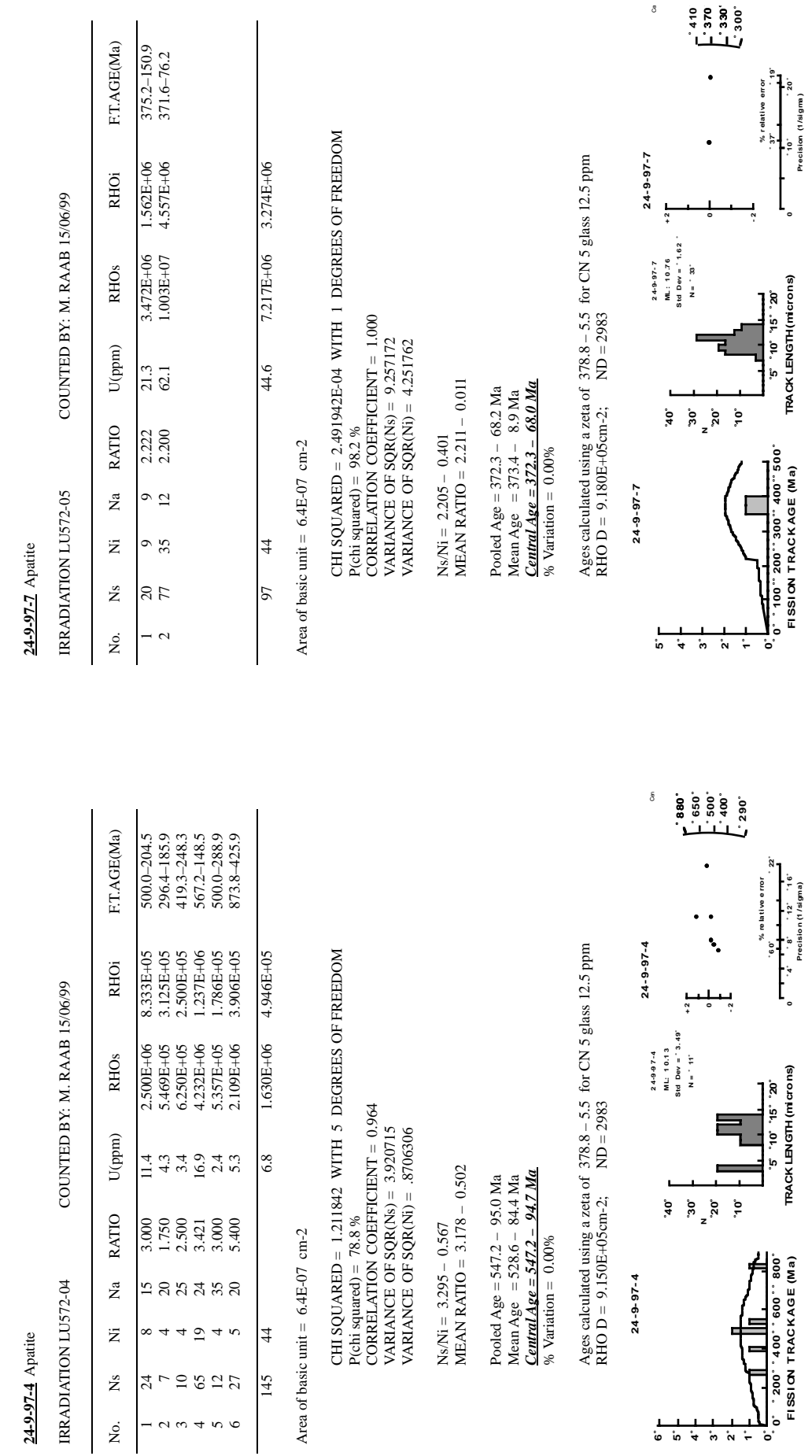

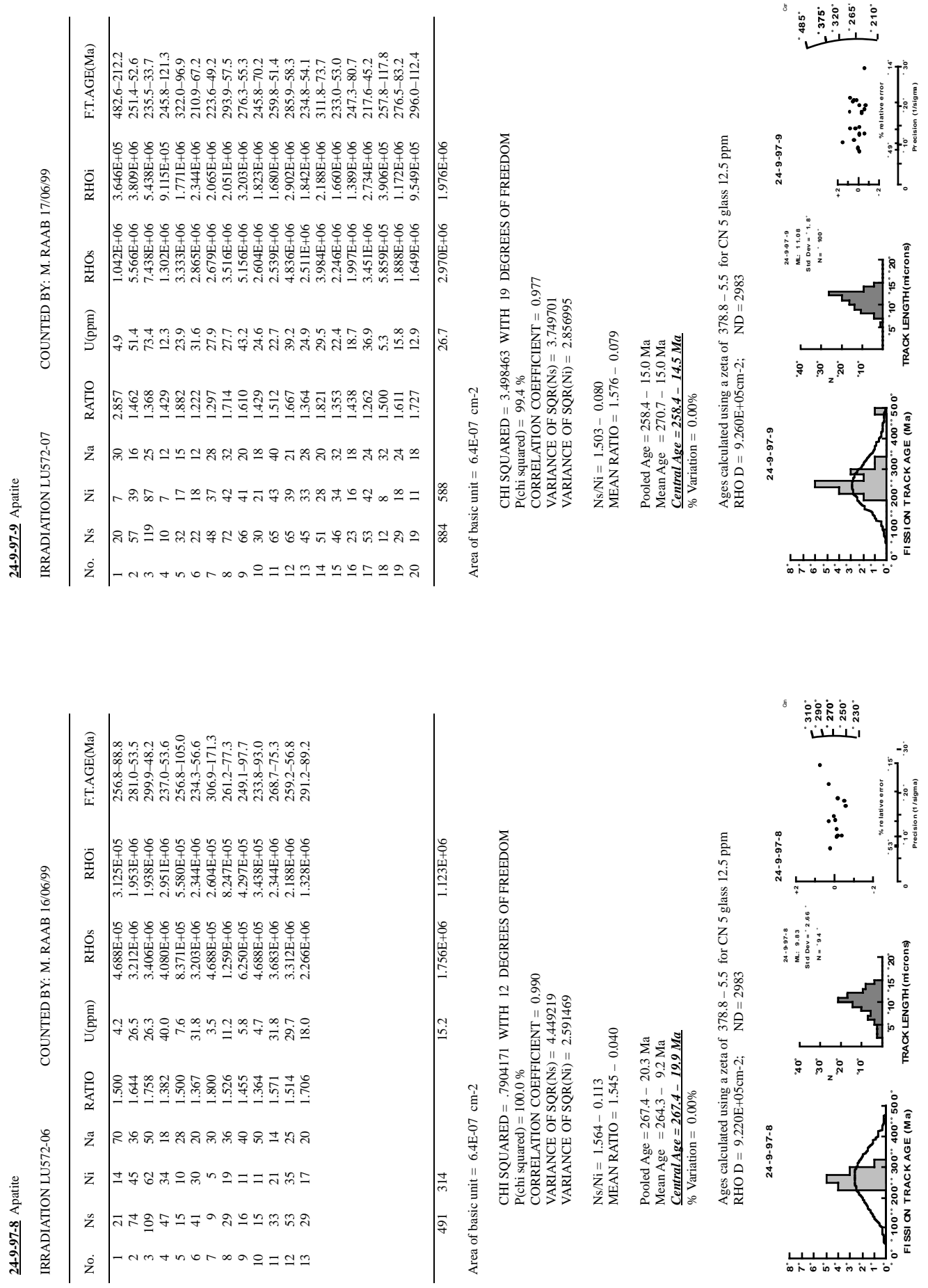

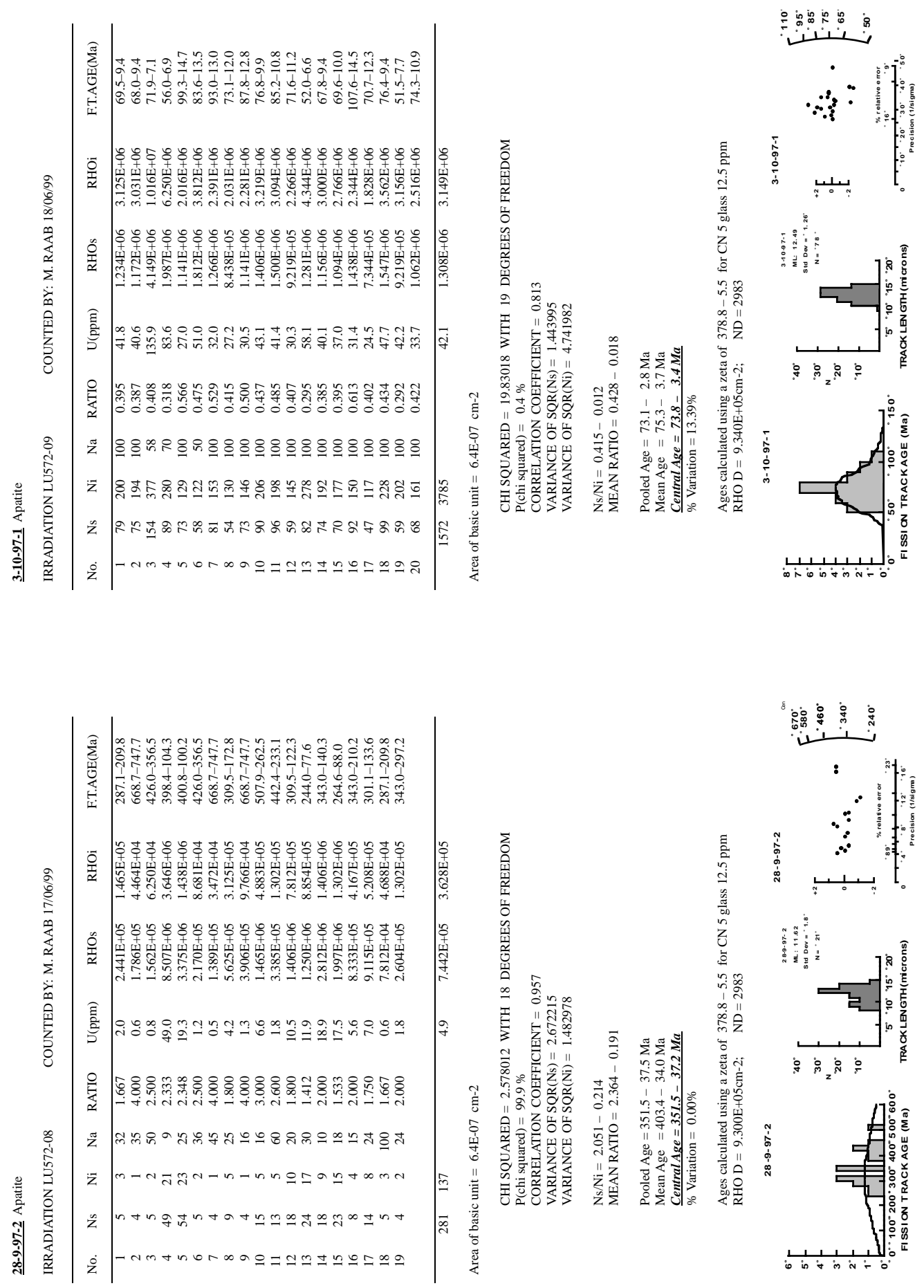

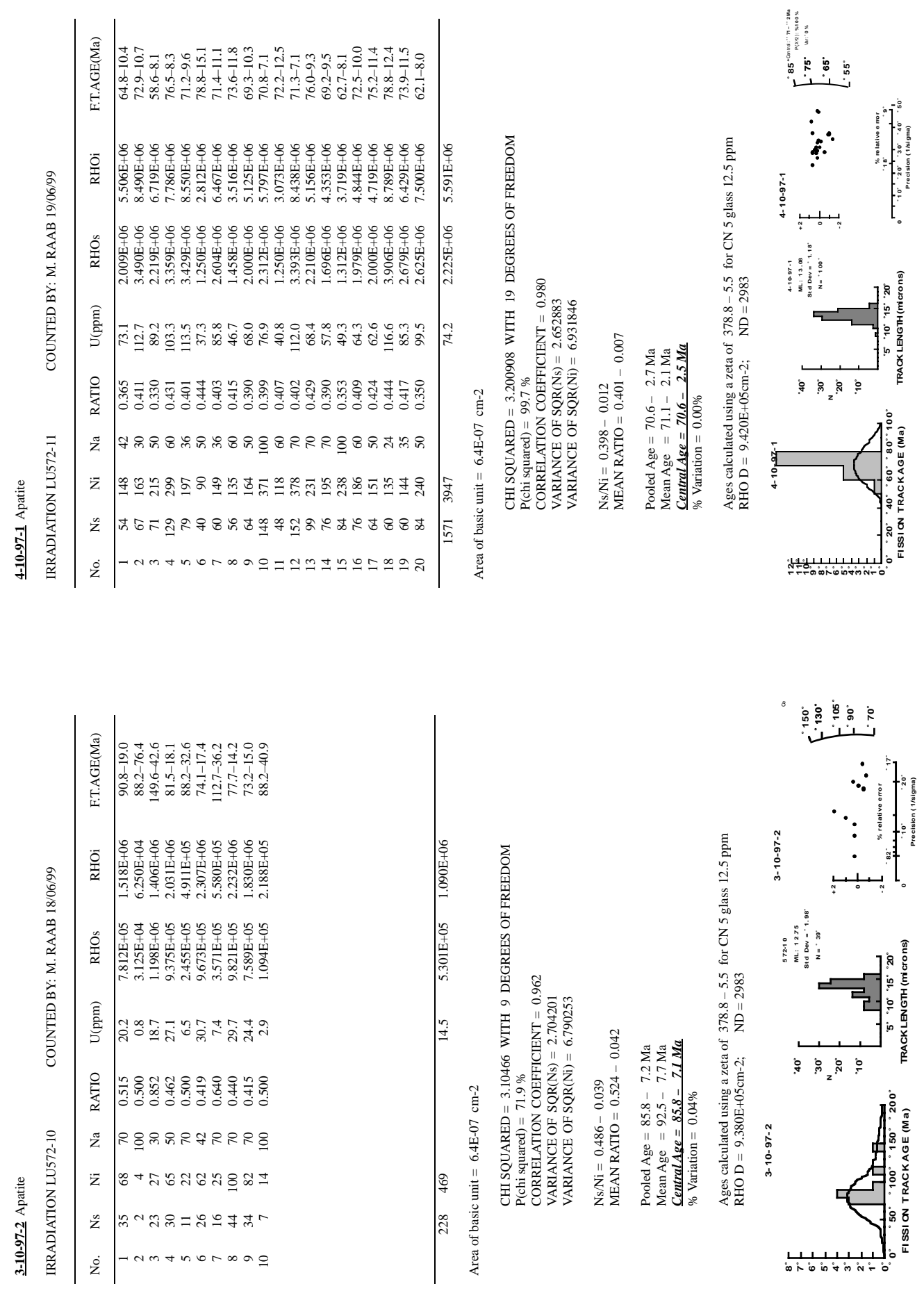

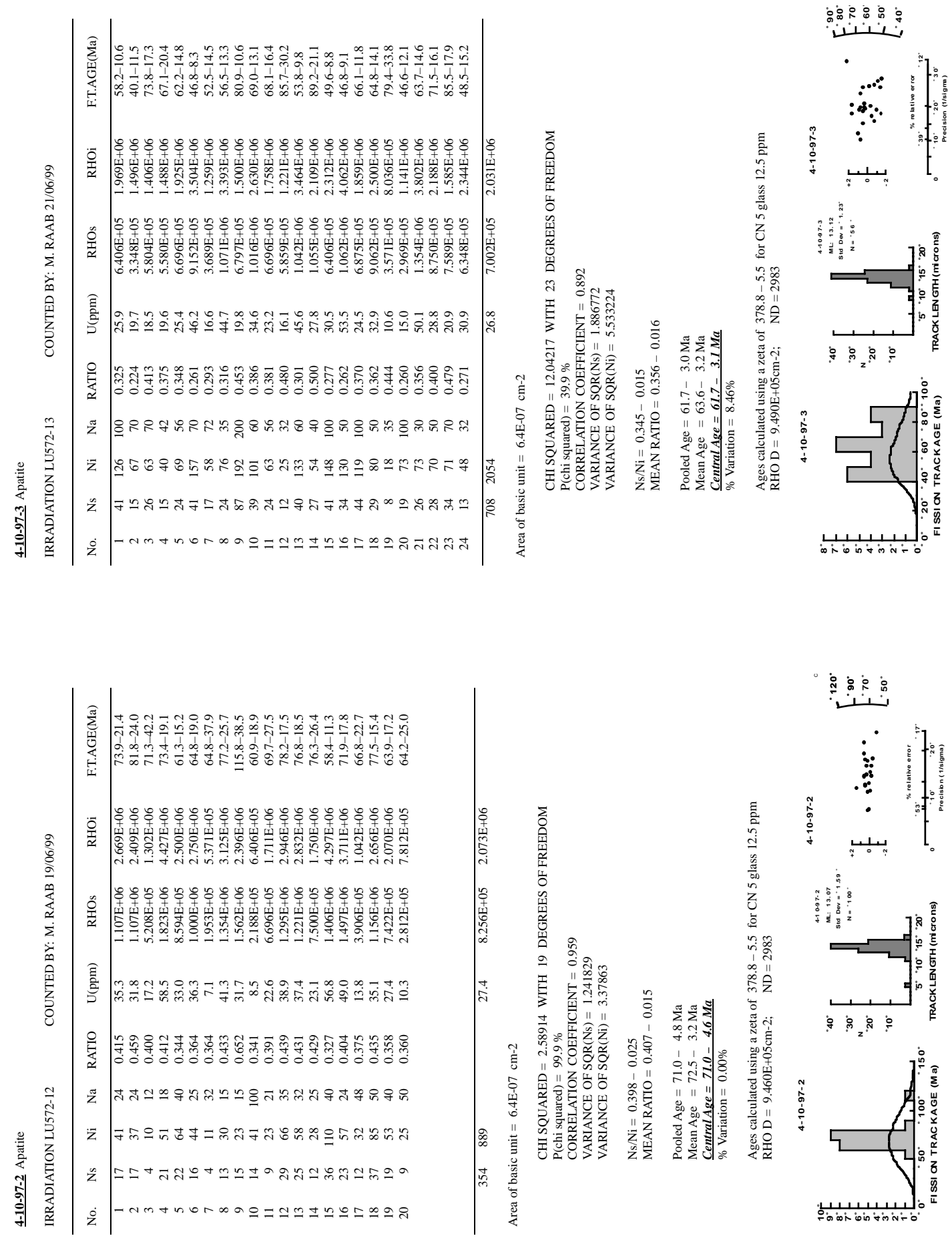

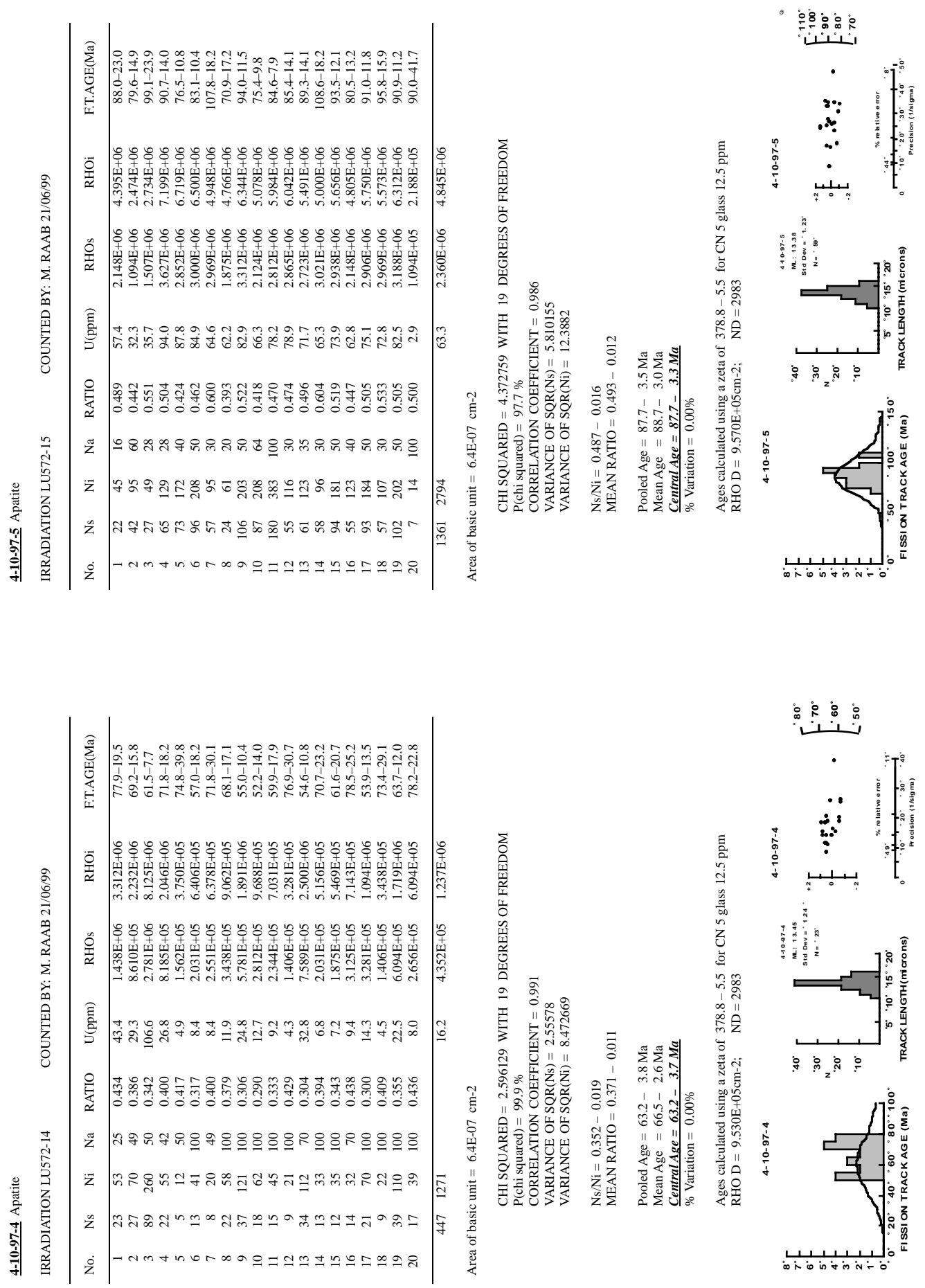

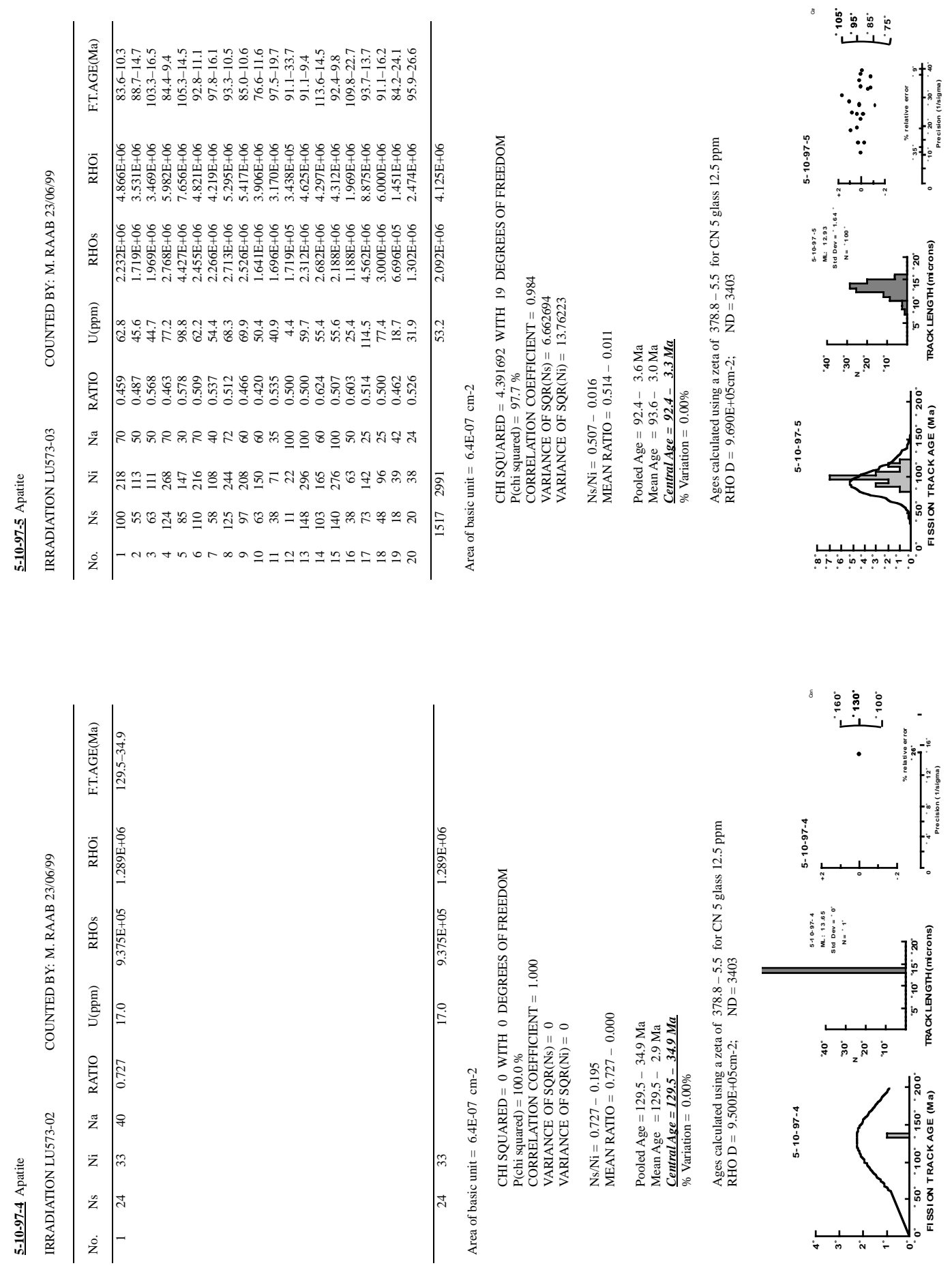

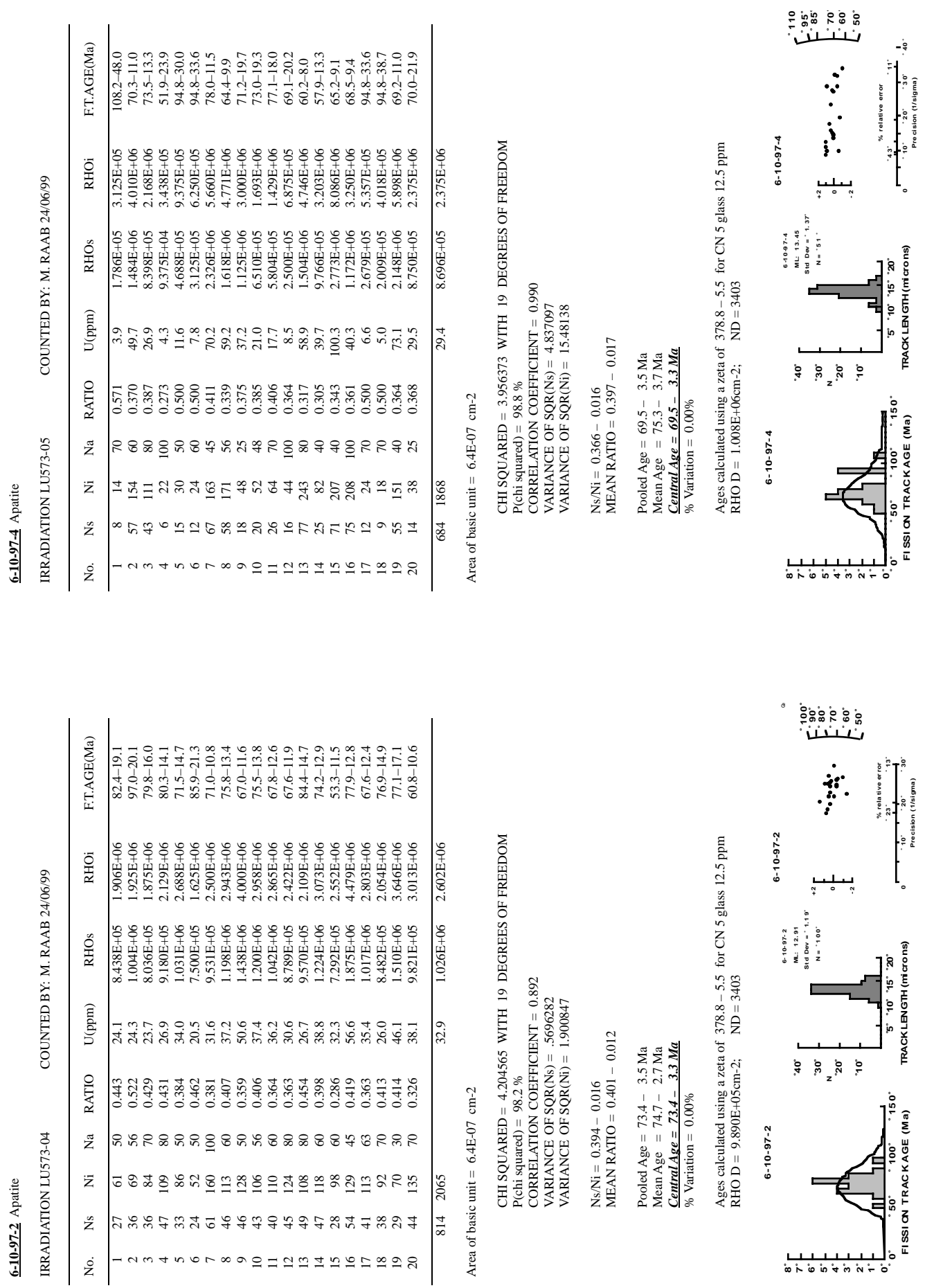

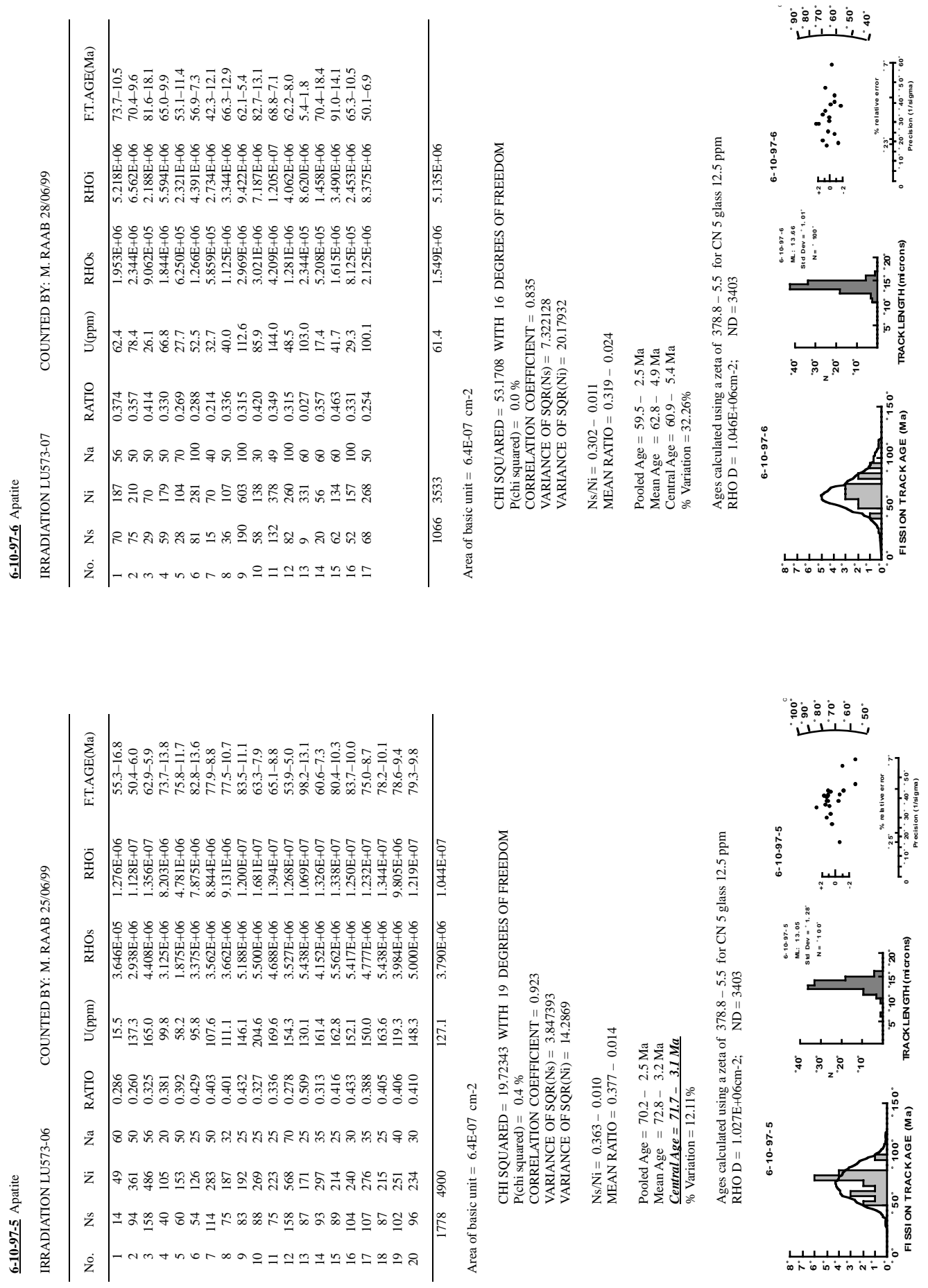

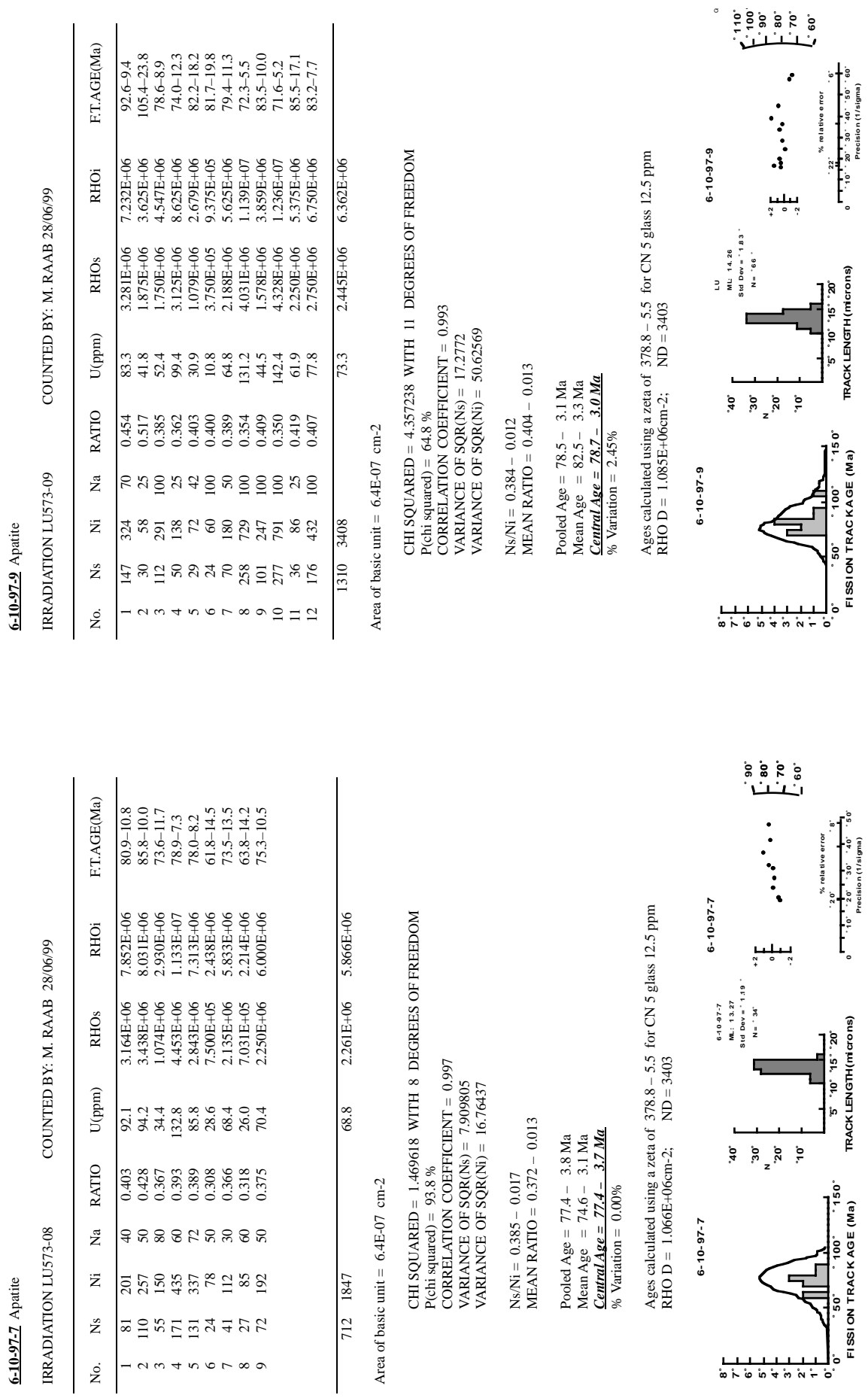

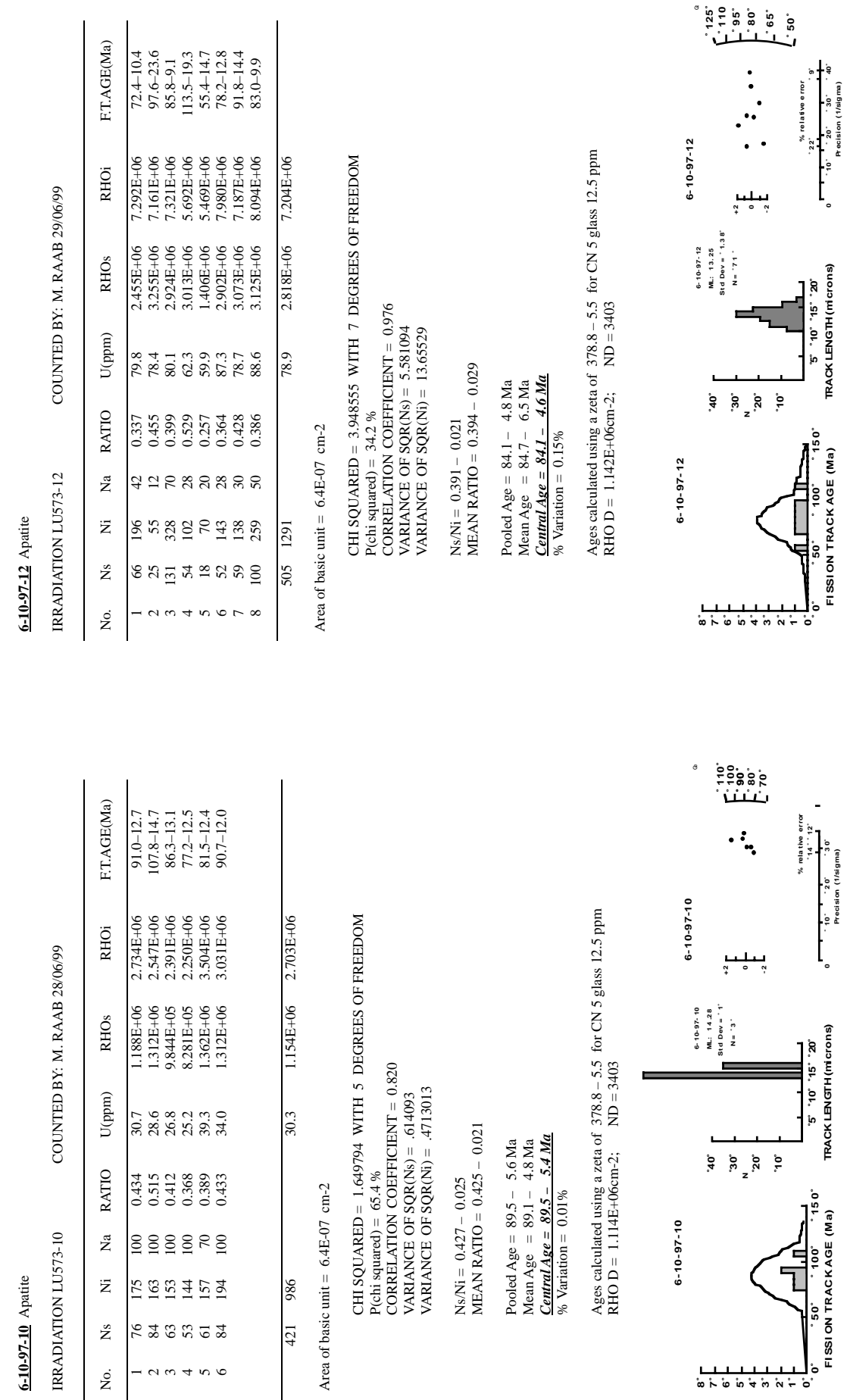

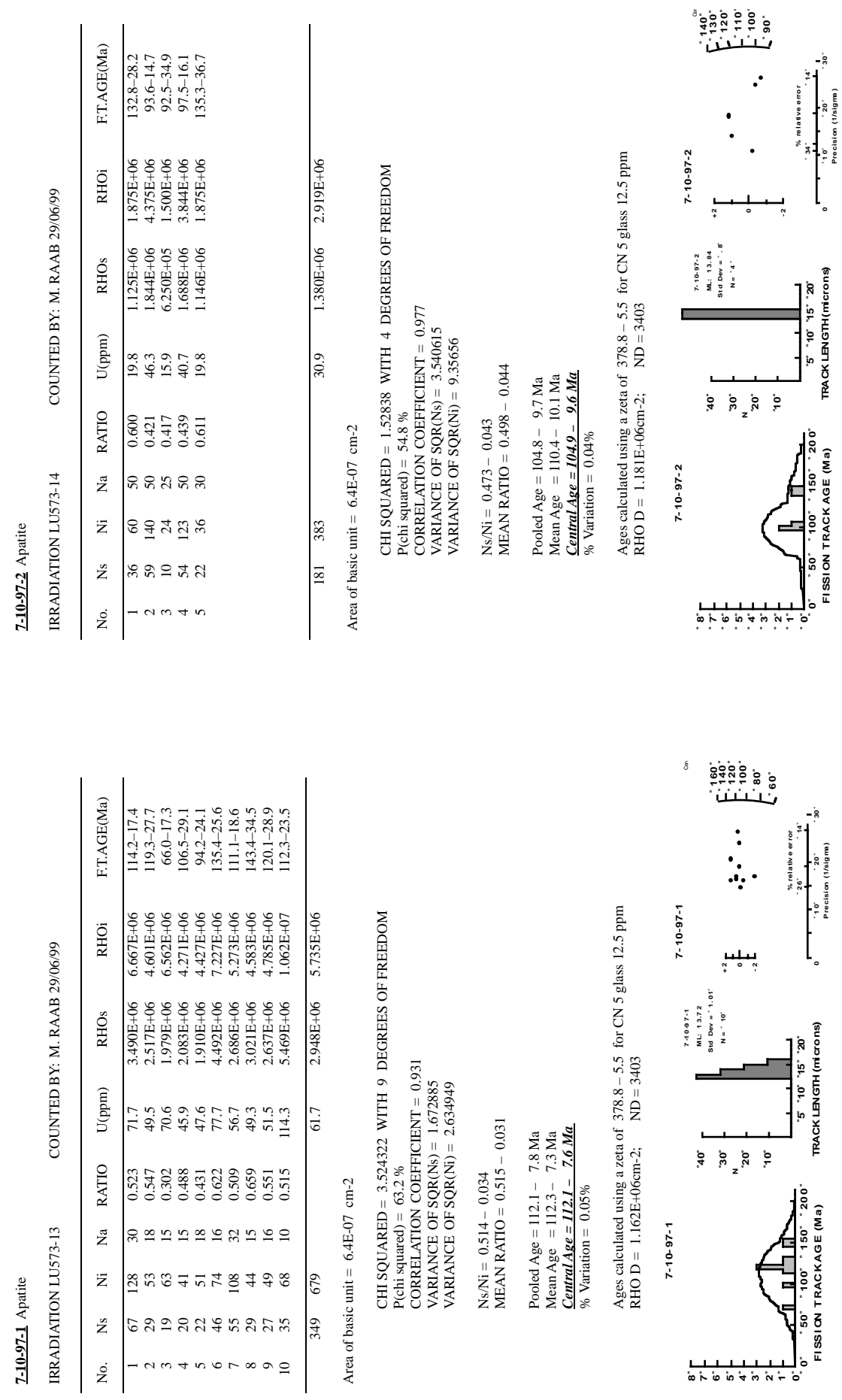

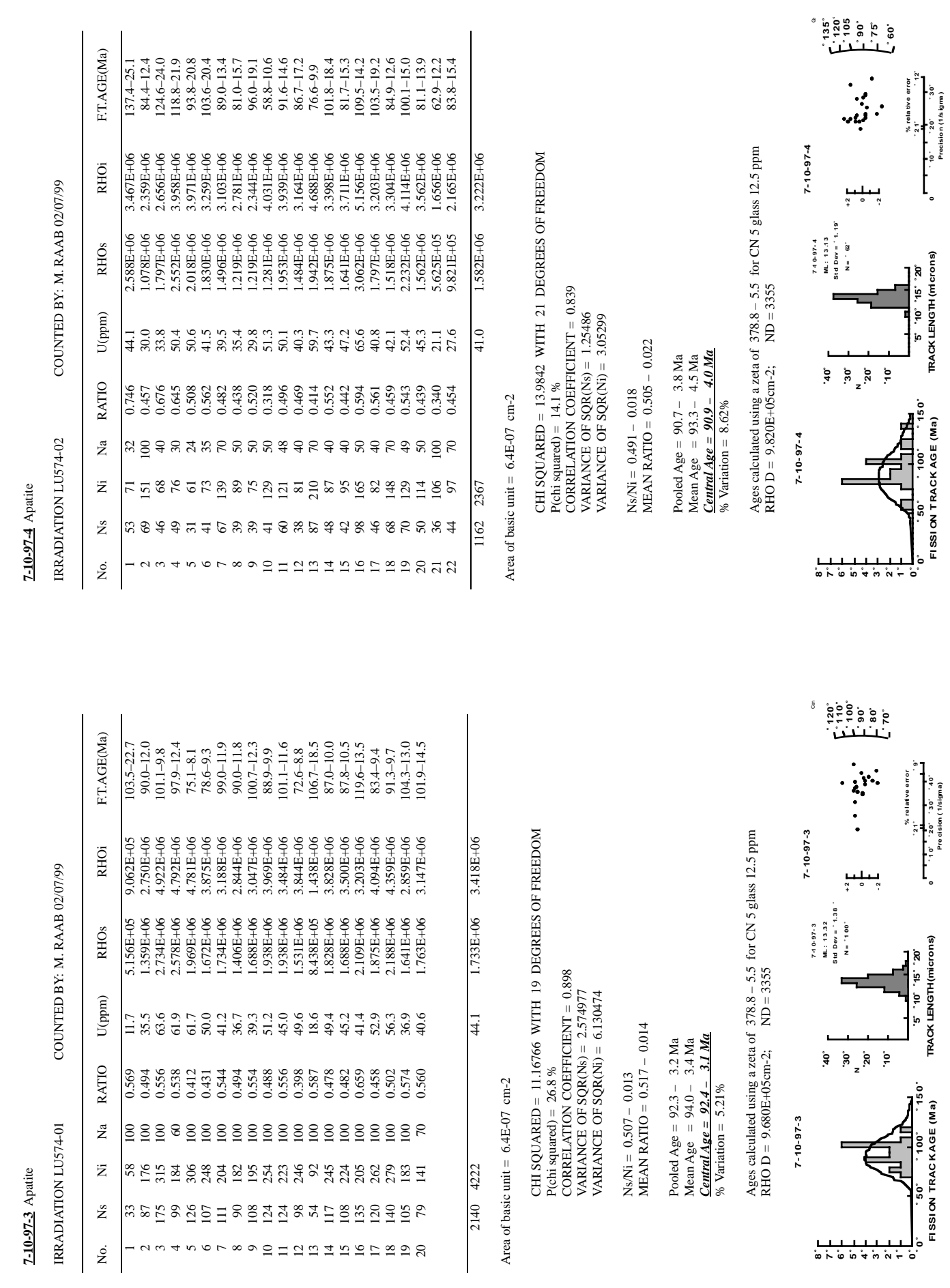

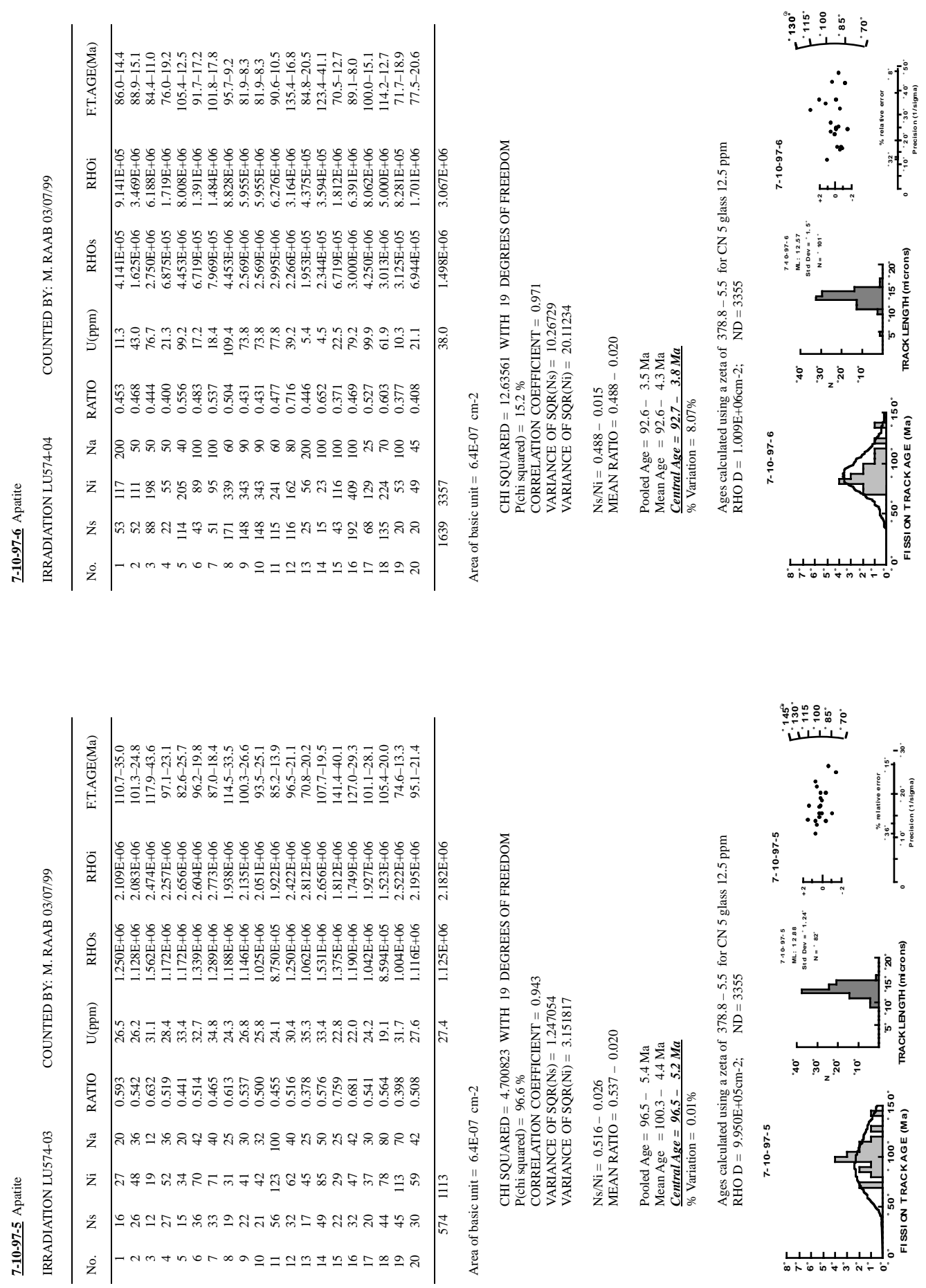

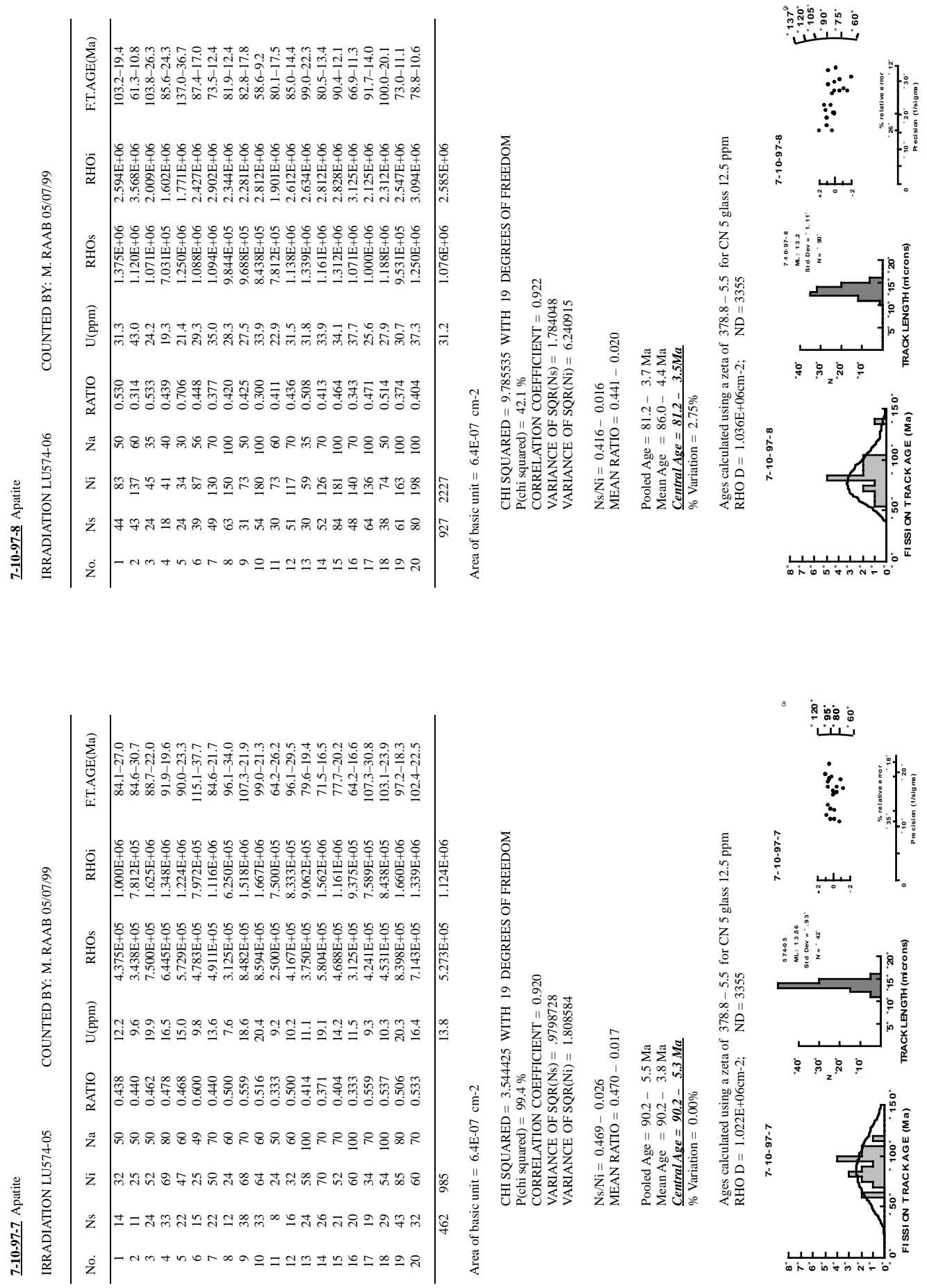

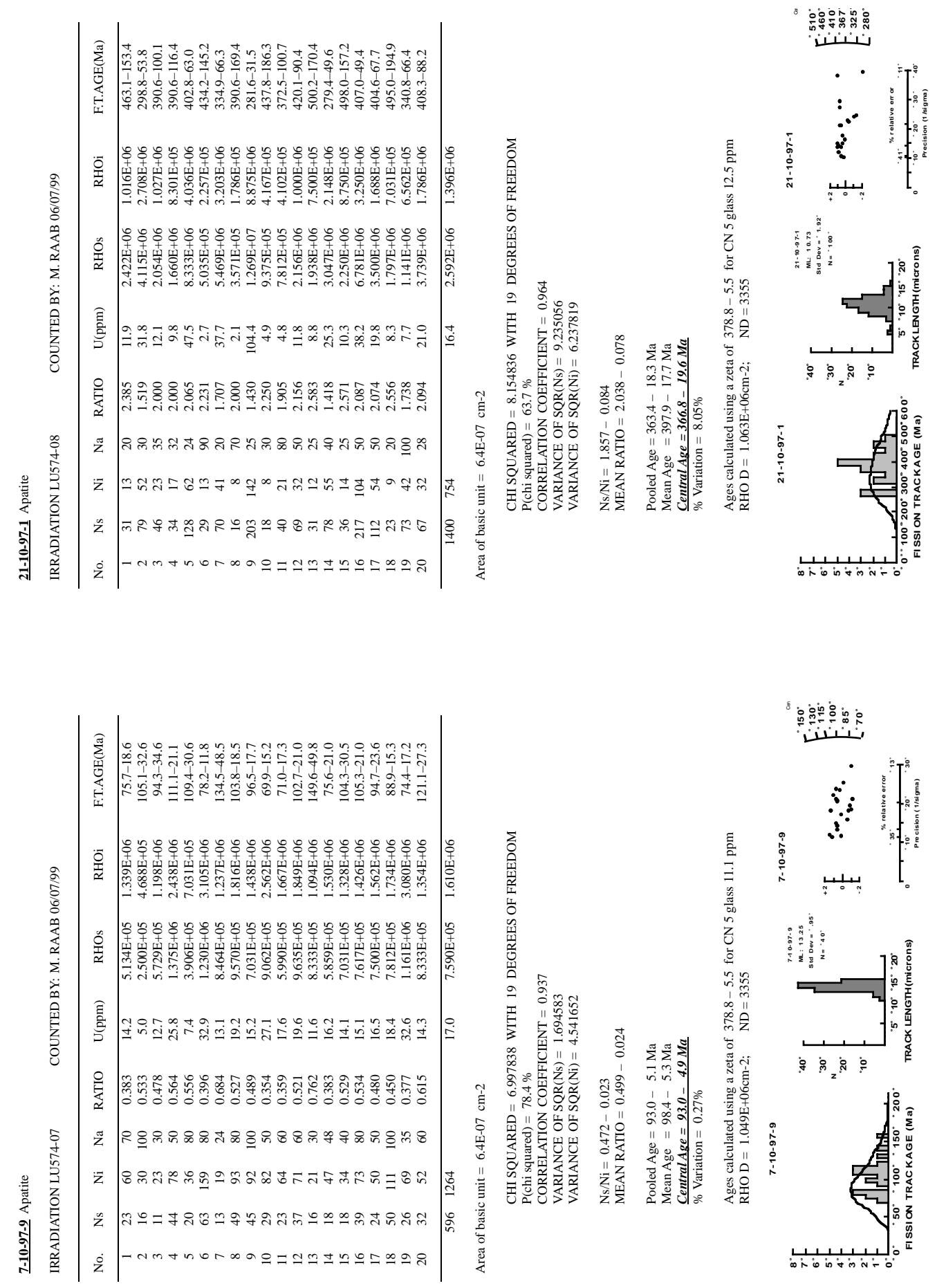

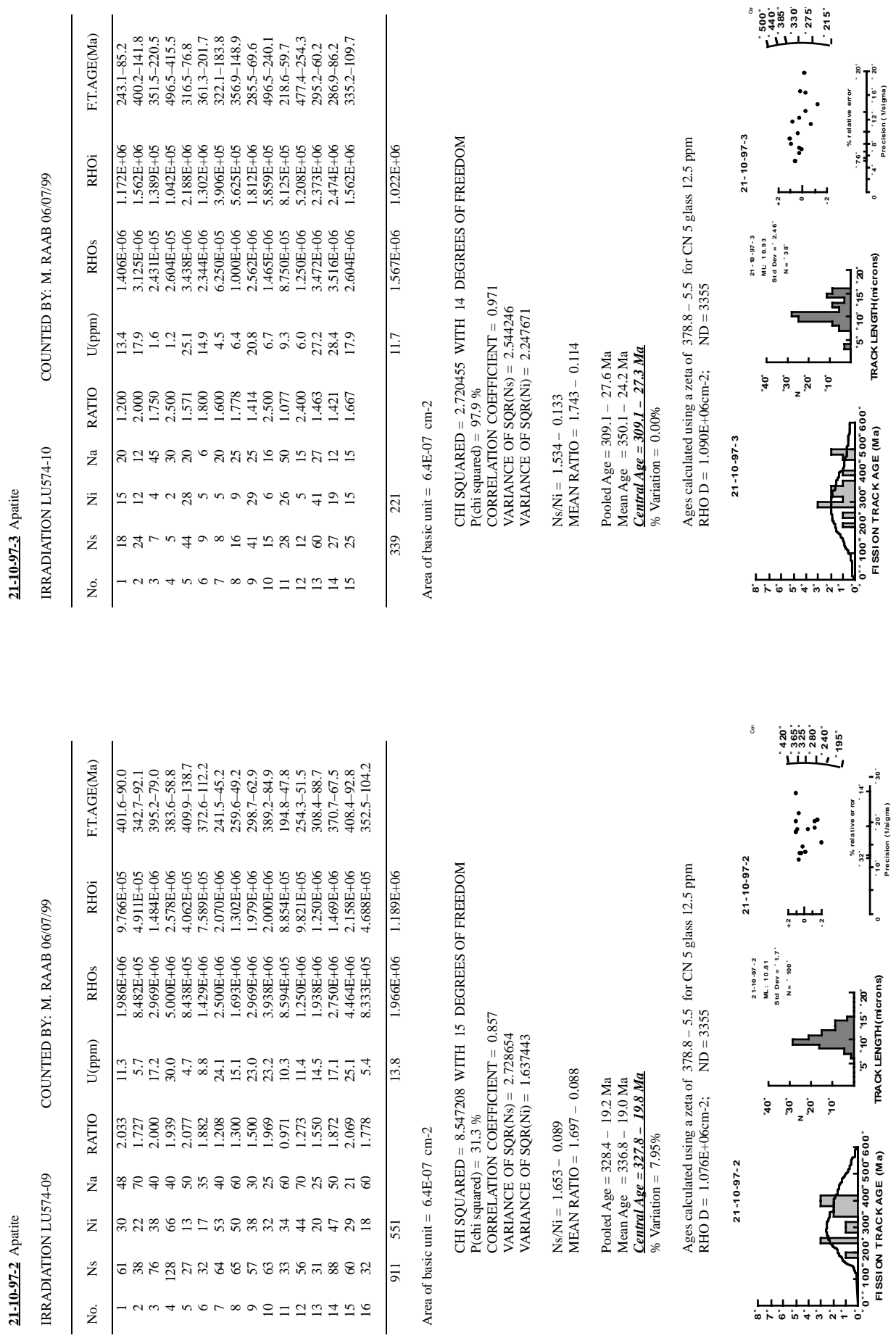

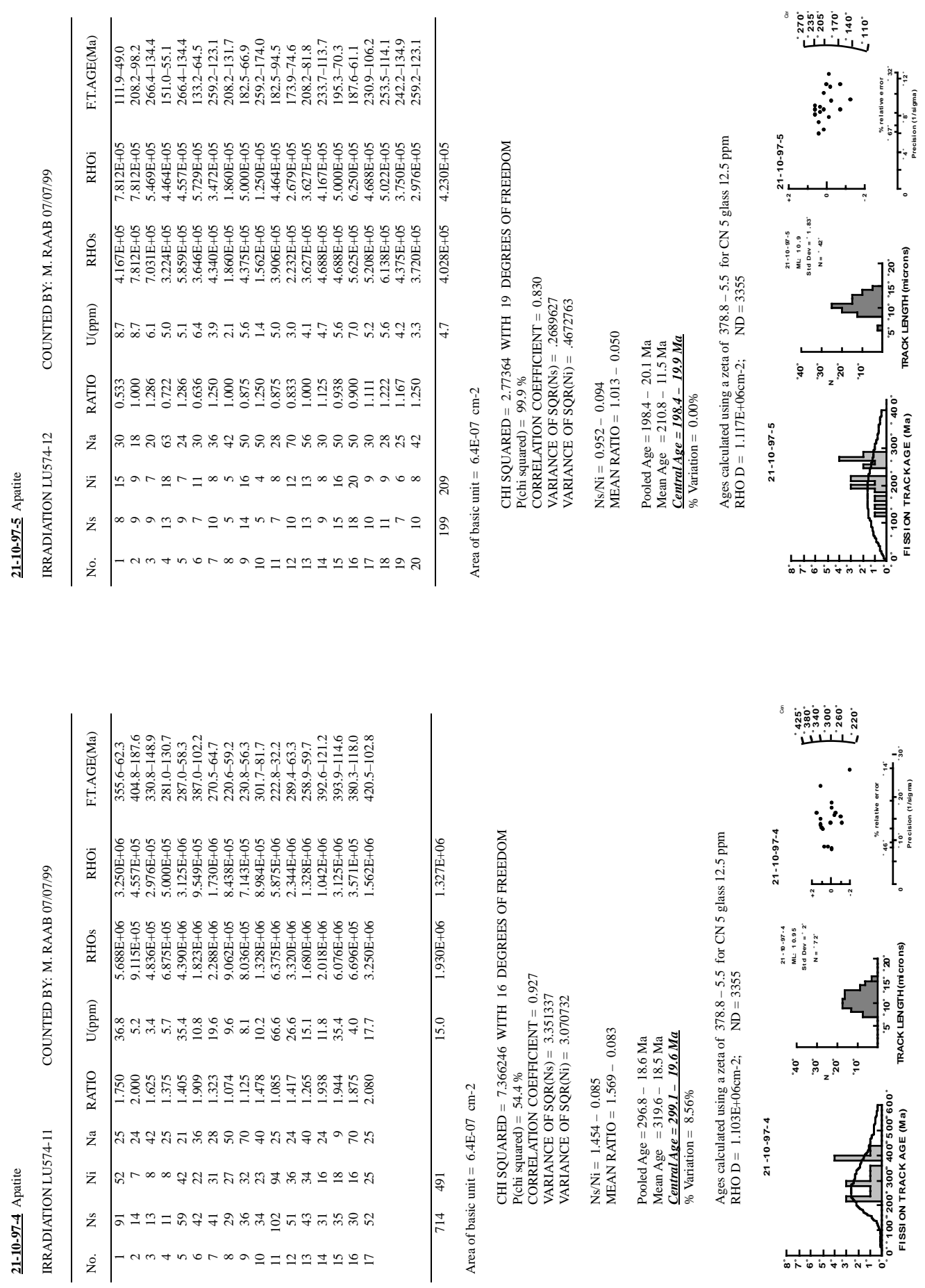

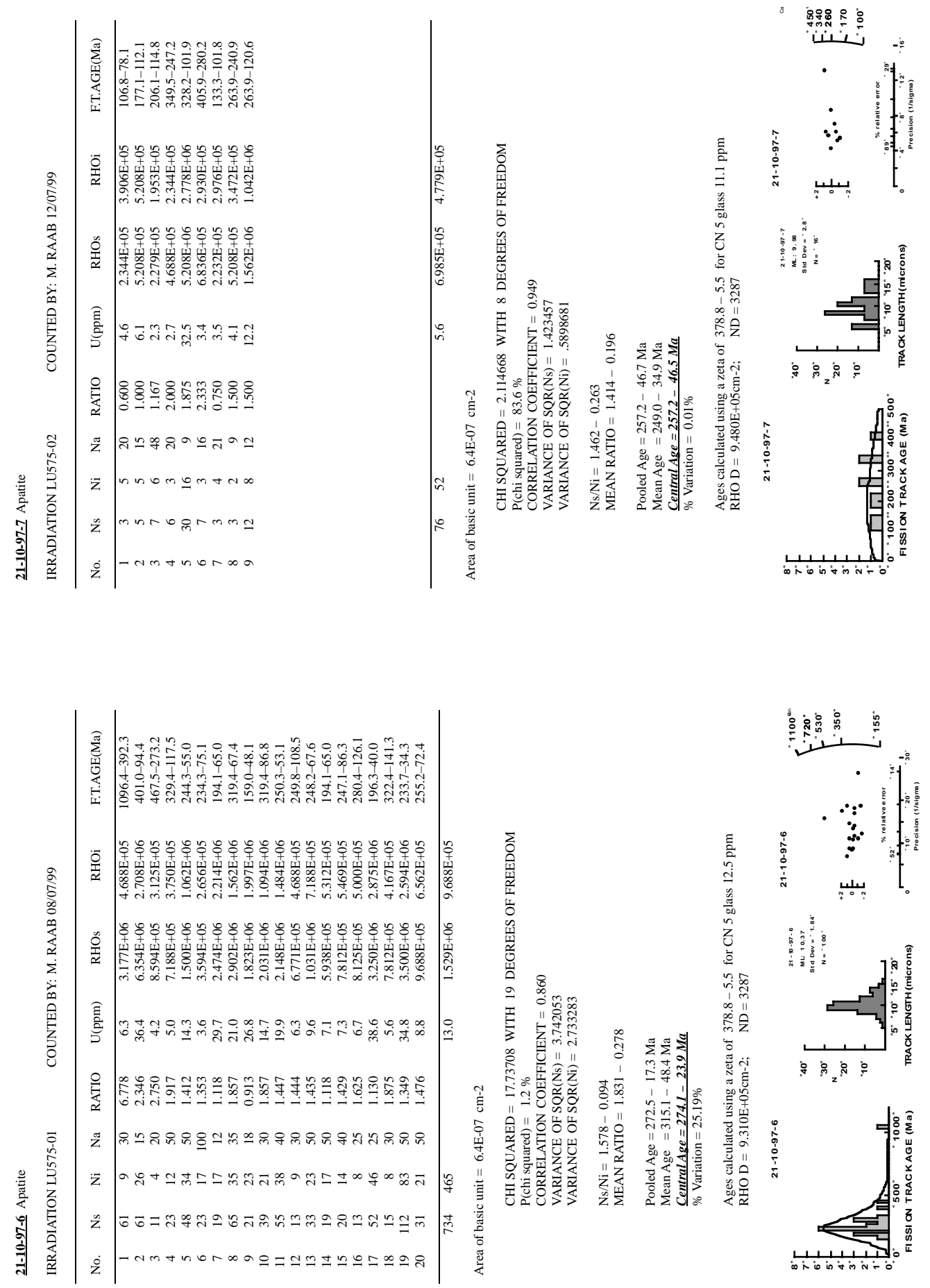

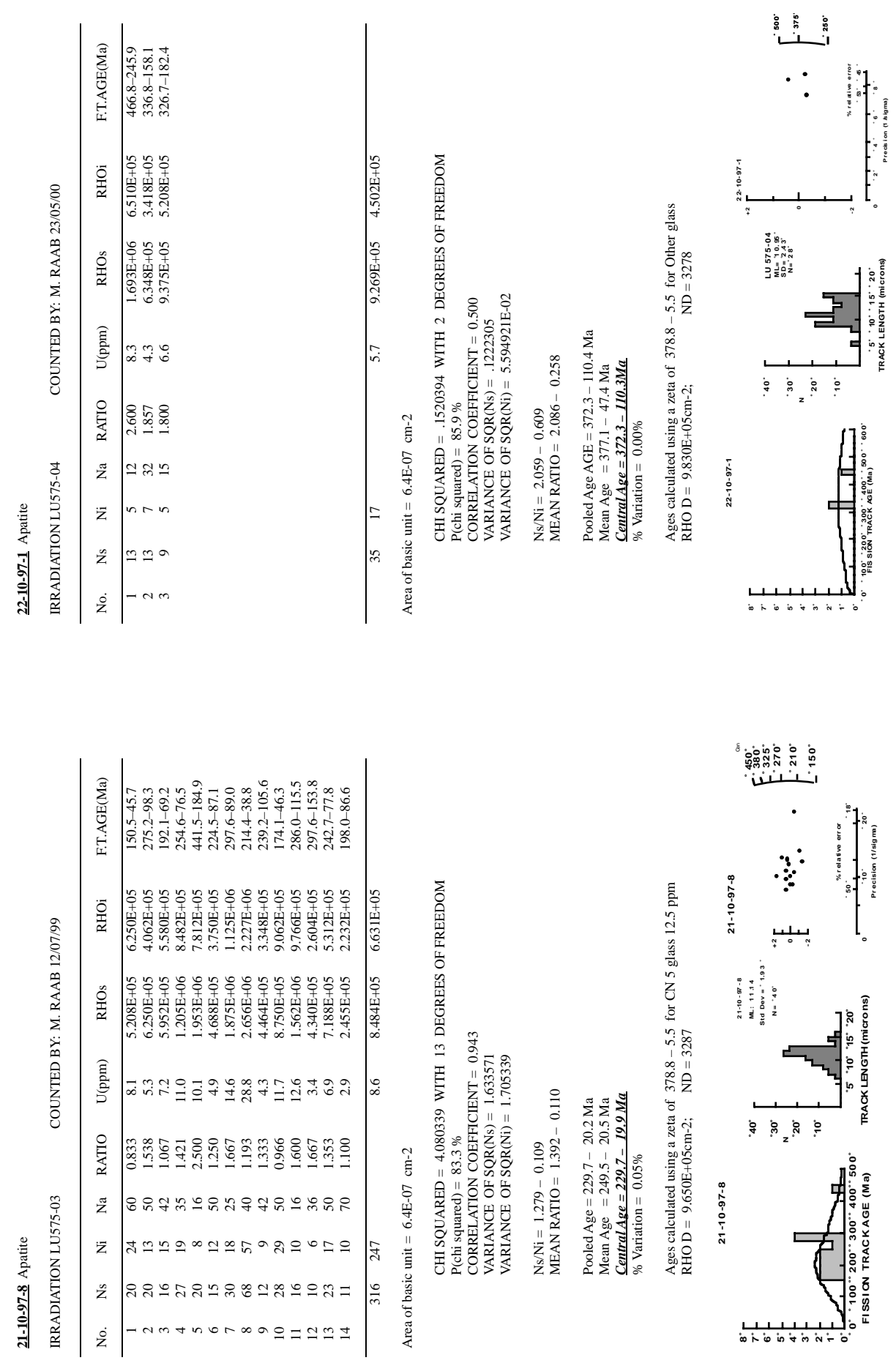

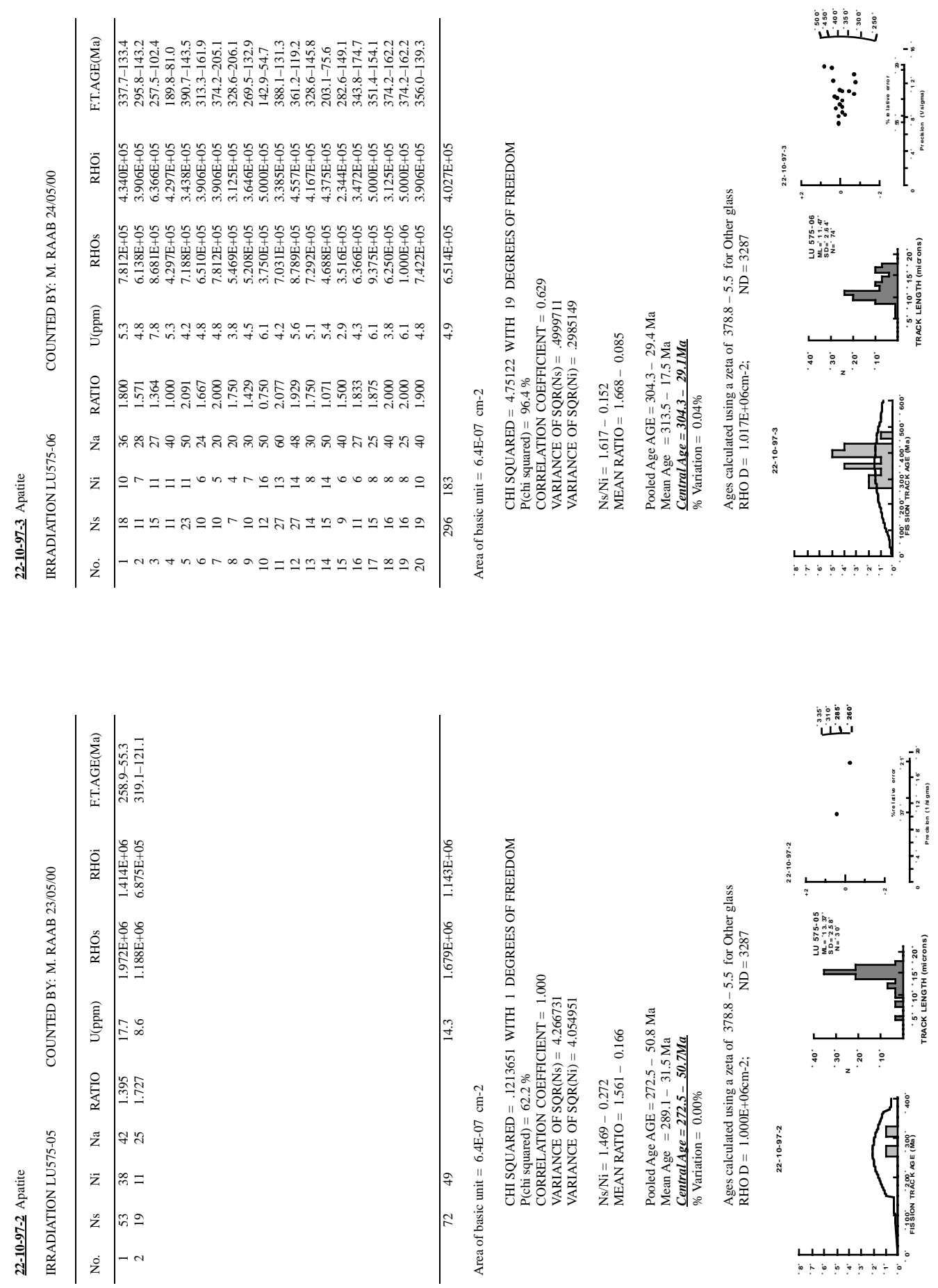

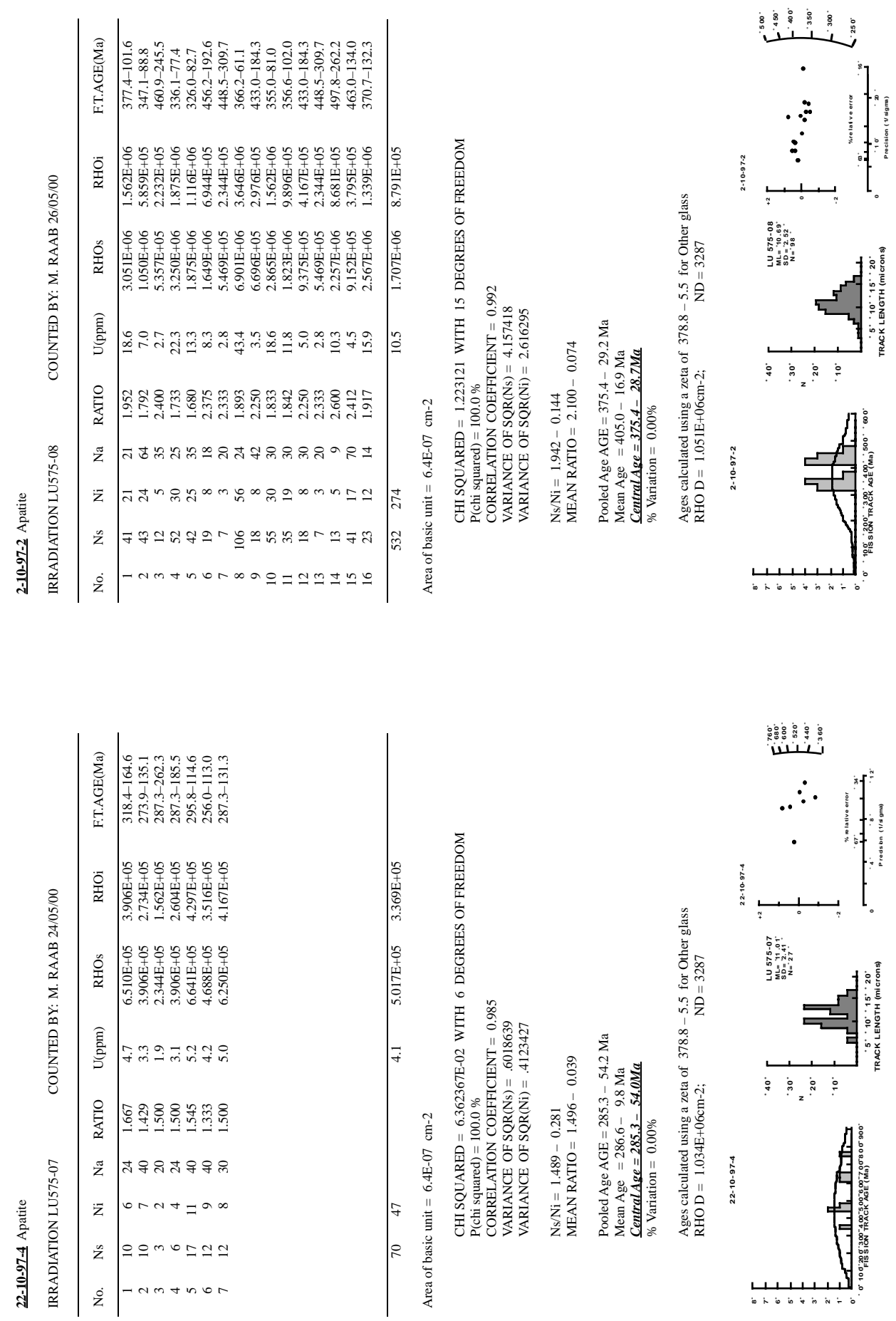

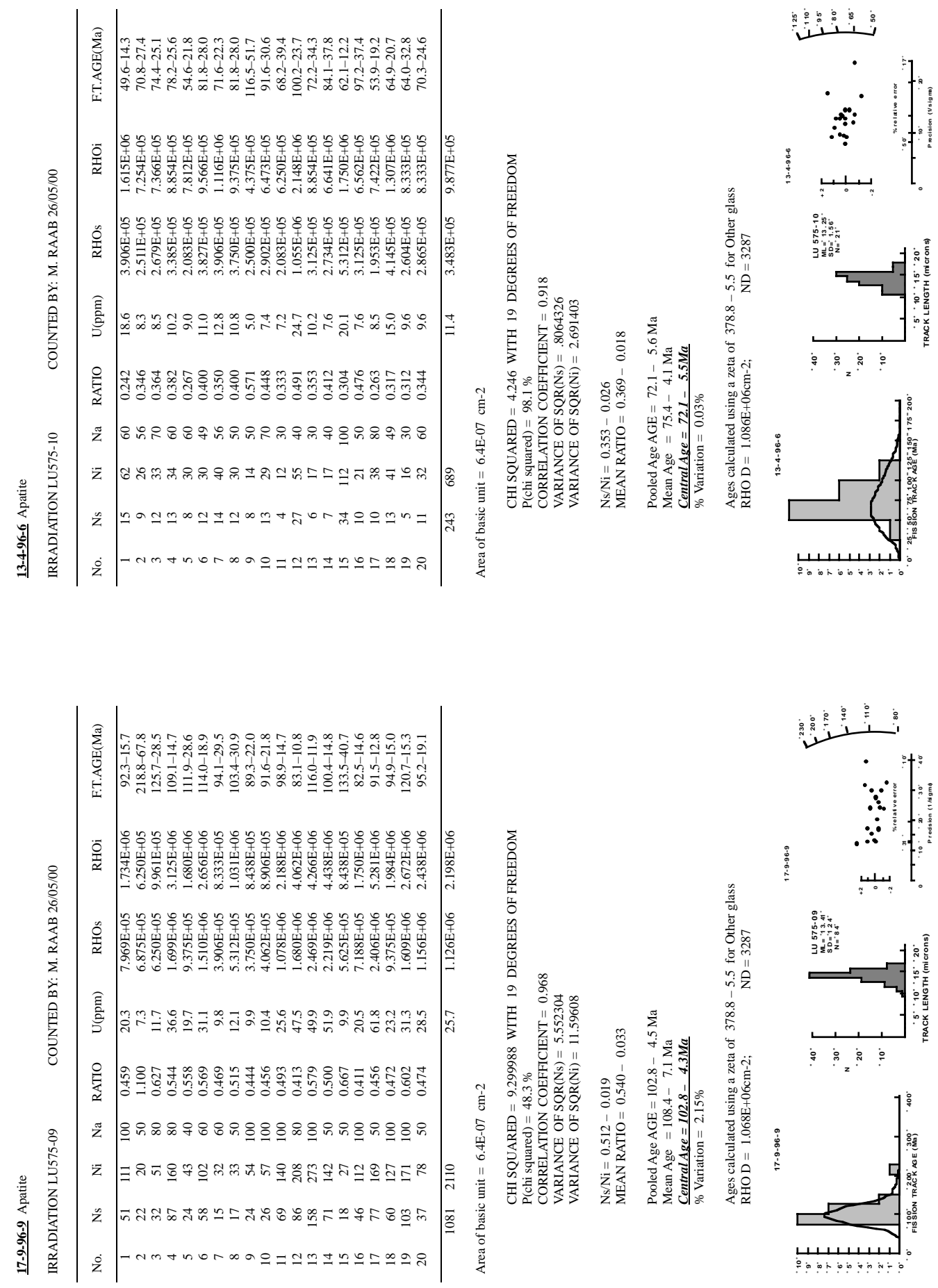

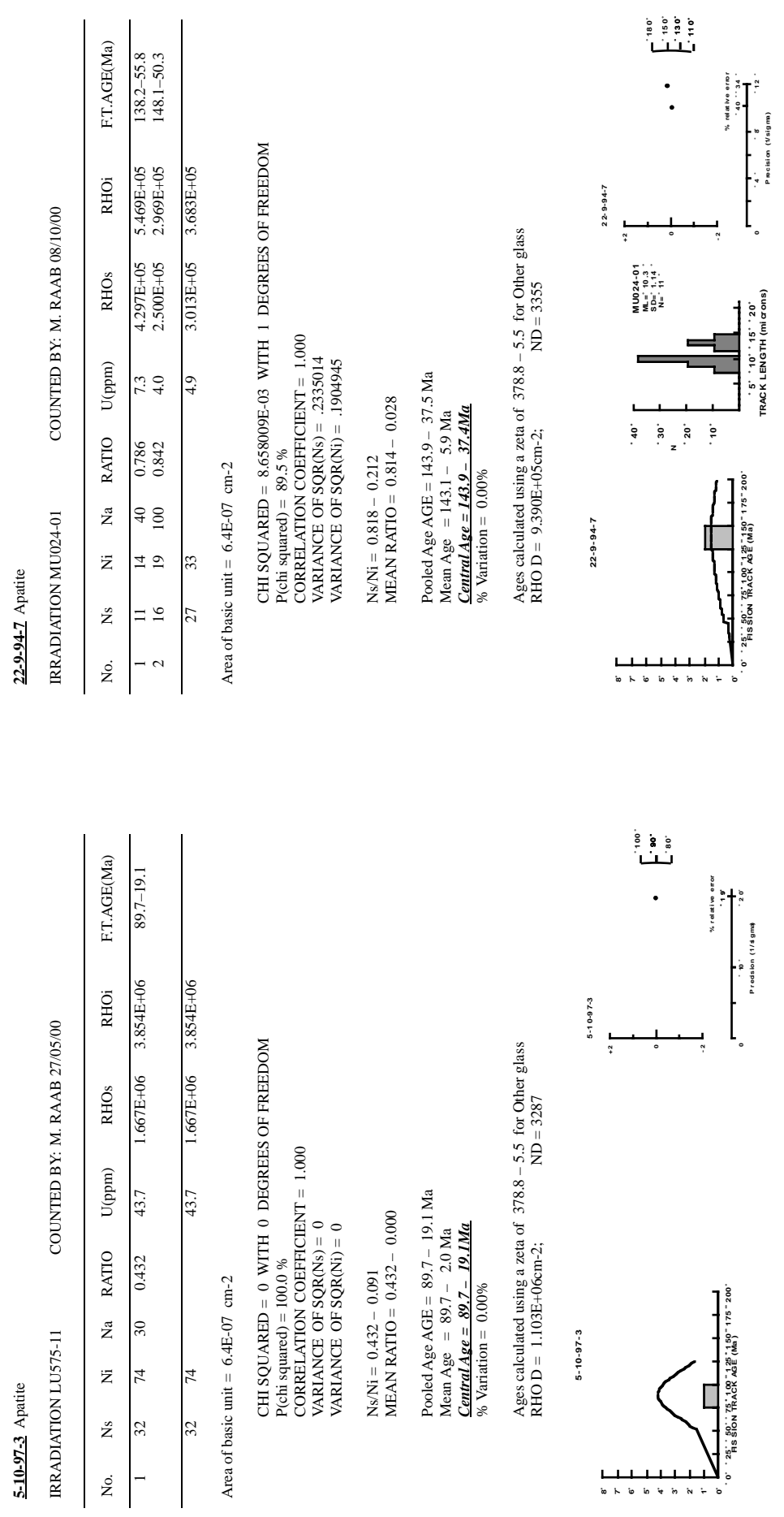

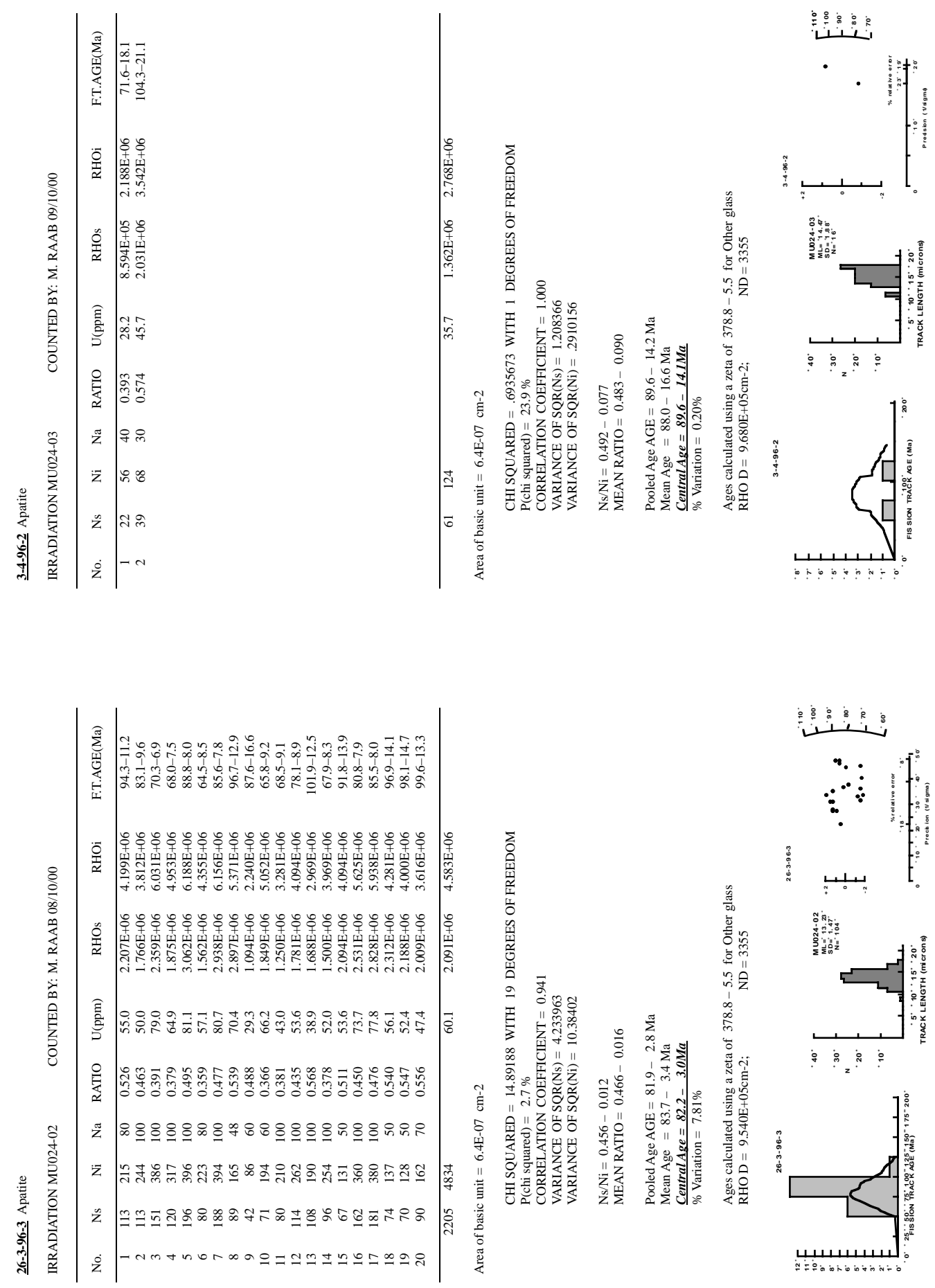

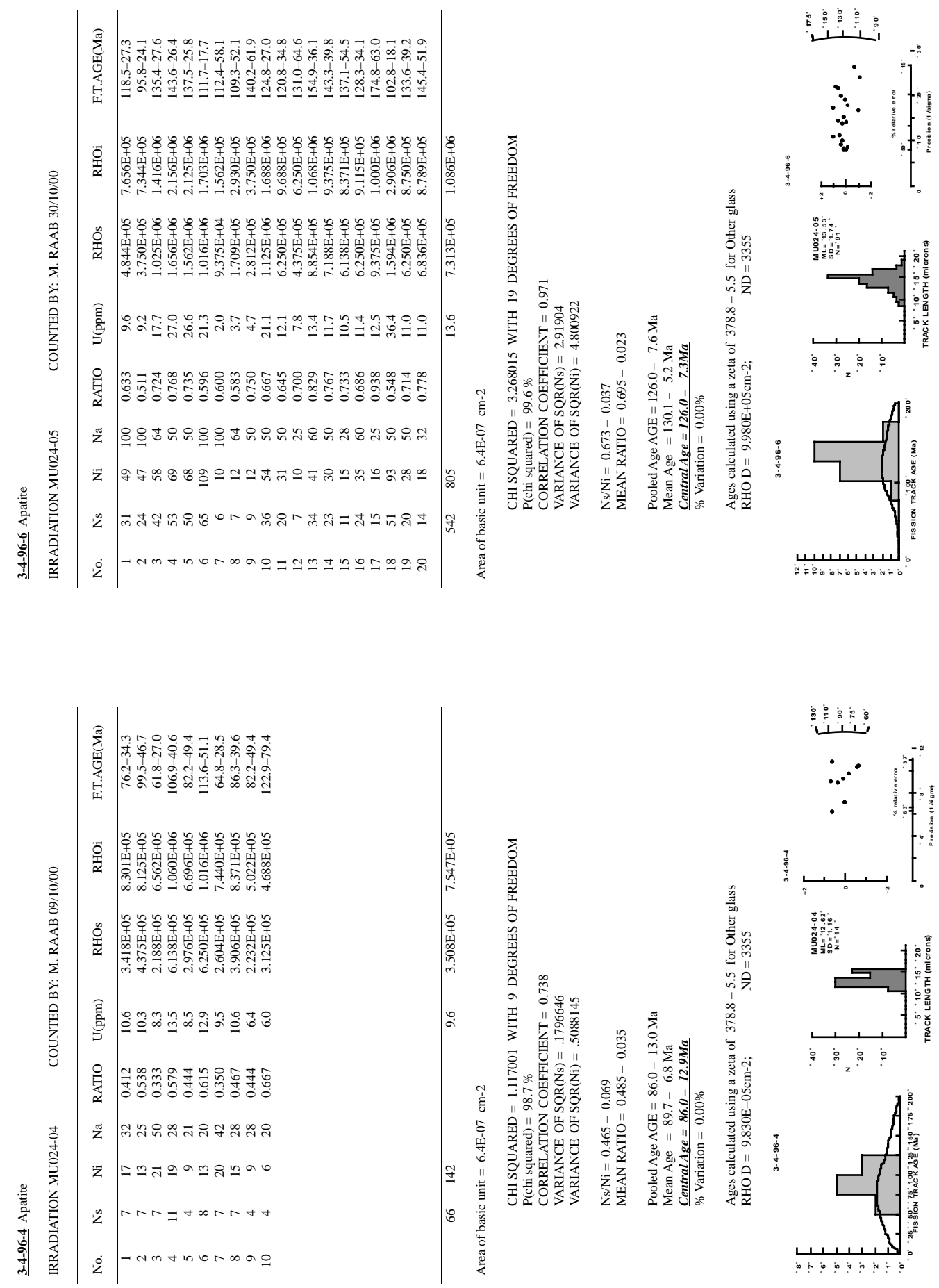

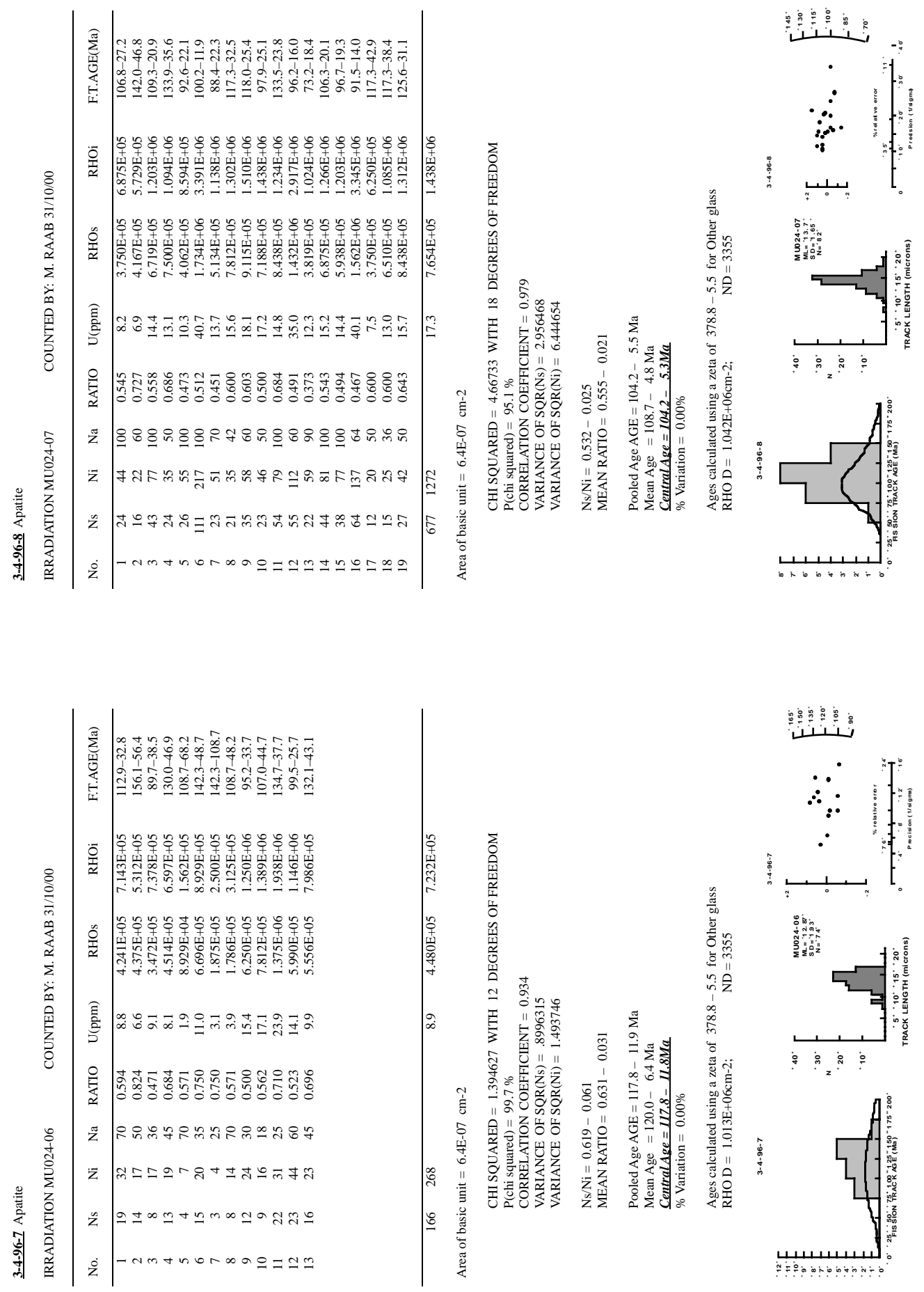

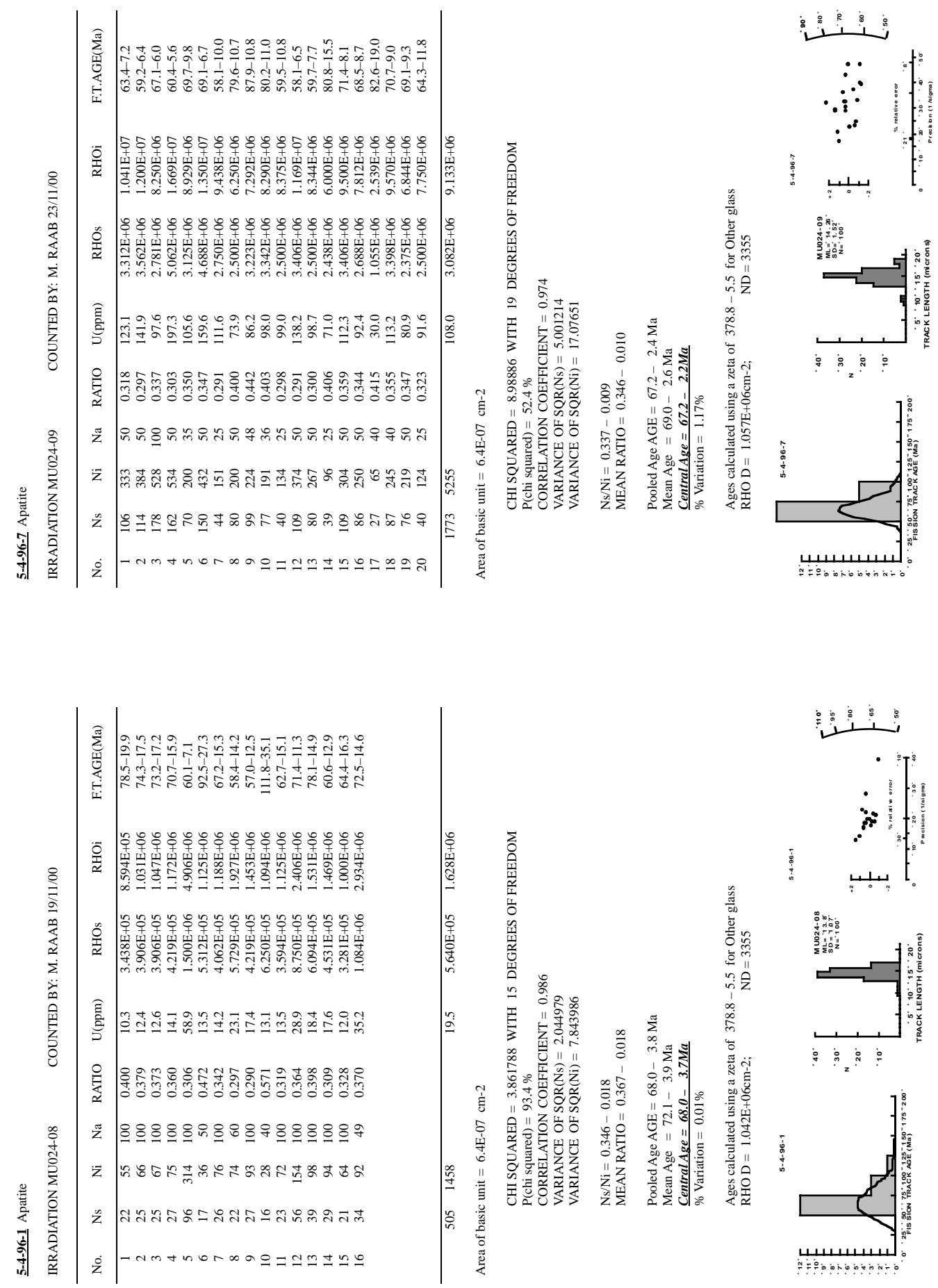

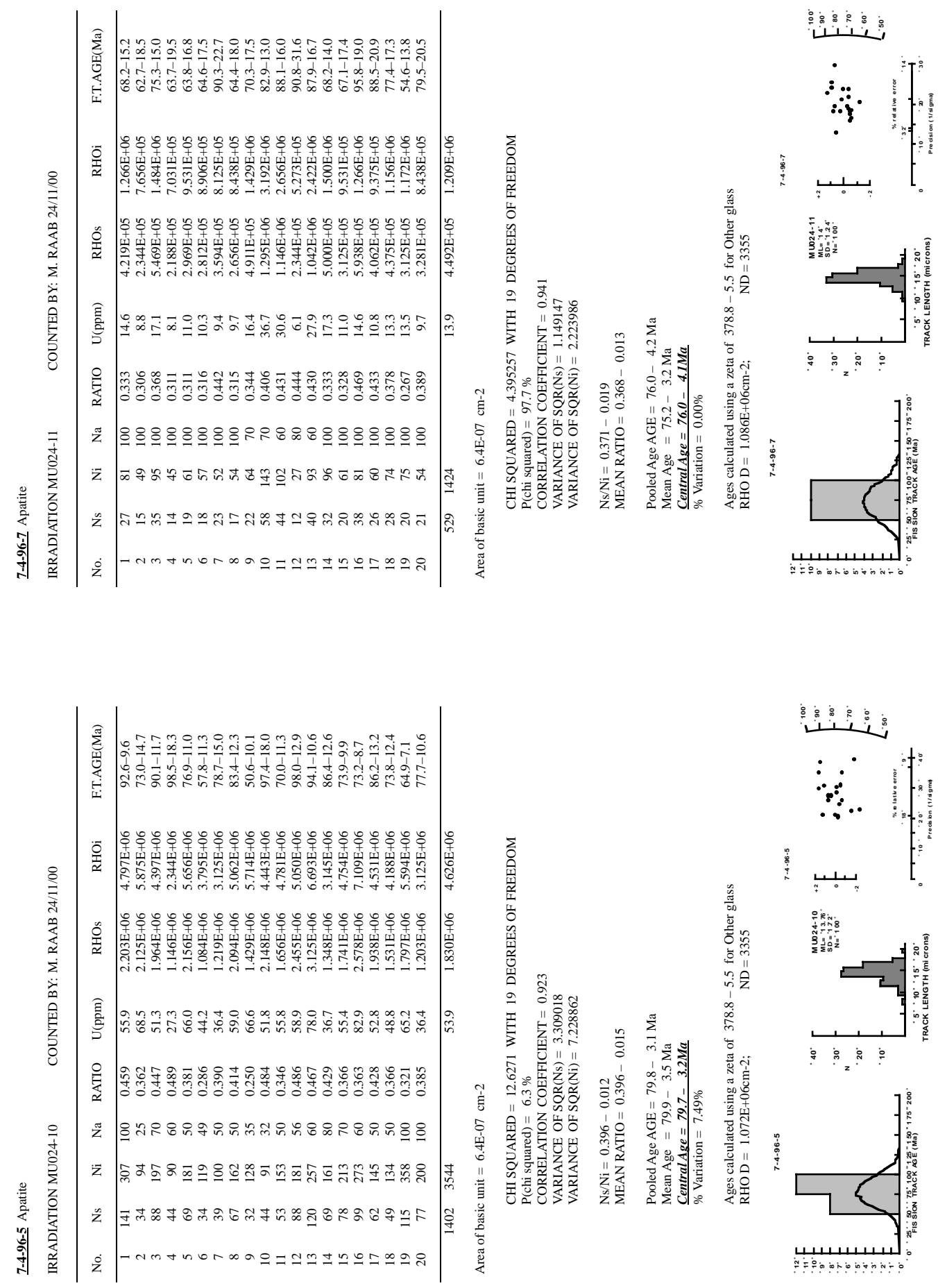

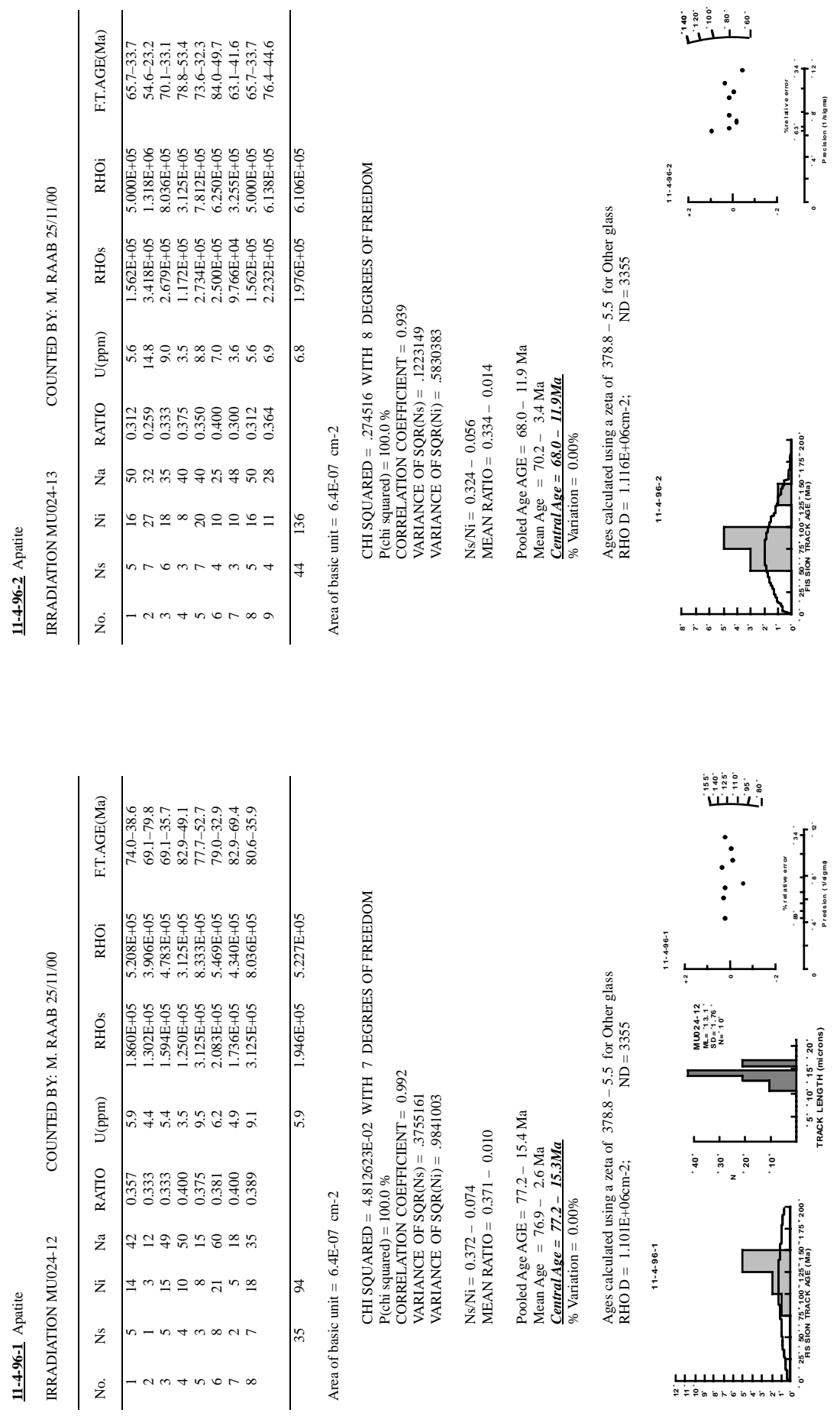

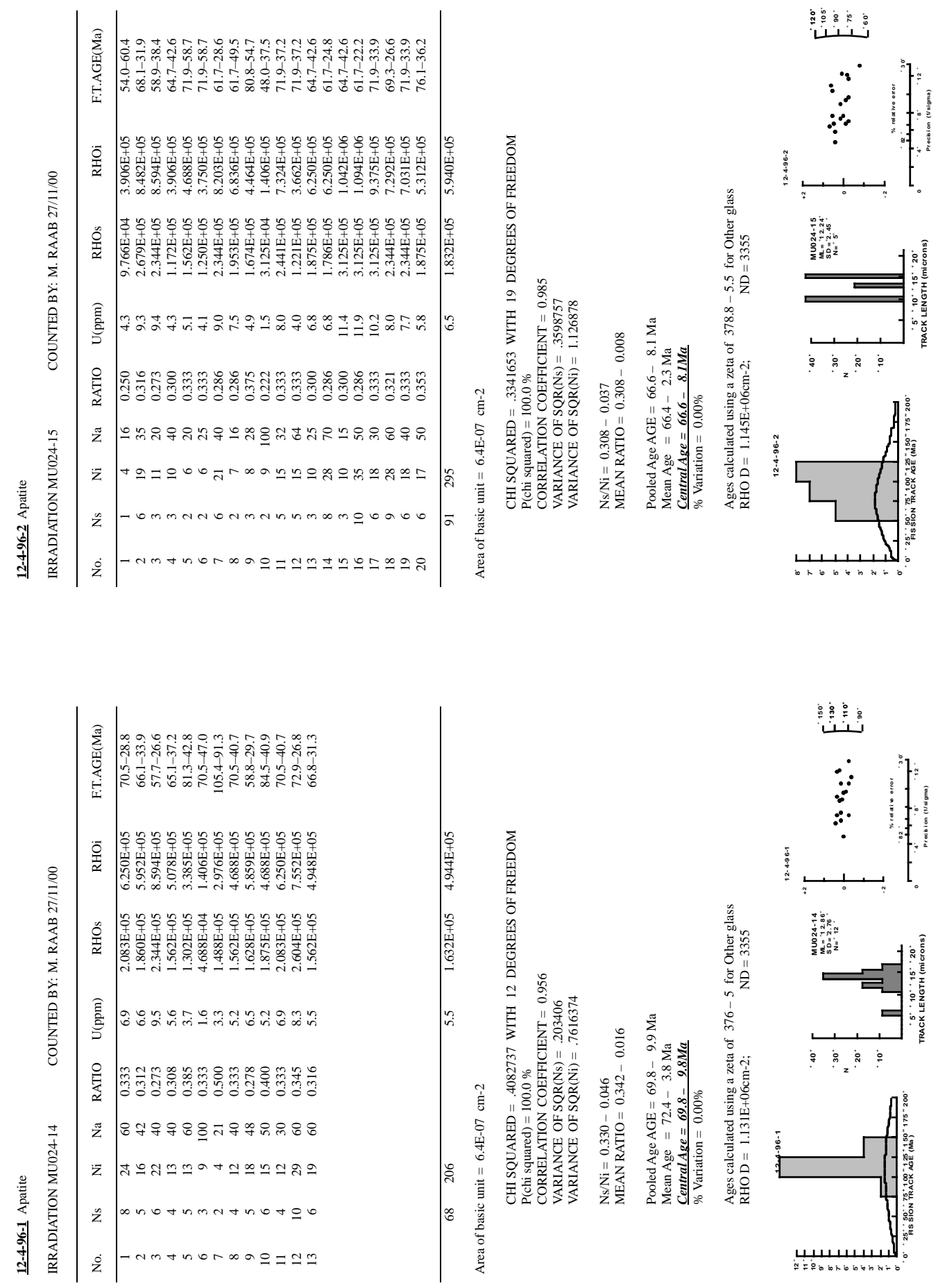

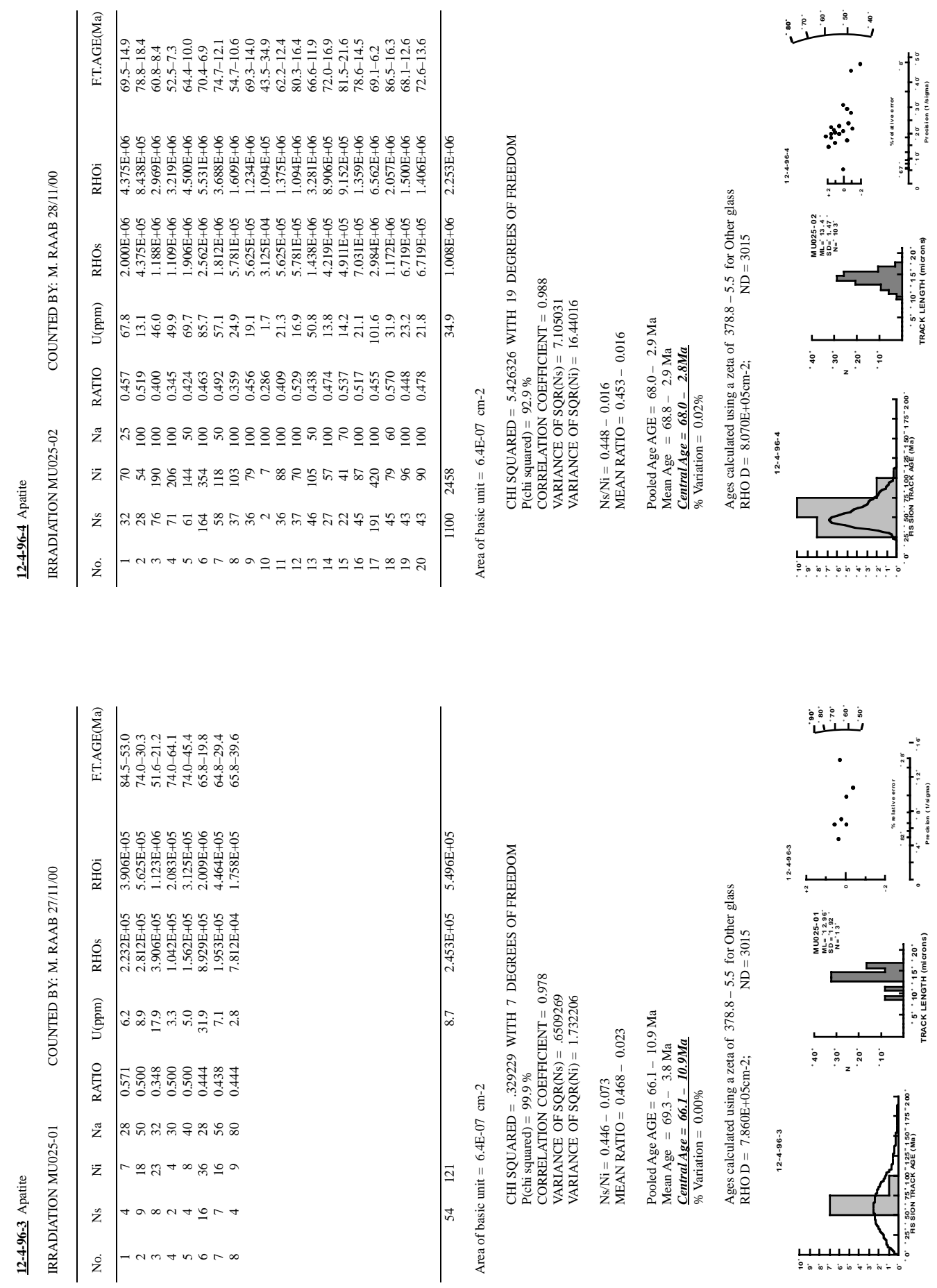

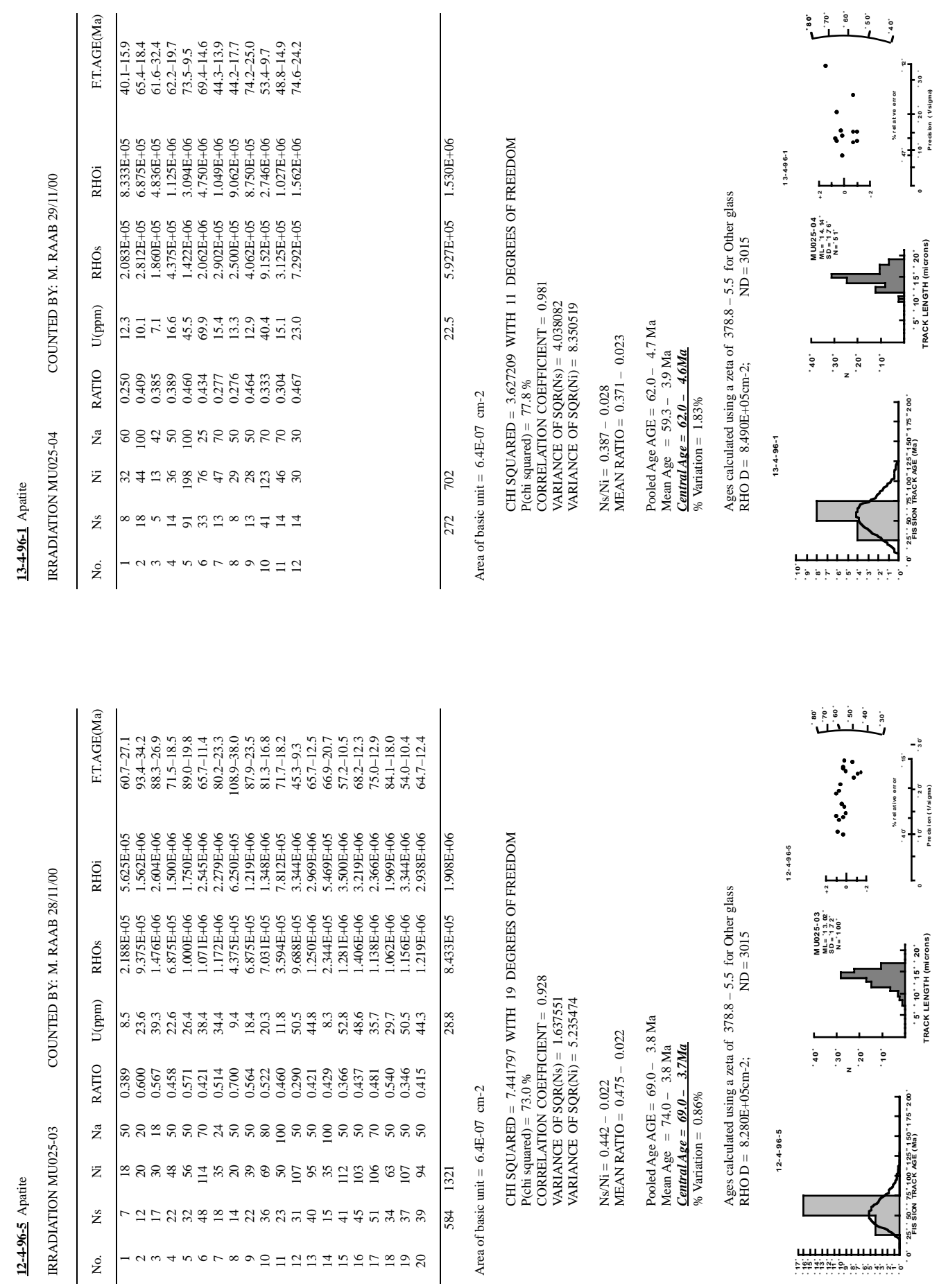

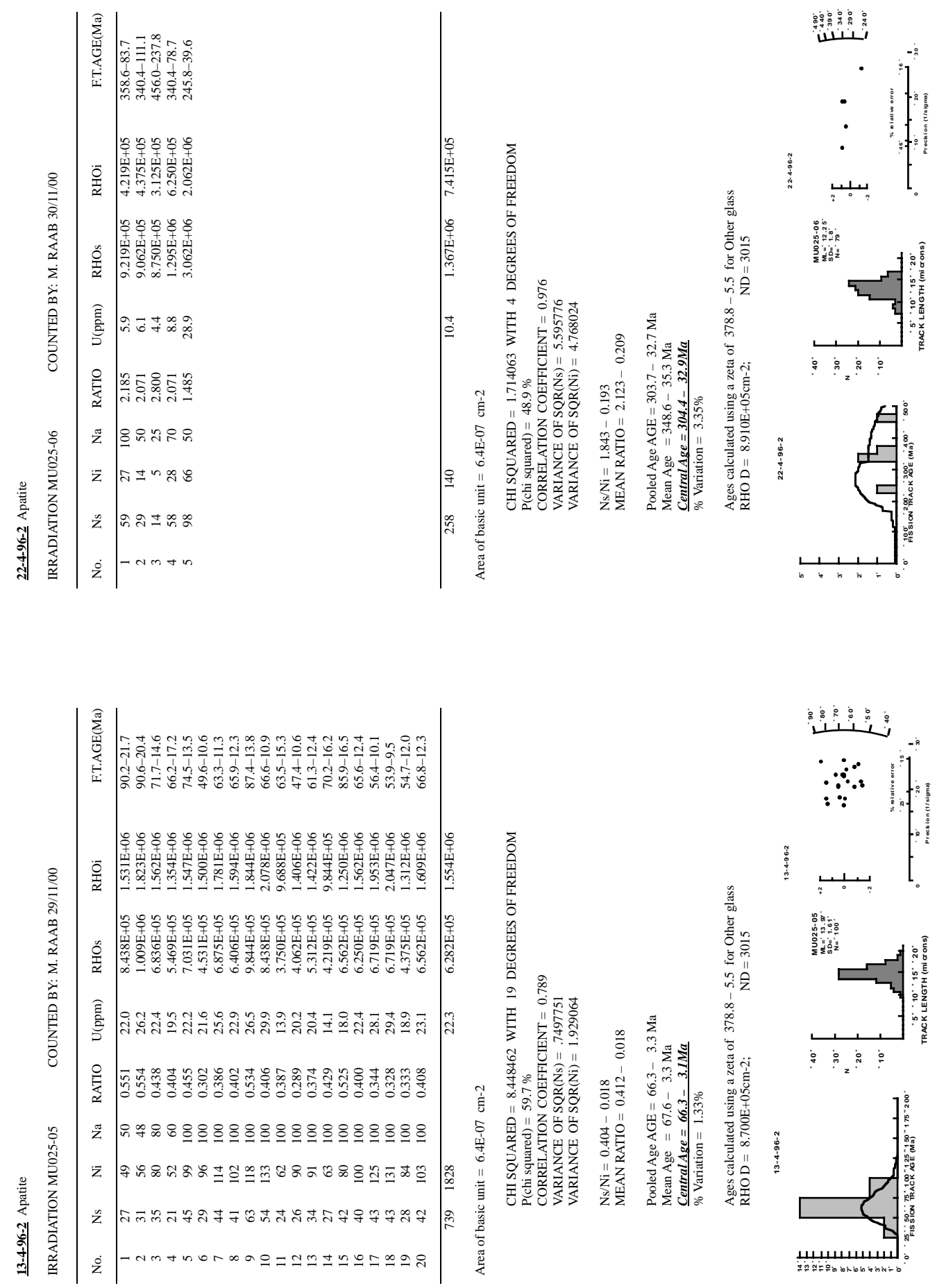

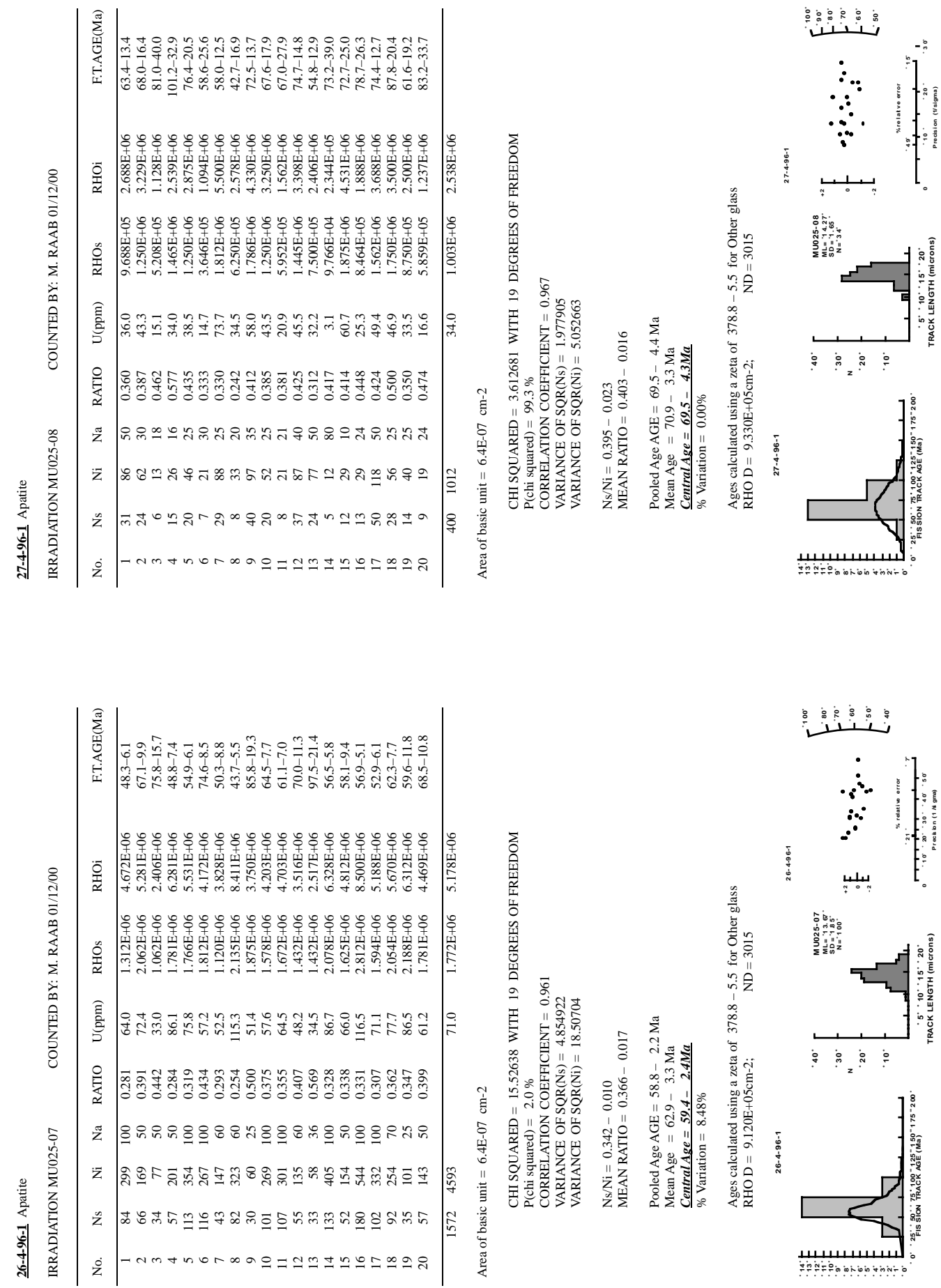

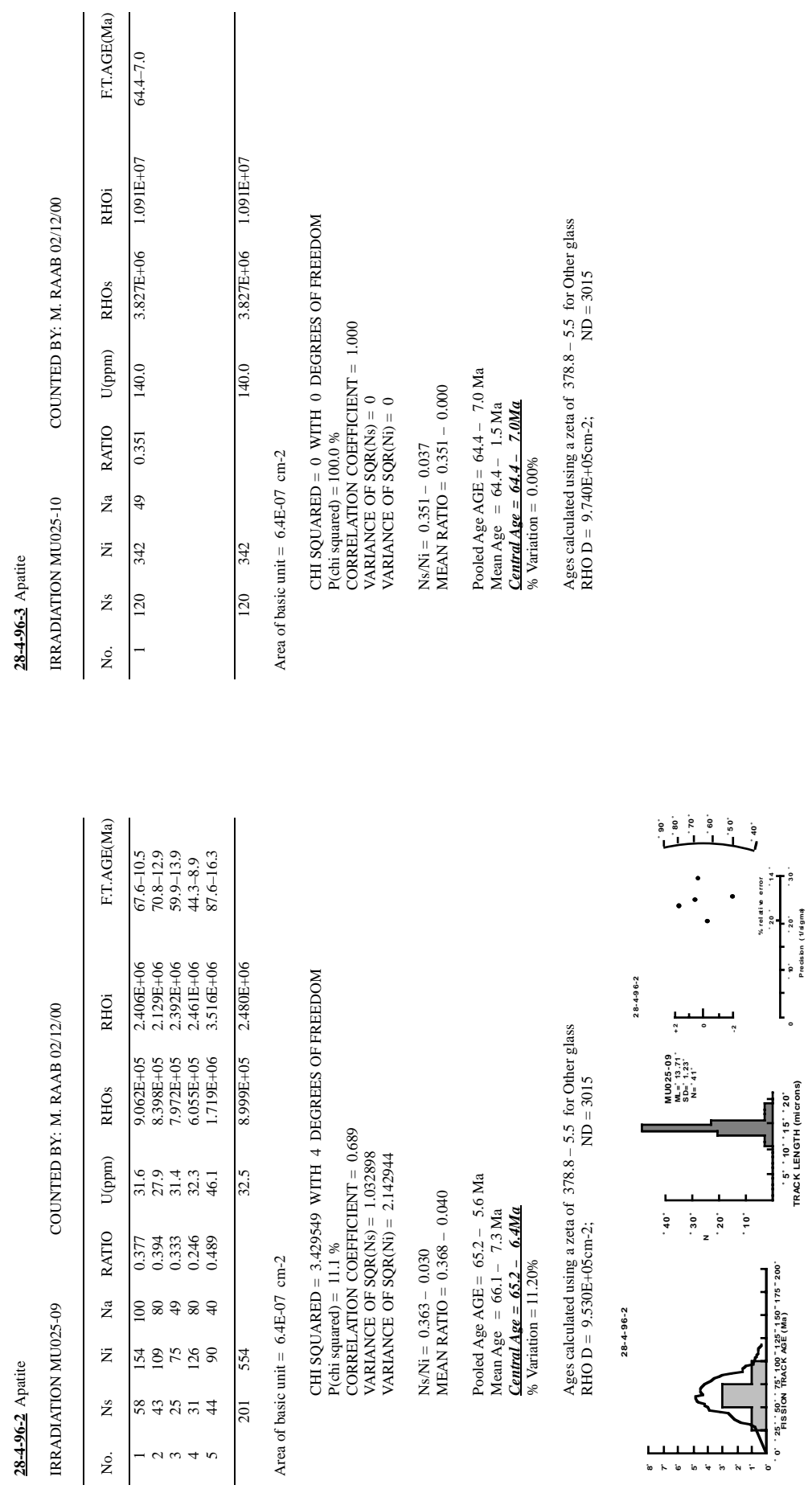

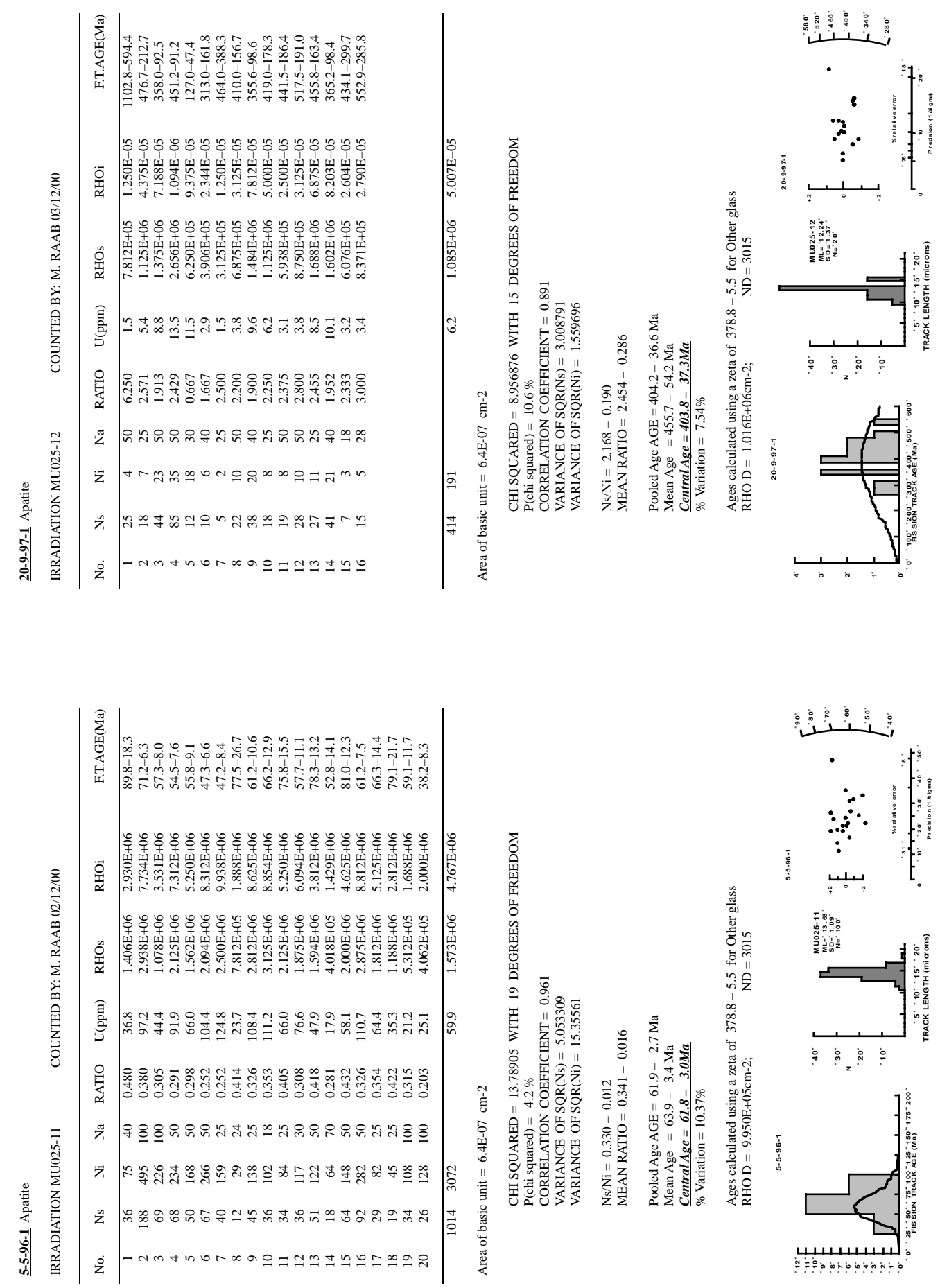

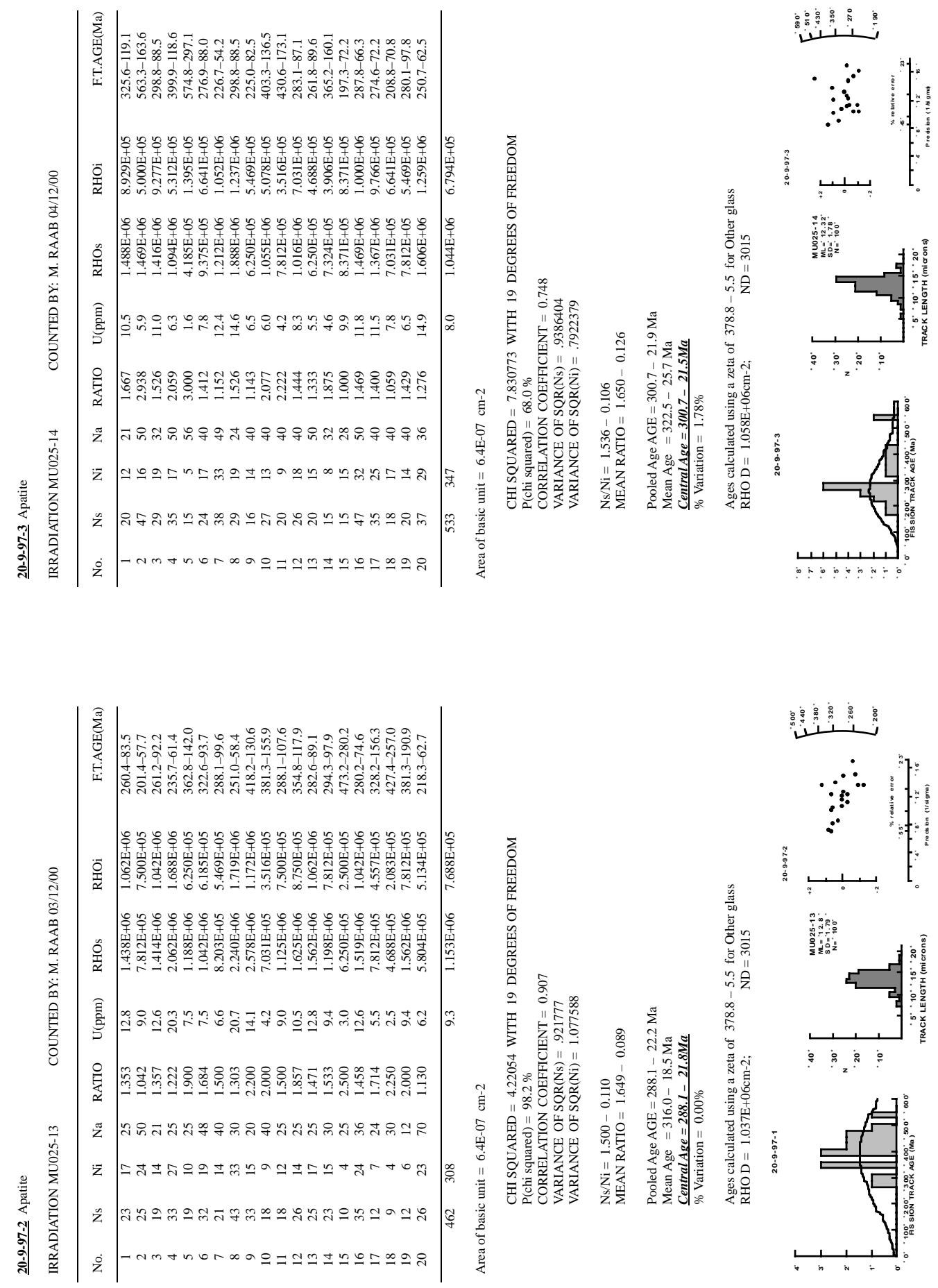

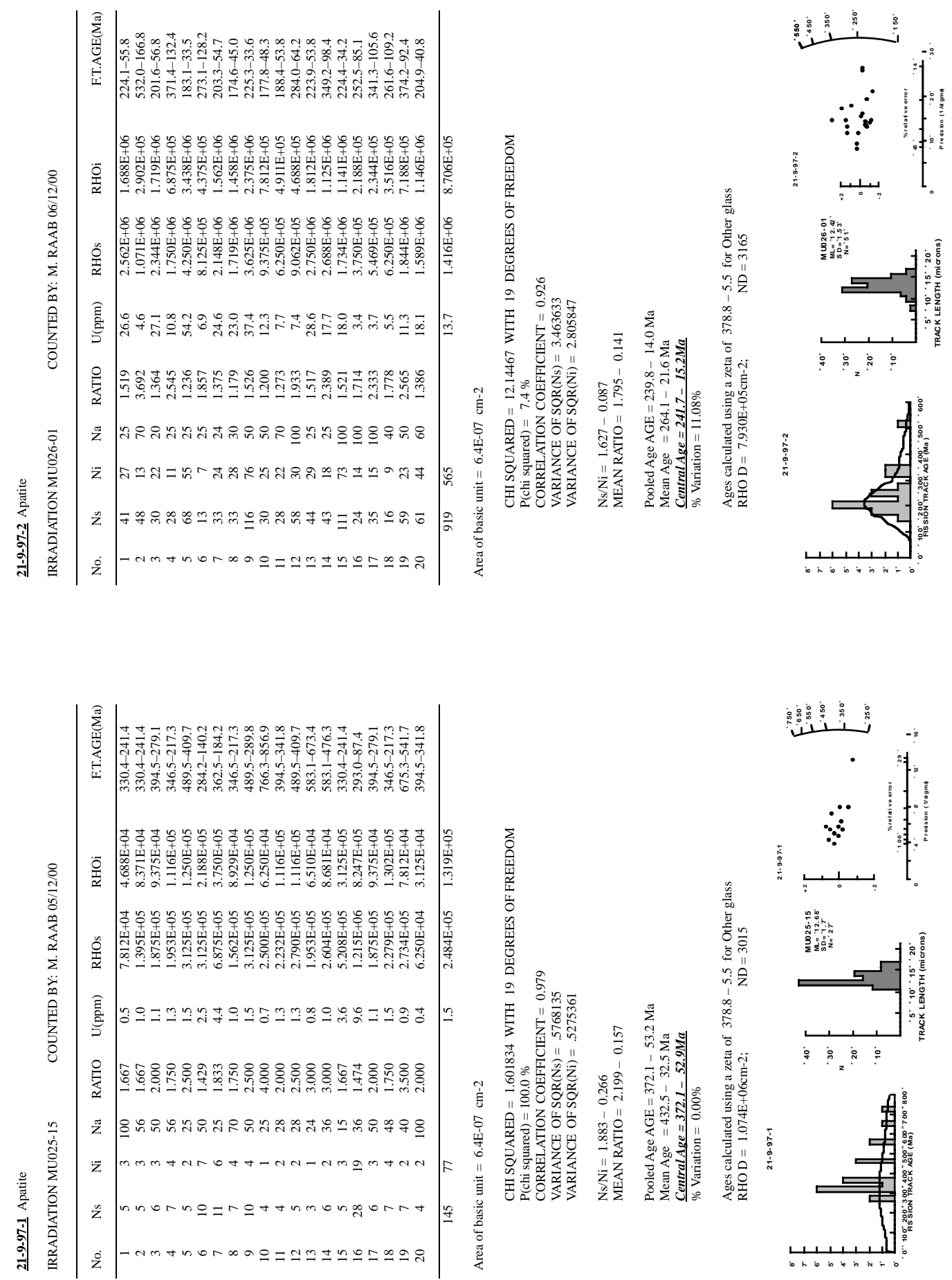

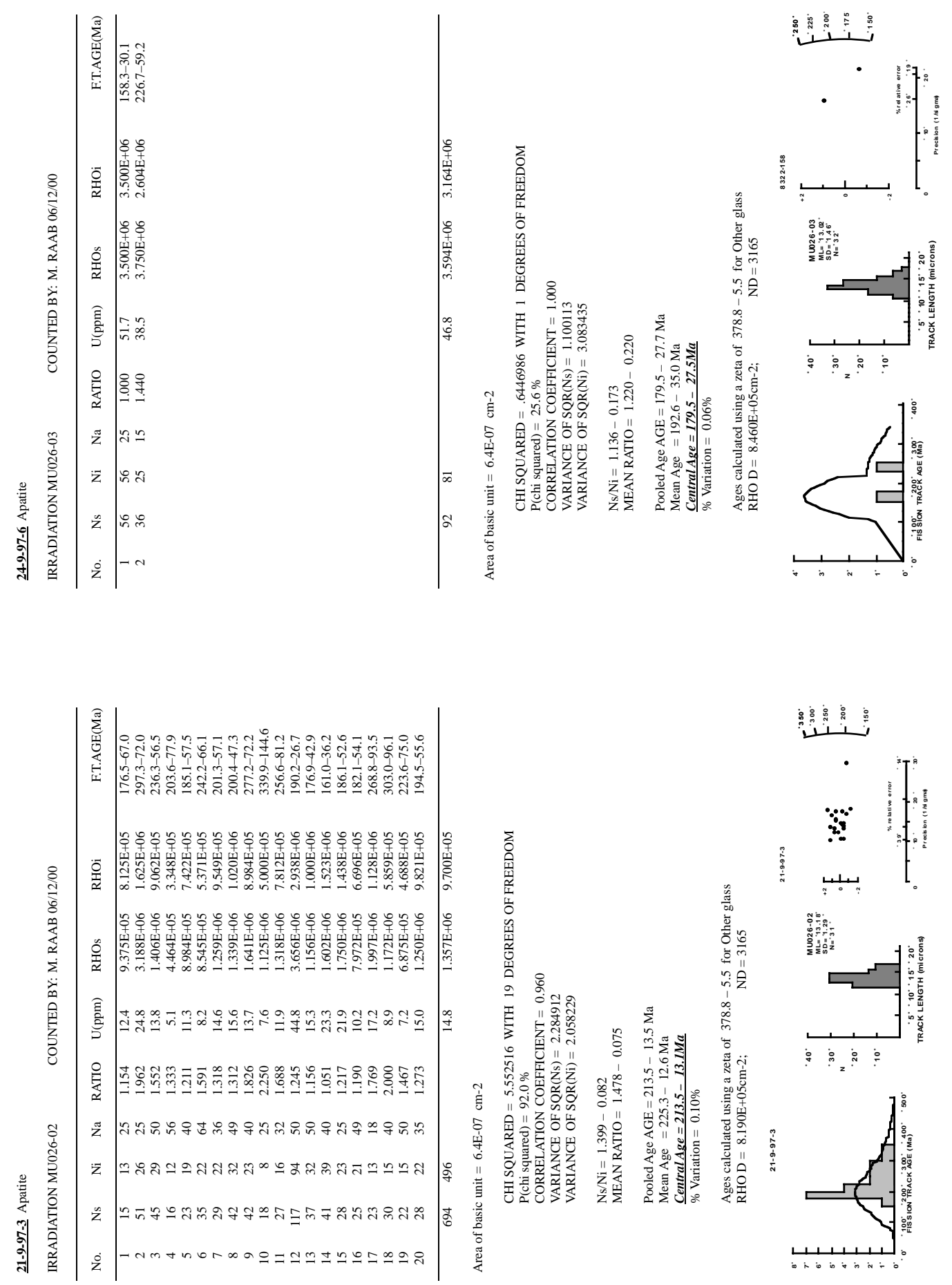

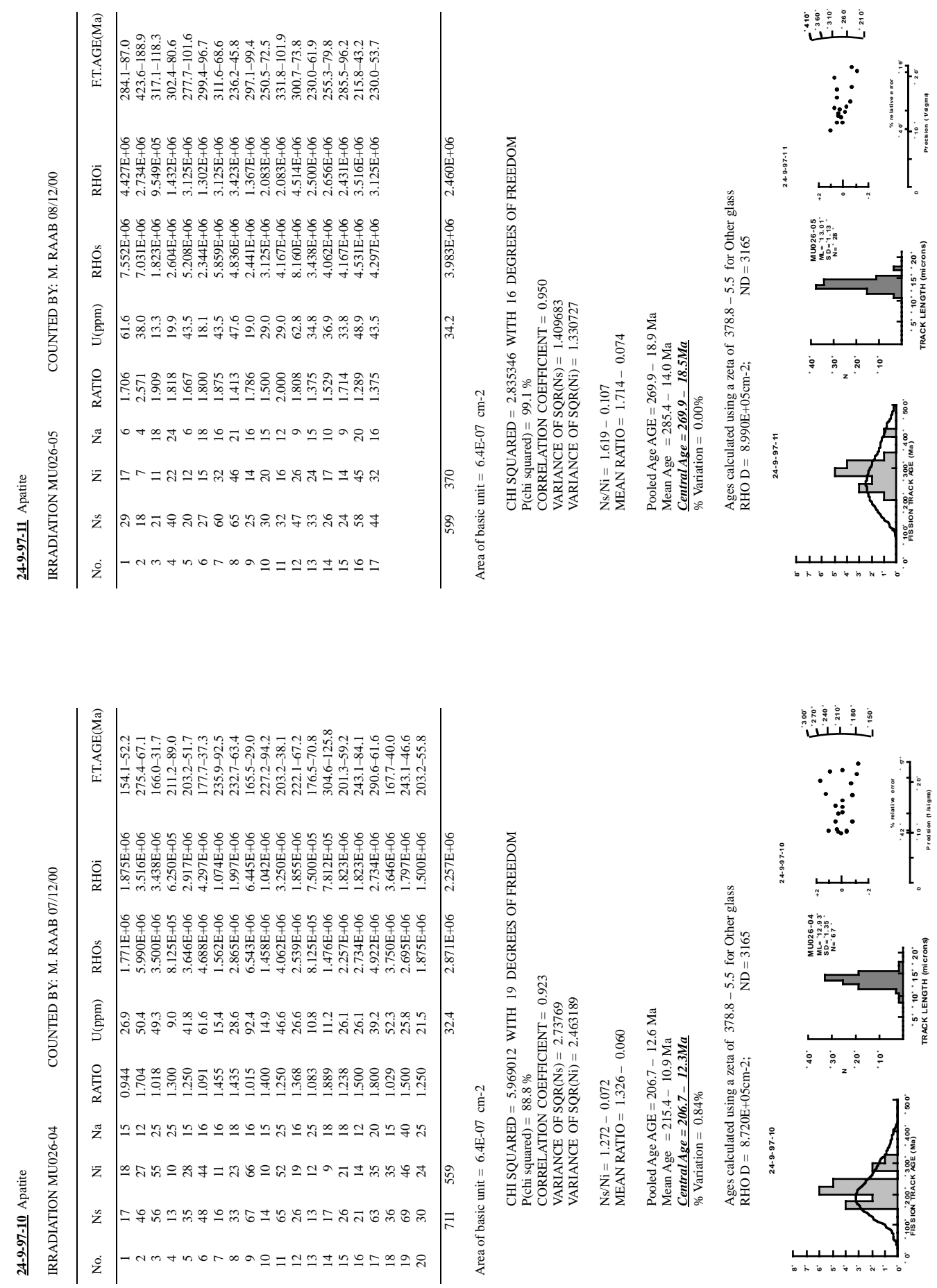

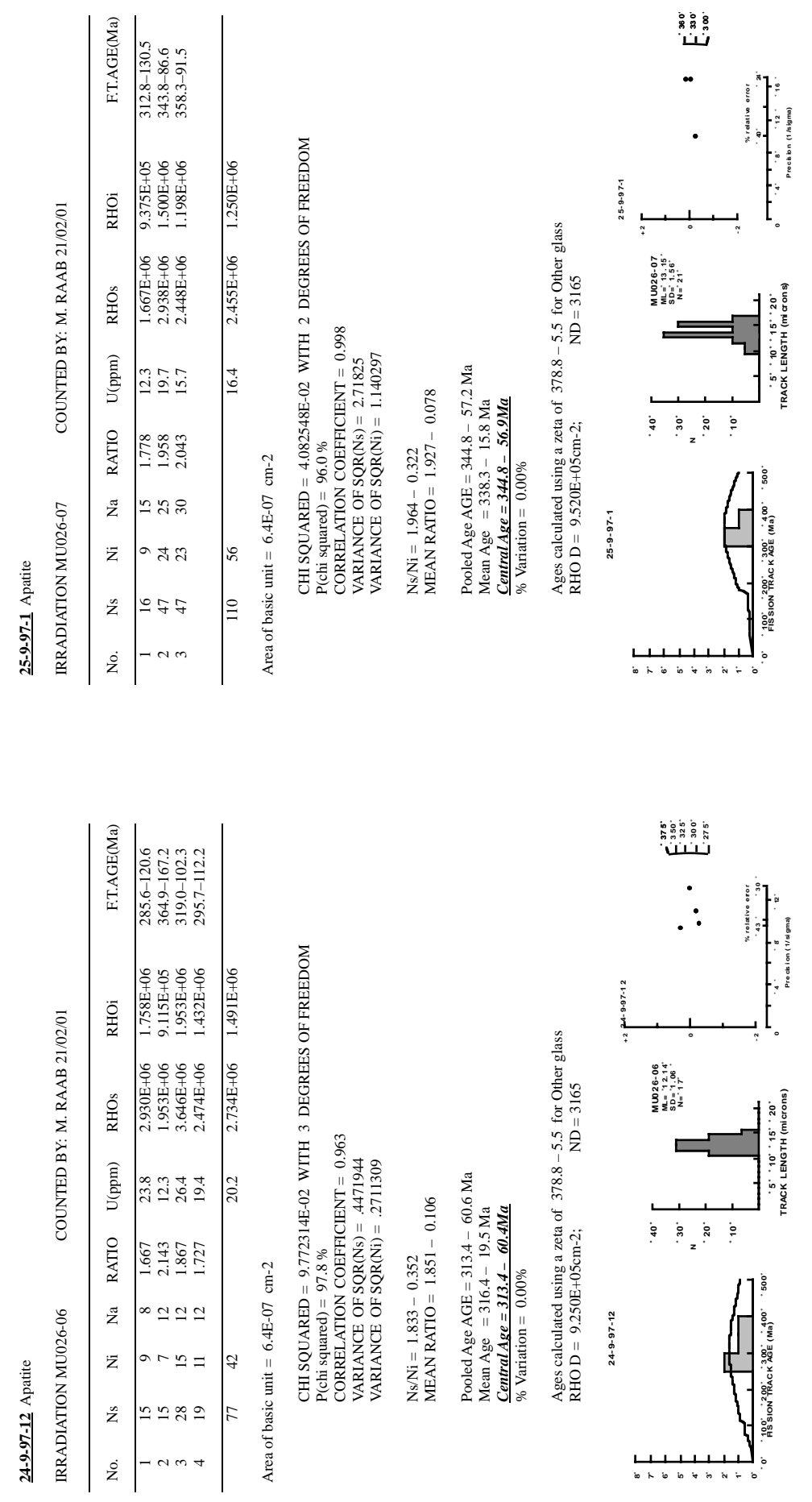

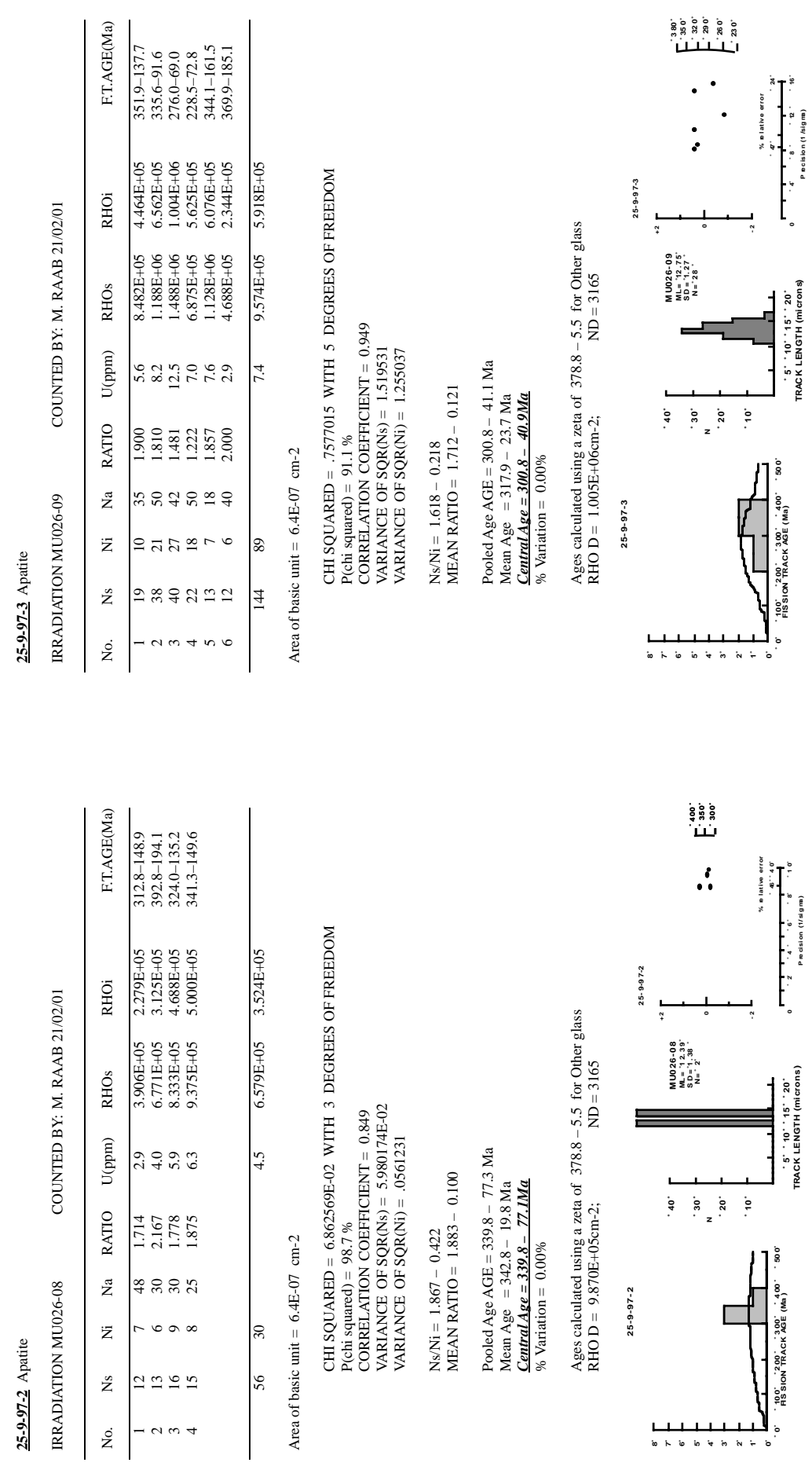

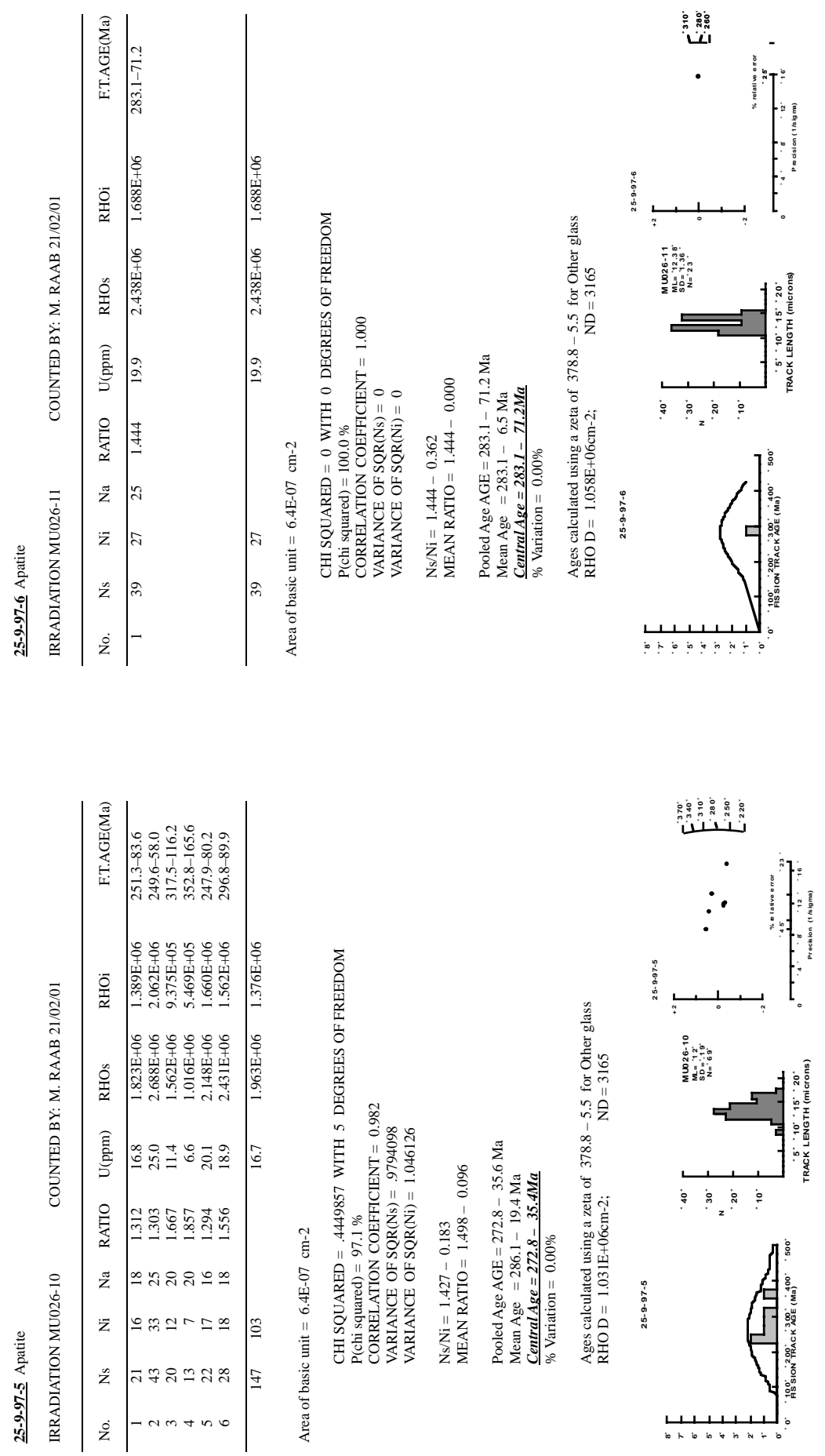

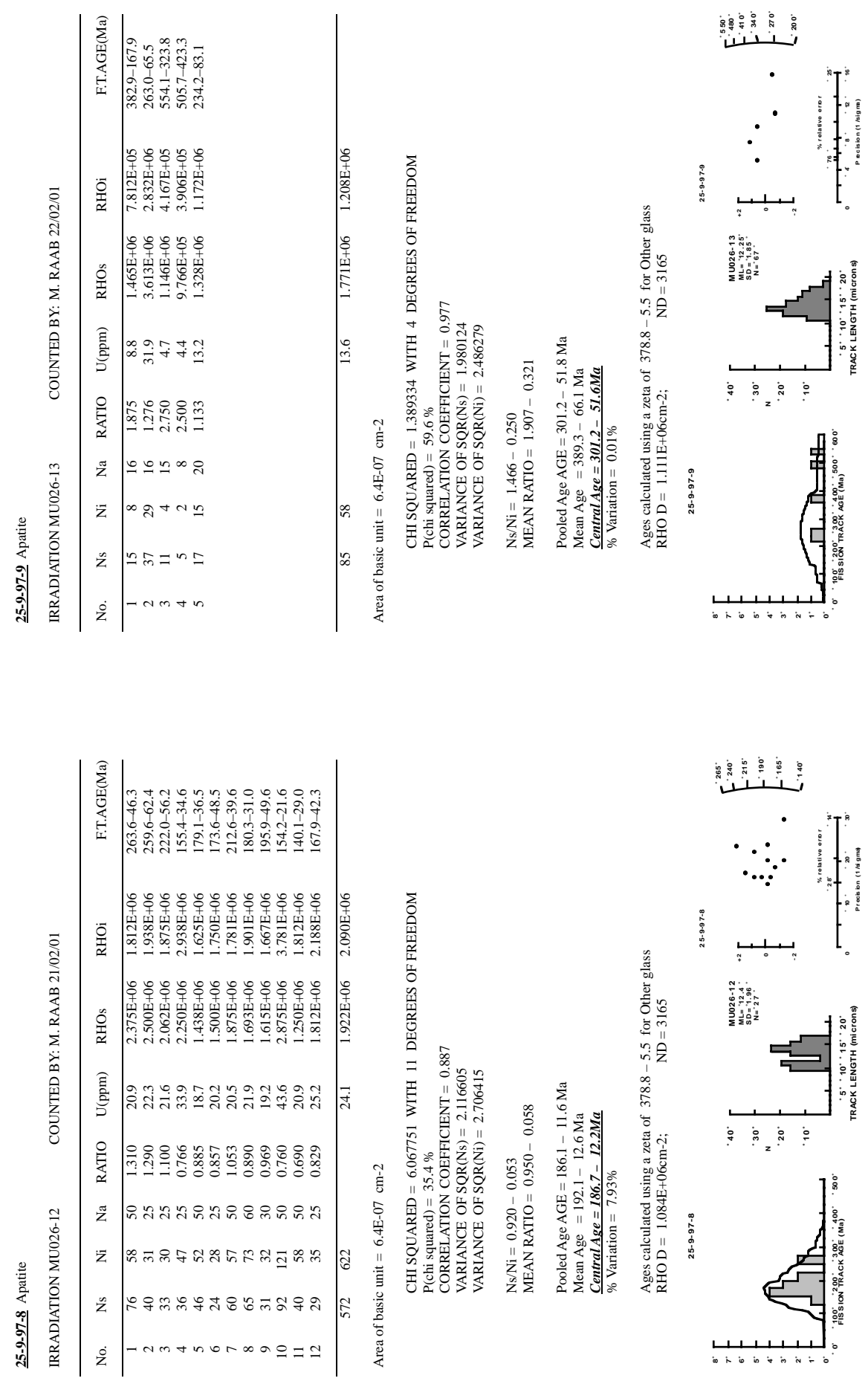

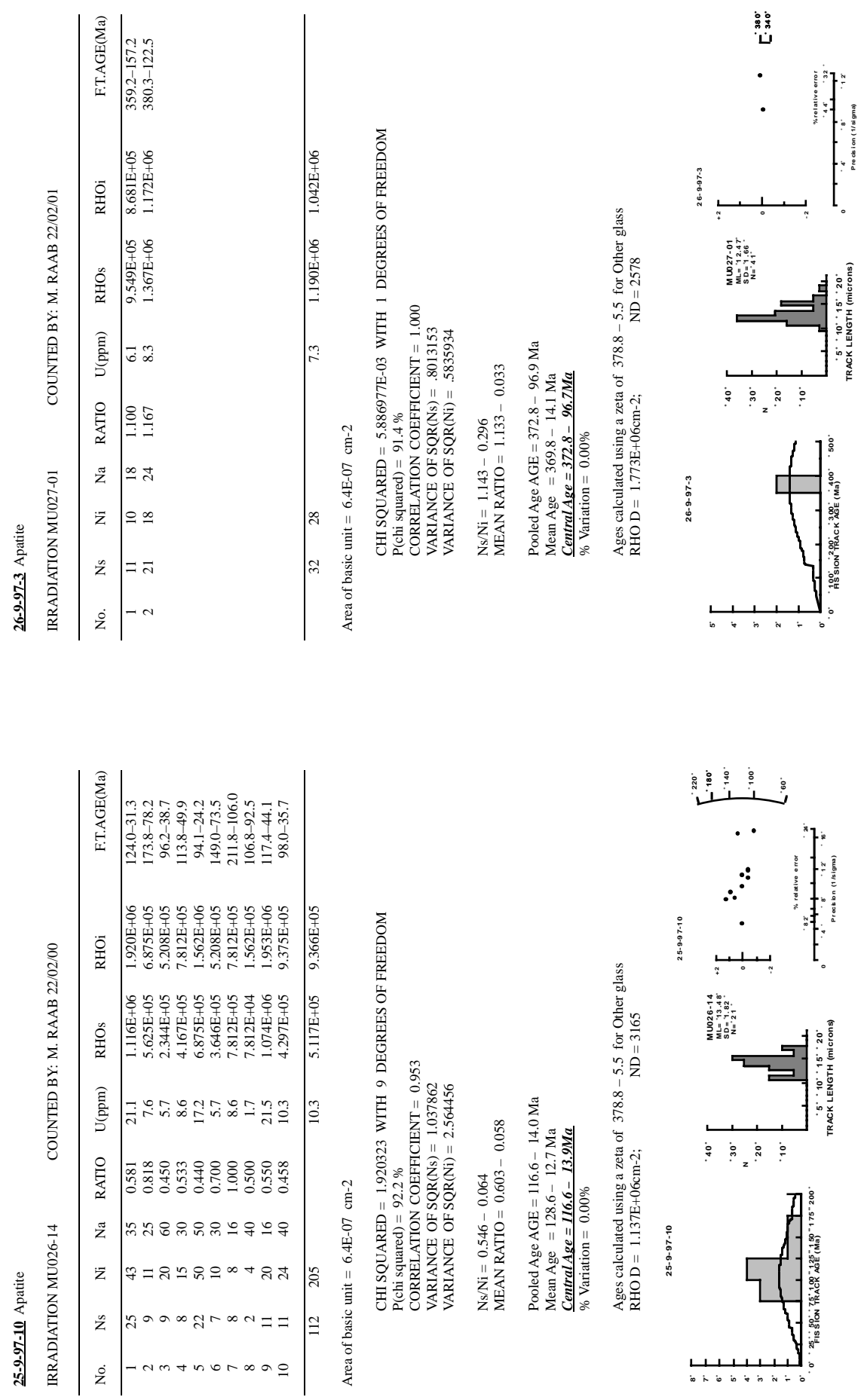

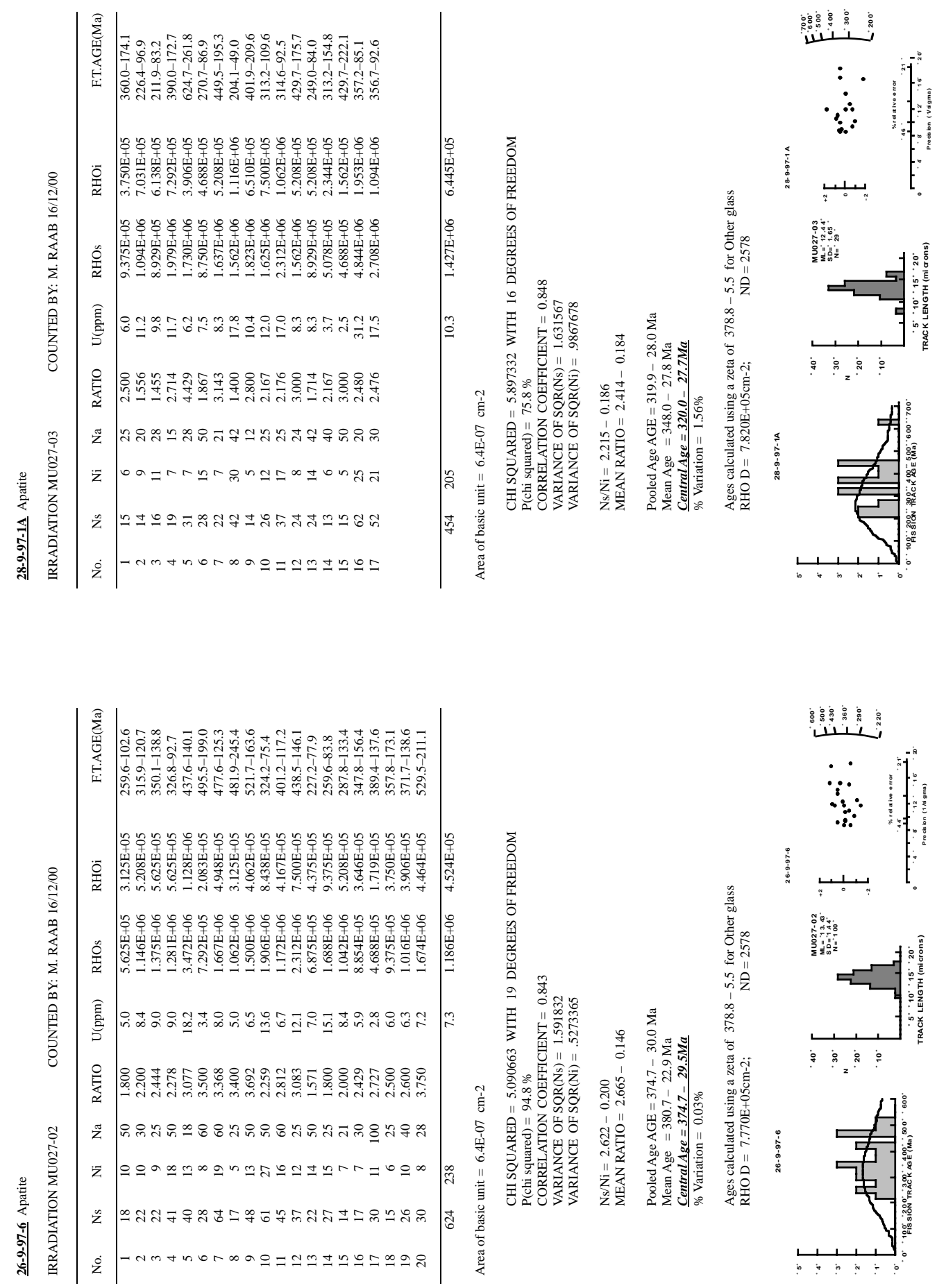

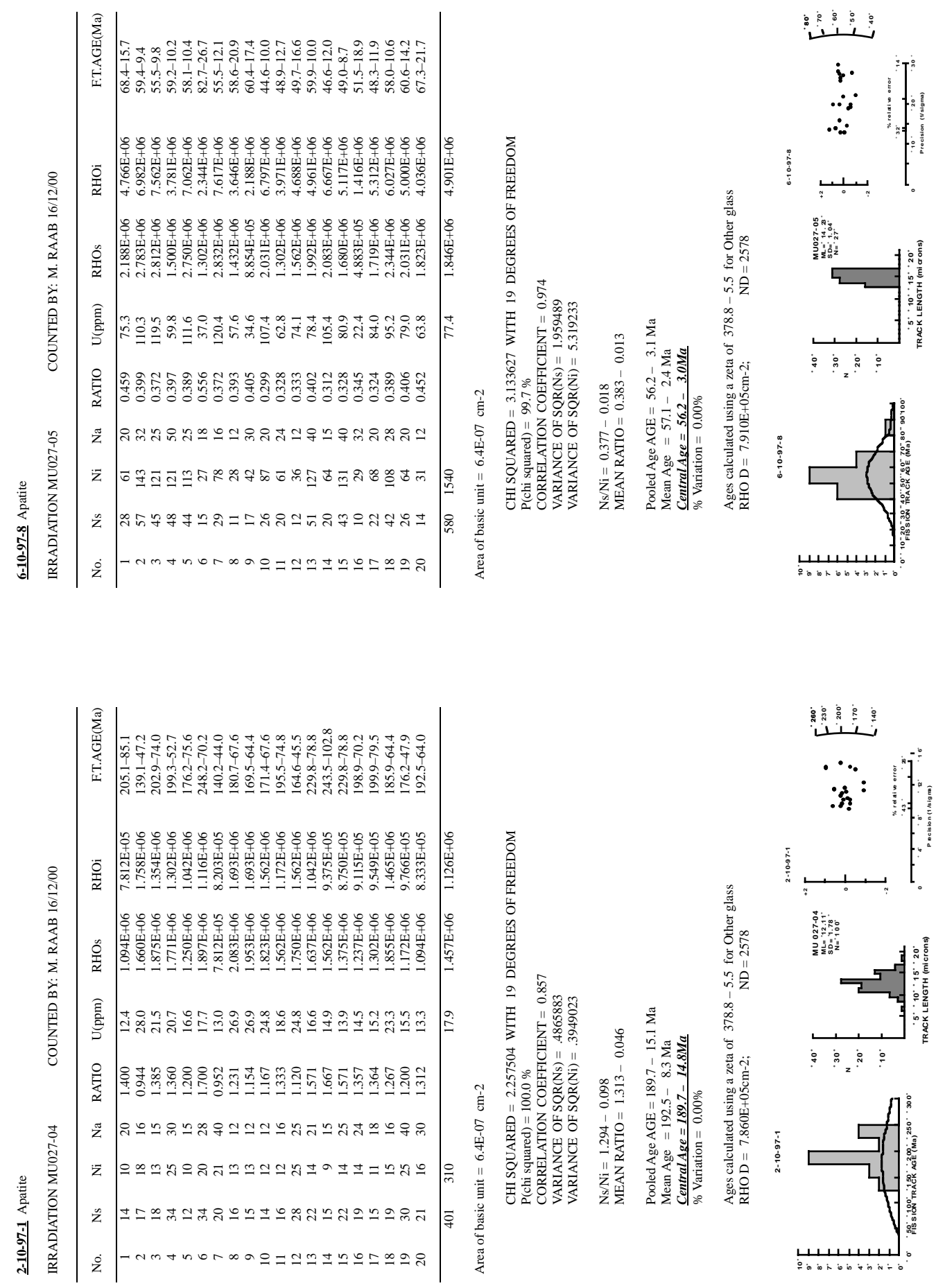

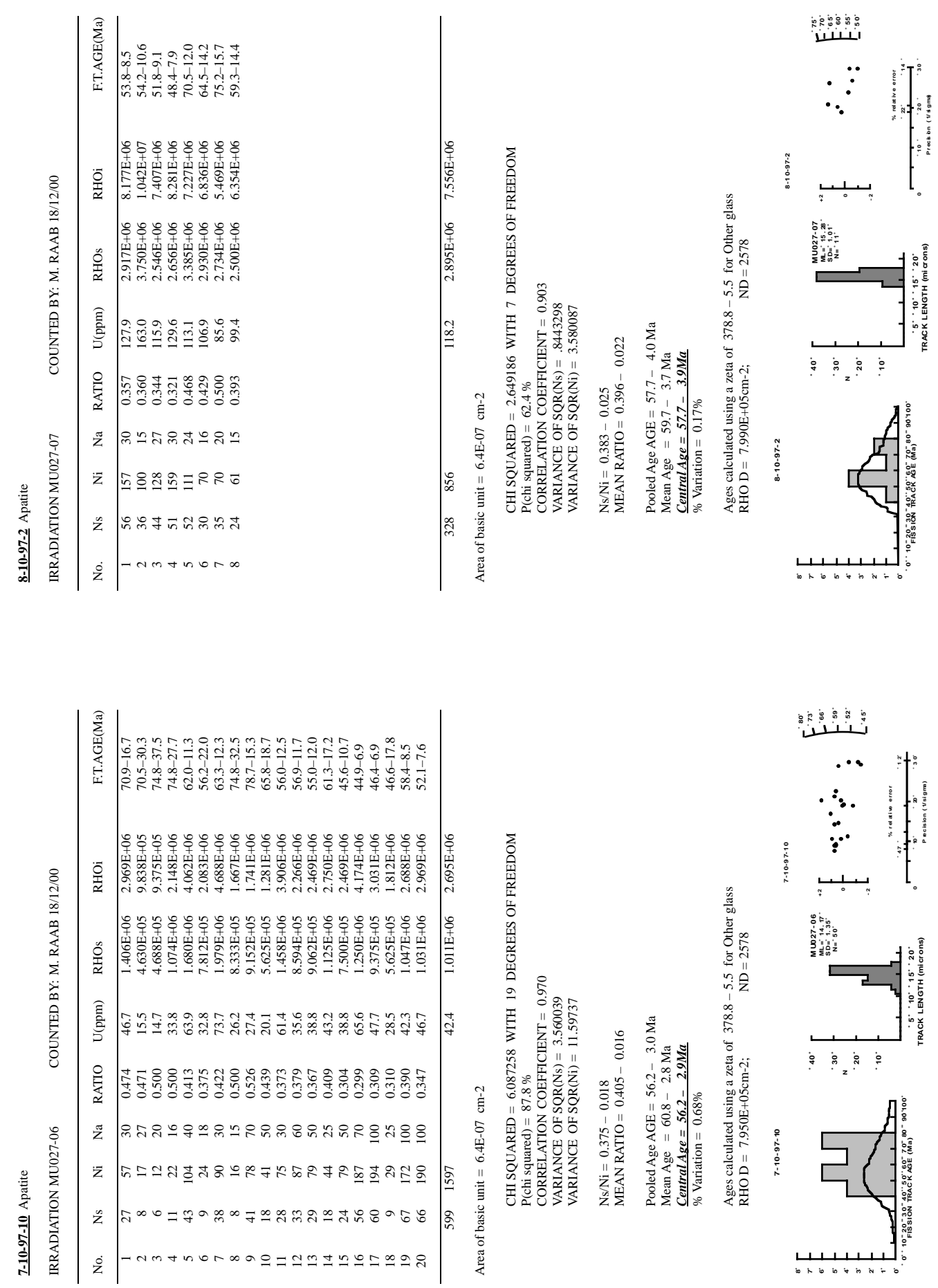

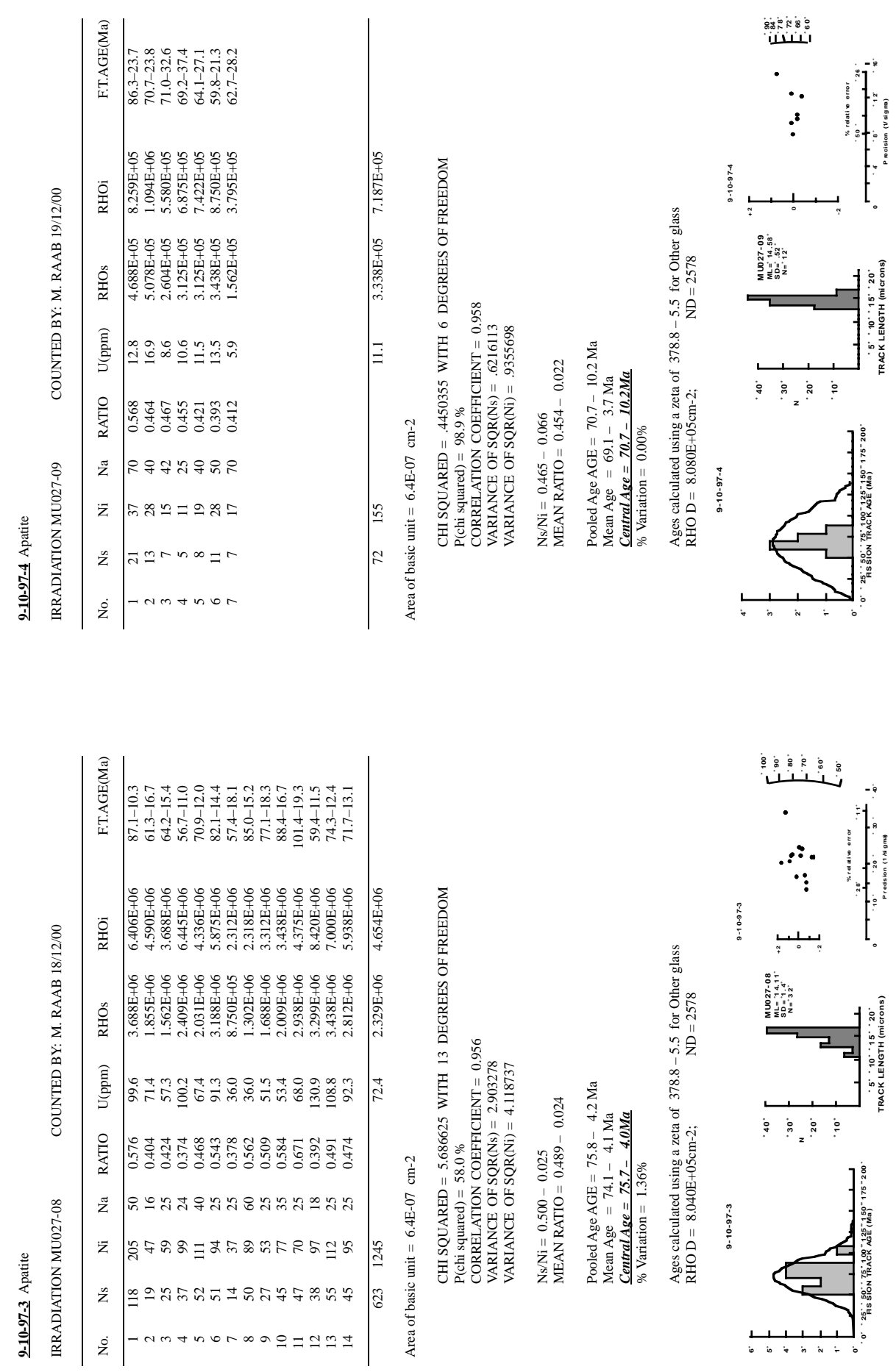

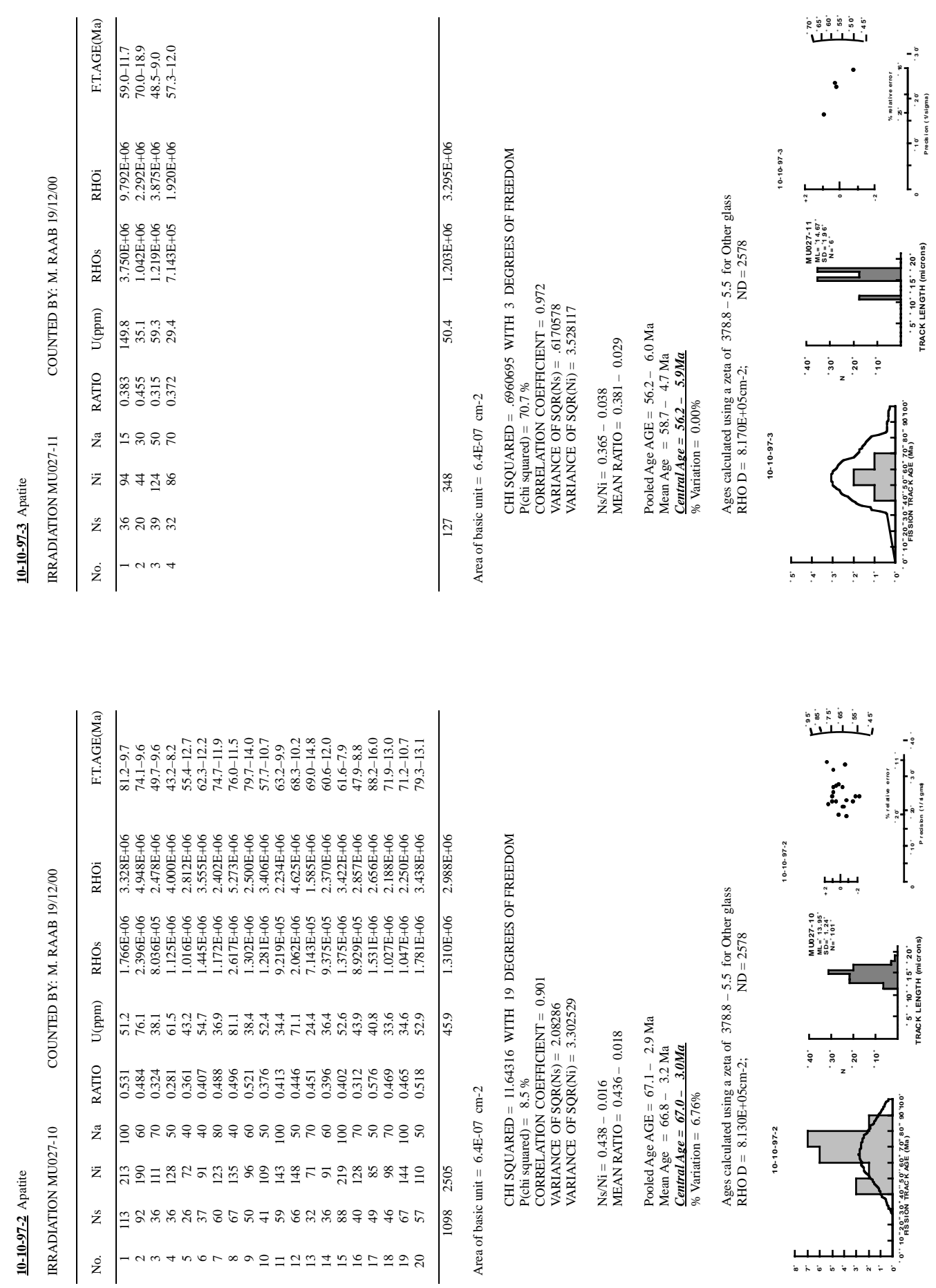

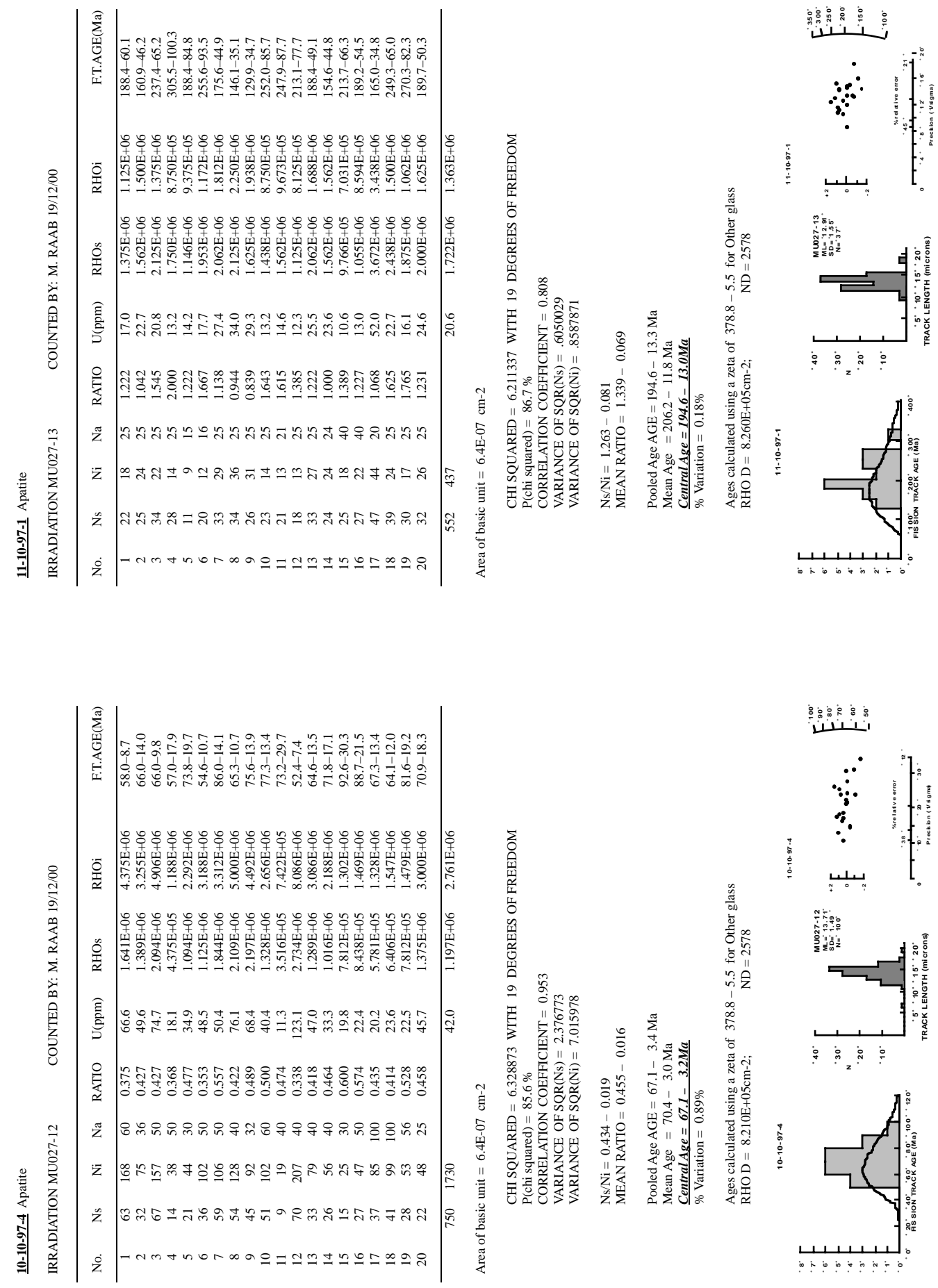

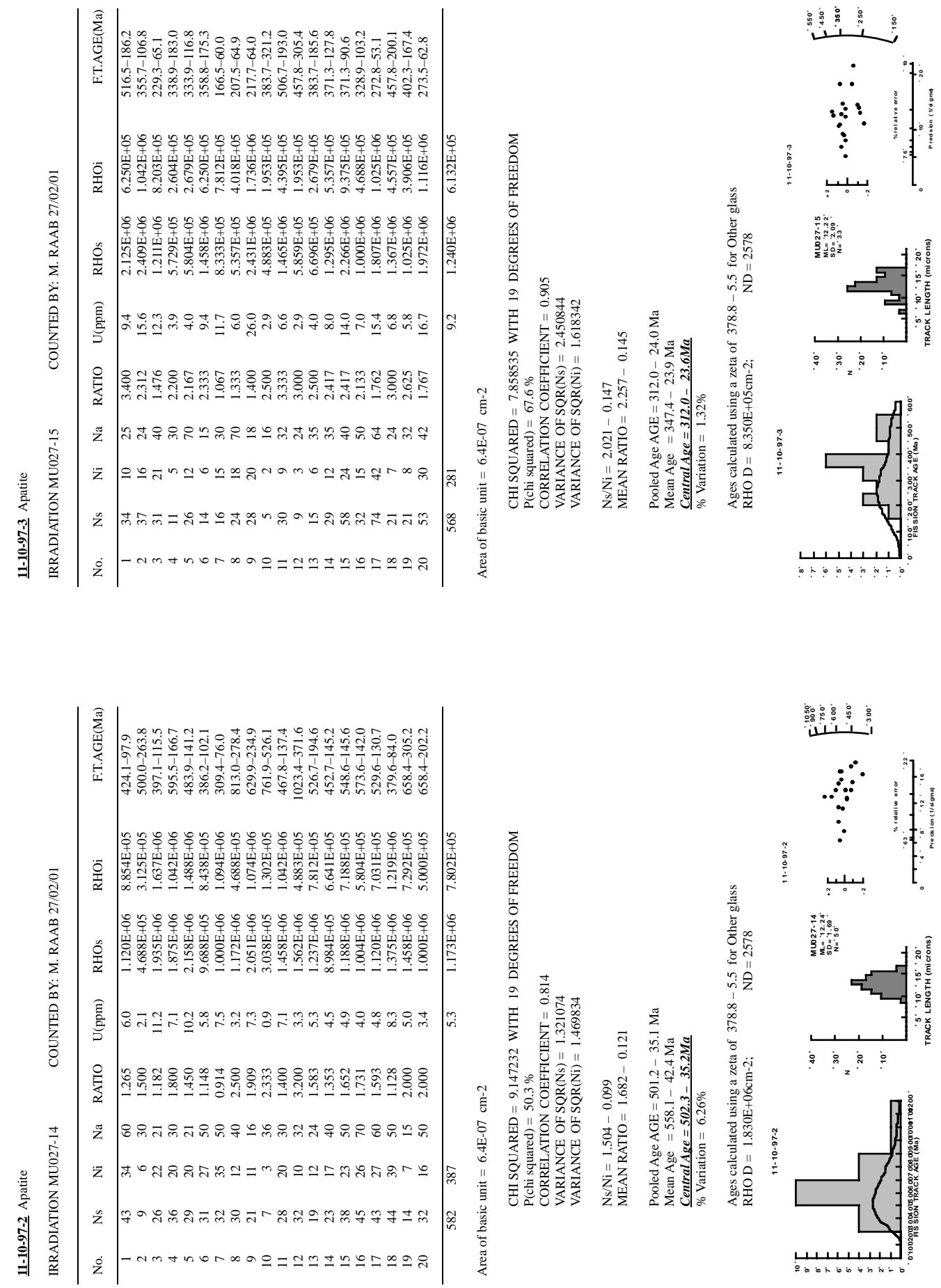

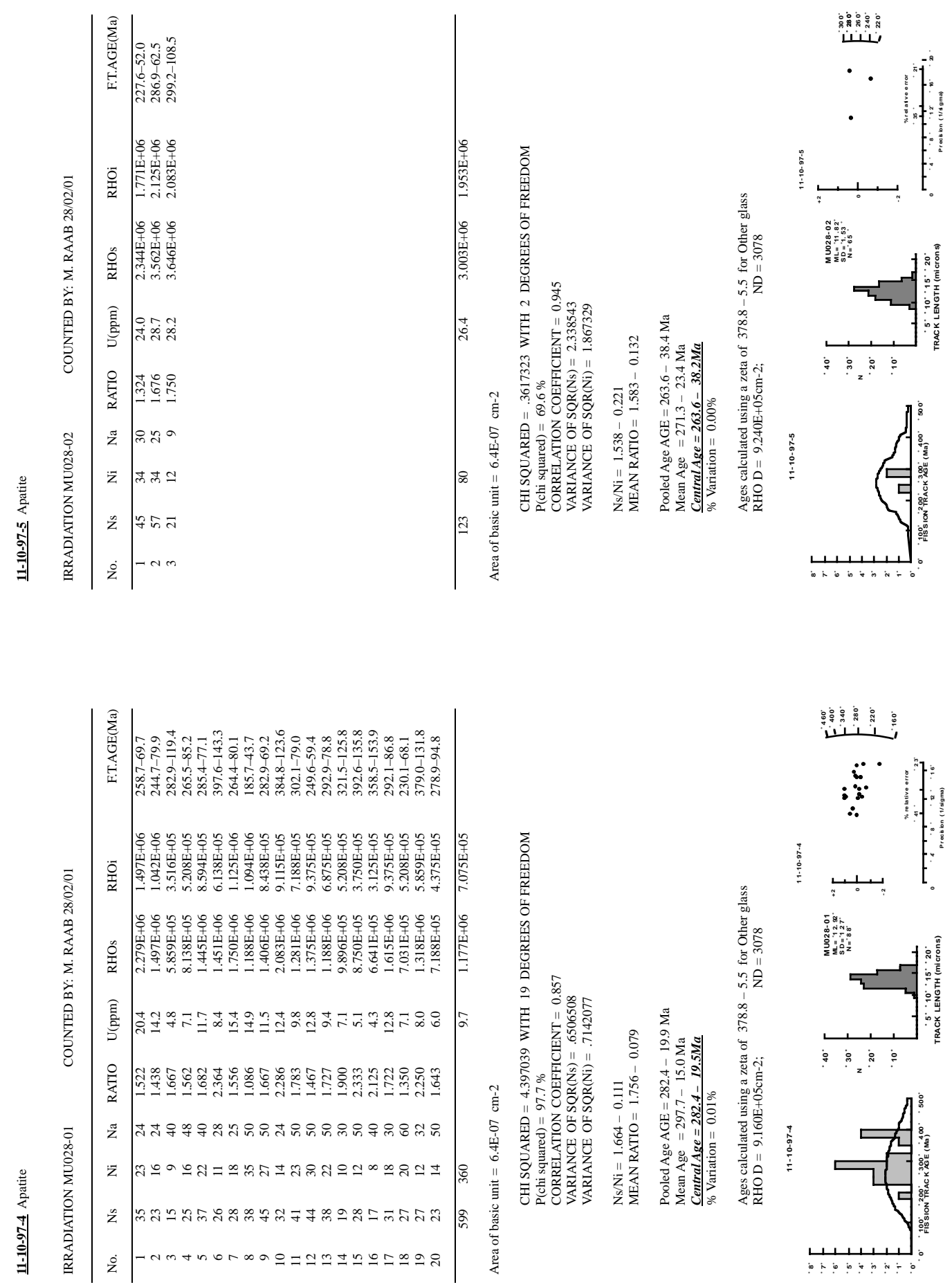

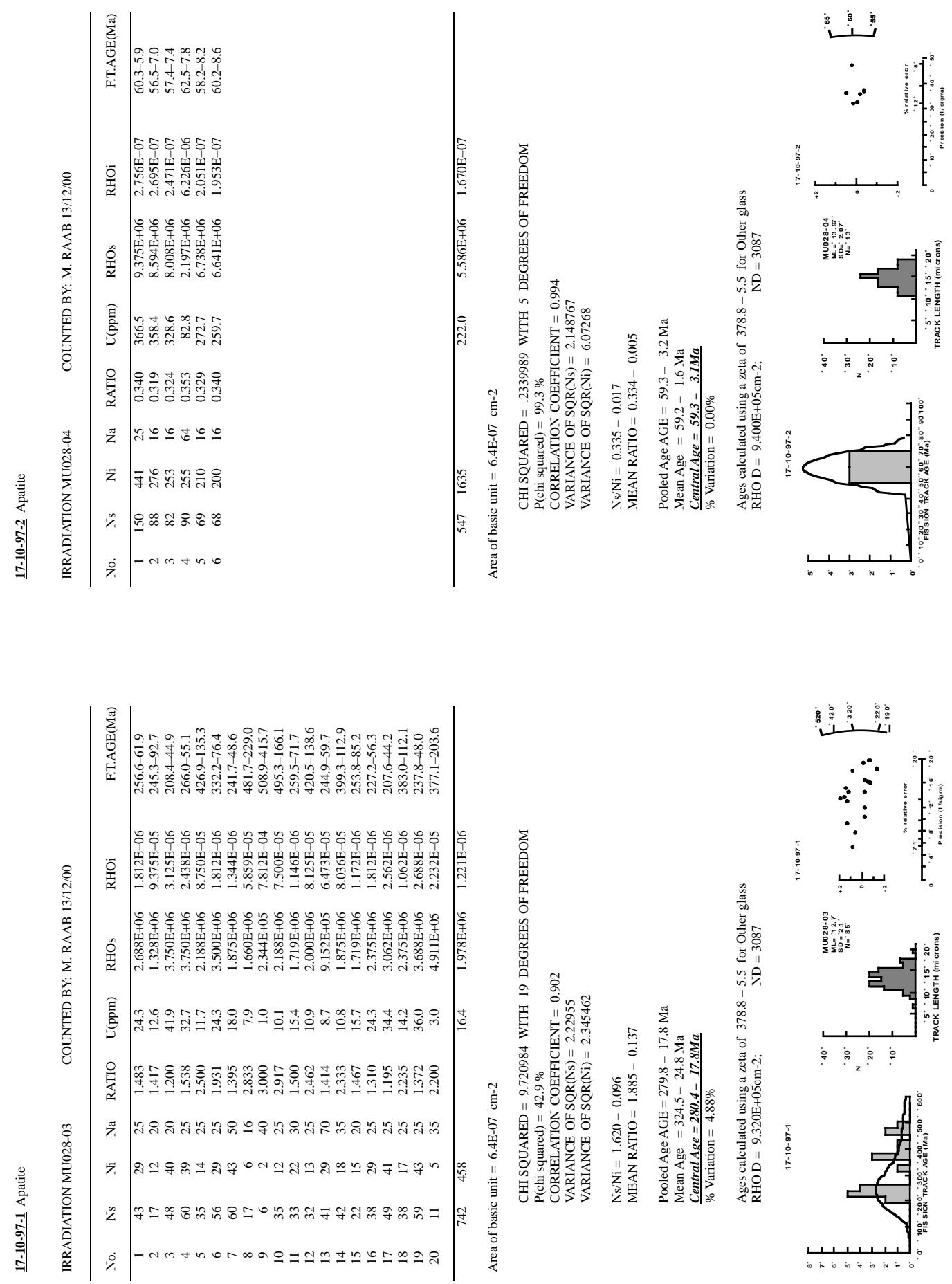

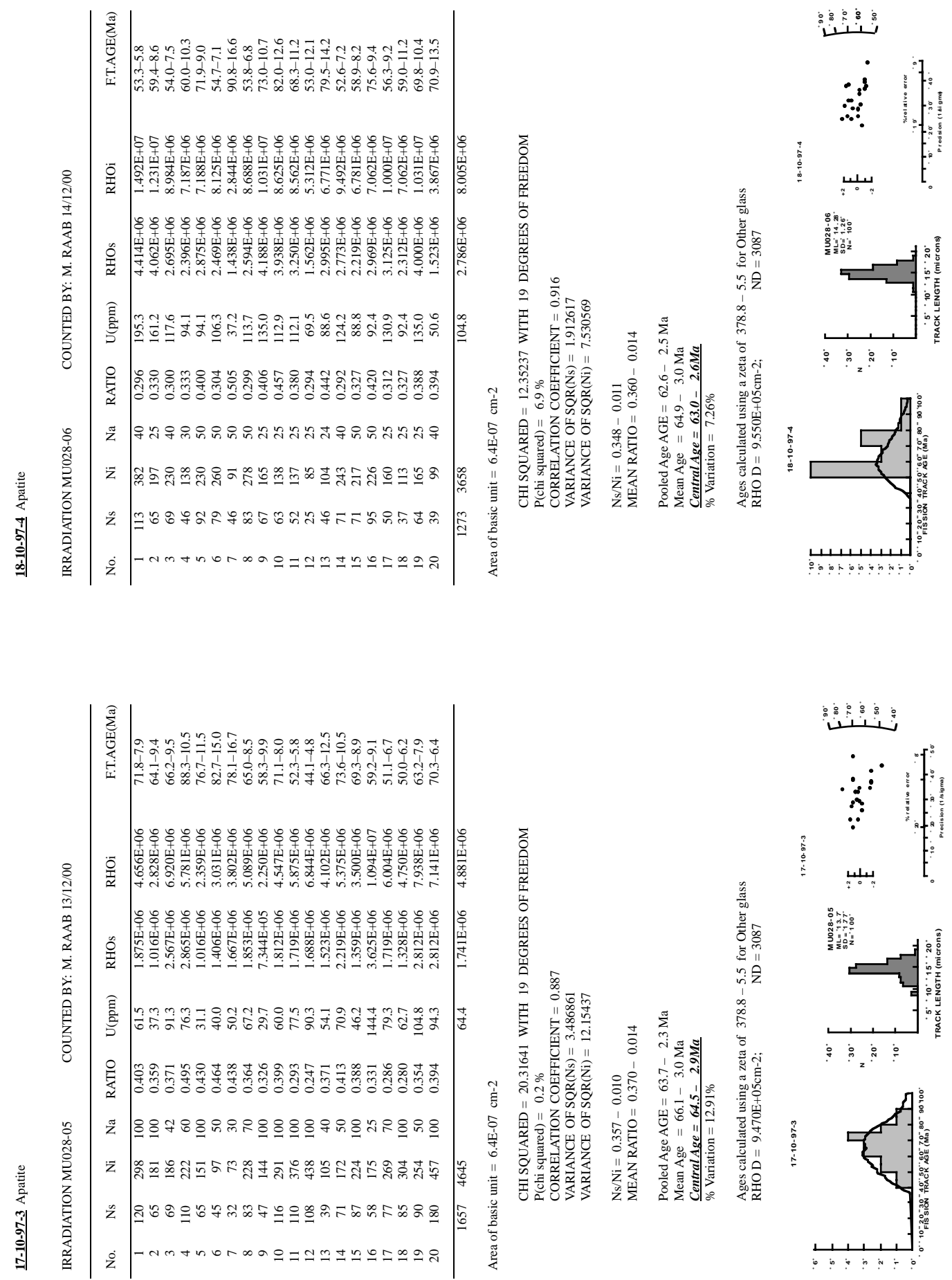

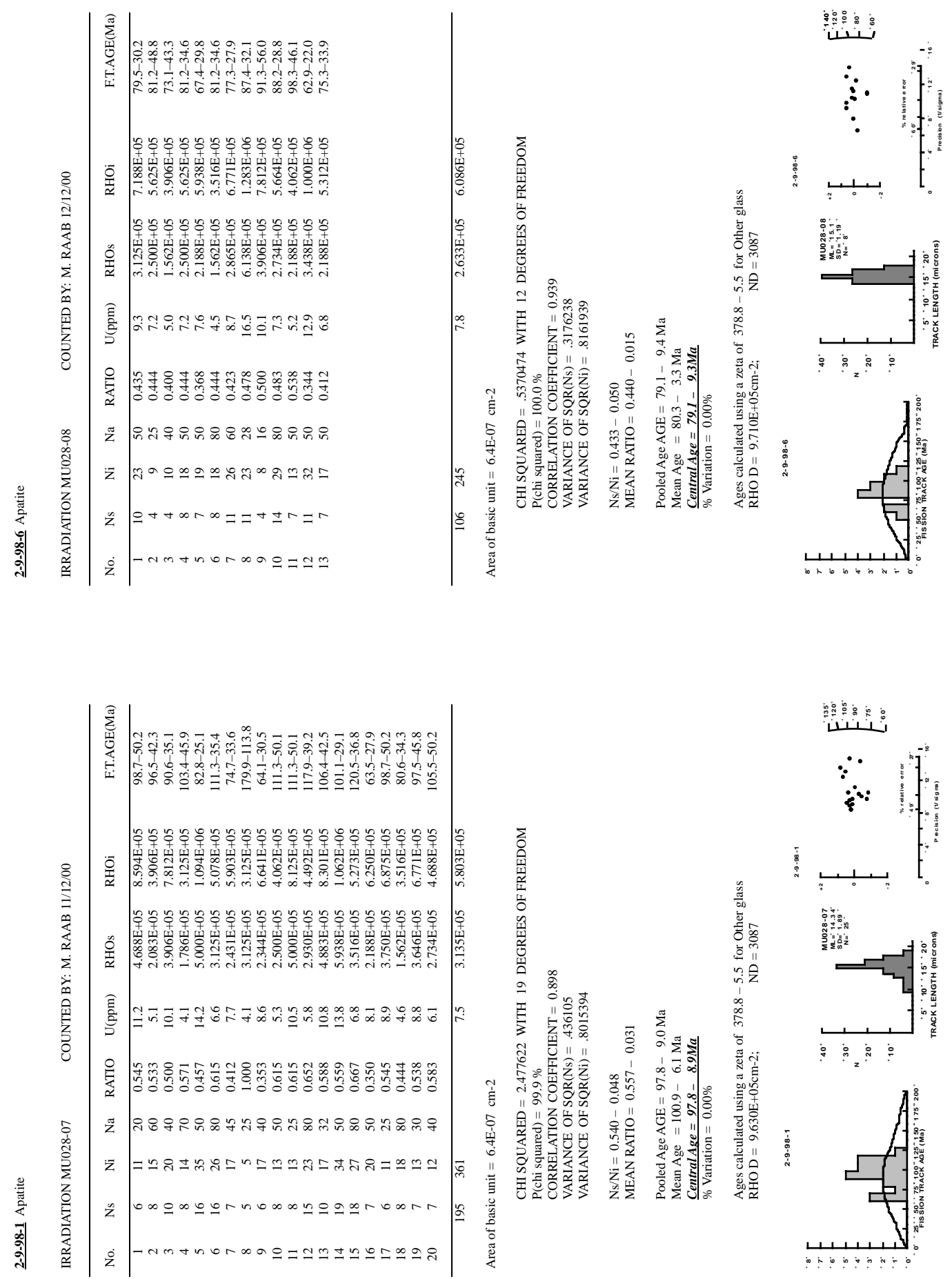

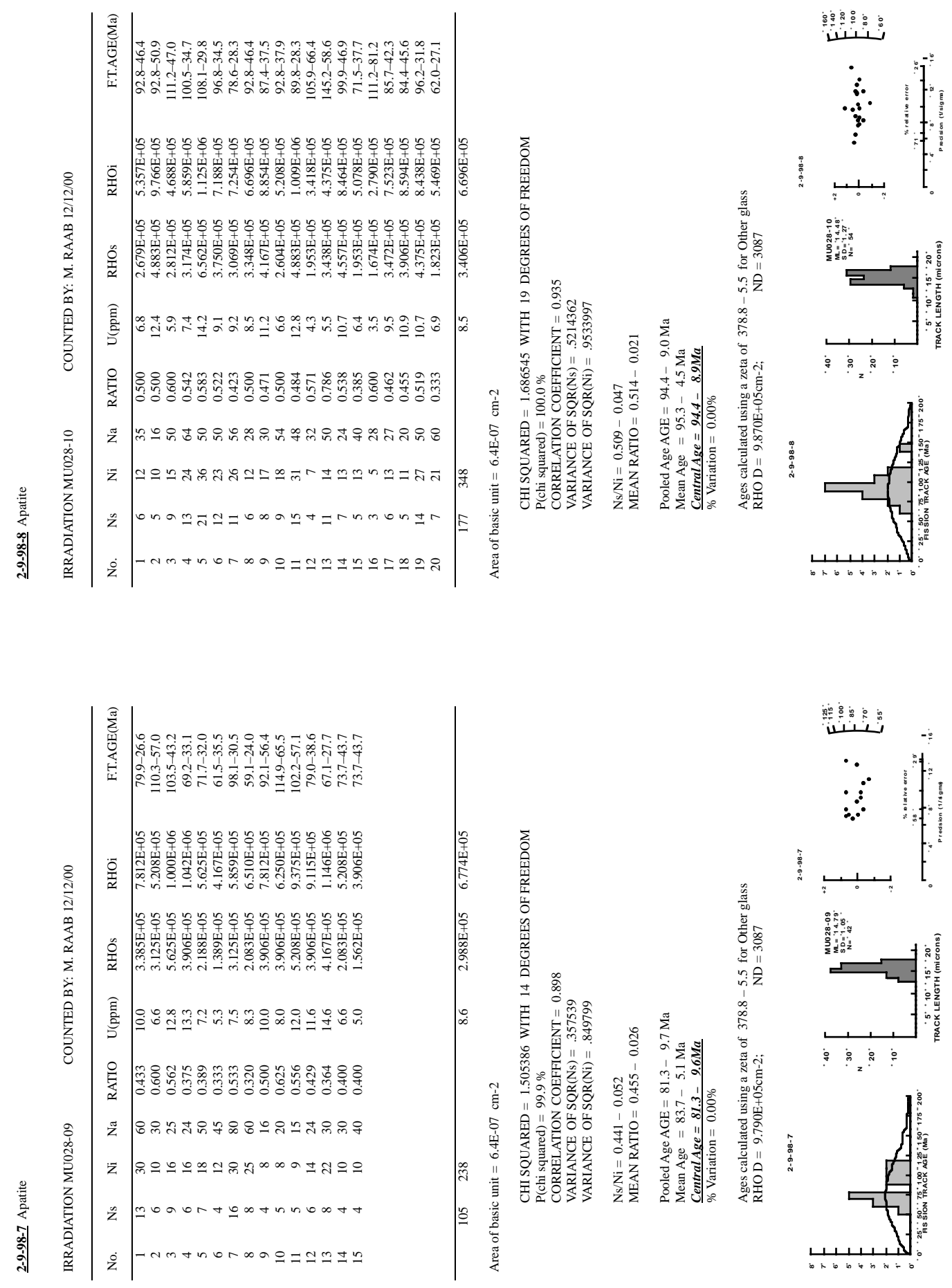

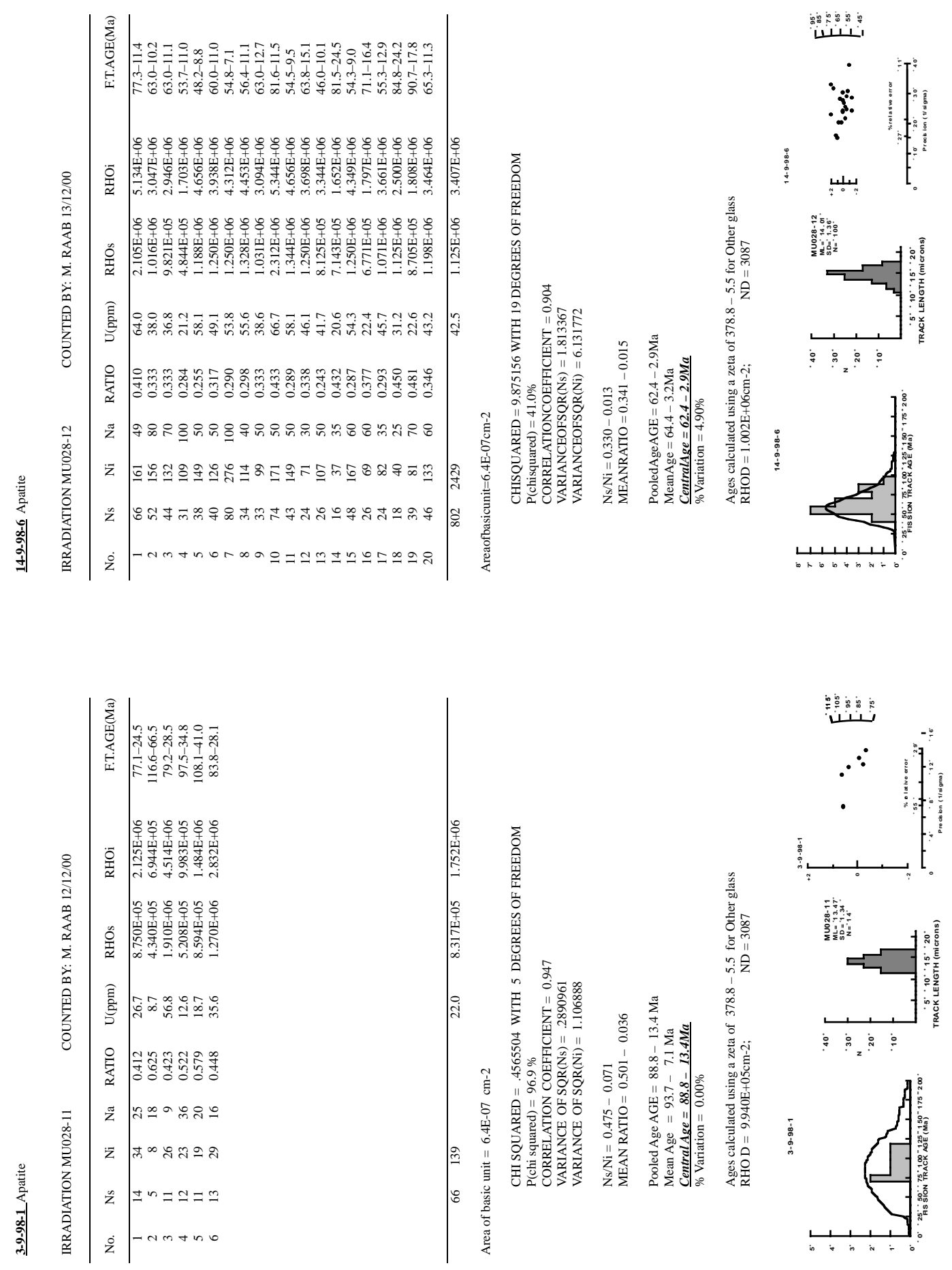

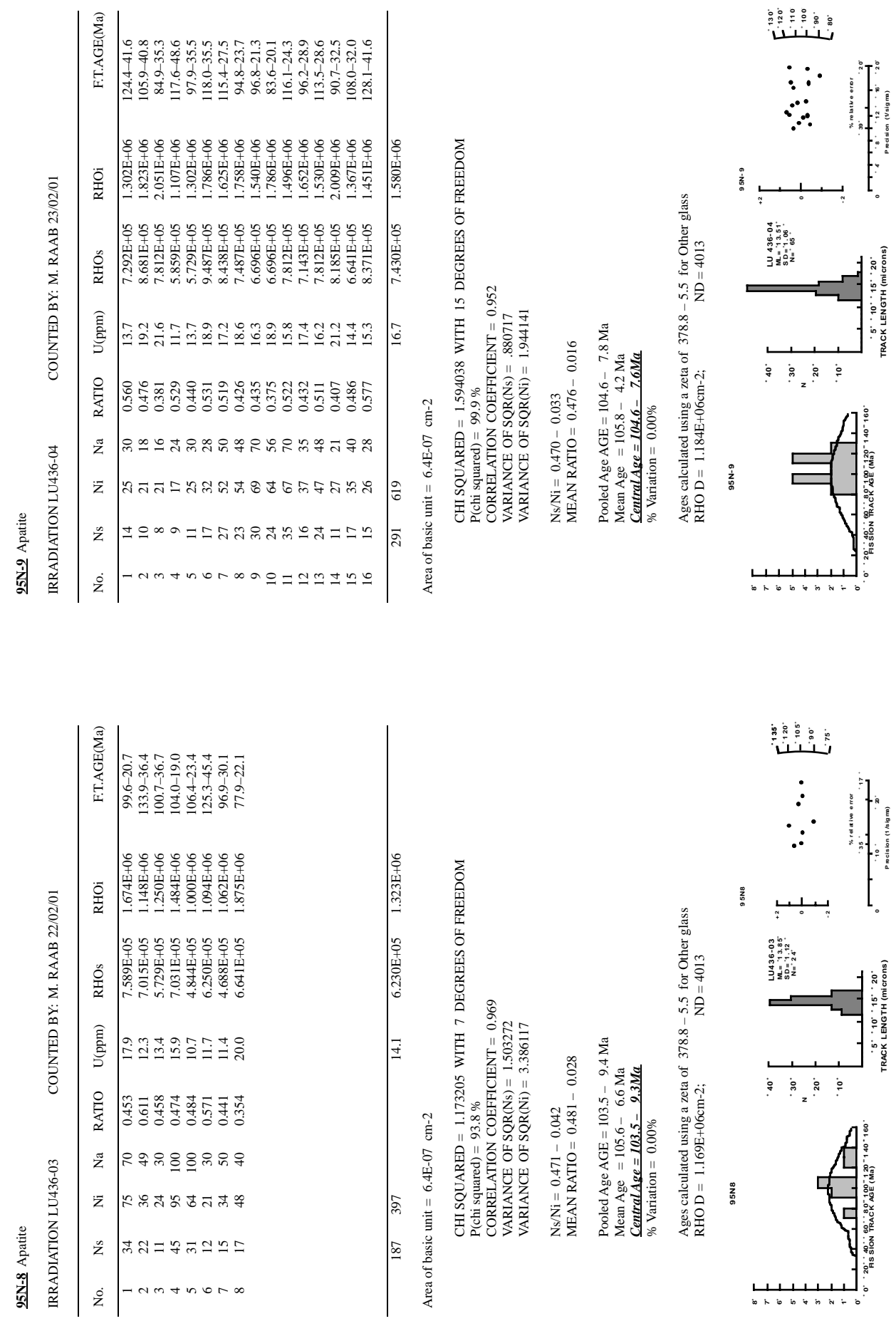

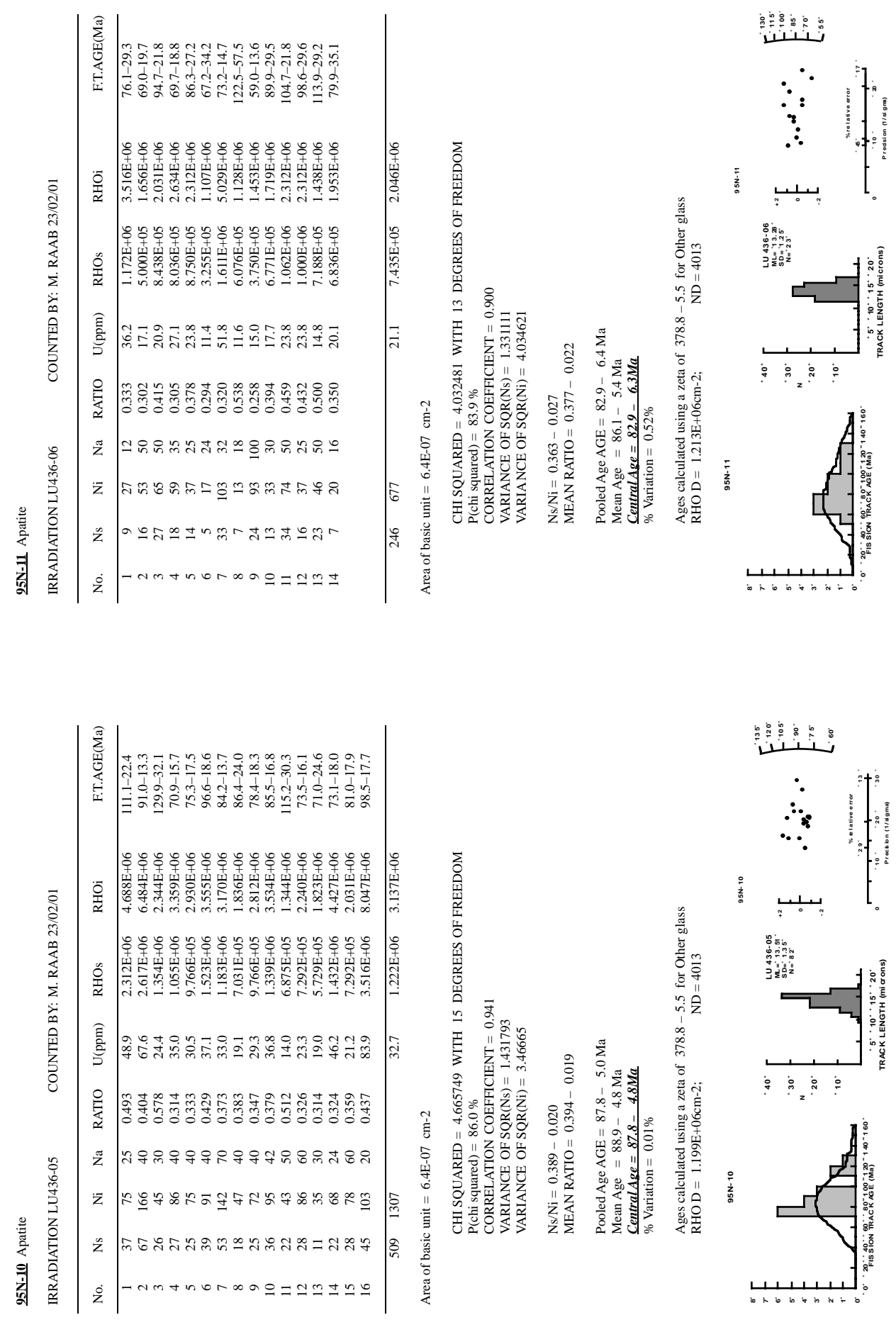

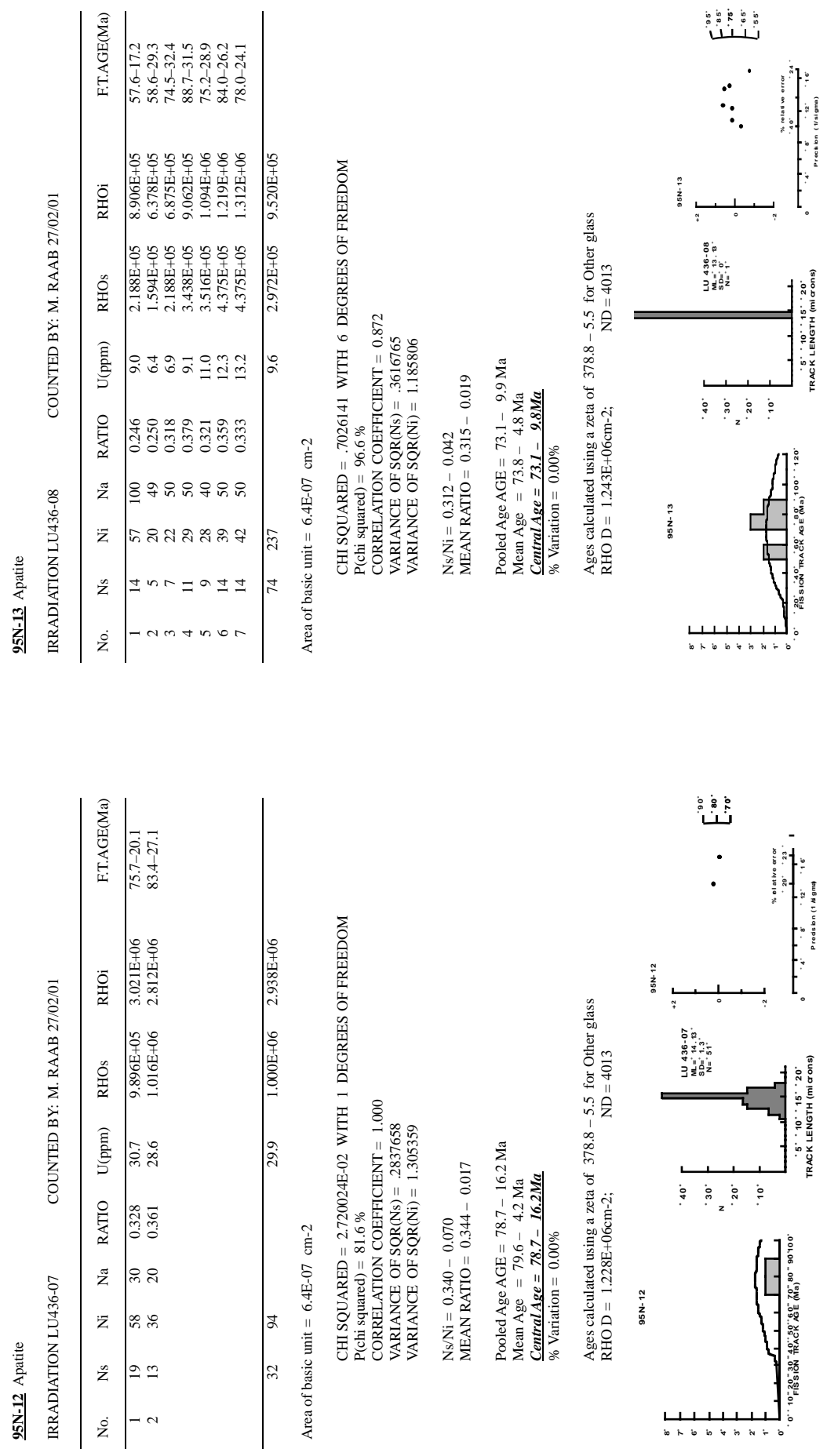

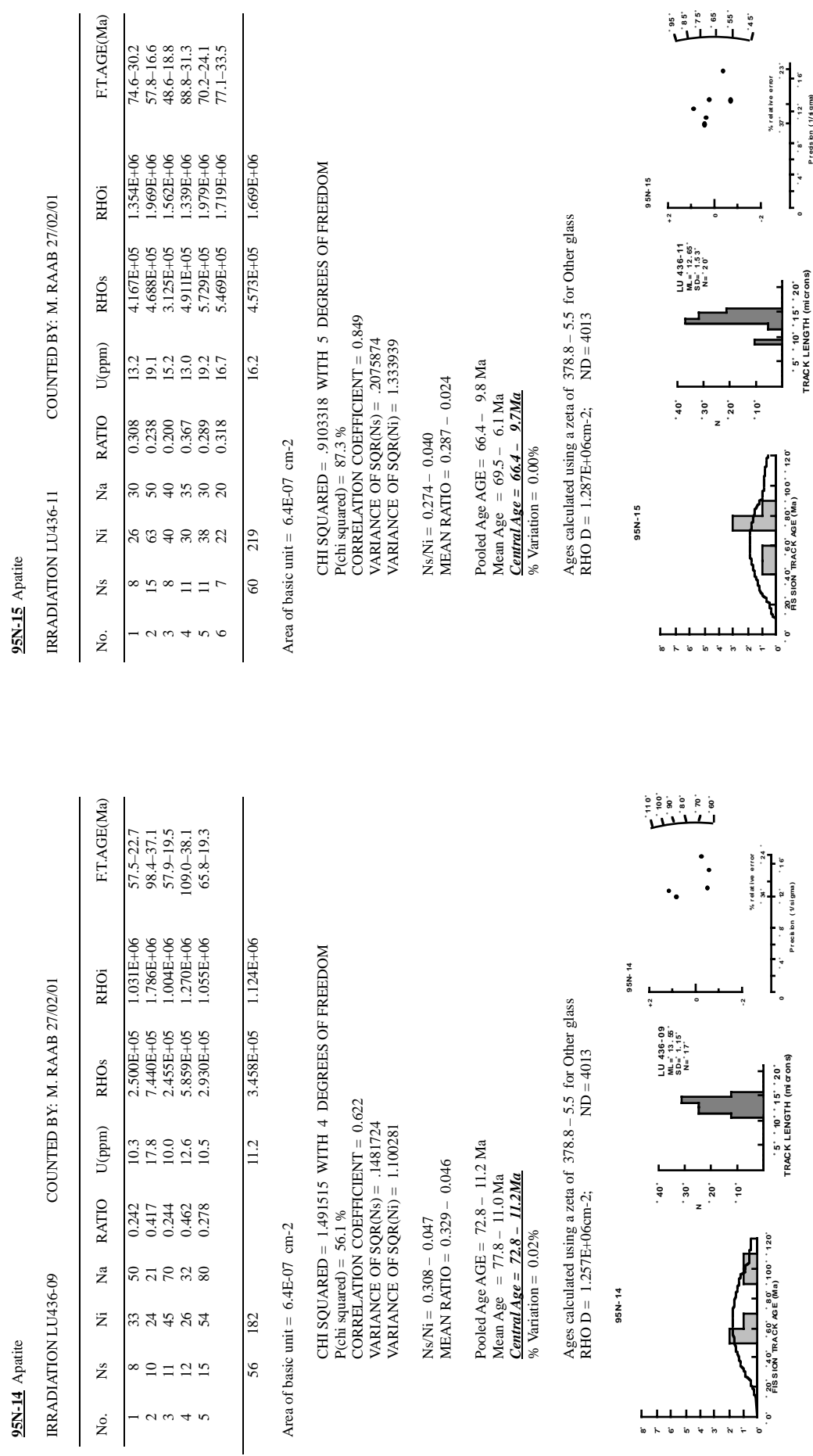

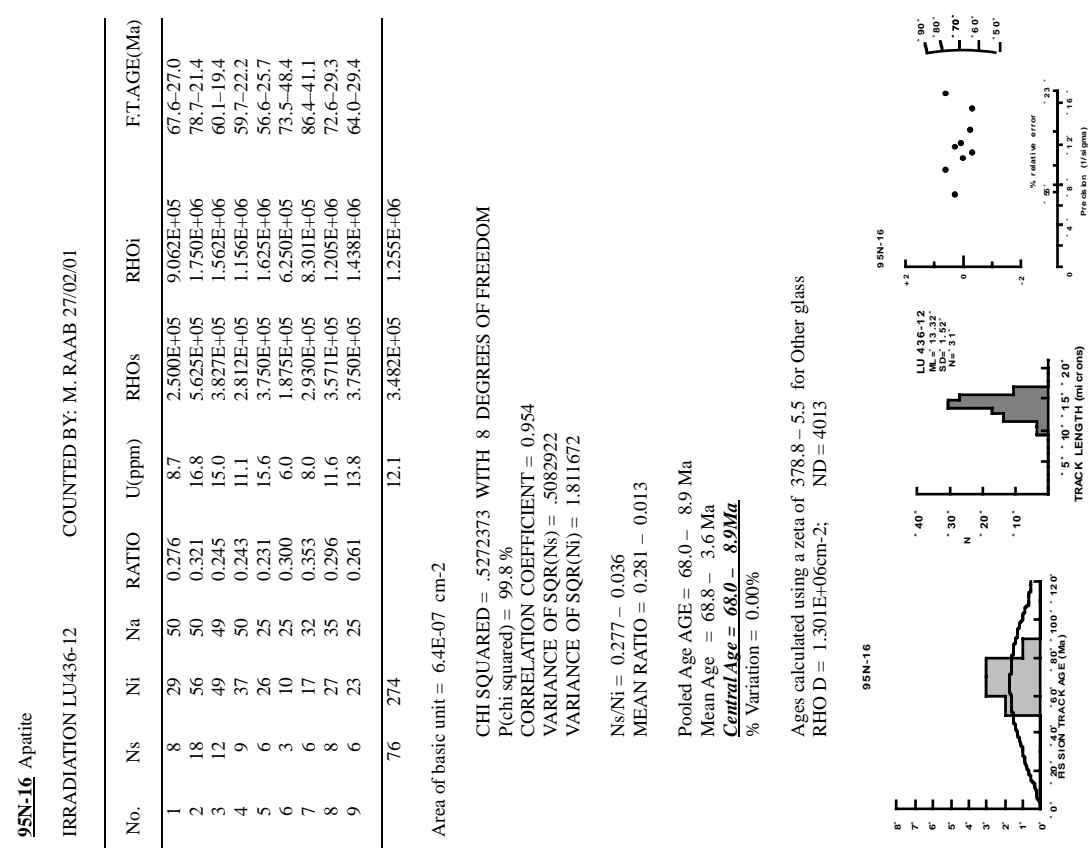


\section{Appendix D}

\section{GMT-Scripts}

\section{D.1 Introduction}

This appendix lists all applied Generic Mapping Tool (GMT) - scripts used for map constructions. GMT (version 3.3.4 used) is a software applied to generate maps and animations on Unix platforms (Wessel and Smith 1991). Scripts listed here were initially programmed by Roderick Brown and altered to different degrees by Matthias Raab.

\section{D.2 Contouring Fission Track Data}

The following script contours the fission track ages as displayed in Figure 5.2.

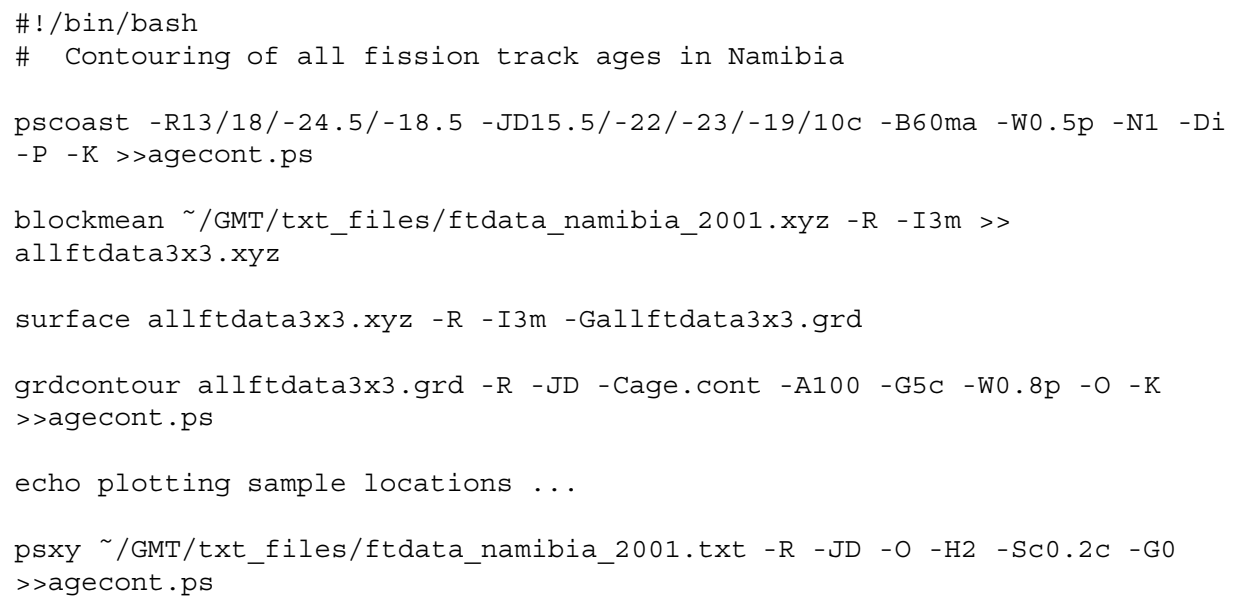




\section{D.3 Generating Location Maps}

Sample locations from different operators are plotted in various symbols on coloured topography (Figure 6.2), using the following script:

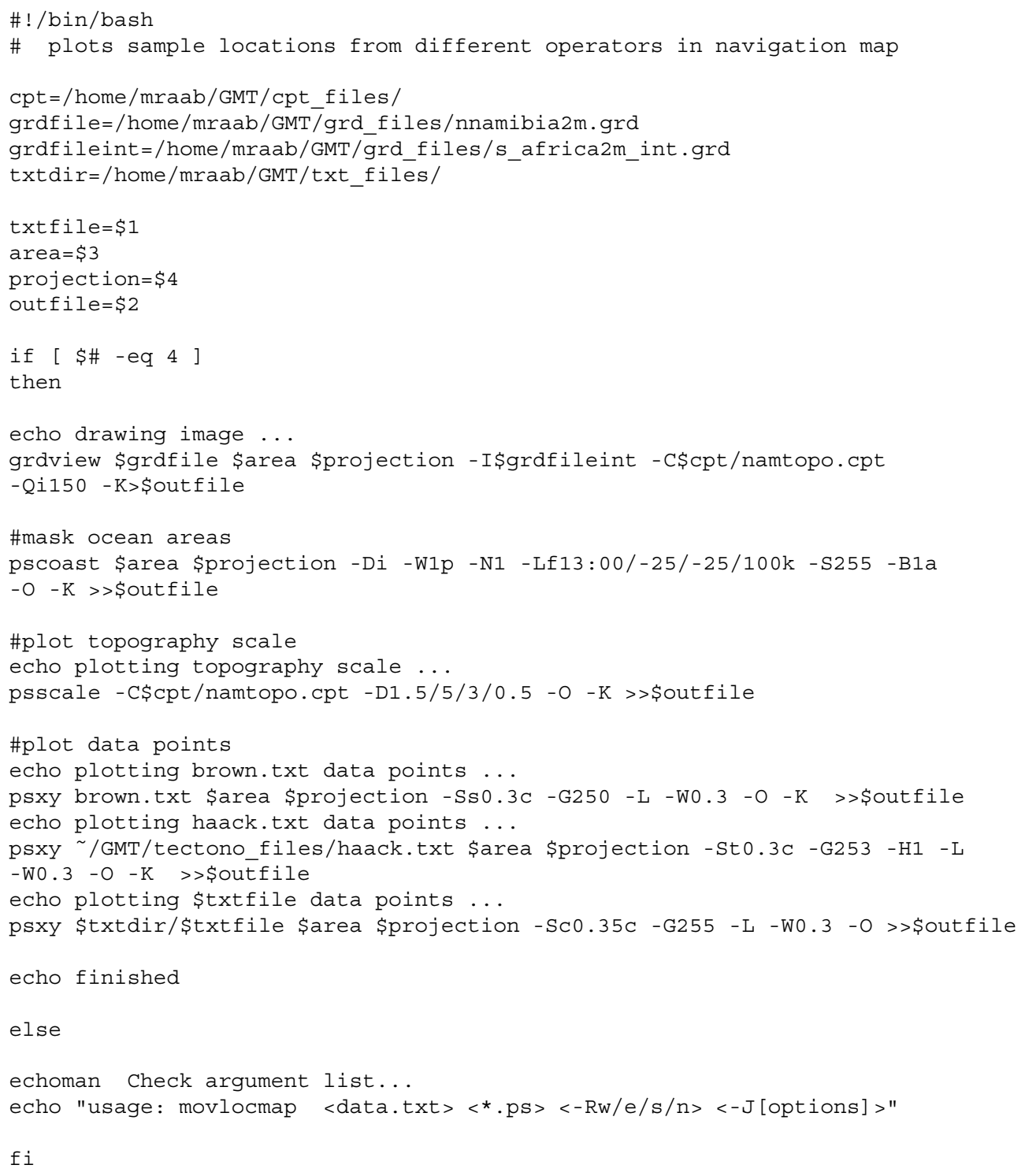




\section{D.4 Generating Age Dependent Location Map}

A coloured topographic map will be drawn with the fission track ages as agedependent circles (Figure 6.3), if invoking the following script:

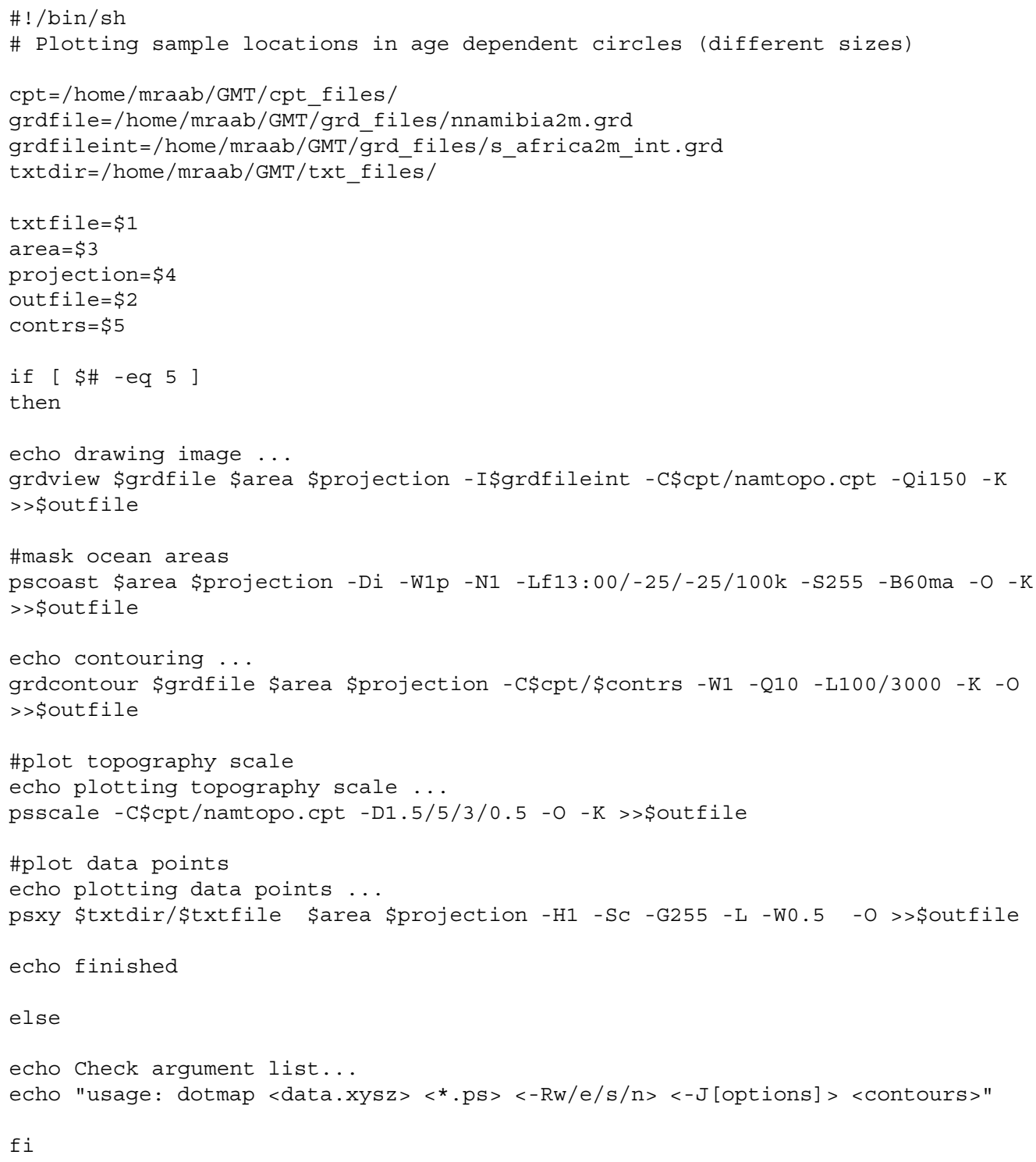




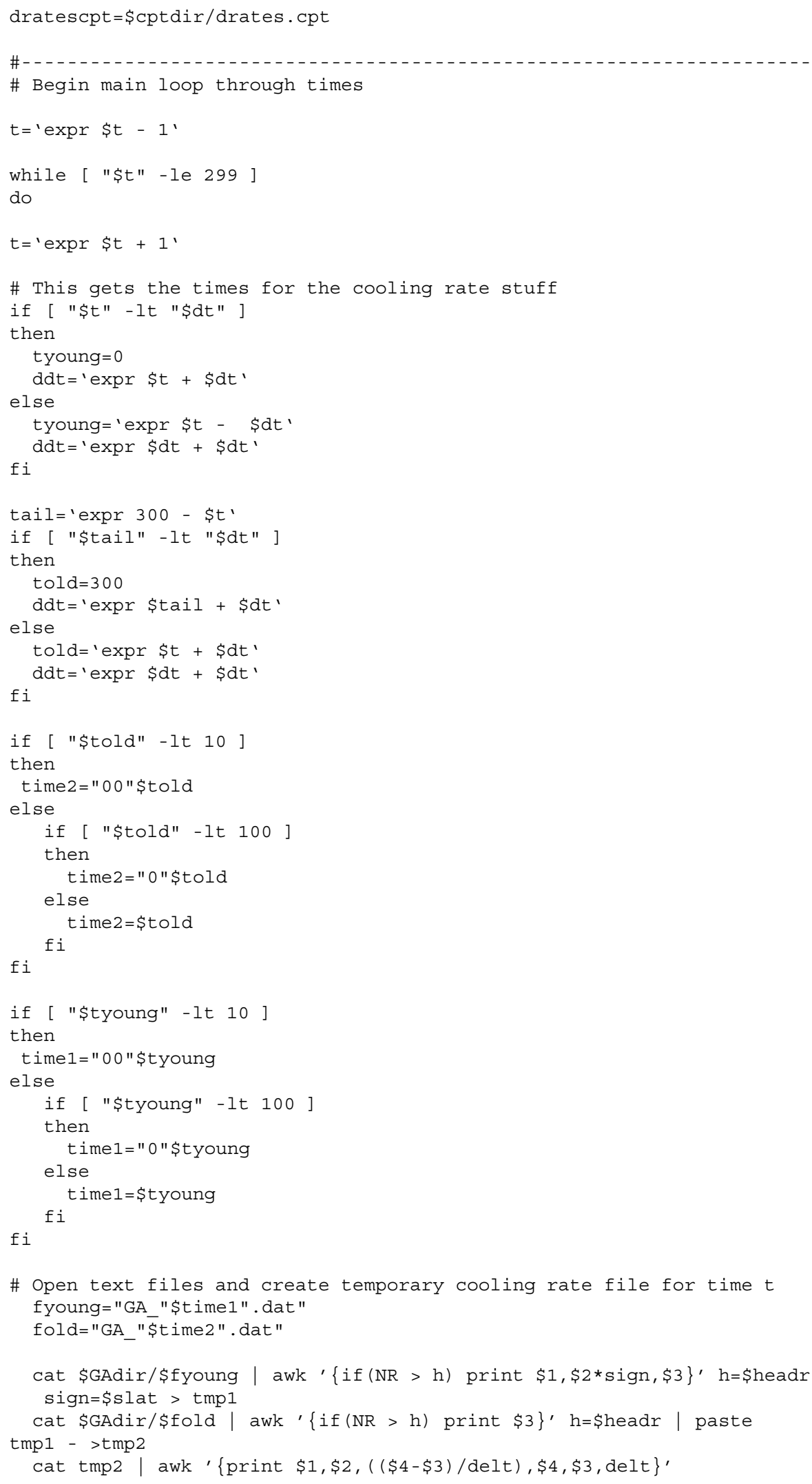




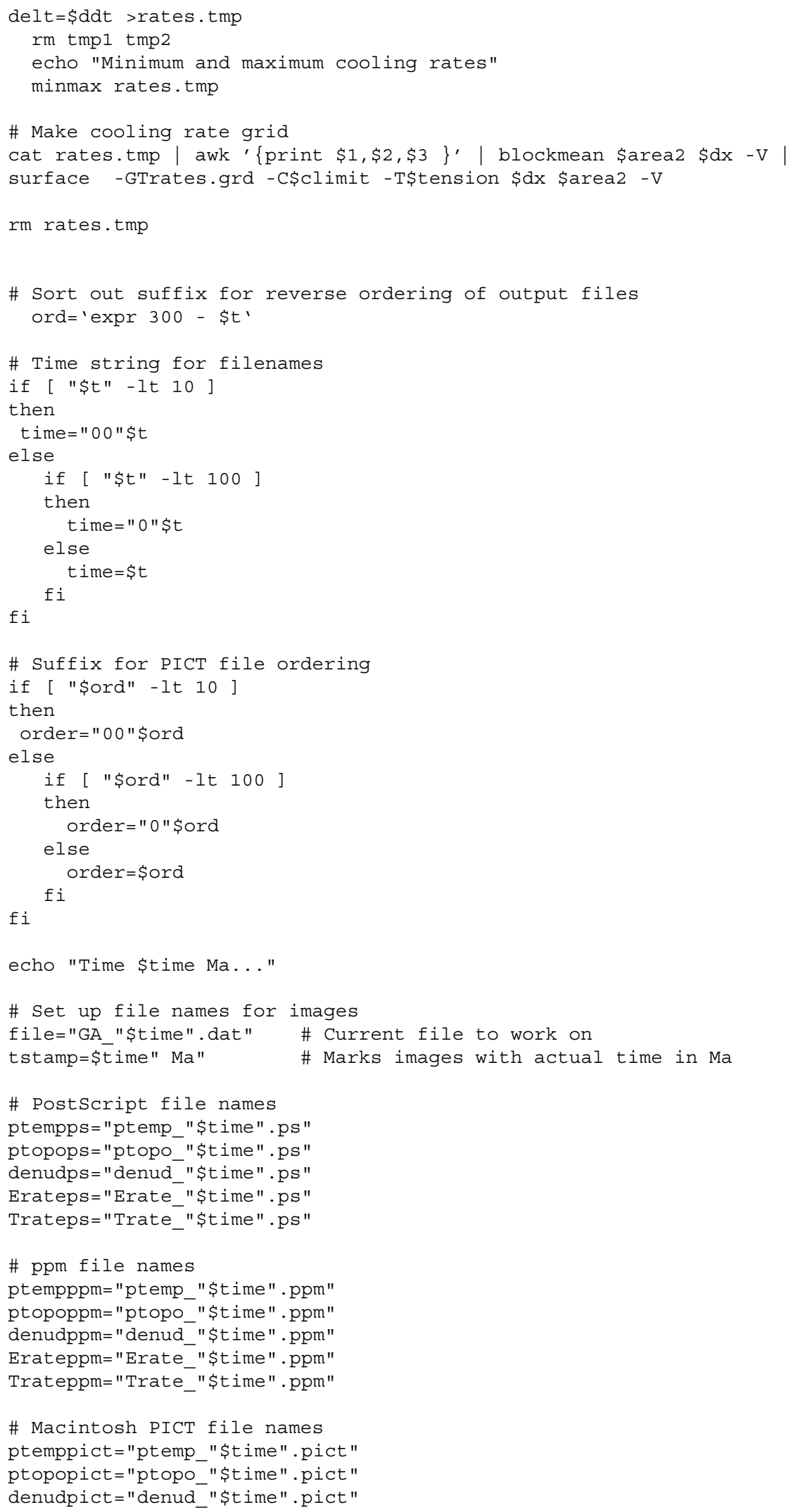




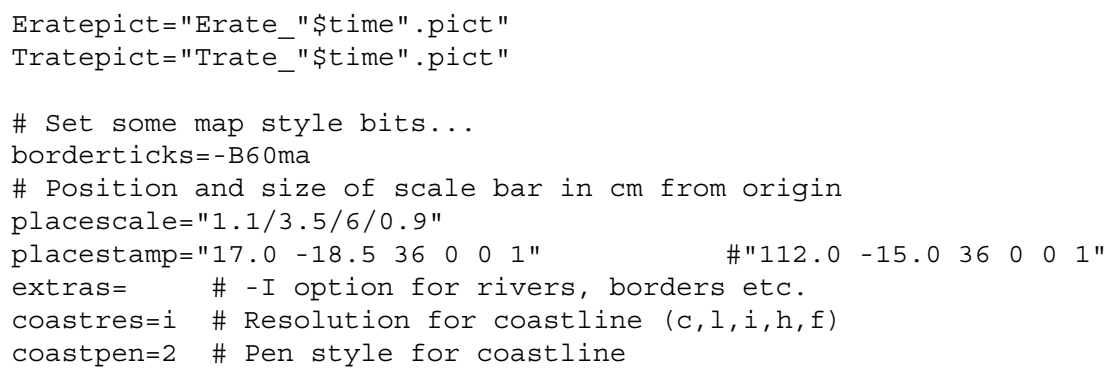




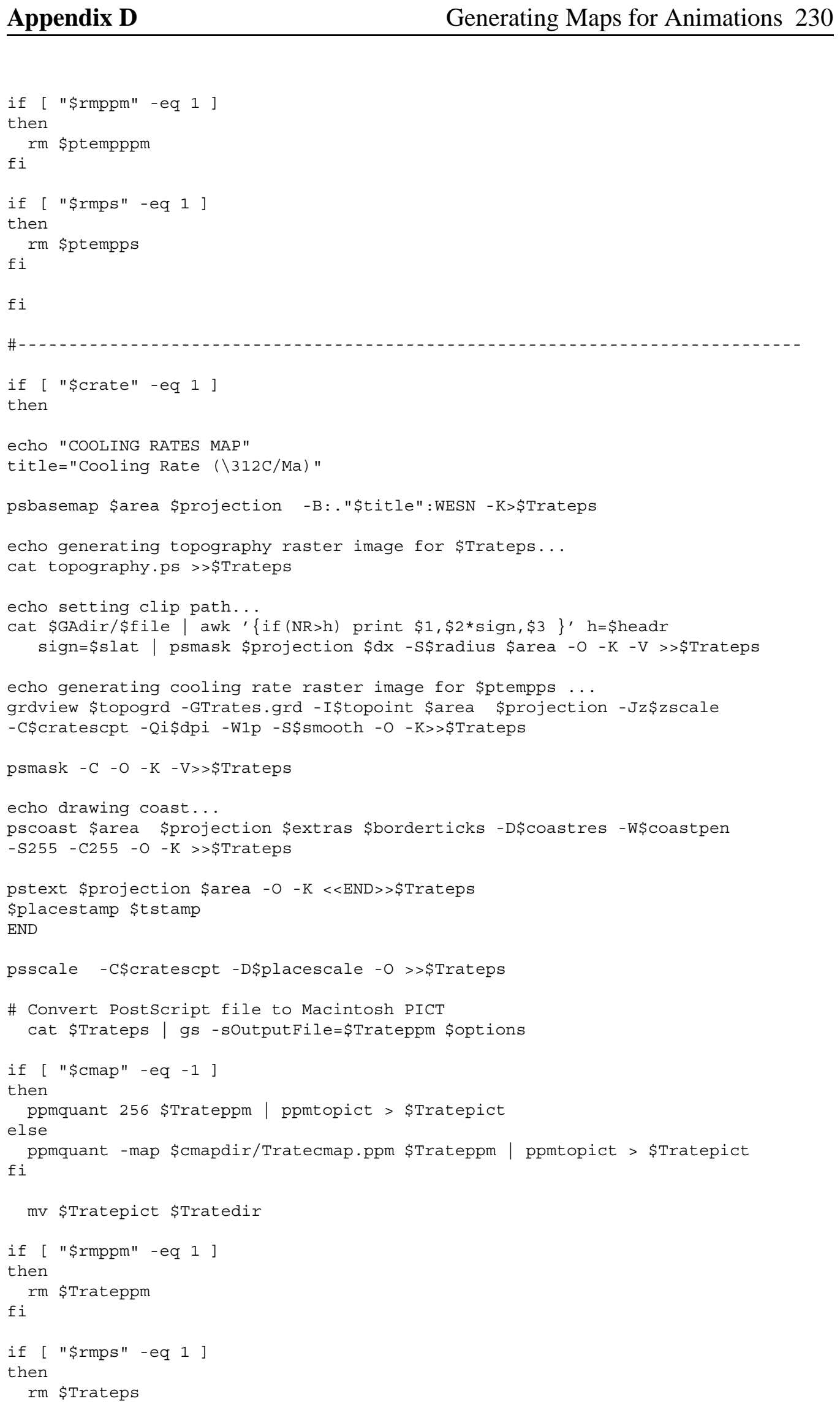




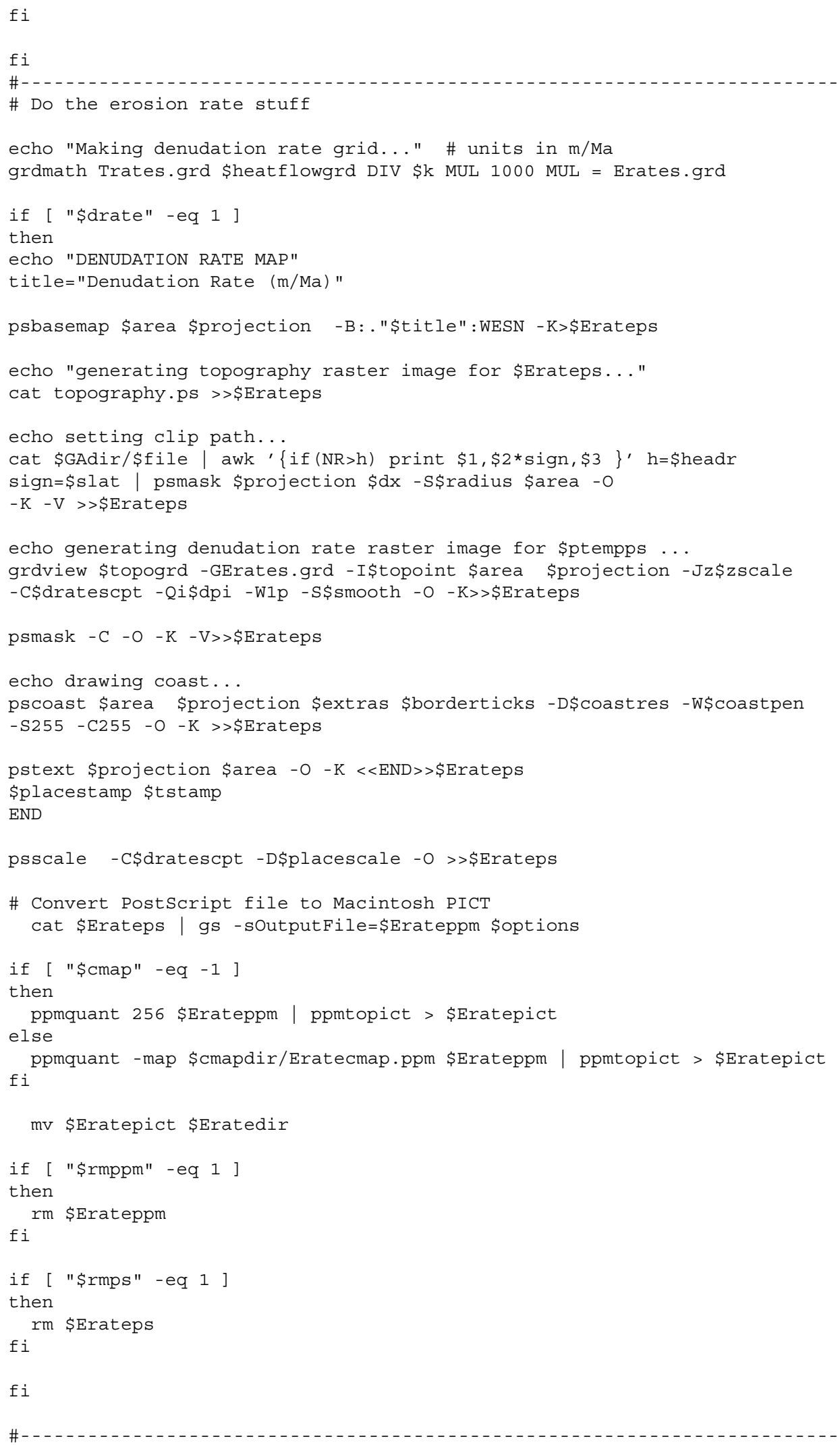




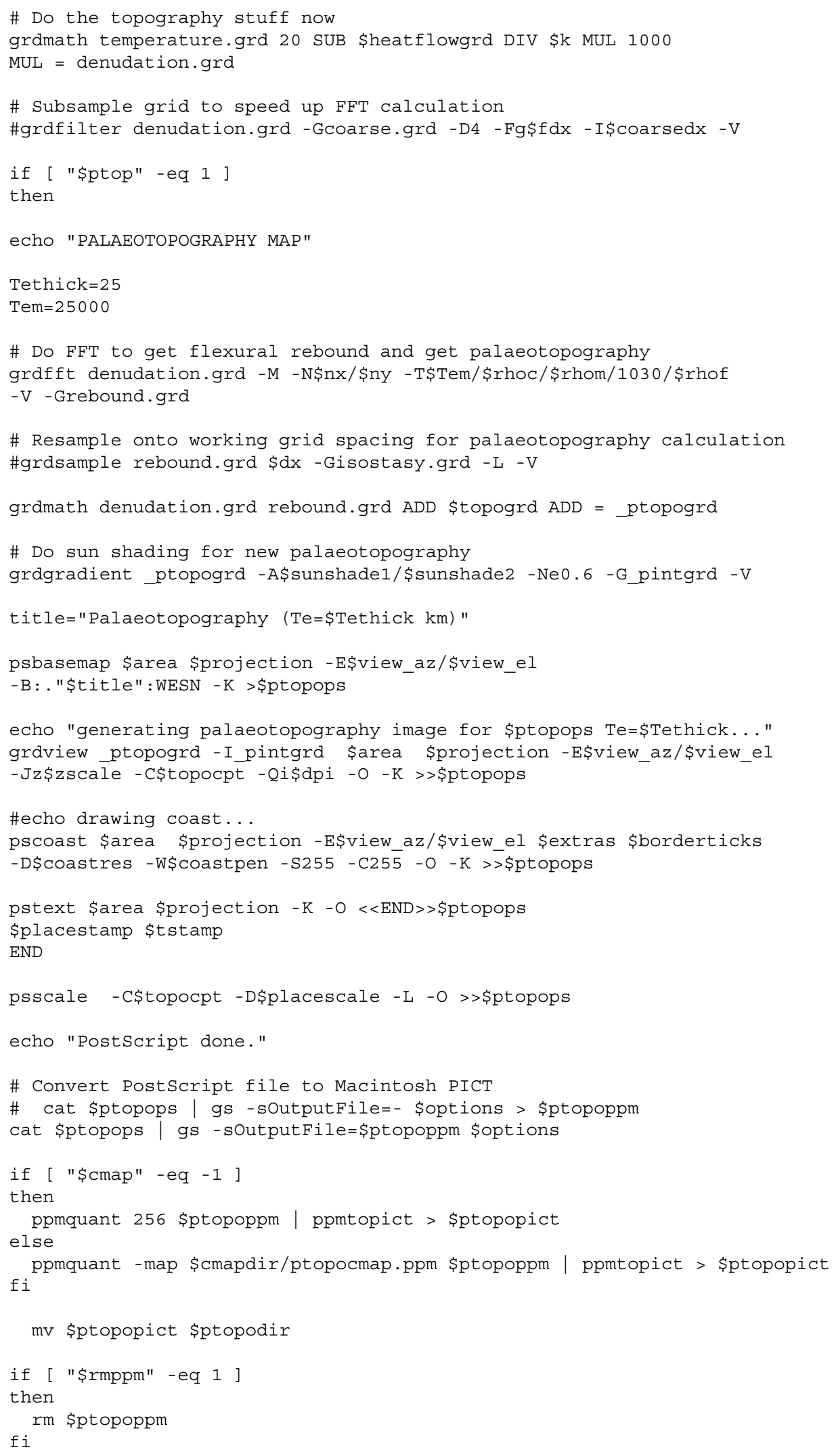




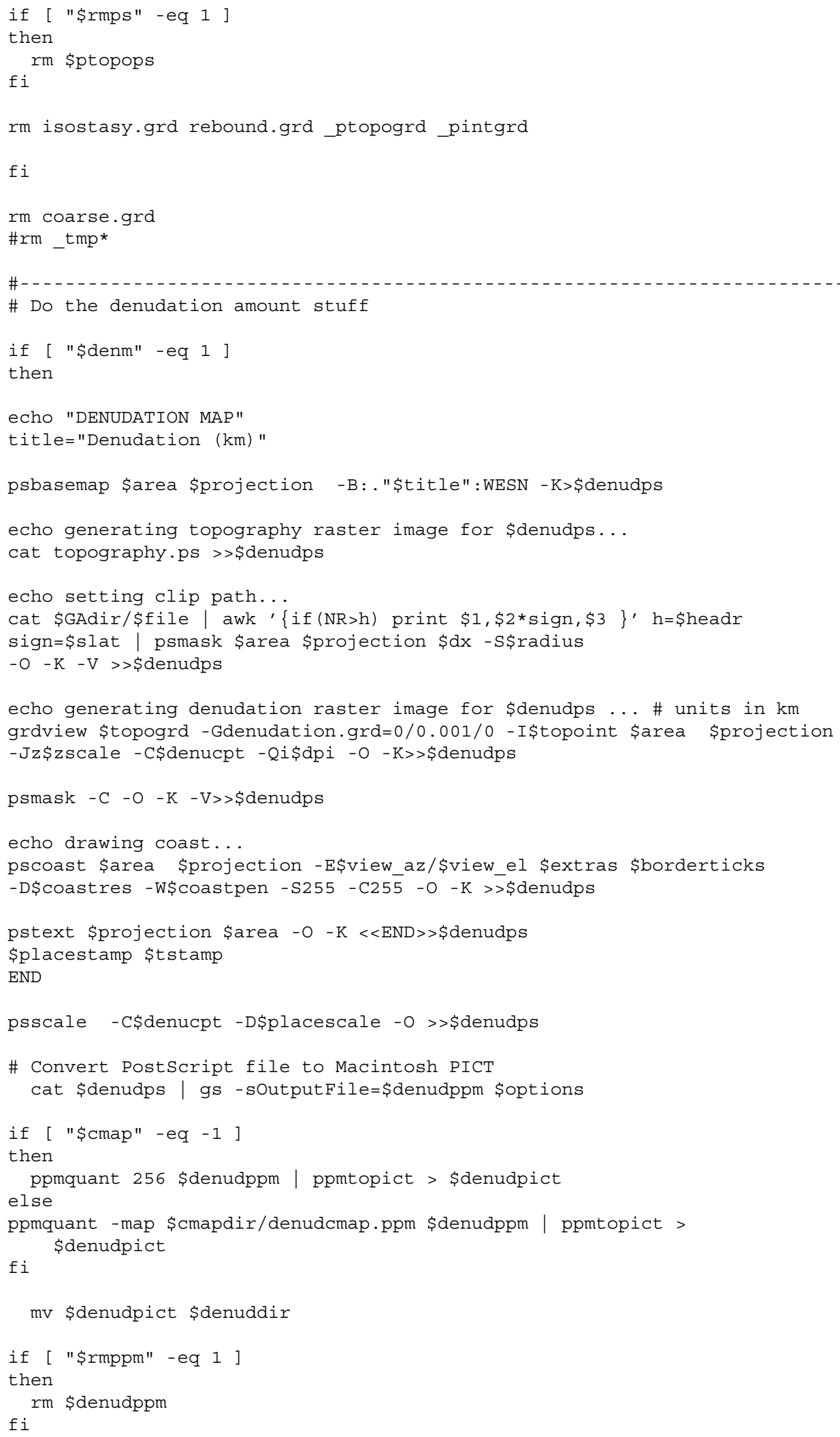




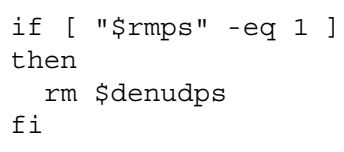




\section{Appendix E}

\section{Data-CD}

\section{E.1 Contents}

The CD-ROM attached to this thesis has the following contents:

Movies contains Thermal History Models (Chapter 6) as Quick-Time ${ }^{1}$ movies for:

Palaeotemperature (ptempsc.mov)

Denudation (densc.mov)

Palaeotopography (ptoposc.moc)

Fission-Track-Analyses contains all raw-data files (track counts and lenghts measurements) for all fission track analyses performed at The University of Melbourne for this thesis.

\footnotetext{
${ }^{1}$ Quick-Time can be downloaded from: http://www.apple.com/quicktime/ for Apple-Macintosh and IBM-compatible computers
} 


\section{References}

Allen, P. A. and Allen, J. R. (1990). Basin Analysis, Principles and Applications, Blackwell Scientific, Oxford.

Allsop, H. L., Bristow, J. W., Logan, C. T., Eales, H. V. and Erlank, A. J. (1984). $\mathrm{Rb}-\mathrm{Sr}$ geochronology of three Karoo-related intrusive complexes, in A. J. Erlank (ed.), Petrogenesis of the Volcanic Rocks of the Karoo Sequence, Vol. 13, Special Publication Geological Society South Africa, pp. 281-287.

Anderson, D. (1982). Hotspots, polar wander, Mesozoic convection, and the geoid, Nature 297: 391-393.

Arne, D. C. (1994). Phanerozoic exhumation history of northern Prince Charles Mountains (East Antarctica), Antarctic Science 6: 69-84.

Ballard, S. and Pollack, H. N. (1987). Terrestrial Heat Flow in Botswana and Namibia, Journal of Geophysical Research 92(B7): 6291-6300.

Bauer, K., Neben, S., Schreckenberger, B., Emmermann, R., Hinz, K., Jockat, W., Schulze, A., Trumbull, R. B. and Weber, K. (subm.). Deep structure of the Namibian continental margin as derived from integrated geophysical studies - the MAMBA experiment, Journal of Geophysical Research.

Besler, H. (1996). The Tsondab Sandstone in Namibia and its significance for the Namib Erg, South African Journal of Geology 99: 77-87.

Biermann, P. (1994). Using in situ produced cosmogenic isotopes to estimate rates of landscape evolution: a review from the geomorphic perspective, Journal of Geophysical Research 99: 13885-13896.

Bohannon, R. G., Naeser, C. W., Schmidt, D. L. and Zimmermann, R. A. (1989). The timing of uplift, volcanism and rifting peripheral to the Red Sea: A case for passive rifting, Journal of Geophysical Research 94: 1683-1701.

Bott, M. H. (1992). The stress regime associated with continental break-up, in B. C. Storey, T. Alabaster and R. J. Pankhurst (eds), Magmatism and the 
Causes of Continental Break-up, Vol. 68, Geological Society Special Publications, pp. 125-136.

Braun, J. and Beaumont, C. (1989). A physical explanation of the relation between rift flank uplifts and the breakup unconformity at rifted continental margins, Geology 17: 760-764.

Brown, L. F., Benson, J. M., Brink, G. J., Doherty, S., Jollands, A., Jungslager, E. H. A., Keenen, J. H. G., Muntingh, A. and van Wyk, N. J. S. (1995). Sequence stratigraphy in offshore South African divergent basins, An atlas on exploration for Cretaceous lowstand traps, Vol. 41 of Studies in Geology, Soekor (Pty) Ltd., p. 184 pp.

Brown, R. W. (1991). Backstacking apatite fission track stratigraphy: a method for resolving the erosional and isostatic rebound components of tectonic uplift histories, Geology 19: 74-77.

Brown, R. W. (1992). A fission track thermochronology study of the tectonic and geomorphic development of the sub-aerial continental margins of southern Africa., PhD thesis, La Trobe University, Bundoora, Australia.

Brown, R. W. and Summerfield, M. A. (1997). Some uncertainties in the derivation of rates of denudation from thermochronologic data, Earth Surface Processes and Landforms 22: 239-248.

Brown, R. W., Gallagher, K. and Duane, M. (1994a). A quantitative assessment of the effects of magmatism on the thermal history of the Karoo sedimentary sequence, Journal of African Earth Sciences 18: 227-243.

Brown, R. W., Gallagher, K. and Gleadow, A. J. W. (1997). Plate kinematics of the South Atlantic and Indian Ocean basins and intracontinental tectonics of Southern Africa, Chapman Conference on The History and Dynamics of Global Plate Motions, American Geophysical Union, Marshall, California, p. 13.

Brown, R. W., Gallagher, K. and Gleadow, A. J. W. (2000). Morphotectonic evolution of the South Atlantic margins of Africa and South America, in M. A. Summerfield (ed.), Geomorphology and Global Tectonics, John Wiley and Sons Ltd., Chichester, pp. 255-281.

Brown, R. W., Rust, D. J., Summerfield, M. A., Gleadow, A. J. W. and Wit, M. C. J. D. (1990). An early Cretaceous phase of accelerated erosion on the southwestern margin of Africa: Evidence from apatite fission track analysis and the offshore sedimentary record, Nuclear Tracks and Radiation Measurements 17: 339-351. 
Brown, R. W., Summerfield, M. A. and Gleadow, A. J. W. (1994b). Apatite fission track analysis: Its potential for the estimation of denudation rates and implications for models of long-term landscape development, in M. J. Kirkby (ed.), Process Models and Theoretical Geomorphology, Wiley, Chichester, pp. 23-53.

Buck, W. R. (1986). Small-scale convection induced by passive rifting: the cause for uplift of rift shoulders, Earth and Planetary Science Letters 77: 362-372.

Cande, S. C., LaBreque, J. L. and Haxby, W. F. (1988). Plate kinematics of the South Atlantic: Chron 34 to present, Journal of Geophysical Research 93: 13479-13492.

Carlson, W. D. (1990). Mechanism and kinetics of apatite fission-track annealing, American Mineralogist 75: 1120-1139.

Carlson, W. D. and Donelick, R. A. (1993). Compositional dependence of apatite fission track annealing rates, EOS Transactions American Geophysical Union 74: 168.

Castro, A. C. M. (1987). The northeastern Brazil and Gabon basins: a double rifting system associated with multiple crustal detachment surfaces, Tectonics 6: $727-738$.

Chadderton, L. T. (1988). On the anatomy of a fission fragment track, Nuclear Tracks and Radiation Measurements 15: 11-29.

Chang, H. K., Kowsmann, R. O., Figueiredo, A. M. F. and Bender, A. A. (92). Tectonics and stratigraphy of the East Brazil Rift system: an overview, Tectonophysics 213: 97-138.

Clemson, J., Cartwright, J. and Booth, J. (1997). Structural segmentation and the influence of basement structure on the Namibian passive margin, Journal of the Geological Society of London 154: 477-482.

Clemson, J., Cartwright, J. and Swart, R. (1999). The Namib Rift: a rift system of possible Karoo age, offshore Namibia, in N. R. Cameron, R. H. Bate and V. S. Clure (eds), The Oil and Gas Habitats of the South Atlantic, Vol. 153, Geological Society Special Publications, pp. 381-402.

Cochran, J. R. (1983). Effect of finite rifting times on the development of sedimentary basins, Earth and Planetary Science Letters 66: 289-302.

Cockburn, H. A. P. (1998). Landscape Evolution in Namibia and Antarctica: Quantifying Denudation Rates Using In-Situ Cosmogenic Isotope Analysis, Phd thesis, The University of Edinburgh, Scotland, United Kingdom. 
Cockburn, H. A. P., Brown, R. W., Summerfield, M. A. and Seidl, M. A. (2000). Quantifying passive margin denudation and landscape development using a combined fission-track thermochronology and cosmogenic isotope analysis approach, Earth and Planetary Science Letters 179: 429-435.

Cockburn, H. A. P., Seidl, M. A. and Summerfield, M. A. (1999). Quantifiying denudation rates on inselbergs in the central Namib Desert using in situproduced cosmogenic ${ }^{10} \mathrm{Be}$ and ${ }^{26} \mathrm{Al}$, Geology 27: 399-402.

Corner, B. (1983). An interpretation of the aeromagnetic data covering the western portion of the Damara Orogen in South West Africa/Namibia, in R. M. Miller (ed.), Evolution of the Damara Orogen, Vol. 11 of Special Publications Geological Society of South Africa, Geological Society of South Africa, pp. 339-354.

Coward, M. P. and Daly, M. C. (1984). Crustal lineaments and shear zones in Africa: Their relationships to plate movements, Precambrian Research 24: $27-45$.

Cox, K. G. (1988). The Karoo Province, in J. D. Macdougall (ed.), Continental Flood Basalts, Kluwer Academics, Norwell, Massachusetts, pp. 239-271.

Crowley, K. D., Cameron, M. and Schaefer, R. L. (1991). Experimental studies of annealing of etched fission tracks in fluorapatite, Geochimica Cosmochimica Acta 55: 1449-1465.

Daly, M. C. (1986). Crustal shear zones and thrust belts: their geometry and continuity in Central Africa, Philosophical Transactions Royal Society London A 317: 111-128.

Daly, M. C. (1989). Rift basin evolution in Africa: the influence of reactivated steep basement shear zones, in G. D. W. M. A. Cooper (ed.), Inversion tectonics, Vol. 44, Geological Society Special Publications, pp. 309-334.

Daly, M. C., Lawrence, S. R., Kimun'a, D. and Binga, M. (1991). Late Palaeozoic deformation in central Africa: a result of distant collision?, Nature 350: 605607.

Davies, C. P. N. and van der Spuy, D. (1992). The Kudu wells: Results of a biomarker study related to burial history modelling, Communications of the Geological Survey of Namibia 8: 45-56.

DeWit, M. C. J., Ward, J. D. and Spaffiari, R. (1992). A reappraisal of the Kangnas dinosaur site, Bushmanland, South Africa, South African Journal of Science 88: 504-507. 
Diehl, M. (1986). Prelimanary report on the Cape Cross-Uis pegmatite field, Communications of the Geological Survey of Namibia 2: 39-45.

Diehl, M. (1990). Geology, Mineralogy, Geochemistry and Hydrothermal Alsteration of the Brandberg Alkaline Complex, Namibia, Memoirs Geological Survey of Namibia 10: 1-55.

Donath, F. A. (1961). Experimental study of shear failure in anisotropic rocks, Geological Society of America Bulletin 72: 985-989.

Donelick, R. A., Roden, M. K., Mooers, J. D., Carpenter, B. S. and Miller, D. S. (1990). Etchable length reduction of induced fission tracks in apatite at room temperature $\left(\sim 23^{\circ} \mathrm{C}\right)$ : Crystallographic orientation effects and "initial" mean lengths, Nuclear Tracks and Radiation Measurements 17: 261-265.

Downing, K. N. and Cowards, M. P. (1981). The Okahandja Lineament and its Significance for Damaran Tectonics in Namibia, Geologische Rundschau 70: $972-1000$.

Dumitru, T. A. (2000). Fission-Track Geochronology, Quartenary Geochronology: Methods and Applications, American Geophysical Union, pp. 131-155.

Duncan, R., Hooper, P., Rehacek, J., March, J. and Duncan, A. (1997). The timing and duration of the Karoo igneous event, southern Gondwana, Journal of Geophysical Research 102: 18127-18138.

Erlank, A. J. (1984). Petrogenesis of the Volcanic Rocks of the Karoo Sequence, Vol. 13, Special Publication Geological Society South Africa.

Fairhead, J. D. (1988). Mesozoic plate tectonic reconstructions of the central South Atlantic Ocean: The role of the West and Central African rift system, Tectonophysics 155: 181-191.

Fairhead, J. D. and Brinks, R. M. (1991). Differential opening of the Central and South Atlantic Oceans and the opening of the West African rift system, Tectonophysics 187: 191-203.

Fitzgerald, P. G. (1994). Thermochronologic constraints on post-Paleozoic tectonic evolution of the central Transantarctic Mountains, Tectonics 13: 818836.

Fitzgerald, P. G. and Gleadow, A. J. W. (1988). Fission track geochronology, tectonics and structure of the Transantarctic Mountains in northern Victoria Land, Antarctica, Chemical Geology (Isotope Geoscience Section) 73: 169198. 
Fitzgerald, P. G. and Gleadow, A. J. W. (1990). New approaches in fission track geochronology as a tectonic tool: Examples from the Transantarctic Mountains, Nuclear Tracks and Radiation Measurements 17: 351-357.

Fitzgerald, P. G., Sorkhabi, R. B., Redfield, T. F. and Stump, E. (1995). Uplift and denudation of the central Alaska Range: a case study in the use of apatite fission track thermochronology to determine absolute uplift parameters, Journal of Geophysical Research 100: 20175-20191.

Fleischer, R. L., Price, P. B. and Walker, R. M. (1965). Effects of temperature, pressure and ionisation of the formation and stability of fission tracks in minerals and glasses, Journal of Geophysical Research 70: 1497-1582.

Fleischer, R. L., Price, P. B. and Walker, R. M. (1975). Nuclear Tracks in Solids, University of California Press, Berkeley.

Fleming, A., Summerfield, M. A., Stone, J. O., Fifield, L. K. and Cresswell, R. G. (1999). Denudation rates for the southern Drakensberg escarpment, SE Africa, derived from in-situ-produced cosmogenic ${ }^{36} \mathrm{Cl}$ : initial results, Journal of the Geological Society, London 156: 209-212.

Foster, D. A. and Gleadow, A. J. W. (1992a). Reactivated tectonic boundaries and implications for the reconstruction of southeastern Australia and northeastern Victoria Land, Antarctica, Geology 20: 267-270.

Foster, D. A. and Gleadow, A. J. W. (1992b). Reactivated tectonic boundaries and implications for the reconstruction of southeastern Australia and northern Victoria Land, Antarctica, Geology 20: 267-270.

Foster, D. A. and Gleadow, A. J. W. (1996). Structural framework and denudation history of the flanks of the Kenya and Anza Rifts, East Africa, Tectonics 15: $258-271$.

Foster, D. A., Gleadow, A. J. W. and Mortimer, G. (1994). Rapid Pliocene exhumation in the Karakoram, revealed by fission-track thermochronology of the K2 gneiss, Geology 22: 19-22.

Foster, D. A., Gleadow, A. J. W., Reynolds, S. J. and Fitzgerald, P. G. (1993). The denudation of metamorphic core complexes and the reconstruction of the Transition Zone, west central Arizona: constraints from apatite fission track thermochronology, Journal of Geophysical Research 98: 2167-2185.

Fuller, A. O. (1971). South Atlantic fracture zones and lines of old weakness in Southern Africa, Nature 231: 84-85.

Galbraith, G. F. (1990a). The radial plot: graphical assessment of spread in ages, Nuclear Tracks and Radiation Measurements 17: 207-214. 
Galbraith, R. F. (1981). On statistical models for fission track counts, Mathematical Geology 13: 471-488.

Galbraith, R. F. (1985). Some remarks on statistical estimation in fission-track dating, Nuclear Tracks and Radiation Measurements 10: 361-363.

Galbraith, R. F. (1990b). Apatite fission track analysis: geological thermal history analysis based on a three-dimensional random process of linear radiation damage, Philosophical Transactions Royal Society London A 332: 419-438.

Galbraith, R. F. (1990c). Estimating the component ages in a finite mixture, $\mathrm{Nu}$ clear Tracks and Radiation Measurements 17: 197-206.

Galbraith, R. F. and Laslett, G. M. (1993). Statistical models for mixed fission track ages, Nuclear Tracks and Radiation Measurements 21: 459-470.

Gallagher, K. (1995). Evolving temperature histories from apatite fission-track data, Earth and Planetary Science Letters 136: 421-435.

Gallagher, K. and Brown, R. W. (1997). The onshore record of passive margin evolution, Journal of the Geological Society, London 154: 451-457.

Gallagher, K. and Brown, R. W. (1999a). Denudation and uplift at passive margins: the record on the Atlantic Margin of southern Africa, Philosophical Transactions Royal Society London A 357: 835-859.

Gallagher, K. and Brown, R. W. (1999b). The Mesozoic denudation history of the Atlantic margins of southern Africa and southeast Brazil and the relationship to offshore sedimentation, in N. R. Cameron, R. H. Bate and V. S. Clure (eds), The Oil and Gas Habitats of the South Atlantic, Vol. 153, Geological Society Special Publications, pp. 41-53.

Gallagher, K., Brown, R. W. and Johnson, C. (1998). Fission track analysis and its application to geological problems, Annual reviews of Earth Planetary Sciences 26: 519-572.

Gallagher, K., Hawkesworth, C. J. and Mantovani, M. S. M. (1994). The denudational history of the onshore continental margin of SE Brazil from fission track data, Journal of Geophysical Research 99: 18117-18145.

Gerrard, I. and Smith, G. C. (1982). Post Palaeozoic succession and structure of the southwestern African continental margin, American Association of Petroleum Geology Memoires 34: 49-74.

Gilchrist, A. R., Kooi, H. and Beaumont, C. (1994). Post Gondwana geomorphic evolution of southwestern Africa: Implications for the controls on landscape development from observations and numerical experiments, Journal of Geophysical Research 99: 12211-12228. 
Gilchrist, A. R. and Summerfield, M. A. (1990). Differential denudation and flexural isostasy in formation of rifted margin upwards, Nature 246: 739742.

Gilchrist, A. R. and Summerfield, M. A. (1994). Tectonic Models of Passive Margin Evolution and their Implications for Theories of Long-term Landscape Development, in M. J. Kirkby (ed.), Process Models and Theoretical Geomorphology, Wiley, Chichester, pp. 55-84.

Gladzenko, T. P., Hinz, K., Eldholm, O., Meyer, H., Neben, S. and Skogseid, J. (1997). South Atlantic volcanic margins, Journal of the Geological Society, London 154: 465-470.

Gleadow, A. J. W. and Brown, R. W. (2000). Fission-track thermochronology and the long-term denudational response to tectonics, in M. A. Summerfield (ed.), Geomorphology and Global Tectonics, John Wiley and Sons Ltd., Chichester, pp. 57-75.

Gleadow, A. J. W. (1981). Fission track dating methods: what are the real alternatives?, Nuclear Tracks and Radiation Measurements 5: 3-14.

Gleadow, A. J. W. (1990). Fission track thermochronology - reconstructing the thermal and tectonic evolution of the crust, Proceedings of the Pacific Rim Congress, Vol. III, pp. 15-21.

Gleadow, A. J. W. and Duddy, I. R. (1981). A natural long term annealing experiment for apatite, Nuclear Tracks and Radiation Measurements 5: 169-174.

Gleadow, A. J. W. and Fitzgerald, P. G. (1987). Uplift history and structure of the Transantarctic Mountains: New evidence from fission track dating of basement apatites in the Dry Valleys area, Southern Victoria Land, Earth and Planetary Science Letters 82: 1-14.

Gleadow, A. J. W. and Lovering, J. F. (1977). Geometry factor for external detectors in fission track dating, Nuclear Track Detection 1: 99-106.

Gleadow, A. J. W. and Lovering, J. F. (1978). Fission track geochronology of King Island, Bass Strait, Australia: Relationship to continental rifting, Earth and Planetary Science Letters 37: 429-437.

Gleadow, A. J. W., Duddy, I. R. and Lovering, J. F. (1983). Fission track analysis: a new tool for the evaluation of thermal histories and hydrocarbon potential, Journal Australian Petrology Engeneering Association 23: 93-102.

Gleadow, A. J. W., Duddy, I. R., Green, P. F. and Lovering, J. F. (1986). Confined fission track length in apatite: a diagnostic tool for thermal history analysis, Contributions to Mineralogy and Petrology 94: 405-415. 
Green, P. F. (1981a). A new look at statistics in fission track dating, Nuclear Tracks and Radiation Measurements 5: 77-86.

Green, P. F. (1981b). "Track-in-Track" length measurements in annealed apatites, Nuclear Tracks and Radiation Measurements 5: 121-128.

Green, P. F. (1985). Comparison of zeta calibration baselines for fission-track dating of apatite, zircon and sphene, Chemical Geology(Isotope Geoscience Section) 58: 1-22.

Green, P. F. (1988). The relationship between track shortening and fission track age reduction in apatite: combined influences of inherent instability, annealing anisotropy, length bias and system calibration, Earth and Planetary Science Letters 89: 335-352.

Green, P. F. and Hurford, A. J. (1984). Thermal neutron dosimetry for fission track dating, Nuclear Tracks and Radiation Measurements 9: 231-241.

Green, P. F., Duddy, I. R., Gleadow, A. J. W. and Lovering, J. F. (1989a). Apatite Fission-Track Analysis as a Palaeotemperature Indicator for Hydrocarbon Exploration, in N. D. Naeser (ed.), Thermal History of Sedimentary Basins Methods and Case Histories, Springer, New York, pp. 181-195.

Green, P. F., Duddy, I. R., Gleadow, A. J. W., Tingate, P. R. and Laslett, G. M. (1986). Thermal annealing of fission tracks in apatite 1. A Qualitative Description, Chemical Geology (Isotope Geoscience Section) 59: 237-253.

Green, P. F., Duddy, I. R., Laslett, G. M., Hegarty, K. A., Gleadow, A. J. W. and Lovering, J. F. (1989b). Thermal annealing of fission tracks in apatite 4. Qualitative modelling techniques and extension to geological timescales, Chemical Geology (Isotope Geoscience Section) 79: 155-182.

Gudmundsson, A. (1990). Dyke emplacement at divergent plate boundaries, in A. J. Parker, P. C. Rickwood and D. H. Tucker (eds), Mafic Dykes and Emplacement Mechanisms, Rotterdam: Balkena, pp. 47-48.

Haack, U. (1983). Reconstruction of the cooling history of the Damara Orogen by correlation of radiometric ages with geography and altitude, in $\mathrm{H}$. Martin and F. W. Eder (eds), Intracontinental fold belts, Springer Verlag, Berlin, pp. 837-884.

Handin, J. (1969). On the Coulomb-Mohr failure criterion, Journal of Geophysical Research 74: 5343-5348. 
Harman, R., Gallagher, K., Brown, R., Raza, A. and Bizzi, L. (1998). Accelerated denudation and tectonic/geomorphic reactivation of the cratons of northeastern Brazil during Late Cretaceous, Journal of Geophysical Research 103: $27,091-27,105$.

Harrison, T. M. and Clarke, G. K. C. (1979). A model of thermal effects of igneous intrusion and uplift as applied to Quotton pluton, British Columbia, Canadian Journal of Earth Sciences 16: 411-420.

Hegenberger, W. (1988). Karoo Sediments of the Erongo Mountains, their environmental setting and correlation, Communications of the Geological Survey of Namibia 4: 51.

Hill, R. I. (1991). Starting plumes and continental break-up, Earth and Planetary Science Letters 67: 398-416.

Hoal, B. G. (1990). The Kudu offshore drilling project, Communications of the Geological Survey of Namibia 6: 1-73.

Holzförster, F., Stollhofen, H. and Stanistreet, I. G. (1999). Lithostratigraphy and depositional environments in the Waterberg-Erongo area, central Namibia, and correlation with the main Karoo Basin, South Africa, Journal of African Earth Sciences 29: 105-123.

Hunter, D. R. and Reid, D. L. (1987). Mafic dyke swarms in southern Africa, in H. C. Halls and W. F. Fahrig (eds), Mafic dyke swarms, Vol. 34 of Geological Association Canada Special Paper, Montreal: Pierre Des Marais Inc., pp. 445-456.

Hurford, A. J. (1990a). International Union of Geological Sciences Subcommission on Geochronology recommendation for the standardization of fission track dating calibration and data reporting, Nuclear Tracks and Radiation Measurements 17: 233-236.

Hurford, A. J. (1990b). Standardization of fission track dating calibration; recommendation by the Fission Track Working Group of the I.U.G.S. Subcommission on Geochronology, Chemical Geology (Isotope Geoscience Section) 80: $171-178$.

Hurford, A. J. and Green, P. F. (1982). A users' guide to fission track dating calibration, Earth and Planetary Science Letters 59: 343-354.

Hurford, A. J., Flisch, M. and Jaeger, E. (1989). Unravelling the thermo-tectonic evolution of the Alps: a contribution from fission track analysis and mica dating, Geological Society Special Publications 45: 369-398. 
Janse, A. J. A. (1975). Kimberlites and related rocks from the Nama plateau of south-west Africa, Physics and Chemistry of the Earth 9: 81-94.

Janssen, M. E., Stephenson, R. A. and Cloetingh, S. (1995). Temporal and spatial correlations between changes in plate motions and the evolutions of rifted basins in Africa, Geological Society of America Bulletin 107: 1317-1332.

Jerram, D., Mountney, N., Holzförster, F. and Stollhofen, H. (1999). Internal stratigraphic relationships in the Etendeka group in the Huab Basin, NW Namibia: understanding the onset of flood volcanism, Journal of Geodynamics 28: 393-418.

Johnson, C. and Gallagher, K. (2000). A preliminary Mesozoic and Cenozoic denudation history of the North East Greenland onshore margin, Global and Planetary Change 24: 261-274.

Johnson, M. R., van Vuuren, W. F., Hegenberger, W. F., Key, R. and Shoko, U. (1996). Stratigraphy of the Karoo Supergroup in southern Africa: an overview, Journal of African Earth Sciences 23: 3-16.

King, L. C. (1962). The Morphology of the Earth, 2nd edn, Oliver \& Boyd, Edinburgh.

King, L. C. (1983). Wandering Continents and Spreading Sea Floors on an Expanding Earth, Wiley, Chichester.

Kooi, H. and Beaumont, C. (1994). Escarpment evolution on high-elevated rifted margins: insights derived from a surface process model that combines diffusion, advection, and reactivation, Journal of Geophysical Research 99: 12191-12209.

Laplin, L. L. (1990). Probability and statistics for modern engineering, 2nd edn, Duxbury Press, California.

Laslett, G. M., Gleadow, A. J. W. and Duddy, I. R. (1984). The relationship between fission track length and density in apatite, Nuclear Tracks and Radiation Measurements 9: 29-38.

Laslett, G. M., Green, P. F., Duddy, I. R. and Gleadow, A. J. W. (1987). Thermal annealing of fission track in apatite 2. A quantitative analysis, Chemical Geology 65: 1-13.

Laslett, G. M., Kendall, W. S., Gleadow, A. J. W. and Duddy, I. R. (1982). BIAS in measurement in fission track length distribution, Nuclear Tracks and Radiation Measurements 6: 79-85. 
LePichon, X. and Hayes, D. E. (1971). Marginal offsets, fracture zones and early opening of the South Atlantic, Journal of Geophysical Research 76: 62836293.

Light, M. P. R., Maslanyj, M. P. and Banks, N. L. (1992). New geophysical evidence for extensional tectonics on the divergent margin offshore Namibia, in B. C. Storey, T. Alabaster and R. J. Pankhurst (eds), Magmatism and the Causes of Continental Break-Up, Vol. 71, Geological Society Special Publications, pp. 163-191.

Light, M. P. R., Maslanyj, M. P., Greenwood, R. J. and Banks, N. L. (1993). Seismic sequence stratigraphy and tectonics offshore Namibia, in G. D. Williams and A. Dobb (eds), Tectonics and Seismic Sequence Stratigraphy, Vol. 71, Geological Society Special Publications, pp. 163-191.

Lord, J., Oliver, G. and Soulsby, J. (1996). Landsat MSS imagery of a Lower Cretaceous regional dyke swarm, Damaraland, Namibia: a precursor to the splitting of Western Gondwana, International Journal of Remote Sensing 17: $2945-2954$.

Manton, W. I. and Siedner, G. (1967). Age of the Paresis Complex, South West Africa, Nature 216: 1197-1198.

Marsh, J. S. (1973). Relationship between transform directions and alkaline igneous rock lineaments in Africa and South America, Earth and Planetary Science Letters 18: 317-323.

Marsh, J. S., Hooper, P. R., Rehacek, J., Duncan, R. and Duncan, A. (1997). Stratigraphy and age of Karoo basalts of Lesotho and implications for correlations within the Karoo Igneous Province, in J. J. Mahoney and M. Coffin (eds), Large Igneous Provinces, Geophysical Monograph Series, AGU, Washington D.C.

Martin, H. (1975). Structural and palaeogeographical evidence for an Upper Palaeozoic sea between South Africa and South America, IUGS 3rd Gondwana Symposium, Canberra, pp. 37-51.

Martin, H. and Eder, F. W. (1983). Intracontinental Fold Belts, Springer, Berlin.

Marzoli, A., Melluso, L., Morra, V., Renne, P. R., Sgrosso, I., D’Antonio, M., Morais, L. D., Morais, E. A. A. and Ricci, G. (1999). Geochronology and petrology of Cretaceous basaltic magmatism in the Kwanza basin (western Angola), and relationships with the Paraná-Etendeka continental flood basalt province, Journal of Geodynamics 28: 341-356. 
Maslanyj, M. P., Light, M. P. R., Greenwood, R. J. and Banks, N. L. (1992). Extension tectonics offshore Namibia and evidence for passive rifting in the South Atlantic, Marine and Petroleum Geology 9: 590-601.

Miller, R. M. (1980). Geology of a portion of central Damaraland, South West Africa/Namibia, Memoirs geological Survey South Africa, South West Africa Series 6: $78 \mathrm{pp}$.

Miller, R. M. (1983). Evolution of the Damara Orogen, Vol. 11, Geological Society South Africa Special Publications.

Milner, S. C., le Roex, A. P. and O'Connor, J. M. (1995). Age of Mesozoic igneous rocks in northwestern Namibia, and their relationship to continental breakup, Journal of the Geological Society of London 152: 97-104.

Moore, M. A. and England, P. C. (2001). On the inference of denudation rates from cooling ages of minerals, Earth and Planetary Science Letters 185: $265-284$.

Moore, M. E., Gleadow, A. J. W. and Lovering, J. F. (1986). Thermal evolution of rifted continental margins: new evidence from fission tracks in basement apatites from southeastern Australia, Earth and Planetary Science Letters 78: $255-270$.

Naeser, C. W. (1981). The fading of fission tracks in the geologic environment - data from deep drill holes, Nuclear Tracks and Radiation Measurements 5: $248-250$.

Nürnberg, D. and Müller, D. R. (1991). The tectonic evolution of the South Atlantic from Late Jurassic to present, Tectonophysics 191: 27-53.

O'Connor, J. M. and le Roex, A. P. (1992). South Atlantic hot spot-plume systems, 1, Distribution of volcanism in space and time, Earth and Planetary Science Letters 113: 343-364.

Ollier, C. D. (1978). Inselbergs of the Namib Desert: processes and history, Zeitschrift für Geomorphologie, Supplement Band 31: 161-176.

Ollier, C. D. (1985). Morphotectonics of continental margins with great escarpments, in M. Morisawa and J. T. Hack (eds), Tectonic Geomorphology, Allen and Unwin, Boston, pp. 3-25.

Ollier, C. D. and Pain, C. F. (1997). Equating the basal unconformity with the palaeoplain: a model for passive margins, Geomorphology 19: 1-15.

Omar, G. I. and Steckler, M. S. (1995). Fission track evidence for the initial rifting of the Red Sea, Science 270: 1341-1344. 
Omar, G. I., Steckler, M. S., Buck, W. R. and Kohn, B. P. (1989). Fission-track analysis of basement apatites at the western margin of the Gulf of Suez rift, Egypt: Evidence for synchroneity of uplift and subsidence, Earth and Planetary Science Letters 94: 316-328.

O'Sullivan, P. B. and Brown, R. W. (1998). Effects on surface cooling on apatite fission track data: evidence for Miocene climatic change, North Slope, Alaska, in P. van den Haute and F. de Corte (eds), Advances in Fission-Track Geochronology, Kluwer Academic Publishers, pp. 255-267.

O'Sullivan, P. B. and Parrish, R. R. (1995). The importance of apatite composition and single-grain ages when interpreting fission track data from plutonic rocks: a case study from the Coast Ranges, British Columbia, Earth and Planetary Science Letters 132: 213-224.

O’Sullivan, P. B., Wallace, W. K. and Murphy, J. M. (1998). Fission-track evidence for apparent out-of-sequence Cenozoic deformation along the Philip Smith Mountain front, northeastern Brooks Range, Alaska, Earth and Planetary Science Letters 164: 435-449.

Parish, R. R. (1983). Cenozoic thermal evolution and tectonics of the coast mountains of British Columbia, 1, Fission track dating, apparent uplift rates and patterns of uplift, Tectonics 2: 601-632.

Park, R. G. and Jaroszewski, W. (1994). Craton tectonics, stress and seismicity, in P. L. Hankock (ed.), Continental Deformation, Oxford: Pergamon Press, pp. 200-222.

Pazzaglia, F. J. and Gardner, T. W. (2000). Late Cenozoic landscape evolution of the US Atlantic passive margin; insights into a North American Great Escarpment, in M. A. Summerfield (ed.), Geomorphology and Global Tectonics, John Wiley and Sons Ltd., Chichester, pp. 283-302.

Peate, D. W. (1997). The Paraná-Etendeka Province, in J. J. Mahoney and M. Coffin (eds), Large Igneous Provinces, Geophysical Monograph Series, AGU, Washington D.C., pp. 217-245.

Pickford, M., Senut, B. and Dauphin, Y. (1995). Biostratigraphy of the Tsondab Sandstone (Namibia) based on gigantic avian eggshells, Geobios 18: 85-98.

Pollack, H. N., Hurta, S. J. and Johnson, J. R. (1993). Heat flow from the Earth's interior: analysis of the global data set, Review Geophysics 31: 267-280.

Porada, H. (1989). Pan-African Rifting and Orogenesis in southern to equitorial Africa and eastern Brazil, Precambrian Research 44: 103-136. 
Price, P. B. and Walker, R. M. (1962a). Chemical etching of charged particle tracks in solids, J. Appl. Phys. 33: 3407-3412.

Price, P. B. and Walker, R. M. (1962b). Observation of fossil particle tracks in natural micas, Nature 196: 732-734.

Price, P. B. and Walker, R. M. (1963). Fossil tracks of charged particles in mica and the age of minerals, Journal of Geophysical Research 68: 4847-4862.

Raab, M. J., Brown, R. W., Gallagher, K., Carter, A. and Weber, K. (in press). Late Cretaceous reactivation of major crustal shear zones in northern Namibia: constraints from apatite fission track analysis, Tectonophysics.

Ravenhurst, C. E. and Donelick, R. A. (1992). Fission track thermochronology, in I. M. Zentill and P. H. Reynolds (eds), Short Course Handbook on Low Temperature Thermochronology, Mineral Association of Canada, p. 256.

Reeves, C. V. (1972). Rifting in the Kalahari?, Nature 237: 95-96.

Renne, P. R., Deckart, K., Ernesto, M., Féraud, G. and Piccirillo, E. M. (1996a). Age of the Ponta Grossa dyke swarm (Brazil) and implications to Paraná flood volcanism, Earth and Planetary Science Letters 144: 199-211.

Renne, P. R., Ernesto, M., I. G. Pacca, R. S. C., Glen, J. M., Prevot, M. and Perrin, M. (1992). The age of Paraná flood vocanism, rifting of Gondwanaland, and the Jurassic-Cretaceous boundary, Science 258: 975-979.

Renne, P. R., Glen, J., Milner, S. M. and Duncan, A. R. (1996b). Age of the Etendeka flood volcanism and asociated intrusions in southwestern Africa, Geology 24: 659-662.

Ritter, O., Bauer, K., Vietor, T., Trumbull, R., Emmermann, R., Haak, V., Ryberg, T., Schulze, A., Wackerle, R. and Weber, K. (subm.). Cretaceuos tectonic and igneous reworking of continental crust at the Namibian passive margin, Geology.

Rosendahl, B. R. (1987). Architecture of continental rifts with special reference to East Africa, Annual Reviews of Earth and Planetary Sciences 15: 445-503.

Royden, L. and Keen, C. E. (1980). Rifting processes and thermal evolution of continental lithosphere, Earth and Planetary Science Letters 51: 343-361.

Royer, J. Y., Patriat, P., Bergh, H. W. and Scotese, C. R. (1988). Evolution of the Southwest Indian Ridge from the Late Cretaceous (anomaly C34) to the Middle Eocene (anomaly 20), Tectonophysics 155: 235-260. 
Rust, D. J. and Summerfield, M. A. (1990). Isopach and borehole data as indicators of rifted margin evolution in southwestern Africa, Marine and Petroleum Geology 7: 277-287.

Schmitt, A. K., Emmermann, R., Trumbull, R. B., Bühn, B. and Henjes-Kunst, F. (2000). Petrogenesis and ${ }^{40} \mathrm{Ar}^{-39} \mathrm{Ar}$ Geochronology of the Brandberg Complex, Namibia: Evidence for a Major Mantle Contribution in Metaluminous and Peralkaline Granites, Journal of Petrology 41: 1207-1239.

Selby, M. J. (1993). Hillslope Materials and Processes, 2nd edn, Oxford University Press, Oxford.

Sengor, A. M. C. and Burke, K. (1978). Relative timing of rifting and volcanism on Earth and its tectonic implications, Geophysical Research Letters 5: 419421.

Senut, B. and Pickford, M. (1995). Fossil eggs and Cenozoic continental biostratigraphy of Namibia, Palaeontologica Africana 32: 33-37.

Siesser, W. G. (1978). Aridification of the Namib Desert: Evidence from oceanic cores, in E. M. V. Z. Bakker (ed.), Antarctic glacial history and world palaeoenvironments, Balkena, pp. 105-112.

Siesser, W. G. (1980). Late Miocene origin of the Benguela upwelling system off northern Namibia, Science 208: 283-285.

Silk, E. C. H. and Barnes, R. S. (1959). Examination of fission fragments tracks with an electron microscope, Phil. Mag. 4: 970-972.

Smith, R. M. H. (1986). Sedimentation and palaeoenvironments of Late Cretaceous crater-lake deposits in Bushmanland, South Africa, Sedimentology 33: $369-386$.

Stewart, K. S., Turner, S., Kelly, S., Hawkesworth, C. J., Kirstein, L. and Mantovani, M. S. M. (1996). 3D ${ }^{40} \mathrm{Ar}-{ }^{39} \mathrm{Ar}$ geochronology in the Paraná flood basalt province, Earth and Planetary Science Letters 143: 95-110.

Storey, B. C. (1995). The role of mantle plumes in continental breakup: case histories from Gondwanaland, Nature 377: 301-308.

Storey, B. C., Alabaster, T., Hole, M. J., Pankhurst, R. J. and Wever, H. E. (1992). Role of subduction-plate boundary forces during the initial stages of Gondwana break-up: evidence from the proto-Pacific margin of Antarctica, in B. C. Storey, T. Alabaster and R. J. Pankhurst (eds), Magmatism and the Causes of Continental Break-up, Vol. 68, Geological Society Special Publications, pp. 149-164. 
Storey, B. C. and Kyle, P. R. (1997). An active mantle mechanism for Gondwana break-up, South African Journal of Geology 100: 283-290.

Summerfield, M. A. (1991). Global Geomorphology, Longman, London.

Summerfield, M. A. and Brown, R. W. (1998). Geomorphic factors in the interpretation of thermochronologic data, in P. van den Haute and F. de Corte (eds), Advances in Fission-Track Geochronology, Kluwer, Dordrecht, pp. 269284.

Summerfield, M. A. and Hulton, N. J. (1994). Natural controls of fluvial denudation rates in major world drainage basins, Journal of Geophysical Research 99: $13871-13884$.

Tamrat, E. and Ernesto, M. (1999). Magnetic fabric and rock-magnetic character of the Mesozoic flood basalts of the Paraná Basin, Brazil, Journal of Geodynamics 28: 419-437.

Tankard, A. J., Jackson, M. P., amd D. K. Hobday, K. A. E., Hunter, D. R. and Minter, W. E. L. (1982). Crustal Evolution of Southern Africa: 3.8 Billion Years of Earth History, Springer, New York.

Thomas, D. S. G. and Shaw, P. A. (1990). The deposition and development of the Kalahari Group sediments, Central Southern Africa, Journal of African Earth Sciences 10: 187-197.

Tingate, P. R. (1990). Apatite fission track studies from the Amadeus Basin, Central Australia, PhD thesis, The University of Melbourne.

Tommasi, A. and Vauchez, A. (2001). Continental rift parallel to ancient collisional belts: an effect of the mechanical anisotropy of the lithospheric mantle, Earth and Planetary Science Letters 185: 199-201.

Topping, J. (1972). Errors of Observation and Their Treatment, Chapman and Hall, Science Paperbacks.

Tucker, G. E. and Slingerland, R. L. (1994). Erosion dynamics, flexural isostasy, and long-lived escarpments: a numerical modeling study, Journal of Geophysical Research 99: 12229-12243.

Turner, S., Hawkesworth, C., Gallagher, K., Stewart, K., Peate, D. and Mantovani, M. (1996). Mantle plumes, flood basalts, and thermal models for melt generation beneath continents: Assessment of a conductive heating model and application to the Parana, Journal of Geophysical Research 101: 1150311518. 
Turner, S., Regelous, M., Kelley, S., Hawkesworth, C. J. and Mantovani, M. S. M. (1994). Magmatism and continental break-up in the South Atlantic: high precision ${ }^{40} \mathrm{Ar} /{ }^{39} \mathrm{Ar}$ geochronology, Earth and Planetary Science Letters 121: 333-348.

Unternehr, P., Curie, D., Oliviet, J. L., Goslin, J. and Beuzart, P. (1988). South Atlantic fits and intraplate boundaries in Africa and South America, Tectonophysics 155: 169-179.

van der Beek, P. and Braun, J. (1998). Numerical modelling of landscape evolution on geological time-scales: a parameter analysis and comparison with the south-eastern highlands of Australia, Basin Research 10: 49-68.

Versfelt, J. W. and Rosendahl, B. R. (1989). Relationships between pre-rift structure and rift architecture in Lakes Tanganyika and Malawi, East Africa, $\mathrm{Na}$ ture 337: 354-357.

Wagner, G. and van den Haute, P. (1992). Fission-Track Dating, Vol. 6 of Solid Earth Library, Kluwer Academic Publishers.

Ward, J. D. (1987). The Cenozoic succession in the Kuiseb Valley, Central Namib Desert, Geological Survey of South West Africa/Namibia, Memoir 9: 1-124.

Ward, J. D. (1988). Geology of the Tsondab Sandstone Formation, Journal of Sedimentary Geology 55: 143-162.

Ward, J. D. and Martin, H. (1987). A terrestrial conglomerate of Cretaceous age. A new record from the Skeleton Coast, Namib Desert, Communications of the Geological Survey of Namibia 3: 57-58.

Watkins, R. T., McDougall, I. and le Roex, A. P. (1994). K-Ar ages of the Brandberg and Okenenya igneous complexes, north-western Namibia, Geologische Rundschau 83: 348-356.

Wessel, P. and Smith, W. H. F. (1991). Free software helps to map and display data, $\operatorname{EOS~72:~441-446.~}$

White, R. and McKenzie, D. (1989). Magmatism at Rift Zones: The Generation of Volcanic Continental Margins and Flood Basalts, Journal of Geophysical Research 94: 7685-7729.

Wickens, H. D. V. and McLachlan, I. R. (1990). The stratigraphy and sedimentology of the reservoir interval of the Kudu 9A-2 and 9A-3 boreholes., Communications of the Geological Survey of Namibia 6: 9-22.

Wilson, M. (1993). Plate-moving mechanisms: constraints and controversies, Journal of the Geological Society of London 5: 923-926. 


\section{Lebenslauf}

Ich wurde am 25 Mai 1967 als Sohn von Christine Raab (geborene Hubrecht) und Erhard Raab in Göttingen geboren. Von 1973 bis 1977 besuchte ich die Grundschule Bonifatiusschule I in Göttingen. Von 1977 bis 1984 besuchte ich das Hainberg-Gymnasium und von 1984 bis 1987 das Fachgymnasium Wirtschaft in Göttingen, welches ich im Mai 1987 mit der allgemeinen Hochschulreife (Abitur) verliess. Im Oktober 1991 wechselte ich vom Studium der Chemie in den Fachbereich Geowissenschaften an der Georg-August-Universität zu Göttingen, und erreichte den Diplomabschluss im November 1995. Im April 1996 nahm ich den Promotionsstudiengang im Fachbereich Geowissenschaften an der Georg-AugustUniversität zu Göttingen auf.

Im September 1997 heiratete ich Claudia Annette Raab, geborene Löber. Im Juli 1998 wurde mir ein HSP III - Stipendium des DAAD für Australien verliehen. Seit September 1998 füre ich meine Fachstudien an der La Trobe University und der University of Melbourne, Australien, fort. Im Juli 1999 wurde unser Sohn Connor Liam Raab in Melbourne, Australien, geboren. 